Aus der Abteilung Gastroenterologie und Endokrinologie

(Prof. Dr. med. Dr. h. c. G. Ramadori) im Zentrum Innere Medizin

der Medizinischen Fakultät der Universität Göttingen

\title{
Untersuchungen zur Assoziation genetischer Polymorphismen im Gen des Endotoxinrezeptors CD14 mit der transkriptionellen Aktivität
}

\author{
INAUGURAL-DISSERTATION \\ zur Erlangung des Doktorgrades \\ der Medizinischen Fakultät \\ der Georg-August-Universität zu Göttingen
}

vorgelegt von

Rusudan Bregadze

aus

Tbilisi / Georgien

Göttingen 2010 
Dekan: Prof. Dr. med. C. Frömmel

I. Berichterstatter/in: Prof. Dr. rer. nat. S. Mihm

II. Berichterstatter/in: Prof. Dr. rer. nat. D. Kube

III. Berichterstatter/in: Prof. Dr. med. R. Dressel

Tag der mündlichen Prüfung: 20.10.2010 
Gewidmet meinem Vater, der mir die deutsche Sprache beigebracht hat 


\section{Inhaltsverzeichnis}

1. $\quad$ Einleitung..........................................................1

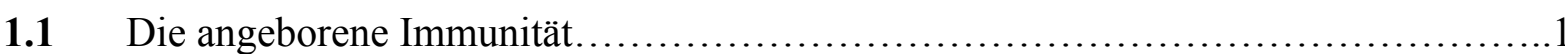

1.1.1 Erkennungsstrukturen und Rezeptoren des angeborenen Immunsystems.........1

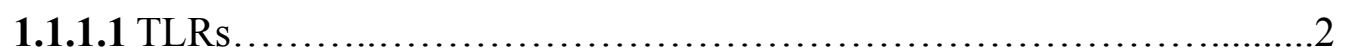

1.1.1.2 CD14 .........................................................

1.1.1.3 LPS und dessen Erkennung durch den TLR4-CD14-MD2-

Rezeptorkomplex..........................................

1.1.1.4 Regulation der Zellantwort auf LPS.............................12

1.1.1.5 TLR4 und CD14 in der Leber ....................................14

1.1.1.6 CD14 und Atopie.................................................15

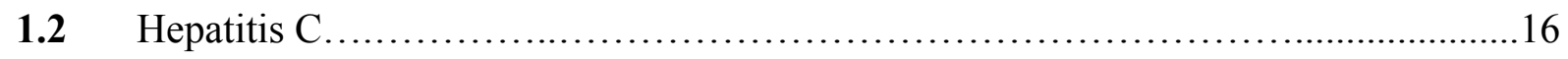

1.2.1 Erreger der Hepatitis C.................................................. 16

1.2.1.1 Strukturelle Organisation und Replikation des Virus....................16

1.2.2 Epidemiologie der Hepatitis C............................................19

1.2.3 Der natürliche Verlauf einer HCV-Infektion............................. 19

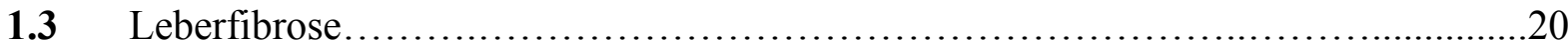

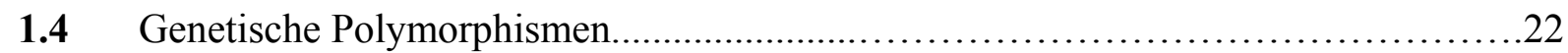

1.4.1 Das menschliche Genom und dessen Polymorphismen.............................22

1.4.2 Haplotyp und Kopplungsungleichgewicht (linkage disequilibrium, LD)......23

1.4.3 Hardy-Weinberg equilibrium (HWE)....................................24

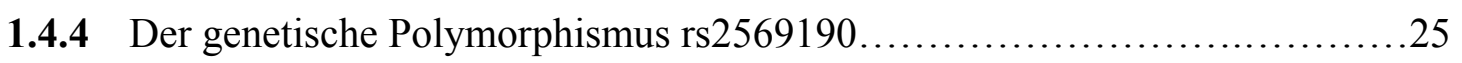

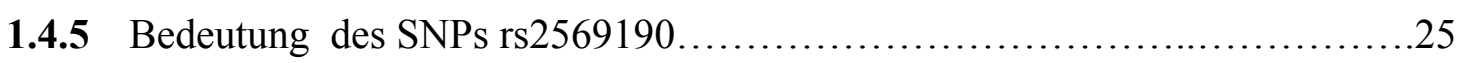

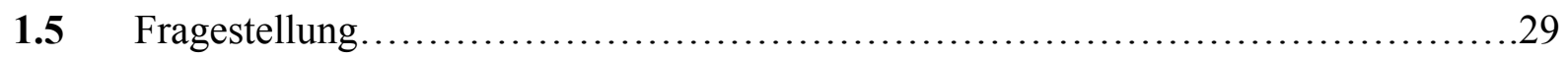

2. Material und Methoden......................................................30

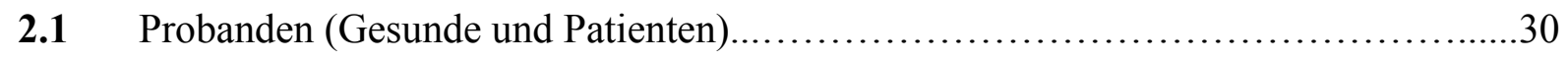

2.2 Material..........................................................................

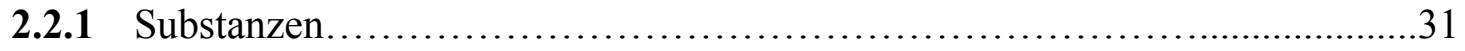

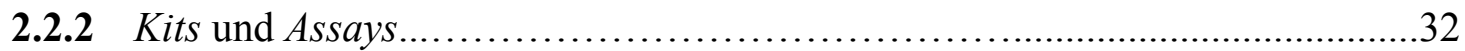

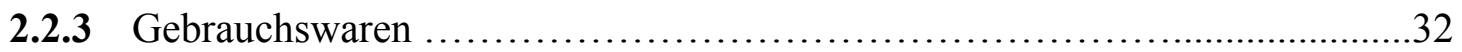

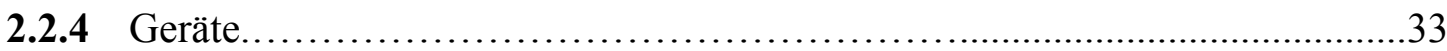


2.3 Methoden. .34

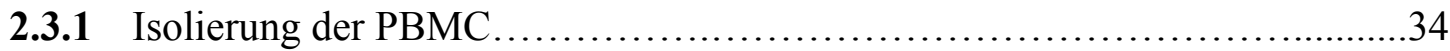

2.3.2 Extraktion der genomischen DNA (gDNA) aus dem Vollblut....................34

2.3.3 Extraktion der gDNA und RNA aus PBMC.

2.3.4 Bestimmung der DNA- / RNA-Konzentration und -Reinheit und Nachweis der DNA- / RNA-Integrität.......................................... 36

2.3.5 cDNA(complementary DNA)-Synthese (reverse Transkription, RT )..............37

2.3.6 Genotypisierung genetischer Polymorphismen mittels allelischer Diskriminierung.................................................... 37

2.3.6.1 Genotypisierung am SNP rs 2569190 / C-159T........................42

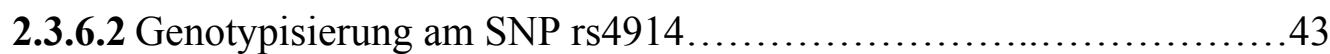

2.3.7 Genotypisierung genetischer Polymorphismen mittels tetra-PrimerARMS(Amplification Refractory Mutation System)-PCR....................44

2.3.7.1 Genotypisierung am SNP rs5744455 ..........................44

2.3.7.2 Genotypisierung am SNP rs2563298...........................47

2.3.8 Haplotypisierung...................................................... 49

2.3.9 Quantifizierung der CD14-Genexpression.................................54

2.3.10 Ermittlung der CD14-mRNA-splice-Variante..............................56

2.3.11 Bestimmung der Konzentration des löslichen CD14 (sCD14) im Serum / Plasma mithilfe von ELISA....................................57

2.3.12 Allel-spezifische Transkriptquantifizierung (ASTQ)......................58

2.3.12.1 ASTQ mittels real time TaqMan-RT-PCR ...........................58

2.3.12.2 ASTQ mittels RFLP........................................58

2.3.13 Auswertung und Statistik.............................................63

3. Ergebnisse.........................................................64

3.1 Untersuchung zur Assoziation des SNPs rs2569190 mit der CD14-Genexpression...64

3.1.1 Genotypisierung am SNP rs2569190.....................................64

3.1.2 CD14-mRNA-Expression in PBMC bei gesunden Probanden vs Patienten und in Abhängigkeit des SNP-rs2569190-Genotyps.

3.1.3 Konzentration des sCD14 im Serum und Analyse der Daten in Bezug auf den SNP rs2569190. 
3.2 Analyse der CD14-Genexpression in Bezug auf weitere SNPs im CD14-Gen.... .68

3.2.1 Genotypisierung an den SNPs rs5744455, rs4914 und rs2563298 und Kopplungsungleichgewicht bei den untersuchten SNPs.

3.2.2 CD14-mRNA-Expression und sCD14-Serumkonzentration in Abhängigkeit von Genotypen an der Positionen rs5744455, rs4914 und rs2563298..........71

3.3 CD14-mRNA-Expression in der Leber.................................... 78

3.4 Haplotypisierung....................................................... 80

3.5 Korrelationen zwischen verschiedenen Parametern der CD14-Genexpression...........81

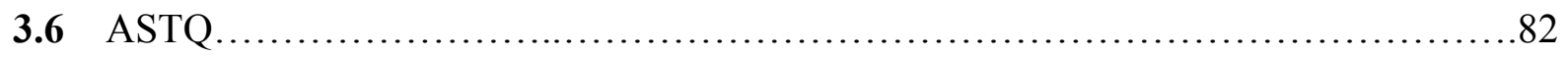

3.6.1 Ermittlung der CD14-mRNA-splice-Varianten in PBMC und Leber..............82

3.6.2 Identifizierung eines für ASTQ geeigneten SNPs im transkribierten Bereich des CD14-Gens.................................................... 84

3.6.3 Ausführung der ASTQ............................................. 85

3.6.4 Allelische Expression des CD14-Gens in PBMC..........................85

3.6.4.1 ASTQ mittels real time TaqMan-RT-PCR ........................85

3.6.4.2 ASTQ mittels RFLP......................................... 88

3.6.5 Allelische Expression des CD14-Gens in der Leber.......................89

4. Diskussion................................................................92

5. Zusammenfassung...............................................97

6. Literaturverzeichnis...................................................99 


\section{Abkürzungen}

A

Abb.

ARMS

ASTQ

bp

C

cDNA

CpG-Motiv

CT

DNA

dNTP

dsRNA

DTT

EDTA

EGF

ELISA

EMSA

FRET

G

GPI

$\mathrm{HCV}$

HGP

HIV

H. pylori

HSC

HWE

IFN- $\alpha$

IFN- $\beta$

IKK

IL

IRF

JNK

LBP
Adenin

Abbildung

Amplification Refractory Mutation System

Allele Specific Transkript Quantification

Basenpaar

Cytosin

complementary DNA

Cytosin-Phosphat-Guanin-Motiv

Threshold Cycle

Desoxyribonukleinsäure

Desoxyribonukleotid

doppelsträngige RNA

Dithiothreitol

EthyleneDiamineTetraacetic Acid

Epidermal Growth Factor

Enzyme Linked Immunosorbent Assay

Electrophoretic Mobility Shift Assay

Fluorescence Resonance Energy Transfer

Guanin

Glykosylphosphatidilinositol

Hepatitis-C-Virus

Human Genome Project

Human Immunodeficiency Virus

Helicobacter pylori

Hepatic Stellate Cell

Hardy-Weinberg Equilibrium

Interferon- $\alpha$

Interferon- $\beta$

Inhibitor der NF- $\kappa \mathrm{B}-$ Kinase

Interleukin

Interferon Regulatory Factor

p38/c-Jun N-Terminal Kinase

LPS Binding Protein 
LD

LDL

LPS

LRR

MAF

MAL

$\mathrm{mCD} 14$

MD2

MGB

MMLV

MyD88

$\mathrm{n}$

NCBI

NCR

$\mathrm{NF}-\kappa \mathrm{B}$

NTC

NTPase

ORF

$\mathrm{p}$

PAMP

PBMC

PBS

PCR

Poly (I:C)

PRR

r

rER

RFLP

$\mathrm{Rn}$

RNasin

RT

sCD14

SiRNA

SNP
Linkage Disequilibrium

Low Density Lipoprotein

Lipopolysaccharid

Leucine Rich Repeat

Minor Allele Frequency

MyD88-Adaptor-Like Protein

membranständiges CD14

Myeloid Differentiation Protein 2

Minor Groove Binder

Moloney Murine Leukemia Virus

Myeloid Differentiation Factor 88

Probenanzahl

National Center for Biotechnology Information

Non Coding Region

nukleärer Transkriptionsfaktor- $\kappa \mathrm{B}$

No Template Control

Nukleotidtriphophatase

Open Reading Frame

Irrtumswahrscheinlichkeit

Pathogen-Associated Molecular Pattern

mononukleäre Zellen des peripheren Blutes

Phosphate Buffered Saline

Polymerase Chain Reaction

Polyriboinosinic: Polyribocytidilic Acide

Pattern Recognition Receptor

linearer Korrelationskoeffizient

raues Endoplasmatisches Retikulum

Restriktions-Fragmentlängen-Analyse

normalised Reporter

Ribonuclease inhibitor

Raumtemperatur bzw. reverse Transkription

soluble CD14

short interfering RNA

Single Nucleotide Polymorphism 
SR-BI

$\mathrm{T}$

Tab.

Taq

TBE

TGF- $\beta$

TIR

TLR

$\mathrm{Tm}$

TMB

TNF- $\alpha$

TRAF

TRIF

UDG

UTR

UV

WHO
Scavenger Receptor Class B Type I

Thymin

Tabelle

Thermus aquaticus

Tris-Borat-EDTA

Transforming Growth Factor beta

Toll/interleukin-1 Receptor

Toll-like-Rezeptoren

Schmelztemperatur

Tetramethylbenzidine

Tumornekrosefaktor- $\alpha$

Tumor Necrosis Receptor Associated Factor

TIR-Domain Containing Adaptor Inducing IFN- $\beta$

Uracil-DNA-Glykosylase

Untranslated Region

ultraviolettes Licht

World Health Organisation 


\section{Abbildungsverzeichnis}

Abb. 1.1: $\quad$ Schematische Darstellung der TLR-Signalwege............................5

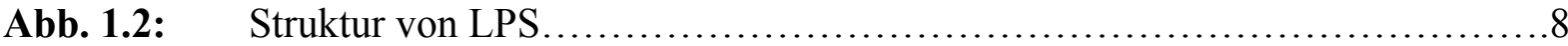

Abb. 1.3: Lokalisation des LPS (Endotoxin) in bakterieller Zellwand (links) und Organisation der großen Aggregate des gereinigten Endotoxins nach der Extraktion aus Bakterien (rechts) ...............................9

Abb. 1.4: CD14-unabhängige und CD14-abhängige Signalleitung von TLR4-MD-2 ....11

Abb. 1.5: Konzentrationsabhängige Wirkung von LBP auf die Zellantwort auf LPS ....13

Abb. 1.6: Inhibierender Mechanismus von sCD14...............................14

Abb. 1.7: Genomische Organisation des HCV und Prozessierungswege des Polyproteins............................................................ 17

Abb. 1.8: HCV-Replikationszyklus............................................... 18

Abb. 1.9: Transkriptvarianten des CD14-Gens und Lokalisation des SNPs rs2569190_..25

Abb. 2.1: $\quad$ Allelische Diskriminierung................................................

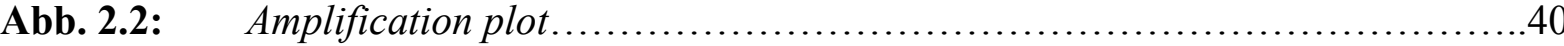

Abb. 2.3: $\quad$ Ergebnisse einer allelischen Diskriminierung............................. 41

Abb. 2.4: Die relevante Nukleotidsequenz im Bereich des Polymorphismus rs2569190 / C-159T und die für die Genotypisierung eingesetzten Primer und Sonden

Abb. 2.5: Die relevante Nukleotidsequenz im Bereich des untersuchten SNPs rs4914 und die für die Genotypisierung eingesetzten Primer und Sonden .43

Abb. 2.6: Die relevante Nukleotidsequenz im Bereich des Polymorphismus rs 5744455 und die für die Genotypisierung verwendeten tetra-Primer.

Abb. 2.7: $\quad$ Tetra-Primer-ARMS-PCR zur Genotypisierung am SNP rs5744455...........47

Abb. 2.8: Die relevante Nukleotidsequenz im Bereich des Polymorphismus rs 2563298 und die für die Genotypisierung verwendeten tetra-Primer .................48

Abb. 2.9: $\quad$ Tetra-Primer-ARMS-PCR zur Genotypisierung am SNPs rs2563298.... .49

Abb. 2.10: Haplotypisierung der polymorphen Positionen im CD14-Gen (rs5744455, rs2569190, rs4914, rs2563298).

Abb. 2.11: Haplotypisierung unter Verwendung eines TaqMan-

Genotypisierungs-Assays .52 
Abb. 2.12: Haplotypisierung unter Verwendung von tetra-Primern......................54

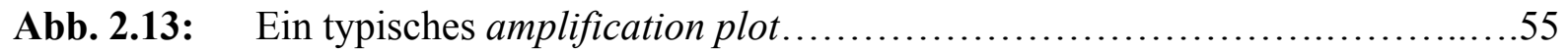

Abb. 2.14: Quantitative RFLP-Analyse einer mit SatI (A) und Alw21I (B) geschnittenen gDNA-Probe

Abb. 3.1: CD14-mRNA-Expression in PBMC von gesunden Probanden und Patienten mit chronischer Hepatitis C....

Abb. 3.2: $\quad$ CD14-mRNA-Expression in PBMC von gesunden Probanden und Patienten mit chronischer Hepatitis C in Bezug auf den Genotyp am SNP rs2569190...66

Abb. 3.3: $\quad$ Der Vergleich der sCD14-Serumkonzentrationen zwischen gesunden Probanden und Patienten. .67

Abb. 3.4: $\quad$ sCD14-Serumkonzentrationen bei gesunden Probanden (A) und Patienten mit chronischer Hepatitis C (B) in Bezug auf den Genotyp am SNP rs2569190_...68

Abb. 3.5: CD14-mRNA-Expression in PBMC von gesunden Probanden und Patienten mit chronischer Hepatitis C in Bezug auf den Genotyp am SNP rs5744455...72

Abb. 3.6: CD14-mRNA-Expression in PBMC von gesunden Probanden und Patienten mit chronischer Hepatitis C in Bezug auf den Genotyp am SNP rs4914......73

Abb. 3.7: CD14-mRNA-Expression in PBMC von gesunden Probanden und Patienten mit chronischer Hepatitis C in Bezug auf den Genotyp am SNP rs2563298....74

Abb. 3.8: $\quad$ sCD14-Serumkonzentrationen bei gesunden Probanden (A) und Patienten mit chronischer Hepatitis C (B) in Bezug auf den Genotyp am SNP rs5744455....75

Abb. 3.9: $\quad$ sCD14-Serumkonzentrationen bei gesunden Probanden (A) und Patienten mit chronischer Hepatitis C (B) in Bezug auf den Genotyp am SNP rs4914 ...76

Abb. 3.10: sCD14-Serumkonzentrationen bei gesunden Probanden (A) und Patienten mit chronischer Hepatitis C (B) in Bezug auf den Genotyp am SNP rs2563298...77

Abb. 3.11: CD14-mRNA-Expression in der Leber von Patienten mit chronischer Hepatitis C in Bezug auf den Genotyp an SNPs rs5744455 (A), rs2569190 (B), rs4914 (C) und rs2563298 (D). .79

Abb. 3.12: Amplifizierung einer cDNA-Probe mit 4 verschiedenen Assays zur Ermittlung der splice-Variante (A) und eine gDNA-Kontrolle (B).

Abb. 3.13: Schematische Darstellung der Struktur des CD14-Gens und der 2 splice-Varianten. .84

Abb. 3.14: Expression der Allele des SNPs CD14 rs4914 in cDNA- und gDNA-Proben 


\section{Tabellenverzeichnis}

Tab. 2.1: Primer und Sonden für Genotypisierung an der Position rs4914 ...............43

Tab. 2.2: $\quad$ Tetra-Primer für die Genotypisierung des SNPs rs $5744455 \ldots \ldots \ldots \ldots \ldots \ldots . . . \ldots 45$

Tab. 2.3: $\quad$ Produkte der tetra-Primer-ARMS-PCR-Genotypisierung am SNP

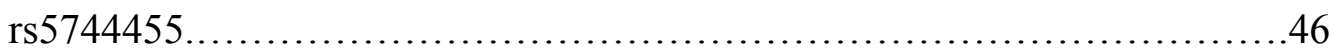

Tab. 2.4: Tetra-Primer für Genotypisierung an der Position rs $2563298 \ldots \ldots \ldots \ldots \ldots \ldots . . . . .47$

Tab. 2.5: $\quad$ Produkte der tetra-Primer-ARMS-PCR-Genotypisierung am SNP

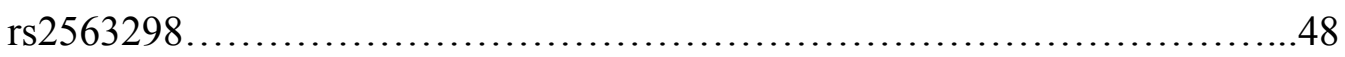

Tab. 2.6: Allel-spezifische Primer für den SNP rs5744455 ............................50

Tab. 2.7: Allel-spezifische Primer für den SNP rs2569190........................53

Tab. 2.8: $\quad$ Primer für die ASTQ mittels RFLP........................................59

Tab. 2.9: SNP-rs4914-spezifische relevante Restriktionsendonukleasen und deren Erkennungssequenzen................................................60

Tab. 2.10: DNA-Fragmente nach dem Verdau..................................60

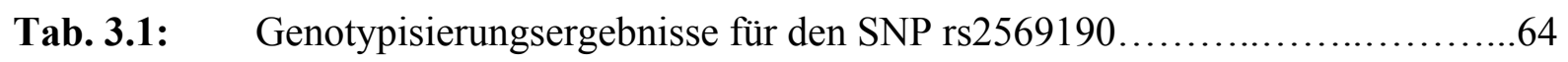

Tab. 3.2: Die bekannten SNPs im CD14-Gen mit höchster Heterozygotie.................69

Tab. 3.3: Genotypverteilungen an 3 relevanten SNPs im Kollektiv der gesunden Probanden.

Tab. 3.4: Genotypverteilungen an 3 relevanten SNPs im Kollektiv der Patienten mit chronischer Hepatitis C..........................................70

Tab. 3.5: Die Grade des paarweisen Kopplungsungleichgewichts zwischen den SNPs rs5744455, rs2569190, rs4914 und rs2563298 im Kollektiv der gesunden Probanden.

Tab. 3.6: Die Grade des paarweisen Kopplungsungleichgewichts zwischen den SNPs rs5744455, rs2569190, rs4914 und rs2563298 im Kollektiv der Patienten mit chronischer Hepatitis C.

Tab. 3.7: Genotypverteilungen an 4 relevanten SNPs im Kollektiv der Patienten mit Lebergewebeproben. . .78

Tab. 3.8: Verteilung der Haplotypen bei gesunden Probanden und Patienten mit chronischer Hepatitis C

Tab. 3.9: Verteilung der Haplogenotypen bei gesunden Probanden und Patienten mit chronischer Hepatitis C.

Tab. 3.10: Quantifizierung der rs4914-CD14-Transkriptvarianten in PBMC mittels TaqMan-Sonden (für gesunde Probanden). 
Tab. 3.11: Quantifizierung der rs4914-CD14-Transkriptvarianten in PBMC mittels TaqMan-Sonden (für Patienten mit chronischer Hepatitis C)................87

Tab. 3.12: Quantifizierung der rs4914-CD14-Transkriptvarianten in PBMC mittels RFLP (für gesunde Probanden). .88

Tab. 3.13: Quantifizierung der rs4914-CD14-Transkriptvarianten in PBMC mittels RFLP (für Patienten mit chronischer Hepatitis C). .89

Tab. 3.14: Quantifizierung der rs4914-CD14-Transkriptvarianten in der Leber mittels TaqMan-Sonden .90

Tab. 3.15: Quantifizierung der rs4914-CD14-Transkriptvarianten in der Leber mittels RFLP 


\section{Einleitung}

\subsection{Die angeborene Immunität}

Als Immunsystem (vom lateinischen immunis eigentlich „steuerfrei“, im übertragenen Sinne unberührt, frei, rein) wird ein Netzwerk aus verschiedenen Zellen, Geweben und Molekülen bezeichnet, das die Widerstandsfähigkeit bzw. Immunität des Organismus gegen Infektionen vermittelt (Abbas und Lichtman 2006-2007, S. 1).

Das Immunsystem wird traditionsgemäß in zwei Teile eingegliedert: Angeborenes und erworbenes Immunsystem. Die beiden haben zwar ziemlich unterschiedliche Funktionen und Wirkungsmechanismen, sind aber miteinander eng vernetzt und tragen zur Aufrechterhaltung der Immunität des Organismus gleichermaßen bei (Medzhitov und Janeway 2000 a) .

Die Aktivierung der angeborenen sowie erworbenen immunologischen Abwehrvorgänge setzt die Erkennung des Krankheitserregers durch das Immunsystem voraus. Die Fähigkeit des Organismus, zwischen harmlosen bzw. körpereigenen und pathogenen Strukturen unterscheiden zu können, beruht auf Rezeptoren des angeborenen Immunsystems, die diese Pathogen-assoziierten Strukturen erkennen können (Medzhitov und Janeway 2000 a).

\subsubsection{Erkennungsstrukturen und Rezeptoren des angeborenen Immunsystems}

Die Strukturen, die das angeborene Immunsystem spezifisch erkennt, werden als pathogenassoziierte molekulare Muster (pathogen-associated molecular patterns, PAMPs) bezeichnet. PAMPs weisen einige Gemeinsamkeiten auf (Medzhitov und Janeway 2000 b):

- Sie werden ausschließlich von mikrobiellen Pathogenen und nicht von Wirtsorganismus produziert. Das ermöglicht, zwischen „selbst“ und „fremd“ zu unterscheiden

- Sie sind essentiell für das Überleben der Pathogene. Deswegen können Mikroben sie nicht verändern, um Immunreaktionen $\mathrm{zu}$ entgehen (,escape mutants"). Die Strukturen sind also hochkonserviert und können durch das angeborene Immunsystem effektiv angegriffen werden

- Sie sind größeren Gruppen von Mikroorganismen gemeinsam. Dadurch kommt das angeborene Immunsystem bei der Bekämpfung einer großen Anzahl der Mikroorganismen mit relativ wenigen Rezeptoren aus

- Oft sind PAMPs „molekulare Kennzeichen“ (,,molecular signatures“) für bestimmte Klassen von Pathogenen, z. B. Lipopolysacharid (LPS) für gram-negative Bakterien, Lipoteichonsäure für gram-positive Bakterien, Lipoarabinomannan und 
Muramyldipeptid für Mykobakterien, Mannane und Glukane für Pilze usw. Dadurch weist die Erkennung von PAMPs nicht nur auf das Vorhandensein der Infektion, sondern auch auf den Typ der Pathogene hin. Das Immunsystem kann dabei die effektivste Vorgehensweise gegen eingedrungene Mikroben wählen.

Für die Erkennung der PAMPs besitzt das angeborene Immunsystem spezielle Rezeptoren. Diese Rezeptoren sind Keimbahn-kodiert, d. h. es ist genetisch festgelegt, welche pathogenen Strukturen sie erkennen können. Sie werden auch als Muster-Erkennungsrezeptoren (pattern recognition receptors, PRRs) bezeichnet. PRRs sind auf vielen Zellen des angeborenen Immunsystems, insbesondere auf Makrophagen, dendritischen Zellen und B-Lymphozyten exprimiert (Medzhitov und Janeway 2000 a) .

Eine wichtige Gruppe der PRRs bilden die Toll-like Rezeptoren (TLRs).

\subsubsection{TLRs}

Der erste Rezeptor dieser Familie wurde in Drosophila entdeckt, als ein essentieller Faktor für die Bestimmung der dorso-ventralen Polarität während der Embryogenese des Insekts (Hashimoto et al. 1988). Später wurde die wichtige Rolle dieses Rezeptors auch in der Immunabwehr des Insekts erkannt (Lemaitre et al. 1996). Homologe des Toll-Rezeptors von Drosophila, die in Säugetieren und Menschen identifiziert wurden, werden als Toll-like Rezeptoren bezeichnet (Medzhitov et al. 1997; Rock et al. 1998). Der erste TLR (nun als TLR4 bezeichnet) im menschlichen Organismus wurde 1997 charakterisiert (Medzhitov et al. 1997).

TLRs gehören zu den signalleitenden, membranständigen PRRs (Medzhitov und Janeway 2000 b). Bislang sind im menschlichen Organismus 10 Mitglieder der TLR-Familie bekannt (Seki und Brenner 2008). Aufgrund der Homologie in der intrazellulären Domäne gehören die TLRs zur Superfamilie, die auch Interleukin-1-(IL-1)-Rezeptoren einschließt. Die Domäne wird als TIR-(Toll/interleukin-1 receptor)-Domäne bezeichnet. Die extrazelluläre Domäne der TLRs unterscheidet sich stark von der des IL-1-Rezeptors: Während der Extrazellulärteil des IL-1-Rezeptors 3 Immunglobulin-ähnliche Domänen enthält, besitzen TLRs 19-25 Leucinreiche Proteinsequenzen (leucine rich repeats, LRRs) von je 24-29 Aminosäuren Länge (Akira und Takeda 2004). Die konservierte intrazelluläre Domäne der TLRs ist essentiell für die Signalübertragung (Akira und Takeda 2004), während die variante Extrazellulärdomäne für jedes TLR einzigartig ist und damit eine spezifische Ligand-Erkennung ermöglicht (Bell et al. 2003). 
Entsprechend ihrer Rolle in der Erkennung der Pathogene werden TLRs von Zellen exprimiert, die als Erstes bei der Wirtsverteidigung eingesetzt werden, wie Neutrophile, Makrophagen, dendritische Zellen, dermale Endothelzellen und Epithelzellen der Schleimhäute. TLR2 und TLR4 sind auch auf T- und B-Lymphozyten exprimiert (Armant und Fenton 2002).

Die Rezeptoren TLR1, 2, 4, 5, 6 und 10 sind auf der Zellmembran, nach außen gerichtet, exprimiert, während TLR3, 7, 8, und 9 in der endosomalen Membran, zum Lumen gerichtet, verankert sind (Szabo et al. 2006). TLR3 ist in Endosomen der dendritischen Zellen exprimiert, wurde aber auch auf der Zelloberfläche von Epithelzellen nachgewiesen (Akira et al. 2006).

Durch TLRs wird ein breites Spektrum an Produkten mikrobieller Herkunft erkannt. TLR2 erkennt mikrobielle Lipoproteine (Akira und Takeda 2004). TLR1 und TLR6 heterodimerisieren mit TLR2 und erkennen Triacyl- bzw. Diacyl-Lipopeptide (Akira et al. 2006). Unter den Liganden von TLR2 sind verschiedene Bakterien, Pilze, Protozoa (Akira und Takeda 2004; Szabo et al. 2006). TLR4 ist der wichtigste Bestandteil des LPS (Lipopolysaccharid)-Erkennungskomplexes. Dieser Komplex enthält die Ko-Rezeptoren CD14 und MD-2 (myeloid differentiation protein 2) und das LPS-bindende Protein (LBP) (Medzhitov und Janeway 2000 b). TLR5 erkennt Flagellin (Hayashi F et al. 2001). Intrazelluläre TLRs (TLR3, TLR7, TLR8 und TLR9) erkennen Nukleinsäuren. TLR3 erkennt doppelsträngige RNA (double stranded RNA, dsRNA) viraler Herkunft und deren synthetisches Analogon polyriboinosinic : polyribocytidilic acide [(poly (I : C)] (Alexopoulou et al. 2001). TLR7 erkennt nicht-methylierte virale oder synthetische einzelsträngige RNA (single stranded RNA, ssRNA) (Diebold et al. 2004) und ds short interfering RNA (siRNA) (Hornung et al. 2005). TLR8, wie auch TLR7, reagiert auf ssRNA (Heil et al. 2004). TLR9 erkennt nicht-methylierte Cytosin-Phosphat-Guanin-(CpG)-Motive der DNA (Hemmi et al. 2000).

Nach der Bindung eines Liganden an den entsprechenden TLR werden Signale über verschiedene intrazelluläre Adapter-Moleküle zu Transkriptionsfaktoren weitergeleitet, was die Ausschüttung der proinflammatorischen Zytokine (TNF- $\alpha$, IL-6, IL-12) und IFNe (IFN$\alpha / \beta)$ sowie die Expression ko-stimulatorischer Moleküle zur Folge hat. Dadurch werden antibakterielle und antivirale Antworten induziert (Takeda und Akira 2005; Akira et al. 2006). Die Spezifität der TLR-induzierten zellulären Antworten wird durch die in die LigandErkennung involvierte TLR-Kombination, Ko-Rezeptoren, intrazelluläre Adapter und intrazelluläre Signalpfade bedingt (Szabo et al. 2006). Die Adapter, die von verschiedenen 
TLRs für die Signalübertragung benutzt werden, sind unter anderen die folgenden: MyD88 (myeloid differentiation primary response protein 88), TIRAP (TIR-domain-containing adaptor protein; bekannt auch als MyD88-adaptor-like protein, MAL), TRIF (TIR-domaincontaining adaptor protein inducing IFN- $\beta$ ), und TRAM (TRIF-related adaptor molecule) (Akira und Takeda 2004). Humanen TLRs ist das Adapter-Molekül MyD88 gemeinsam, mit Ausnahme von TLR3, der TRIF gebraucht (Yamamoto et al. 2003 a; Dunne und O'Neill 2005). TLR4, als einziger, gebraucht sowohl den TRIF-abhängigen (MyD88-unabhängig), als auch den MyD88-abhängigen Signalpfad (Yamamoto et al. 2003 b).

MyD88 ist essentiell für alle TLR-vermittelten Induktionen proinflammatorischer Zytokine. IFNe können dagegen sowohl über MyD88-abhängige (vermittelt durch TLR7, TLR8 und TLR9), als auch über MyD88-unabhängige Mechanismen (vermittelt durch TLR3 und TLR4) induziert werden. Eine MyD88-unabhängige Antwort ist völlig von TRIF abhängig. Außerdem, um den MyD88-abhängigen Signalpfad zu aktivieren, brauchen TLR2 und TLR4 den Adapter TIRAP, während für die TLR4-vermittelte Aktivierung des MyD88-unabhängigen/TRIF-abhängigen Signalpfads TRAM notwendig ist. Der MyD88abhängige Weg führt zur früheren Phase der Aktivierung des nukleären Transkriptionsfaktors NF-кB, was die Produktion proinflammatorischer Zytokine nach sich zieht. Der MyD88unabhängige Weg aktiviert den IFN-regulierenden Faktor 3 (IFN-regulatory factor 3, IRF-3) und ist für die spätere Phase der NF-kB-Aktivierung verantwortlich. Die beiden (IRF-3- und spätere Phase der NF-кB-Aktivierung) führen zur Produktion von IFN- $\beta$ und zur Expression der IFN-induzierbaren Gene (Akira und Takeda 2004) (Abb. 1.1).

Entsprechend den oben beschriebenen Signalpfaden führt eine Aktivierung über TLR2 zur Produktion sowohl pro- als auch antiinflammatorischer Zytokine, aber nicht zur Freisetzung von IFNen (Takeda und Akira 2005). Eine Stimulation des TLR3 durch einen entsprechenden Liganden führt zur Aktivierung des IRF-3 und Produktion von IFNen. Eine TLR7-, 8- und 9induzierte Aktivierung scheint zellspezifisch zu sein: In plasmazytoiden dendritischen Zellen führt es zu einer hohen Produktion von Typ-I-IFNen, aber in myeloiden dendritischen Zellen und Makrophagen zur Produktion von proinflammatorischen Zytokinen (Szabo et al. 2006). Eine TLR4-Aktivierung induziert sowohl proinflammatorische Zytokine, als auch IFNe (Akira und Takeda 2004). 


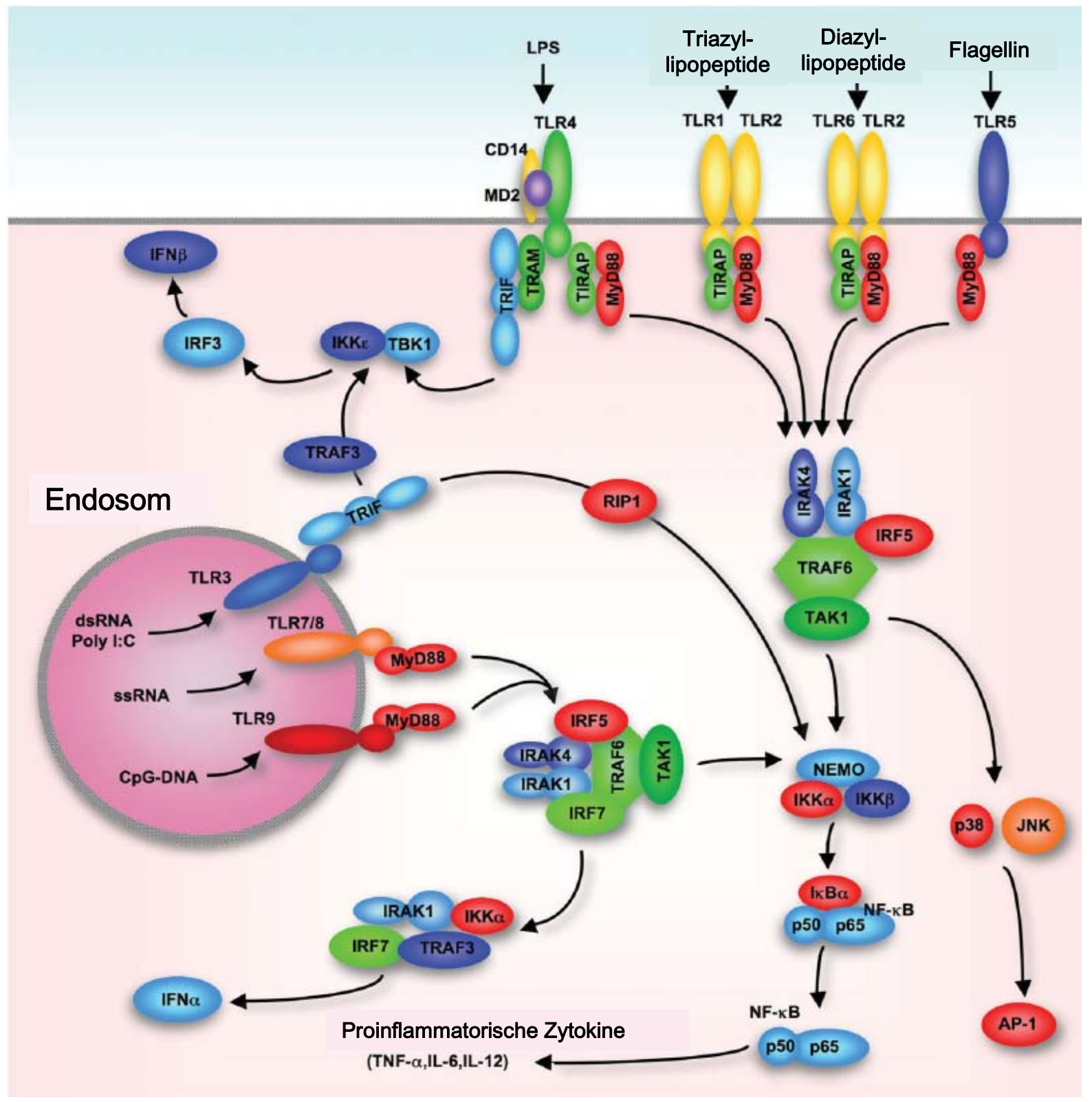

Abb. 1.1: Schematische Darstellung der TLR-Signalwege

TLR4, TLR5, TLR1/2 und TLR2/6 befinden sich auf der Zelloberfläche und erkennen LPS, Flagellin, Triazyllipopeptide und Diazyl-lypopeptide. TLR3, TLR7/8 und TLR9 sind auf der Endosommembran exprimiert und erkennen dsRNA, ssRNA und CpG-DNA. Alle TLRs, außer TLR3, benutzen MyD88 für die Signalleitung und die Aktivierung von NF-kB. Die Aktivierung von TLR3 und TLR4/TRAM führt über TRIF zur IRF-3Aktivierung und IFN- $\beta$-Produktion. TLR7/8 und TLR9 induzieren IFN- $\alpha$ über MyD88. 


\subsubsection{CD14}

CD14 (früher als gp55, My4 und My23 bezeichnet) ist neben TLR4 und MD-2 ein Bestandteil des LPS-Erkennungskomplexes.

CD14, das erstmals 1990 als ein Rezeptor für LPS beschrieben wurde (Wright et al. 1990), ist der erste dokumentierte PRR (Pugin et al. 1994), der neben der LPS-Erkennung auch an der Identifizierung von Zellwand- oder Zellmembranbestandteilen von Gram-positiven Bakterien und Mykobakterien, z.B. Peptidoglykan, Lipoteichonsäure und Lipoarabinomannan beteiligt ist (Ulevitch und Tobias 1995).

CD14 wurde zunächst auf der Oberfläche von Monozyten und Makrophagen identifiziert (Griffin et al. 1981). Später wurde die Expression dieses Rezeptors auf Monozyten quantifiziert: Es ergab sich die Zahl von 110000 Molekülen pro Monozyt (Antal-Szalmas et al. 1997). Da CD14 während der Differenzierung von Monozyten-Vorläuferzellen in reifen Monozyten stark hochreguliert wird (Griffin et al. 1981; Simmons et al. 1989), wird es als Differentiationsmarker für Monozyten / Makrophagen benutzt (Jersmann 2005). Mittlerweile ist bekannt, dass CD14 in geringer Dichte auch auf Neutrophilen, Basophilen, dendritischen Zellen und Lymphozyten exprimiert wird. Des Weiteren wurde es auch auf nicht-myeloiden Zellen wie Endothel- und Epithelzellen, glatten Muskelzellen, Fibroblasten, Spermatozoa und pankreatischen Inselzellen gefunden (Jersmann 2005). CD14-Expression in menschlichen Hepatozyten wurde erstmals 1999 experimentell nachgewiesen (Hetherington et al. 1999; Su et al. 1999). Es ist gezeigt worden, dass die Gewebe-spezifische Expression von CD14 auf der Transkriptionsebene stattfindet (Zhang DE et al. 1994 a; Zhang DE et al. 1994 b) und dass die Expression von CD14 im menschlichen Organismus in verschiedenen Zellen (Monozyten und Hepatozyten) unterschiedlich reguliert wird (Pan et al. 2000).

Neben dem membranständigen CD14-Rezeptor (mCD14) auf Zelloberflächen gibt es auch eine lösliche Form des CD14 (soluble CD14, sCD14).

mCD14 ist ein $55 \mathrm{kDa}$-Glykoprotein, das sich mehrfach wiederholende Leucin-reiche Sequenzen enthält (Setoguchi et al. 1989; Ferrero et al. 1990). mCD14 besitzt keine transmembrane Domäne und wird auf der Zellmembran durch Glykosylphosphatidylinositol (GPI) verankert (Haziot et al. 1988). Der GPI-Anker wird dem CD14-Molekül am Cterminalen Ende im endoplasmatisches Retikulum zugefügt (Haziot et al. 1988).

Der löslichen Form des Rezeptors, dem sCD14, fehlt der GPI-Anker (Haziot et al. 1988). Das Vorhandensein von sCD14 in beträchtlichen Konzentrationen wurde im Serum und anderen Körperflüssigkeiten (zerebro-spinale Flüssigkeit, Urin, seminale Flüssigkeit, Speichel, Tränen, Brustmilch) beschrieben (Vidal und Donnet-Hughes 2008). Die Serumkonzentration 
des sCD14 beträgt in gesunden Menschen ca. $4 \mu \mathrm{g} / \mathrm{ml}$ und erhöht sich bei manchen Krankheiten (Ulevitch und Tobias 1995), z. B. bei vielen chronischen Infektions- und Entzündungskrankheiten wie Borreliose, Tuberkulose, Periodontitis und Kawasaki-Syndrom (Lin B et al. 2000; Juffermans et al. 1998; Hayashi J et al. 1999; Takeshita et al. 2000). Klinische Studien zeigen auch, dass der sCD14-Spiegel im Serum bei Sepsis und Trauma steigt (Krüger et al. 1991; Landmann et al. 1996; Landmann et al. 1995; Burgmann et al. 1996).

Zum Ursprung des sCD14 werden zwei Mechanismen vermutet: Abspaltung des Rezeptors von Monozyten durch Proteasen und Phospholipasen (Bazil et al. 1989) oder eine direkte Sekretion der Moleküle unter Umgehung des GPI-Verankerungmechanismus (Labeta et al. 1993; Bufler et al. 1995). Entsprechend sind zwei Formen des sCD14 im Serum konstitutiv nachweisbar: Eine Form ist ca. 50 kDa-Molekül, die nach der Abspaltung von zellgebundenem Rezeptor entsteht (Bazil et al. 1986; Haziot et al. 1988; Haziot et al. 1993), die zweite, mit höherem Molekulargewicht (ca. $56 \mathrm{kDa}$ ) wird von der Zelle vor der GPIVerankerung sezerniert (Labeta et al. 1993; Bufler et al. 1995). An der Produktion des sCD14 sind Hepatozyten erheblich beteiligt (Pan et al. 2000).

\subsubsection{LPS und dessen Erkennung durch den TLR4-CD14-MD-2-Rezeptorkomplex}

LPS. LPS (so wird die gereinigte Form des bakteriellen Endotoxins genannt) macht einen Großteil der äußeren Membran der Gram-negativen Bakterien aus und ist essentiell für deren Überleben. Endotoxine, im Unterschied zu Exotoxinen, lösen ihre toxischen Effekte nicht durch die Tötung der Wirtszellen oder durch die Lähmung der Zellfunktionen aus, sondern durch eine aktive Antwort der Wirtszellen, die eigentlich gegen eingedrungene Pathogene gerichtet ist (Rietschel et al. 1994). LPS besteht aus Lipid (Lipid A), das die Matrix der äußeren Membran von Bakterien ausmacht, und Polysaccharid (PS), welches von der bakteriellen Zellwand nach außen gerichtet ist. PS besteht im Allgemeinen aus zwei unterschiedlichen Regionen, dem core Oligosaccharid (bestehend aus 10-12 Zuckern) und einer hochvariablen, Serotyp-spezifischen Polysaccharidkette (O-Kette) (Caroff et al. 2002) (Abb. 1.2). Die toxische Wirkung des LPS wird durch Lipid A vermittelt, denn das ist gerade die Komponente, wodurch LPS verschiedene Zellen des Wirtsorganismus (mononukleäre Zellen, Endothel- und Glattmuskelzellen, polymorphkernige Granulozyten, Thrombozyten) aktiviert (Rietschel et al. 1994). 


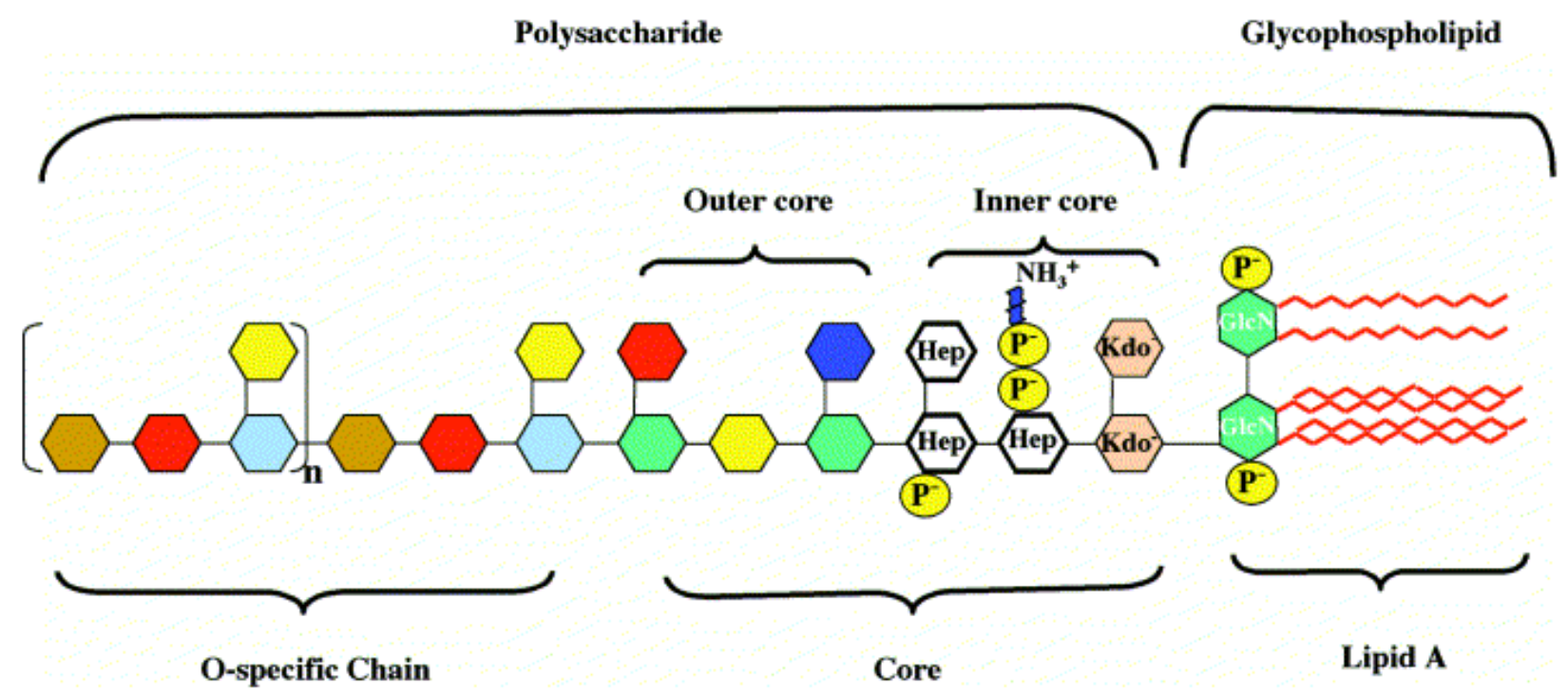

Abb. 1.2: Struktur von LPS

Das LPS-Molekül besteht aus Lipid (Lipid A), das durch divalente Kationen stabilisiert ist, und hydrophilem Polysaccharid (PS). PS besteht in der Regel aus zwei unterschiedlichen Regionen, dem Kernoligosaccharid (core oligosaccharide), das 10-12 Zucker enthält, und einer Polysaccharidkette von sich wiederholenden Einheiten, die als O-spezifische Kette bezeichnet wird. Der Kern ist durch einen sauren Zucker, in der Regel 3-deoxy-Dmanno-oct-2-ulopyranosonic acid (Kdo), mit Lipid A kovalent verbunden. Der innere Teil des Kerns (,,inner core ") enthält Heptosereste (Hep), die oft durch Phosphat (P), Pyrophosphat (PP) oder Diphosphoethanolamin (PPEtN) ersetzt werden. Der äußere Anteil des Kerns (,outer core“) besteht in der Regel aus neutralen Hexosen oder Aminohexosen wie D-Glukose, D-Galaktose, D-Glukosamin, D-Galaktosamin oder N-Azetylderivate

(Caroff et al. 2002, S. 916)

Man unterscheidet zwischen "glattem" (mit O-spezifischer Kette) und "rauem" (ohne Ospezifische Kette) LPS. „Glattes“ LPS wird von Wildtyp-Bakterien produziert, die glatte Kolonien bilden. „Raues“ LPS wird dagegen von mutierten Bakterien hergestellt, deren Kolonien eine charakteristische raue Form besitzen (Caroff et al. 2002).

Das hydrophobe Lipid A ist durch andere Teile des LPS von der wasserhaltigen Umgebung abgegrenzt. In Gram-negativen Bakterien sitzt Lipid A in der äußeren Membran, nach der Extraktion und Reinigung ist es innerhalb der großen Aggregate eingeschlossen (Abb. 1.3) (Gioannini und Weiss 2007). 

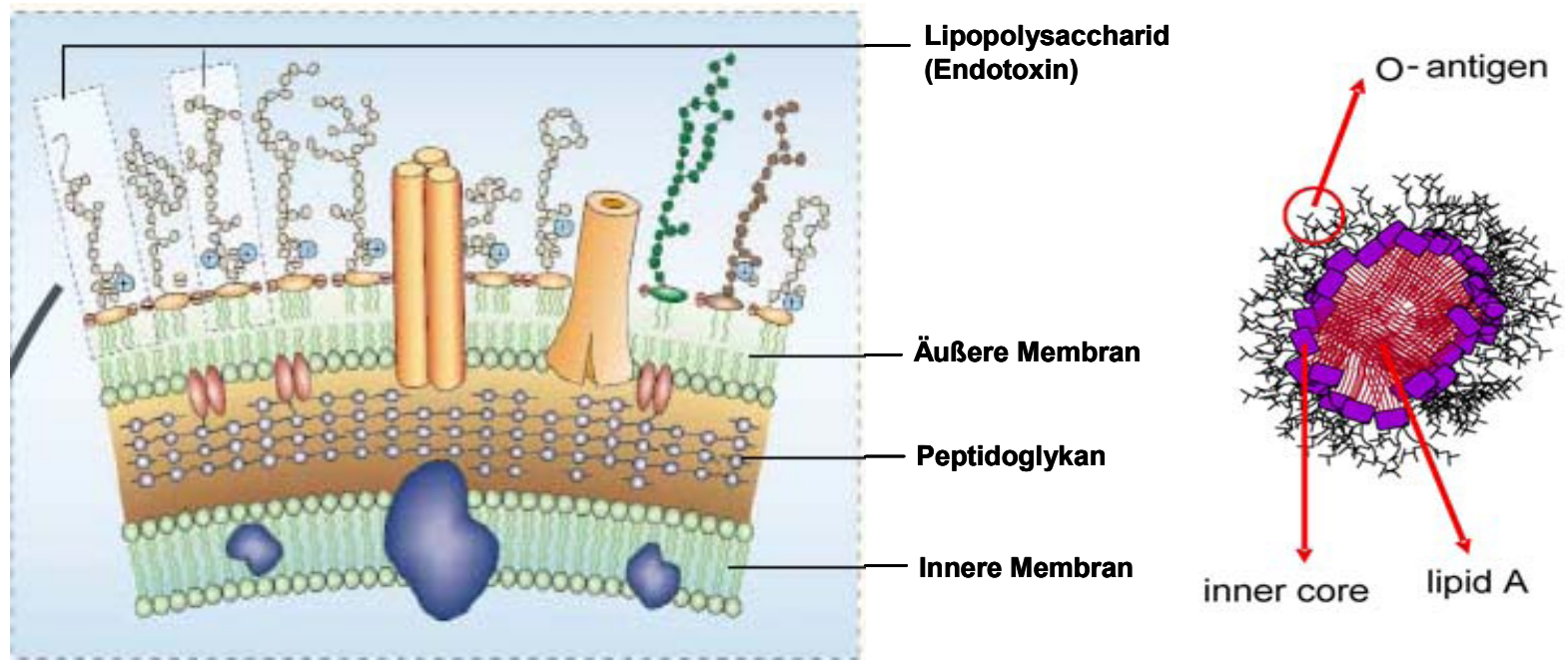

Abb. 1.3: Lokalisation des LPS (Endotoxin) in bakterieller Zellwand (links) und Organisation der großen Aggregate des gereinigten Endotoxins nach der Extraktion aus Bakterien (rechts)

Das hydrophobe Lipid A ist immer durch andere Teile des LPS von der wasserhaltigen Umgebung abgegrenzt. Als ein integraler Teil der Zellwand von Gram-negativen Bakterien sitzt es in der äußeren Membran (links), nach der Extraktion aus Bakterien ist das Lipid A innerhalb der großen Aggregate eingeschlossen (rechts).

(modifiziert nach Beutler und Rietschel 2003, S. 171, Gioannini und Weiss 2007, S. 251)

Erkennung von LPS. Für die Erkennung des LPS durch das angeborene Immunsystem sind neben CD14 noch die folgenden Proteine notwendig: LBP, MD-2 und TLR4 (Beutler und Rietschel 2003; Gioannini et al. 2005; Beutler et al. 2006). LBP wird in der Leber produziert und die Produktion steigert sich in Anwesenheit von großen Mengen des LPS (Beutler und Rietschel 2003). LBP katalysiert die Extraktion der Endotoxinmonomere aus der äußeren Membran der Bakterien oder aus gereinigten Aggregaten des Endotoxins und deren Übertragung an CD14-Moleküle, so dass Endotoxinmonomer:CD14-Komplexe gebildet werden. Von diesen Komplexen werden Endotoxinmonomere auf MD-2 übertragen und Endotoxinmonomer:MD-2-Komplexe gebildet. Die letzteren sind imstande, in pikomolaren Konzentrationen TLR4 zu aktivieren und eine starke Zellreaktion zu verursachen (Gioannini et al. 2005). Das Zusammenspiel von LBP, CD14 und MD-2 kann ein Gram-negatives Bakterium, das ca. $10^{6}$ Endotoxinmoleküle enthält, in $10^{6}$ TLR4-aktivierende Endotoxinmonomer:Protein-Komplexe verwandeln, die die Aktivierung von etwa $10^{3}$ Wirtszellen vermögen. Das ermöglicht dem angeborenen Immunsystem, bereits auf wenige Bakterien zu reagieren (Gioannini und Weiss 2007).

1990 wurde gezeigt, dass LPS über die Aktivierung von NF- $\kappa$ B zur Induktion von TNF- $\alpha$ führen kann (Shakhov et al. 1990). Auch 1990 wurde CD14 als eine Komponente des LPSRezeptorkomplexes erkannt (Wright et al. 1990). Da dem CD14 jedoch eine intrazelluläre 
Domäne fehlt, war lange Zeit nicht klar, über welchen Signalpfad LPS durch CD14 zu einer Zellaktivierung führen konnte. Erst 1998 wurde TLR4 als eine essentielle signalleitende Komponente des LPS-Rezeptorkomplexes erkannt (Poltorak et al. 1998 a; Poltorak et al. 1998 b).

Wie oben schon erwähnt (siehe 1.1.1.1), stehen dem TLR4 sowohl MyD88-abhängige als auch MyD88-unabhängige Signalpfade zur Verfügung. Für eine MyD88-unabhängige IRF3aktivierende Signalleitung ist aber CD14 notwendig. CD14 ermöglicht TLR4 auf glattes LPS zu reagieren. TLR4 im Komplex mit MD-2 in Abwesenheit von CD14 kann nur raues LPS

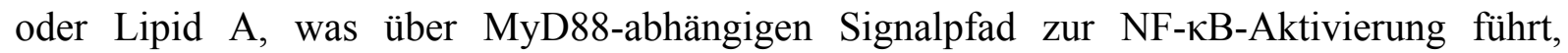
erkennen (Beutler et al. 2006). Eine Stimulation des CD14-TLR4-MD-2-Komplexes durch LPS aktiviert beide Signalpfade (MyD88-abhängigen und -unabhängigen) synergistisch, so dass die Zelle über die Aktivierung von NF-kB und IRF3 sowohl proinflammatorische Zytokine als auch IFNe ausschüttet (Abb. 1.4) (Godowski 2005; Beutler et al. 2006). 


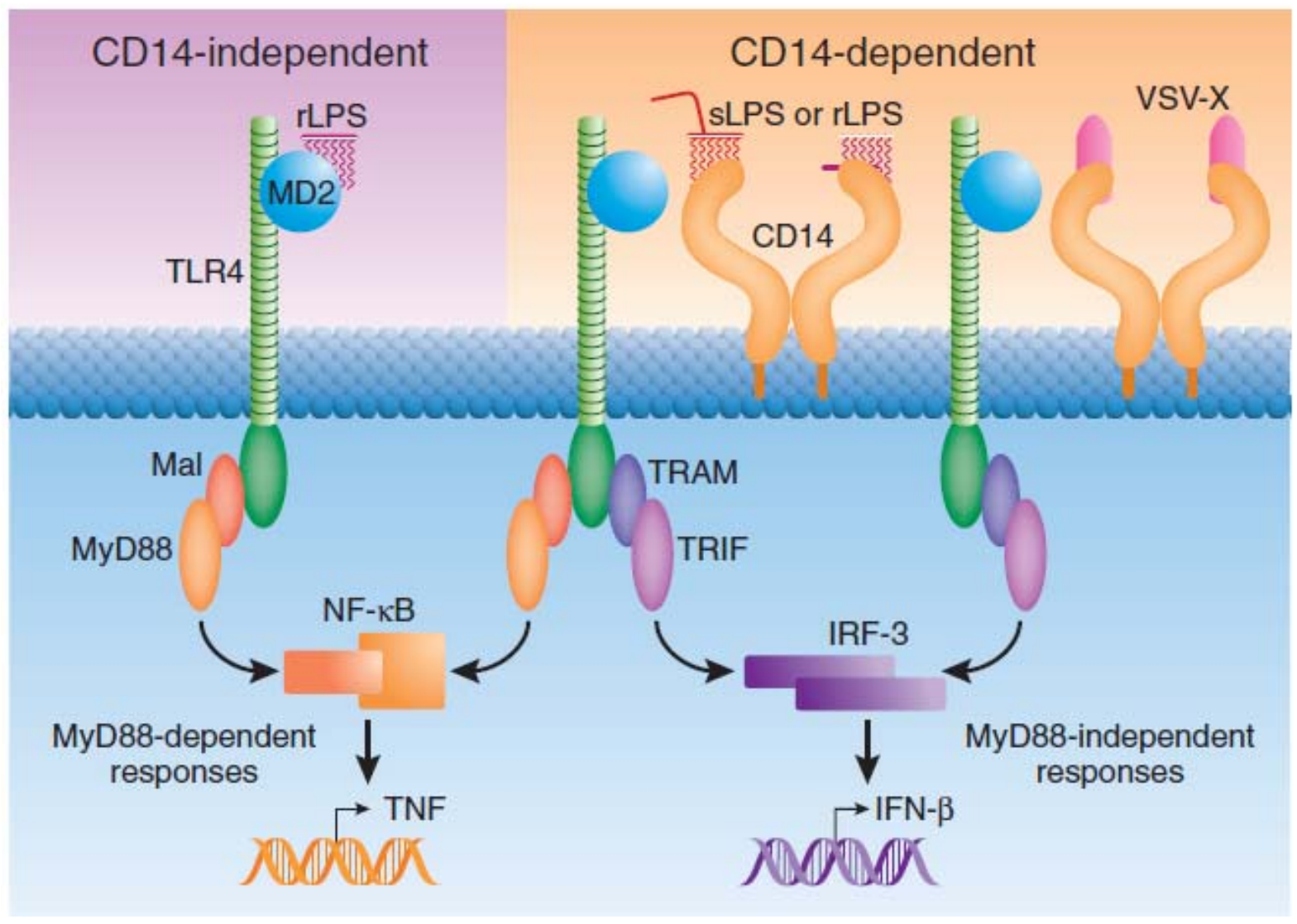

Abb. 1.4: CD14-unabhängige und CD14-abhängige Signalleitung von TLR4-MD-2

TLR4-MD-2 kann ohne CD14 raues, aber kein glattes LPS binden. Dabei können Signale nur über den MyD88abhängigen Pfad durch die Adapter Mal und MyD88 weitergeleitet werden, um NF-kB zu aktivieren, was TNFTranskription zur Folge hat. In Anwesenheit von CD14 kann TLR4-MD-2 sowohl raues LPS (rough LPS, rLPS) als auch glattes LPS (smooth LPS, sLPS) binden. Dabei wird zusätzlich noch der MyD88-unabhängige Signalpfad über die Adapter TRAM und TRIF aktiviert. Dies führt zur IRF3-Aktivierung und IFN- $\beta$ Transkription.

(Godowski 2005, S. 545)

Die Tatsache, dass TLR4 mehrere zelluläre Adapter einbezieht und gleichzeitig zwei Signalpfade aktiviert, ist eine mögliche Erklärung für die starke immunstimulierende Wirkung des LPS, welches einen Endotoxinschock auslösen kann (Akira und Takeda 2004). Ähnlich dem mCD14 kann auch sCD14 LPS-Monomere aus LPS-LBP-Komplexen binden (Thomas et al. 2002). Durch Übertragung der LPS-Monomere auf CD14-positive (Hailman et al. 1996) und CD14-negative (Epithel-, Endothel- und Glattmuskelzellen) Zellen (Frey et al. 1992; Pugin et al. 1993) kann sCD14 an der Zellaktivierung teilnehmen. 


\subsubsection{Regulation der Zellantwort auf LPS}

LBP und sCD14 können die zelluläre Antwort auf LPS nicht nur stimulieren, sondern, abhängig von deren Konzentration, auch inhibieren.

Experimentell konnte gezeigt werden, dass niedrige LBP-Konzentrationen die Zellstimulation begünstigen, während hohe Konzentrationen inhibierend sind (Lamping et al. 1998). Eine Inhibition der zellulären Antwort durch LBP kann über drei Mechanismen erfolgen: (1) LBP kann LPS statt auf CD14 auf Plasmalipoproteine übertragen (Wurfel et al. 1994), (2) LBP kann mit LPS-Aggregaten große Komplexe bilden, die keine Signalleitung durch MD2/TLR4 vermögen, sondern über die Bindung an mCD14 internalisiert und eliminiert werden (Gegner et al. 1995; Gioannini et al. 2003) und (3) LBP kann schon mit mCD14 gebundenes LPS abziehen und an die Zelle als LPS-LBP-Komplex binden, was zu keiner Zellaktivierung führt (Thompson et al. 2003) (Abb. 1.5). Die Konzentration von LBP im Serum erhöht sich während einer akuten Infektion, so dass die Antwort von Monozyten auf LPS deutlich inhibiert wird (Zweigner et al. 2001).

sCD14 kann im unverdünnten Serum von Menschen die Zellantwort auf LPS vermindern, indem es mit mCD14 um LPS konkurriert und es auf Plasmalipoproteine überträgt. In Anwesenheit von Plasmalipoproteinen kann also LPS von mCD14 und sCD14 fortschreitend abgezogen und eliminiert (clearence) werden (Kitchens und Thompson 2005) (Abb. 1.6). Die sCD14-Konzentration erhöht sich während einer akuten Entzündung und Sepsis, wodurch der LPS-Abzug von mCD14 der Monozyten verstärkt wird (Kitchens et al. 2001). Auf diese Weise kann sCD14 systemische antiinflammatorische Wirkungen ausüben, während es in Geweben bzw. in extravaskulären Kompartimenten mit niedrigen basalen Werten von sCD14 und Plasmalipoproteinen proinflammatorisch wirkt (Kitchens und Thompson 2005).

Diese dualen, konzentrations- und umgebungsabhängigen Wirkungen von LPB und sCD14 sind während einer Infektion für den Wirtsorganismus vorteilhaft: Einerseits schützen sie vor einer gefährlichen systemischen Reaktion auf LPS, andererseits fördern sie Entzündungsreaktion in Geweben und damit die Bekämpfung der Pathogene (Kitchens und Thompson 2005). 


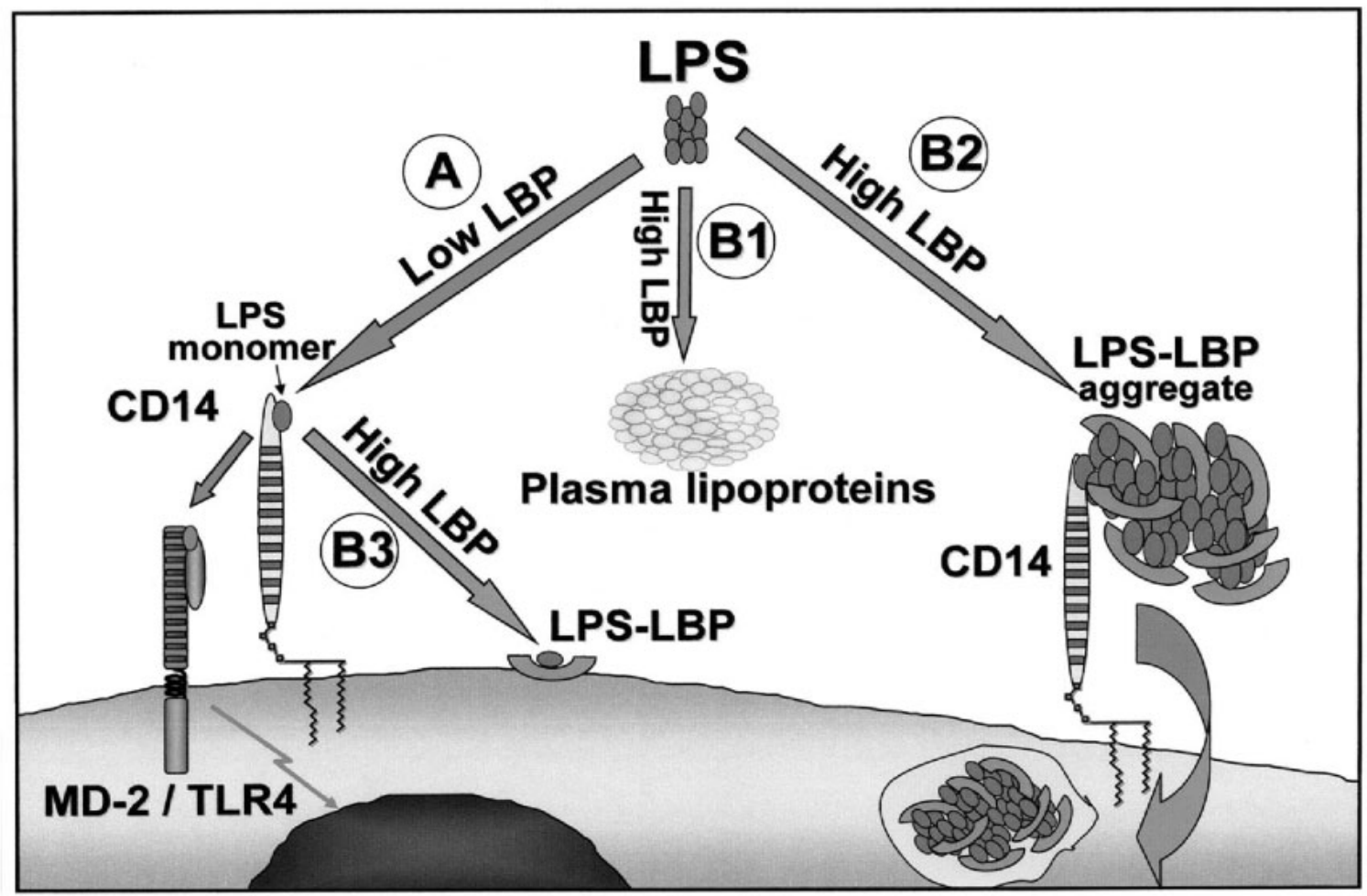

Abb. 1.5: Konzentrationsabhängige Wirkung von LBP auf die Zellantwort auf LPS

In niedriger Konzentration überträgt LBP LPS-Monomere auf den CD14-MD-2-TLR4-Komplex und führt dadurch zur Stimulation der Zelle (A). In höheren Konzentrationen kann LBP LPS auf Plasmalipoproteine übertragen (B1), LBP-LPS-CD14-Aggregate bilden, die internalisiert werden (B2), oder mit mCD14 um bereits gebundenes LPS konkurrieren und als LPS-LBP-Komplex an die Zelle binden (B3). In allen drei Fällen wird die Antwort der Zelle auf LPS durch hohe Konzentrationen von LBP unterdrückt.

(Kitchens und Thompson 2005, S.226) 


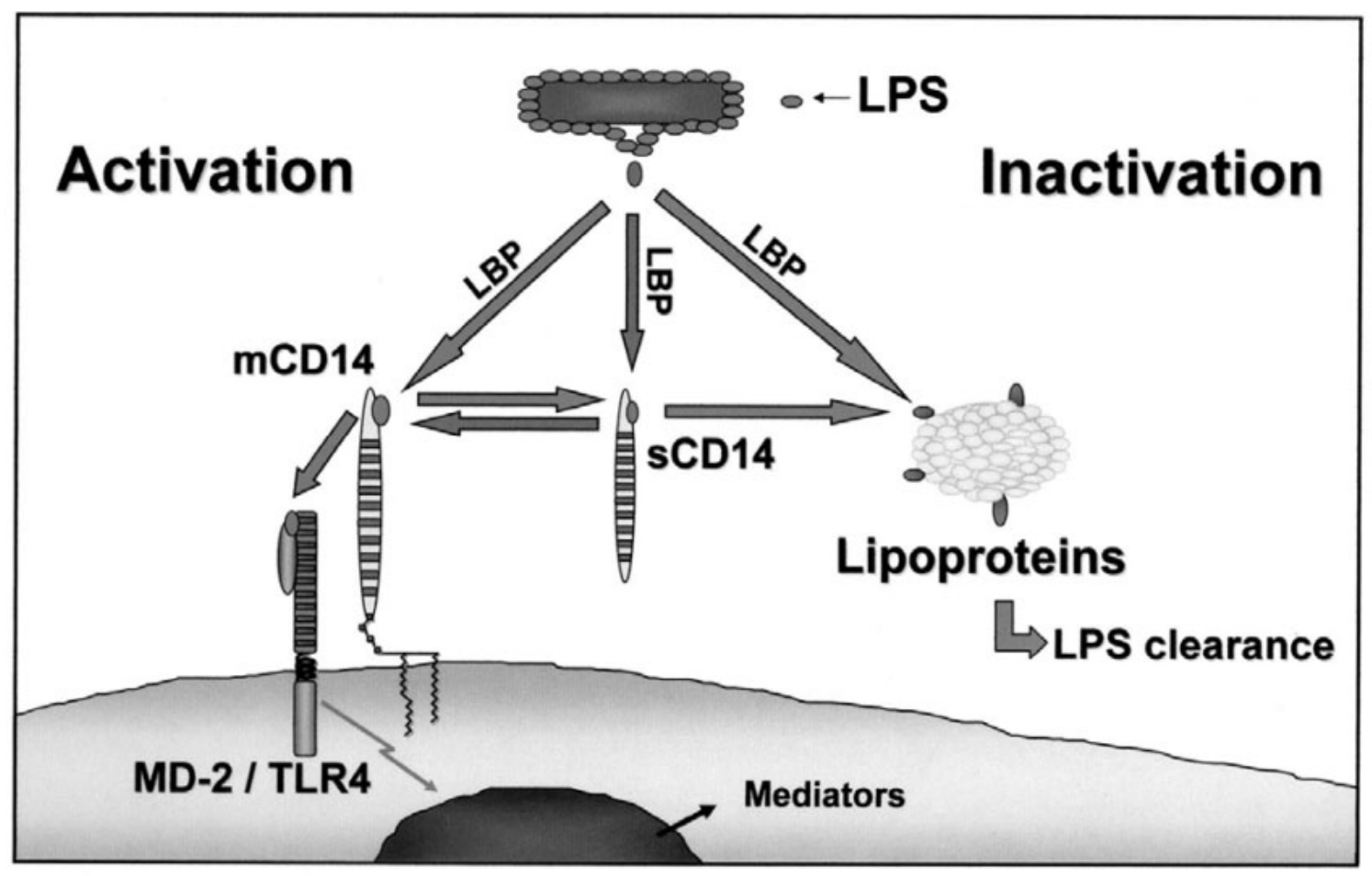

Abb. 1.6: Inhibierender Mechanismus von sCD14

sCD14 kann LPS von mCD14 abziehen, und auf Plasmalipoproteine übertragen und damit die Zellaktivierung inhibieren. Durch Plasmaproteine kann LPS von mCD14 und sCD14 progressiv abgezogen werden.

(Kitchens und Thompson 2005, S. 227)

\subsubsection{TLR4 und CD14 in der Leber}

Die Leber umfasst einen Netzwerk von parenchymalen und nicht-parenchymalen Zellen, die verschiedene TLRs exprimieren (Szabo et al. 2006). Hepatozyten exprimieren mRNA für alle TLRs (Nishimura und Naito 2005).

Kupffer-Zellen (Lebermakrophagen) und sinusoidale Endothelzellen der Leber exprimieren TLR4 und CD14 und reagieren mit NF-kB-Aktivierung (und Produktion der proinflammatorischen Zytokine und reaktiven Sauerstoffradikale) auf LPS-Stimulation (Schwabe et al. 2006).

TLR4 und CD14 werden auch durch Lebersternzellen (hepatic stellate cells, HSCs) exprimiert. Dementsprechend reagieren HSCs auf LPS (NF-kB-Aktivierung, Produktion der proinflammatorischen Zytokine) (Szabo et al. 2006).

Die Gram-negative Flora im Darm ist ein beträchtliches Reservoir des endogenen LPS. LPS wird vom Darm absorbiert und über die Pfortader zur Leber übertragen, wo es schnell durch Kupffer-Zellen detoxifiziert wird (Nolan 1975). 


\subsubsection{CD14 und Atopie}

CD14 spielt auch eine Rolle in der Entwicklung der atopischen Reaktionen, die durch IgE vermittelt werden. Es ist bekannt, dass IgE-Antworte durch die Signale von Typ Th1(inhibierend) und Typ Th2-Zellen (stimulierend) reguliert werden (Romagnani 1992). Es konnte auch gezeigt werden, dass CD14-Stimulation durch Bakterienbestandteile mit einer starken IL-12-Antwort der antigen-präsentierenden Zellen (Monozyten, Makrophagen, dendritischen Zellen) assoziiert ist (Cleveland et al. 1996; Yoshida und Koide 1997; Jiang et al. 2002). IL-12 seinerseits lenkt die Ausreifung der naiven T-Zellen in Th1-Zellen (Macatonia et al. 1995). Also, zusammenfassend, CD14-Stimulation durch Bakterienbestanteile führt, über eine verstärkte Produktion von IL-12, zu Th1-Differenzierung der naiven T-Zellen und dadurch zu einer verminderten IgE-Antwort. 


\subsection{Hepatitis C}

\subsubsection{Erreger der Hepatitis C}

Erreger der Hepatitis $\mathrm{C}$, das Hepatitis-C-Virus (HCV) ist ein umhülltes, einzelsträngiges RNA-Virus mit positiver Polarität (ss(+)RNA). Das Viruspartikel besitzt eine sphärische Form mit einem Durchmesser von 40-70 nm (Kaito et al. 1994). Das Virus wurde 1989 entdeckt (Choo et al. 1989) und als einziger Vertreter der Gattung Hepacivirus der Familie Flaviviridae zugeordnet (Robertson et al. 1998).

Aufgrund der Ungenauigkeit der HCV-RNA-Polymerase und mangelnder replikativen Reparaturmechanismen weist HCV eine ausgeprägte genetische Heterogenität auf. Gemäß der Sequenzanalyse werden die HCV-Genome in mindestens 6 Genotypen (1-6) und in etwa 50 Subtypen (1a, 1b, 3a usw.) unterteilt (Hoofnagle 2002; Robertson et al. 1998; Simmonds et al. 2005).

\subsubsection{Strukturelle Organisation und Replikation des Virus}

HCV ist von einer Lipidhülle umgeben, in die die beiden glykosylierten Oberflächenproteine E1 und E2 verankert sind. Die Virushülle umschließt das Nukleokapsid, das aus dem core(C)-Protein und dem RNA-Genom mit ca. 9.600 Basen gebildet wird (Abb. 1.7). Das Genom enthält einen einzigen offenen Leserahmen (open reading frame, ORF), über den ein ca. 3000 Aminosäuren langes Polyprotein kodiert wird. Das Polyprotein wird während und nach der Translation durch zelluläre und virale Proteasen in Struktur- und Nicht-Struktur-Proteine (NS) gespalten (Bartenschlager et al. 2004).

Das erste translatierte Protein vom 5'-terminalen Bereich des HCV-Genoms ist das C-(core)Protein. C-Proteine bilden ein Kapsid aus, das eine Kopie des viralen Genoms umschließt. Die Proteine E1 und E2 sind wahrscheinlich Glykoproteine der Virushülle, die zur Verankerung des Virus an der Zielzelle (E2) und zur anschließenden Abgabe des Genoms in das Zytoplasma (vermutlich E1) dienen (Bartenschlager et al. 2004).

Das kleine hydrophobe Protein p7 bildet den Übergang zu den NS-Proteinen. Es fungiert vermutlich als ein Ionen-Kanal (Bartenschlager et al. 2004).

Bei NS2-NS5B handelt es sich um Proteine, die für die Prozessierung der viralen Proteine und die Virusreplikation verantwortlich sind (Bartenschlager et al. 2004).

HCV-Partikel binden an die Wirtszelle über eine spezifische Interaktion zwischen den HCVHüllproteinen (E1, E2) und noch nicht genau definierten Rezeptoren (vermutlich CD81, human scavenger receptor class B type I(SR-BI), low density lipoprotein (LDL) receptor). 


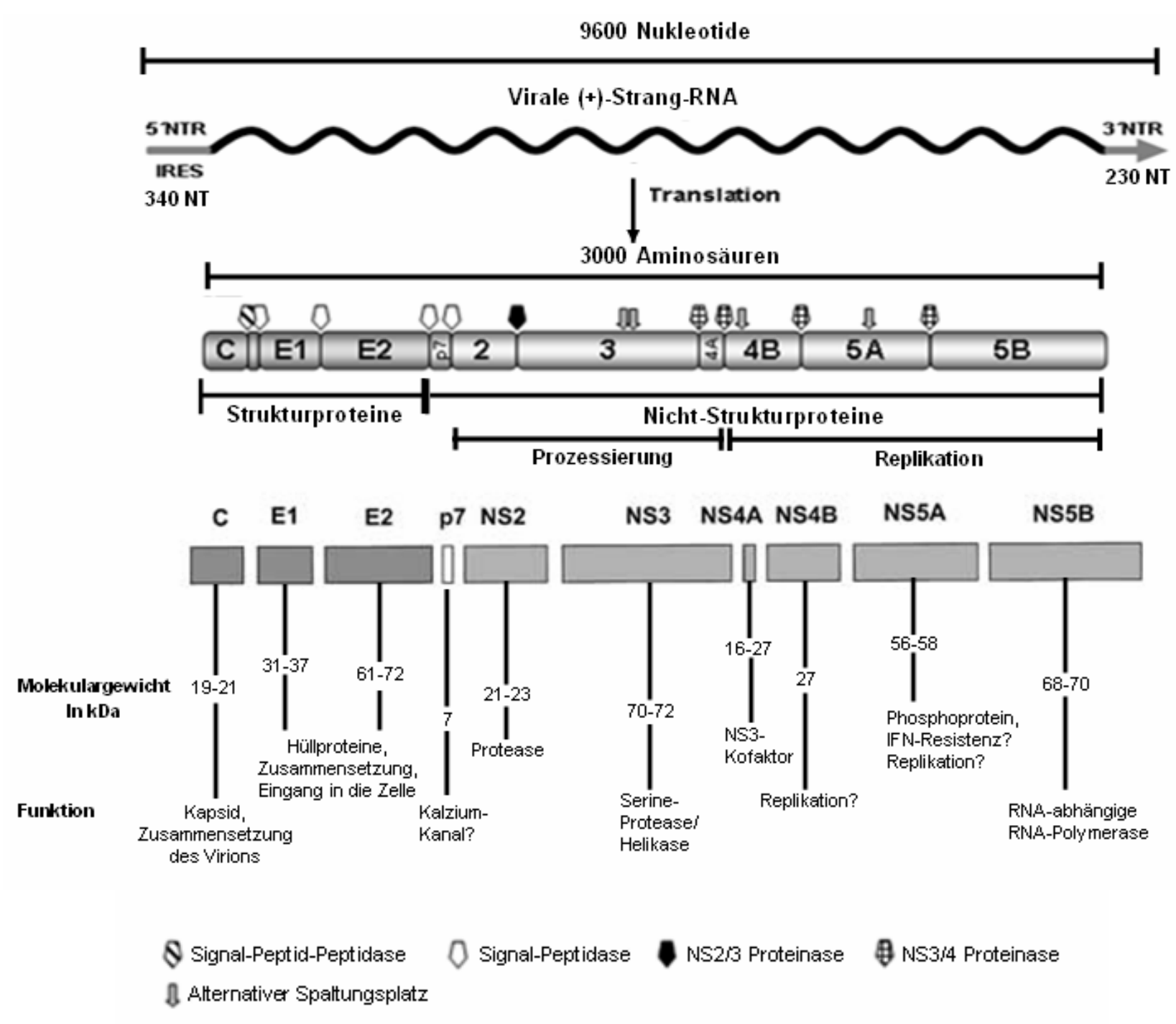

Abb. 1.7: Genomische Organisation des HCV und Prozessierungswege des Polyproteins

Das RNA-Genom des HCV mit ca. 9600 Basen kodiert für ein 3000 Aminosäuren langes Polyprotein. Das Polyprotein wird während und nach der Translation durch zelluläre und virale Proteasen in Struktur- und NichtStruktur-Proteine gespalten. Strukturproteine (C, E1 und E2) dienen zum Aufrechterhalten der äußeren Struktur des Virus, Nicht-Struktur-Proteine (p7, NS2, NS3, NS4A, NS4B, NS5A, NS5B) sind für die Prozessierung der viralen Proteine und die Virusreplikation verantwortlich.

(modifiziert nach Hoofnagle 2002, S. 22 und Bartenschlager et al. 2004, S. 75)

Gebundene Viruspartikel gelangen in die Zelle wahrscheinlich durch eine Rezeptorvermittelte Endozytose. Dort wird das virale Genom vom Nukleokapsid freigesetzt (uncoating) und am rauen endoplasmatischen Retikulum (rER) translatiert. Durch virale und zelluläre Proteasen wird das Polyprotein in die einzelnen, oben beschriebenen Proteine gespalten (Bartenschlager et al. 2004).

NS4B (vielleicht mithilfe anderer viraler oder zellulärer Faktoren) induziert die Formierung von Membranvesikeln (auch als membranous web genannt). Diese Membranen dienen 
wahrscheinlich als Gerüst für den viralen Replikationskomplex. Die RNA-abhängige RNAPolymerase (NS5B) schreibt zunächst die (+)-Strang-RNA in eine komplementäre (-)-StrangRNA, wobei als Intermediat ds RNA entsteht (Abb. 1.8) Dieses replikative Intermediat dient vor allem der Vervielfältigung von (+)-Strang-RNA (Bartenschlager et al. 2004).

Nach der Genomamplifikation und HCV-Proteinexpression werden die Virione zusammengesetzt (vermutlich im ER oder im Golgi-Apparat) und über den sekretorischen Weg in einem nicht-lytischen Prozess aus der Zelle freigesetzt (Bartenschlager et al. 2004).

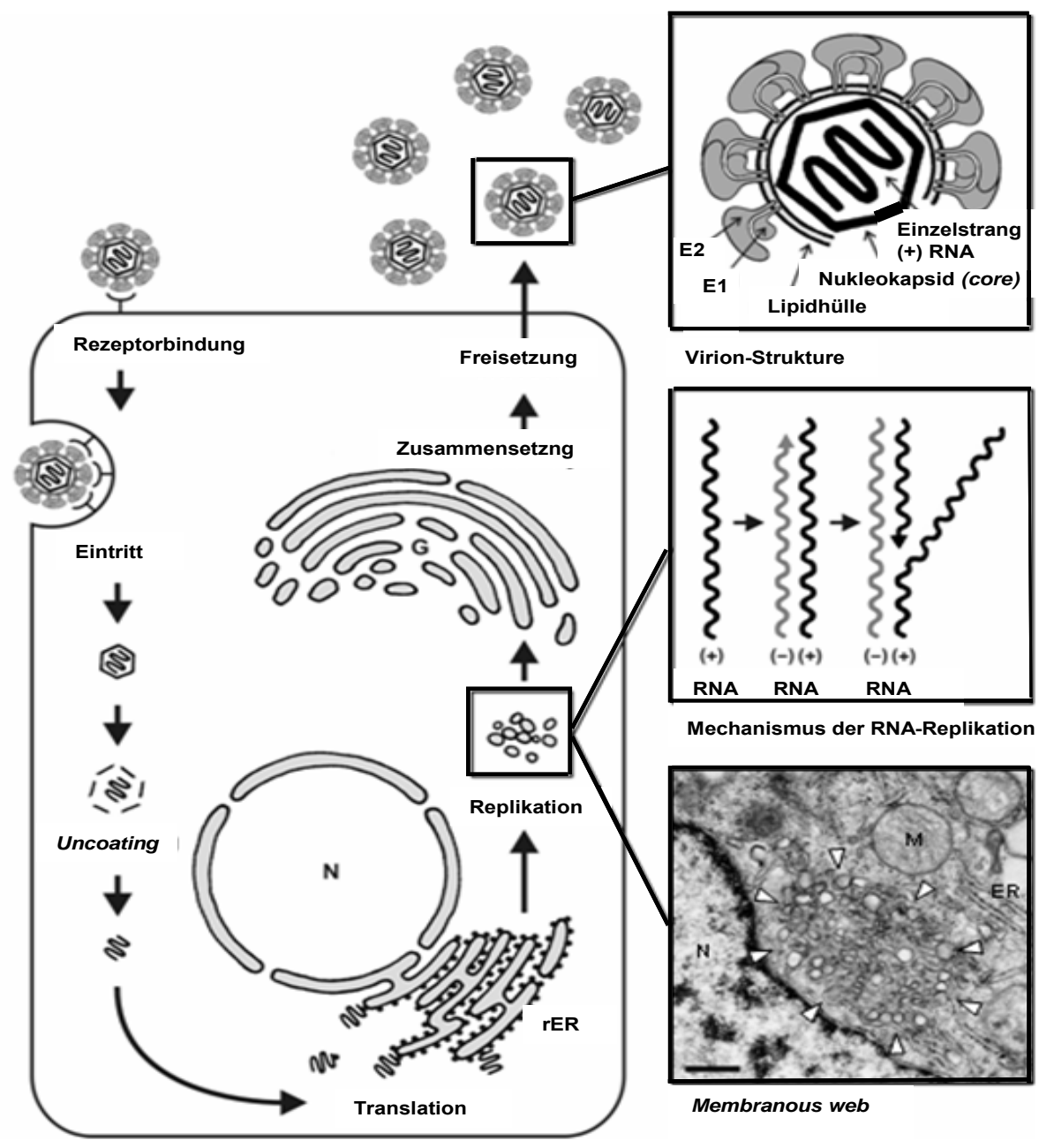

Abb. 1.8: HCV-Replikationszyklus

Das obere rechte Panel der Abbildung ist eine schematische Darstellung des HCV-Partikels. Das mittlere Panel stellt ein Modell für Synthese der (-)-Strang-RNA und (+)-Strang-RNA über das ds replikative Intermediat. Das untere Panel zeigt eine elektronenmikroskopische Aufnahme der Membranvesikel in einer Huh-7-Zelle, die subgenomische HCV-RNA enthält.

N: Nukleus; rER: raues Endoplasmatisches Retikulum; M: Membranvesikel / engl.: membranous web; G: GolgiApparat. 


\subsubsection{Epidemiologie der Hepatitis C}

Nach Angaben der WHO sind ca. 170 Millionen Menschen (3\% der Weltbevölkerung) weltweit chronisch mit dem HCV infiziert. Jährlich gibt es 3-4 Millionen Neuinfektionen. Die Prävalenz ist in Staaten Afrikas, dem östlichen Mittelmeerraum und der Westpazifik-Region signifikant höher als in Nordamerika und Europa (WHO 2009).

In Deutschland leben ca. 400.000-500.000 Virusträger, das entspricht etwa $0,5 \%$ der Gesamtbevölkerung. Im Jahr 2006 betrug die Inzidenz der Hepatitis C in Deutschland 9,1 Fälle pro 100.000 Einwohner (Radun 2007).

Die Erkrankung wird vorwiegend durch eine perkutane Exposition übertragen (intravenöser Drogenmissbrauch, Transfusion von Blut und/oder Blutprodukten, Nadelstichverletzung). Geschlechtsverkehr und vertikale Transmission spielen eher eine untergeordnete Rolle (Shepard et al. 2005).

\subsubsection{Der natürliche Verlauf einer HCV-Infektion}

Eine Infektion mit HCV weist eine ausgeprägte Neigung zur Chronifizierung auf. 75-85\% von HCV-infizierten Patienten entwickeln eine chronische Infektion (Hoofnagle 2002; Chen und Morgan 2006).

Ungefähr 10-15\% der chronisch HCV-infizierten Patienten entwickeln eine Leberzirrhose innerhalb der ersten 20 Jahre nach Infektion (Chen und Morgan 2006). Der andere Teil der Patienten haben Leberentzündung verschiedenes Grades, ohne dass sich eine Fibrose entwickelt oder, falls besteht, nicht fortschreitet (Flamm 2003). Zur Zirrhoseentwicklung können verschiedene Faktoren wie genetische Veranlagung, Alkoholkonsum, Fettleibigkeit, Koinfektionen oder andere begleitende Krankheitszustände beitragen (Flamm 2003; Chen und Morgan 2006).

Bei einer Zirrhose können sich wiederum Komplikationen wie Aszites, Enzephalopathie, variköse Blutung und hepatozelluläres Karzinom entwickeln (Flamm 2003). 


\subsection{Leberfibrose}

Leberfibrose ist eine universelle Antwort der Leber auf chronisch wirkende toxische, infektiöse, metabolische oder autoimmune Schädigungsfaktoren. Sie ist gekennzeichnet durch die abnormale Akkumulation der extrazellulären Matrix (ECM), die eine Formierung fibrotischer Narben bedingt. Der Prozess, der zur Leberfibrose führt, ähnelt dem der Wundheilung: (1) Akute Entzündung, die der Schädigung folgt und mäßige Zellnekrose nach sich zieht; (2) Zellregeneration und Synthese der ECM und (3) Formierung der fibrotischen Narbe (Saile und Ramadori 2007). Die sich anschließende Entwicklung der Knoten von regenerierenden Hepatozyten führt zur Zirrhose (Bataller und Brenner 2005; Saile und Ramadori 2007). Eine Zirrhose bedingt eine hepatozelluläre Dysfunktion und einen erhöhten intrahepatischen Widerstand für den Blutstrom, wodurch Leberinsuffizienz und Portalhypertension entstehen (Gines et al. 2004). Leberzirrhose ist mit einer ausgeprägten Morbidität und Mortalität vergesellschaftet (Saile und Ramadori 2007).

Nach neueren Erkenntnissen könnte die Leberentzündung nicht durch den Untergang von Hepatozyten, sondern durch Leber-residente bzw. rekrutierte Entzündungzellen initiiert werden. Der durch verschiedene Schädigungsfaktoren verursachte hepatozelluläre Stress könnte zur Aktivierung von Kupffer-Zellen führen, d. h. zur Ausschütung von Zytokinen (IFN- $\gamma$, TNF- $\alpha$ u. a.) und zur Rekrutierung weiterer Entzündungzellen. Residente oder rekrutierte Entzündungmakrophagen können durch Aktivierung der fibrogenen Zellen (HSCs, Lebermyofibroblasten, Leberfibroblasten u.a.) eine Synthese der Matrix stimulieren und deren Ablagerung durch Zytokine (insbesondere TNF- $\alpha$, TGF- $\beta$ ) und Zwischenprodukte der reaktiven Sauerstoffspezies/Lipidperoxide fördern. Diese Zellen (Makrophagen) sind an der Endotoxin-vermittelten Leberschädigung weitgehend beteiligt (Saile und Ramadori 2007).

In entwickelten Ländern stellen chronische HCV-Infektion, Alkoholmissbrauch und nichtalkoholische Steatohepatitis die häufigsten Ursachen der Leberfibrose dar (Bataller und Brenner 2005).

In der Pathogenese der Leberfibrose unterschiedlicher Ätiologie spielt LPS auch eine bedeutende Rolle, da die Leber an der LPS-Detoxifikation erheblich beiteiligt ist (Nolan 1975, Jirillo et al. 2002). LPS aktiviert Kupffer-Zellen, sinusoidale Epithelzellen und HSCs über den TLR4-CD14-Komplex, was zur Stimulation der entzündlichen und fibrogenen Signale führen kann (Bataller und Brenner 2005). Alkohol begünstigt im Darm die Vermehrung der Gram-negativen Bakterien und verstärkt die Darmpermeabilität für LPS. Dadurch erhöht sich die Konzentration des LPS im portalen Blut bei alkoholbedingter Lebererkrankung (Enomoto et al. 2001 a). Außerdem gibt es Hinweise dafür, dass Alkohol 
Kupffer-Zellen für Endotoxin sensibilisiert (Enomoto et al. 2001 b). Erhöhte LPSKonzentration im Serum von $\mathrm{HCV}$-infizierten Patienten ist vermutlich auf gestörte phagozytäre Funktionen und verminderte T-Zell-vermittelte antibakterielle Aktivität zurückzuführen (Caradonna et al. 2002). Auch ein LPS-Übergang von der Darmflora in den Blutkreislauf ist wegen der veränderten Darmdurchlässigkeit nicht auszuschließen. Es muss weiter berücksichtigt werden, dass die LPS-Detoxifikation in HCV-geschädigter Leber wahrscheinlich weniger effektiv durchgeführt wird (Caradonna et al. 2002).

Es ist aber $\mathrm{zu}$ bemerken, dass die erhöhte LPS-Konzentration besonders bei Alkoholmissbrauch zu beobachten ist (Fukui et al. 1991). Laut Studien spielt LPS eine essentielle Rolle in der Pathogenese der alkoholbedingten Lebererkrankung (Enomoto et al. 1998; Thurman 1998).

Leberfibrose entsteht durch ein komplexes Zusammenspiel von körpereigenen (verschiedenen Zellen und Mediatoren) und äußeren (Alkohol, Infektion usw.) Faktoren. Deshalb wird der Verlauf der Leberfibrose sowohl von genetischen als auch Umweltfaktoren beeinflusst (Bataller et al.2003; Bataller und Brenner 2005; Saile und Ramadori 2007). 


\subsection{Genetische Polymorphismen}

\subsubsection{Das menschliche Genom und dessen Polymorphismen}

Das menschliche Genom wurde in den Jahren 1990-2003 im Rahmen des internationalen Humangenomprojekts (Human Genome Project, HGP) unter der Leitung des U.S. Department of Energy und National Institutes of Healt, sequenziert. 2004 wurden die Endergebnisse veröffentlicht: Es wurde über die Genomsequenz berichtet, die etwa 3 Milliarden Nukleotide, unterbrochen durch 341 Lücken, enthält. Es macht 99\% des euchromatischen Genoms aus (International Human Genom Sequencing Consortium 2004).

Das gleiche Ziel, nämlich die Sequenzierung des menschlichen Genoms, wurde auch von einer mit HGP konkurrierenden US-amerikanischen Firma Celera Genomics verfolgt, die 1998 ihre Absicht öffentlich angekündigt hat, die Sequenz des humanen Genoms innerhalb der nächsten 3 Jahre zu entziffern. 2001 wurden vorläufige Ergebnisse der Sequenzierung von HGP (Lander et al. 2001) sowie die Ergebnisse von Celera Genomics (Venter et al. 2001) veröffentlicht.

Ein Ergebnis dieser Sequenzierung war, dass zwei beliebige Exemplare des menschlichen Genoms sich voneinander um etwa $0,1 \%$ der Nukleotide unterscheiden (d. h. es kommt im Durchschnitt 1 Variation pro 1000 Nukleotiden vor) (Venter et al. 2001). Die häufigste Form der genetischen Variation stellen die Einzelnukleotidpolymorphismen (single nucleotide polymorphism, SNP) dar. Ein SNP ist eine Position im Genom, an der 2 alternative Nukleotide mit der Häufigkeit von $>1 \%$ in der Population vorkommen (Wang et al. 1998). Mittlerweile gibt es eine öffentliche Datenbank mit Informationen über mehr als 12 Millionen bekannte humane SNPs (http://www.ncbi.nlm.nih.gov/SNP) (Wheeler et al. 2007). Die minor allele frequency (MAF) beschreibt die Frequenz des seltener vorkommenden varianten Allels in der Population.

Ein SNP in der Protein-kodierenden Region des Gens kann zu einem Aminosäureaustausch im Protein führen (nicht-synonyme SNPs), was eine Struktur- oder Funktionsveränderung des Proteins verursachen kann. Ein synonymer SNP führt zwar zu keinem Aminosäureaustausch, er bedingt aber eine Sequenzänderung im Transkript, was z. B. RNA-splicing (Tabor et al. 2002) oder die Translationseffizienz (Sharp et al. 1995) beeinflussen kann.

SNPs können auch außerhalb der Protein-kodierenden Region lokalisiert sein. SNPs in der 3'UTRs können die RNA-Stabilität beeinflussen, indem sie die Sequenzen verändern, an die RNA-bindende Proteine andocken (Vercelli 2002). Sogar sich in Intron befindende SNPs können sich auf Genregulationsprozesse auswirken (Hural et al. 2000; Tabor et al. 2002; Vercelli 2002). 
Polymorphismen in der Promotorregion eines Gens können auf die Genexpressionsrate Einfluss nehmen: Entweder durch direkte Auswirkung auf die Bindungsaffinität zwischen Promotor und Transkriptionsfaktoren oder durch veränderte Beziehung zwischen der Promotorregion und sich distal befindender regulierender Elemente (z.B. enhancer, silencer, Lokus-Kontrol-Regionen) (Vercelli 2002).

Da regulierende Elemente für ein bestimmtes Gen vom Transkriptionsstart weit entfernt liegen können (Hirsch-Kaufmann und Schweiger 2004, S. 396 und 403), ist theoretisch jeder SNP imstande, die Genexpression durch einen oder anderen Mechanismus zu beeinflussen, unabhängig davon auf welchem DNA-Abschnitt oder wie weit entfernt er sich von dem regulierten Gen befindet. Eine Variation in einem Gen kann sogar die Expression eines anderen Gens beeinflussen (trans-Effekt) (Buckland 2004).

Einen SNP nennt man funktionell, wenn er den Phänotyp des Organismus spezifisch verändert: Es kann sich um einen Einfluss auf die Manifestation einer Krankheit oder auf den Arzneimetabolismus handeln (Mottagui-Tabar et al. 2005).

Es ist auch zu bemerken, dass die Rolle der einzelnen Variationen für die Veränderung des Phänotyps eher bescheiden ist (Risch 2000; Botstein und Risch 2003).

\subsubsection{Haplotyp und Kopplungsungleichgewicht (linkage disequilibrium, LD)}

Außer dem Genotyp an einem bestimmten Lokus, kann auch ein Haplotyp mit phänotypischen Merkmalen in Verbindung gesetzt werden. Haplotyp (von griechisch haplóos $=$ einfach und typos = typ), aus ,haploider Genotyp“ zusammengesetzt, bezeichnet die Kombination der Allele zweier oder mehrerer Loci auf einem Chromosom. Die Häufigkeit eines Haplotyps soll idealerweise aus den Häufigkeiten der einzelnen Allele zusammengesetzt werden: Wenn es für zwei Loci die Allele A, a und B, b gibt, die mit den Häufigkeiten p(A), $p(B), p(a)$ und $p(b)$ vorkommen, dann gilt theoretisch $p(A B)=p(A) \times p(B)$ und so weiter. Das setzt eine freie, zufällige (random) Rekombination der Allele voraus. Wenn aber die Assoziation zwischen den Allelen nicht beliebig (non-random) ist, dann weicht die Häufigkeit des entsprechenden Haplotyps von dem theoretischen Wert ab. In diesem Fall spricht man von Kopplungsungleichgewicht. Der Abweichungsgrad von den beliebigen Assoziationen lässt sich durch die folgende Formel bestimmen:

$$
\mathrm{D}=\mathrm{p}(\mathrm{AB}) \mathrm{p}(\mathrm{ab})-\mathrm{p}(\mathrm{Ab}) \mathrm{p}(\mathrm{aB})
$$

Je höher der Abweichungsgrad, desto wahrscheinlicher werden die Allele an bestimmten Loci zusammen vererbt (Strachan und Read 2005, S. 518). 
Allerdings ist das absolute Maximum von D-Wert von den Allelhäufigkeiten an den beiden Loci abhängig. Deshalb wurde eine standardisierte Modifikation von D-Wert eingeführt, $D^{\prime}=\mathrm{D} / \mathrm{D}_{\max }$, wobei $\mathrm{D}_{\max }$ der größte Wert ist, den das Kopplungsungleichgewicht bei den vorgegebenen Allelhäufigkeiten annehmen kann. Der D'-Wert variiert zwischen 0 (kein Kopplungsungleichgewicht) und \pm 1 (vollständige Assoziation). Als Schwellenwert des Kopplungsungleichgewichts gilt häufig D’ > 0,33 (Strachan und Read 2005, S. 518).

Zur Charakterisierung des Kopplungsungleichgewichts verwendet man auch $\mathrm{r}^{2}$, der sich folgendermassen berechnen lässt:

$$
r^{2}=D^{2} / p(A) p(a) p(B) p(b)
$$

Wie beim D-Wert, ist das Maximum von $r^{2}$ von Allelhäufigkeiten abhängig. Interessanterweise, wenn man $r^{2}$ durch $r^{2}{ }_{\text {max }}$ standardisiert, ähnlich wie beim D-Wert, dann kommt wieder D'-Wert heraus (Hedrick und Kummar 2001).

\subsubsection{Hardy-Weinberg equilibrium (HWE)}

HWE beschreibt eine ideale, in der Realität nicht vorzufindende Population, in der die Häufigkeiten der Allele und Genotypen für einen autosomalen Genlokus von Generation zu Generation unverändert bleiben, d. h. sie werden von Evolutionsfaktoren (Mutationen, Migrationen, Selektion, nicht-beliebige Paarung, Umweltfaktoren) nicht beeinflusst. In diesem theoretischen Modell lassen sich die Häufigkeiten (frequency) der Allele für einen einzelnen bi-allelischen Lokus und entsprechende Genotypen auf folgende Weise berechnen:

Wenn die Allele A und a die Häufigkeiten p und q besitzen

$\operatorname{freq}(\mathrm{A})=\mathrm{p} ; \operatorname{freq}(\mathrm{a})=\mathrm{q} ; \mathrm{p}+\mathrm{q}=1$,

dann gilt für die Genotypen AA, Aa und aa

freq $(\mathrm{AA})=\mathrm{p}^{2}$, freq $(\mathrm{Aa})=2 \mathrm{pq}$ und fre $q(\mathrm{aa})=\mathrm{q}^{2}$.

Diese Gesetzmäßigkeit wurde 1908 unabhängig voneinander von G. H. Hardy und W. Weinberg nach früheren Versuchen von W. E. Castle und K. Pearson beschrieben (Mayo 2008).

Wenn sich die reale Verteilung der Genotypen von der erwarteten idealen Distribution nicht signifikant unterscheidet (d. h. $\mathrm{p}>0,05)$, dann sagt man, dass die aktuelle Verteilung im Hardy-Weinberg-Gleichgewicht steht.

Die Analyse der Abweichungen der Genotyphäufigkeiten von HWE für einen bestimmten Genlokus liefert wichtige Information über genetische Eigenschaften der Population, wie eine Abweichung von beliebiger Paarung, eine Unterteilung der Population, Überlebensselektion u.a. (Alvarez 2008). Es ist eines der wenigen Mittel zur Überprüfung auf systemische 
Genotypisierungfehler und wird bei großangelegten Studien der molekularen Marker benutzt (Gomes et al. 1999; Teo et al. 2007).

\subsubsection{Der genetische Polymorphismus rs2569190}

rs2569190 ist ein SNP (Nukleotidaustausch Cytosin (C) $\rightarrow$ Thymin (T) auf dem minus strand) im CD14-Gen. Das CD14-Gen ist auf dem langen Arm von Chromosom 5 zwischen den Banden 5q23 und 31 lokalisiert (Ferrero et al. 1990) und überspannt ca. 1500 Basenpaare (Ferrero and Goyert 1988). Je nach der Transkriptvariante (splice-Variante) des Gens befindet sich der SNP rs2569190 entweder im transkribierten oder im nicht-transkribierten (Intron) Bereich (Abb. 1.9).

Es war ursprünglich angenommen, dass der SNP rs2569190 sich im Promotor des Gens befindet und der SNP wurde gemäß der vermuteten Lokalisation -159 (Position vom Transkriptionsstart rückwärts) oder -260 (Position vom Translationsstart rückwärts) benannt.

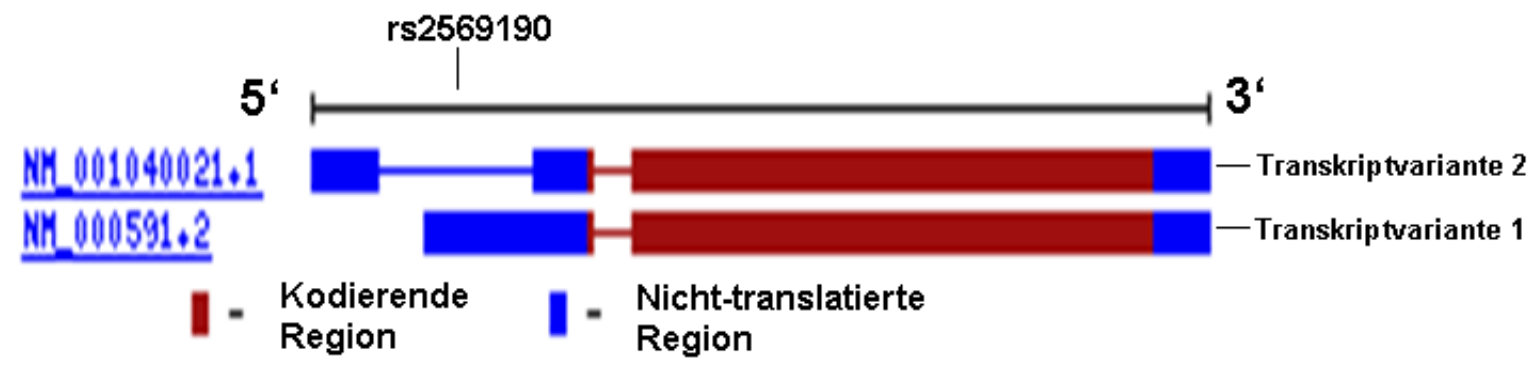

Abb. 1.9: Transkriptvarianten des CD14-Gens und Lokalisation des SNPs rs2569190

Je nach der Transkriptvariante enthält das CD14-Gen zwei bzw. drei Exons, die durch kurze Introns getrennt sind. In der Transkriptvariante 1 (NM_000591.2) befindet sich der SNP rs2569190 im transkribierten Bereich, und zwar in der 5'UTR (untranslated region) (mRNA-Position +95), in der Transkriptvariante 2 (NM_001040021.1) im Intron 1.

(adaptiert von NCBI, http://www.ncbi.nlm.nih.gov/sites/entrez?db=gene\&cmd=Retrieve\&dopt=Graphics\&list_uids=929)

\subsubsection{Bedeutung des SNPs rs2569190}

Da der CD14-Rezeptor in der angeborenen Immunität eine zentrale Rolle spielt und das Ausmaß von Entzündungsreaktionen mitbestimmt, wird eine Beteiligung an der Pathogenese verschiedener Erkrankungen vermutet. Aus diesem Grund könnten Polymorphismen im CD14-Gen für den Verlauf pathologischer Prozesse von Bedeutung sein.

Zur Abschätzung der Bedeutung genetischer Polymorphismen für einen bestimmten Phänotyp spielen Assoziationsstudien eine wichtige Rolle. Dabei werden biologische Parameter oder 
pathologische Zustände in Bezug auf verschiedene Genotypen an einer bestimmten polymorphen Position untersucht.

Der SNP rs2569190 im CD14-Gen wurde erstmals 1999 durch Baldini et al. identifiziert und mit den Serumkonzentrationen für sCD14 und $\mathrm{IgE}$ in Beziehung gesetzt. Dabei stellte sich heraus, dass der TT-Genotyp an der polymorphen Position mit erhöhten sCD14- und niedrigeren IgE-Werten assoziert war (Baldini et al. 1999). Dieselbe Forschungsgruppe hat später den molekularen Hintergrund für die Regulation der CD14-Expression durch den SNP untersucht. Durch EMSA-(electrophoretic mobility shift assay)-Analyse konnte gezeigt werden, dass das T-Allel an der Position rs2569190 die Bindung von bestimmten Transkriptionsfaktoren (Sp1, Sp2, Sp3) an die DNA vermindert. Experimente mit transfizierten Zelllinien zeigten eine erhöhte transkriptionelle Aktivität des T-Allels in monozytären (Mono Mac 6) Zellen, die wenig Sp3 (inhibierender Transkriptionsfaktor) im Vergleich zu aktivierenden Transkriptionsfaktoren Sp1 und Sp2 exprimieren. In Sp3-reichen hepatozytären (HepG2) Zellen dagegen werden beide Allele gleichmässig transkribiert. Insgesamt besagt diese Studie, dass der SNP rs2569190 die Bindungsaffinität von gDNA mit Transkriptionsfaktoren beeinflusst und dass die CD14-Gentranskription in verschiedenen Zellen, abhängig von den Verhältnissen zwischen Transkriptionsfaktoren ([Sp3]:[Sp1+Sp2]), durch diesen SNP unterschiedlich reguliert werden kann (LeVan et al. 2001).

Seitdem ist der SNP rs2569190 Gegenstand zahlreicher Assoziationsstudien. Viele Studien belegen eine Assoziation des SNPs mit Erkrankungen, die mit einer Entzündungskomponente einhergehen, darunter der Myokardinfarkt (Hubacek et al. 1999; Unkelbach et al. 1999), die ulzerative Kolitis (Obana et al. 2002), Asthma (Woo et al. 2003) oder Spondyloarthropathie (Repo et al. 2002).

In Bezug auf Lebererkrankungen berichten Järveläinen et al. (2001) über eine Assoziation des T-Allels vom SNP rs2569190 mit alkoholbedingter Hepatitis und insbesondere mit Leberzirrhose bei alkohlbedingter Lebererkrankung in einer finnischen Population. Dieselbe Studie fand aber keine Assoziation des genannten Polymorphismus mit Leberzellverfettung oder mit gering ausgeprägter Leberfibrose bei Alkoholmissbrauch (Järveläinen et al. 2001). Diese Assoziation wurde in der Studie von Meiler et al. (2005) an einer süddeutschen Population bestätigt: Unter Alkoholikern mit Leberzirrhose fanden sich signifikant mehr TTHomozygote als unter Alkoholikern ohne Leberzirrhose oder bei gesunden Kontrollen (Meiler et al. 2005). In der Studie von Campos et al. (2005) wurde auch eine positive Assoziation zwischen dem rs2569190-TT-Genotyp und fortgeschrittener Lebererkrankung bei Alkoholikern gefunden (Campos et al. 2005). Von Hahn et al. fanden einen signifikant 
höheren Anteil des rs2569190-TT-Genotyps in einer kleinen Gruppe $(\mathrm{n}=41)$ von Patienten mit leichter kryptogener chronischer Lebererkrankung (Von Hahn et al. 2008).

Andererseits berichten verschiedene Studien über eine fehlende Assoziation: Man findet keine Assoziation des SNPs rs2569190 mit der Schwere der akuten Pankreatitis oder mit dem Risiko für die alkoholbedingte akute Pankreatitis (Tukiainen et al. 2008), mit ulzerativer Kolitis in einer chinesischen Population (Guo et al. 2005), mit dem Risiko für die Krankheit der koronaren Arterien (König et al. 2002), mit dem Risiko für zerebrovaskuläre Krankheiten (Ito et al. 2000), mit dem Schweregrad der alkoholbedingten Lebererkrankung (Von Hahn et al. 2008), chronischer Hepatitis C (Meiler et al. 2005; Von Hahn et al. 2008; Askar et al. 2009) oder Lebererkrankungen verschiedener Etiologie (chronische Hepatitis B, autoimmune Hepatitis, PBC, PSC u. a.) (Von Hahn et al. 2008).

Der SNP rs2569190 wurde auch in Verbindung mit allergischen Erkrankungen und Parametern der Allergie intensiv erforscht und die Aussagen sind auch in diesem Bereich unterschiedlich bis widersprüchlich (Martinez 2007; Zhang G et al. 2008).

Es wurde auch untersucht, ob der SNP rs2569190 mit der CD14-Expressionsrate assoziiert ist. Als Parameter für die CD14-Expression wurde bislang hauptsächlich die Konzentration des sCD14 im Serum herangezogen. Eine überwiegende Mehrheit der Studien zeigt, dass das rs2569190-T-Allel mit signifikant höheren sCD14-Serumkonzentration assoziiert ist. In diesen Studien sind verschiedenartige Probandengruppen untersucht worden: Gesunde Kinder (Baldini et al. 1999; Kabesch et al. 2004), gesunde Erwachsene (Karhukorpi et al. 2002; Obana et al. 2002; Amar et al. 2004; Kabesch et al. 2004), Patienten mit chronischer Hepatitis C (Meiler et al. 2005), Patienten mit Erkrankung der koronaren Arterien (König et al. 2002), dyspeptische Patienten (Karhukorpi et al. 2002) u. a. Die Expression des mCD14 auf Monozyten/Makrophagen als Parameter der Expression des CD14-Gens ist unseres Wissens weniger erforscht: Hubacek et al. (1999) berichten über eine signifikant erhöhte mCD14Expression auf Monozyten bei gesunden Probanden mit rs2569190-TT-Genotyp im Vergleich zu anderen Genotypen (CC und CT) (Hubacek et al. 1999).

Manche Studien können als Gegengewicht zur positiven Assoziation des SNPs mit CD14Genexpression herangezogen werden: In der Studie von Heesen et al. (2001) wurden in 95 gesunden Blutspendern mCD14-Expression auf nicht-stimmulierten Monozyten des peripheren Bluts und sCD14-Serumkonzentration in Bezug auf den rs2569190-Genotyp untersucht. Sie fanden keinen Genotyp-assoziierten Unterschied bei diesen beiden Parametern der CD14-Genexpression (Heesen et al. 2001). Ito et al. finden ebenfalls keine Assoziation des SNPs rs2569190 mit der mCD14-Expression auf Monozyten und der sCD14- 
Serumkonzentration bei Patienten mit zerebrovaskulären Krankheiten (Ito et al. 2000). König et al. berichten über eine nur nicht-signifikante Tendenz $(p=0,11)$ zu erhöhten sCD14Werten bei rs2569190-TT-homozygoten gesunden Kontrollen gegenüber den C-Allelträgern (König et al. 2002).

Was in vitro Studien angeht, außer der LeVan et al. (s. oben), finden auch Zhao et al. eine erhöhte transkriptionelle Aktivität des rs2569190-T-Allels, allerdings in hepatozytären (SMMC-7721, HepG2) Zelllinien (Zhao et al. 2007). Liang et al. finden aber keine statistisch signifikanten Unterschiede zwischen transkriptionellen Aktivitäten der wildtyp- und varianten Allele des SNPs rs2569190, weder in monozytären (THP-1 und U937) noch in hepatozytären (HepG2) Zellen (Liang et al. 2006).

Die Uneinheitlichkeit und Widersprüchlichkeit der Aussagen, die die Assoziationsstudien der komplexen Krankheiten meistens aufweisen, könnte durch den Einfluss von Umweltfaktoren, genauer, durch das Zusammenspiel zwischen genetischen und nicht-genetischen Faktoren erklärt werden (gene-environment intraction) (Martinez 2007; Zhang G et al. 2008; Gibson 2009). In manchen Studien konnte gezeigt werden, dass sich genetische Faktoren auf den Phänotyp nur unter bestimmten Bedingungen auswirken können: Zhao et al. berichten über eine Assoziation des SNPs rs2569190 mit erhöhtem Risiko für das Magenkarizinom nur unter den Helicobacter-pylori-infizierten Personen. Unter denen ohne H. pylori-Infektion war der SNP nicht mit dem Risiko der Erkrankung assoziiert. Im Rahmen derselben Studie konnte außerdem gezeigt werden, dass unter den Patienten mit Magenkarzinom und $H$. pyloriInfektion das T-Allel des SNPs rs2569190 mit erhöhten sCD14-Werten im Serum assoziiert war. Die Assoziation war bei Patienten ohne H. pylori-Infektion nicht zu sehen (Zhao et al. 2007). Die kombinierte Auswirkung des SNPs rs2569190 und des H. pylori-Infizierungsstatus auf die Serumkonzentration des sCD14 wurde auch in einer anderen Studie gezeigt (Karhukorpi et al. 2002). Virta et al. berichten, dass die Assoziation des SNPs rs2569190 mit der Serumkonzentration des IgE von H. pylori-Seropositivität abhängig ist (Virta et al. 2008). Simpson et al. belegen, dass der Einfluss des SNPs rs2569190 auf die Entwicklung der allergischen Erkrankungen von Umweltfaktoren abhängig sein kann (Simpson et al. 2006). 


\subsection{Fragestellung}

Auf der Grundlage der vielfältigen und zum Teil widersprüchlichen Daten zur Assoziation des SNPs CD14 rs2569190/C-159T mit dem Verlauf der verschiedenen Erkrankungen stellten wir uns die Frage, ob der SNP tatsächlich die CD14-Genexpression beeinflusst. Als Parameter für die Expression des CD14-Gens in vivo haben wir die CD14-mRNA-Menge (aus frisch isolierten PBMC und frisch konservierten Lebergewebeproben) und die Serumkonzentration des sCD14 herangezogen. Diese Parameter sollten zunächst mit dem rs2569190-Genotyp in Beziehung gesetzt werden. Wir haben auch weitere SNPs im CD14-Gen mit relevanter Heterozygotie einbezogen, um zu prüfen, ob diese ggf. enger mit der CD14-Genexpression korreliert sind. Inwieweit das CD14-Gen tatsächlich Allel-spezifisch exprimiert wird, sollte schließlich mit der Technik der Allel-spezifischen Transkriptquantifizierung (ASTQ) untersucht werden.

Als Untersuchungsmaterial haben wir ein Kollektiv mit gesunden Probanden $(n=42)$ herangezogen, um die Genexpression im Zusammenhang mit dem Genotyp unter krankheitsfreien Bedingungen zu untersuchen. Das zweite Kollektiv besteht aus Patienten mit chronischer Hepatitis C $(\mathrm{n}=42)$. Die Untersuchung der CD14-Genexpression in Bezug auf den SNP rs2569190 bei chronisch HCV-infizierten Patienten komplementierte eine Analyse der Arbeitsgruppe zur Assoziation des genannten SNPs mit Leberentzündungsparametern und dem Leberfibrosegrad bei Patienten mit chronischer Hepatitis C (Askar et al. 2009). Des Weiteren haben wir noch ein Kollektiv von chronisch HCV-infizierten Patienten herangezogen $(n=41)$, von denen Lebergewebeproben zur Verfügung standen. 


\section{Material und Methoden}

\subsection{Probanden (Gesunde und Patienten)}

Für die vorliegende Arbeit wurden vorwiegend aus dem Kreis der Studierenden und Mitarbeiterinnen / Mitarbeiter des Universitätsmedizin Göttingen insgesamt 42 gesunde Probanden rekrutiert. Es handelt sich hauptsächlich um Personen ohne Anhaltspunkte für eine nicht-kaukasische Abstammung und ohne Hinweis auf eine chronische oder aktive Hepatitis-C- oder Hepatitis-B-Infektion oder auf Drogen- oder Alkoholabusus (20 weiblich, 22 männlich; mittleres Alter 31,8 Jahre, Spanne 23-57). Alle Probanden haben etwa $50 \mathrm{ml}$ Blut gespendet, von dem etwa $40 \mathrm{ml}$ in heparinhaltigen Monovetten abgenommen wurde, um mononukleäre Zellen (peripheral blood mononuclear cells, PBMC) zu isolieren und etwa 10 ml Blut in nicht-heparinisierten Monovetten zur Gewinnung einer Serumprobe.

Darüber hinaus konnte auf gDNA-, RNA- (bzw. cDNA)-Proben von 42 Patienten mit chronischer Hepatitis C zurückgegriffen werden. Die Patienten waren ebenfalls hauptsächlich Kaukasier (19 weiblich, 23 männlich; mittleres Alter 49,1 Jahre, Spanne 24-77). Serum/Plasma-Proben standen nur von 40 Patienten aus dieser Gruppe zur Verfügung. Hepatitis-C-Patienten mit gleichzeitiger HIV-Infektion, aktiver Hepatitis-B-Infektion oder mit Drogen- oder Alkoholabusus waren ausgeschlossen.

Des Weiteren sind cDNA-Proben aus der Leber von insgesamt 41 Patienten untersucht worden (19 weiblich, 22 männlich; mittleres Alter 47,2 Jahre, Spanne 23-70). 


\subsection{Material}

\subsubsection{Substanzen}

Agarose (DNase / RNase frei)

Alw $21 I(10 \mathrm{U} / \mu \mathrm{l})$

Ampuwa (DNase / RNase freies Wasser)

Desoxynucleotide dNTP (100 mM)

$(\mathrm{dA}+, \mathrm{dT}+, \mathrm{dC}+, \mathrm{dG}+)$

DTT $(0,1 \mathrm{M})$

Ethanol $100 \%$

Ethidiumbromidlösung (10 mg / ml)

Ficoll-Plaque ${ }^{\mathrm{TM}}$ PLUS

Längenmarker:

O'GeneRuler ${ }^{\mathrm{TM}}$ Low Range DNA Ladder GeneRuler $^{\mathrm{TM}} 100$ bp DNA Ladder Plus $1 \mathrm{~Kb}$ Plus DNA Ladder

Mineralöl (DNase / RNase frei)

$\mathrm{MgCl}_{2}(50 \mathrm{mM})$

MMLV reverse transcriptase $(200 \mathrm{U} / \mu \mathrm{l})$

PBS (ohne $\mathrm{Ca}^{2+}, \mathrm{Mg}^{2+}$ )

PCR Reaktionspuffer $-\mathrm{MgCl}_{2}(10 \mathrm{x})$

Primer (Tab. 2.2, 2.4, 2.6, 2.7, 2.8)

Primer random $\mathrm{p}(\mathrm{dN})_{6} 50 \mathrm{~A}_{260}$ units

RNasin (1000 U / ml)

$\operatorname{SatI}(10 \mathrm{U} / \mu \mathrm{l})$

Taq DNA Polymerase $(5 \mathrm{U} / \mu \mathrm{l})$

TaqMan ${ }^{\circledR}$ Universal PCR Master Mix;

No AmpErase ${ }^{\circledR U} U N G$

TaqMan ${ }^{\circledR}$ Genotyping Master Mix

Trypan-Blau-Lösung $(0,4$ \%)

Thimerosal Stock (0,2 \%)
Invitrogen (Karlsruhe)

Fermentas (St. Leon-Rot)

Fresenius Kabi (Bad Homburg)

Roche (Mannheim)

Invitrogen (Karlsruhe)

MERCK (Darmstadt)

SIGMA (München)

Amersham Biosciences (Freiburg)

Fermentas (St. Leon-Rot)

Fermentas (St. Leon-Rot)

Invitrogen (Karlsruhe)

SIGMA (Steinheim)

Invitrogen (Karlsruhe)

Invitrogen (Karlsruhe)

BIOCHROM KG (Berlin)

Invitrogen (Karlsruhe)

Eurofins MWG Operon (Ebersberg)

Roche (Mannheim)

Promega (Mannheim)

Fermentas (St. Leon-Rot)

Invitrogen (Karlsruhe)

Applied Biosystems (Darmstadt)

Applied Biosystems (Darmstadt)

SIGMA (Steinheim)

biometec (Greifswald) 


\subsubsection{Kits und Assays}

Agilent DNA $1000 \mathrm{Kit}$

AllPrep DNA / RNA Mini Kit (50)

Agilent Technologies (Böblingen)

Enzyme Immunoassay for Determination of soluble human CD14 with matched antibody pairs

GoTaq Colorless- / Green-Master-Mix

Promega (Mannheim)

Platinum ${ }^{\circledR}$ SYBR ${ }^{\circledR}$ Green qPCR SuperMix-UDG $(2 \mathrm{x})$

Invitrogen (Karlsruhe)

$50 \mathrm{mM}$ Magnesium Chloride

ROX Reference Dye

Primer + Sonden (40 x Assay Mix) (Tab.2.1)

Applied Biosystems (Darmstadt)

PrepEase ${ }^{\mathrm{TM}}$ Gel Extraction Kit

usb (Cleveland, Ohio, USA)

QIAamp® DNA Blood Mini Kit (50)

QIAGEN (Hilden)

TaqMan SNP Genotyping Assay-by-design (40 x) (für CD14 rs2569190)

Applied Biosystems (Darmstadt)

TaqMan SNP Genotyping Assay-on-demand (20 x) (für CD14 rs4914)

TaqMan Gene Expression Assays (20 x):

CD14 Hs00169122_g1

GAPDH Hs99999905_m1

CD11b Hs00355885 m1

Applied Biosystems (Darmstadt)

Applied Biosystems (Darmstadt)

\subsubsection{Gebrauchswaren}

ELISA-Platte

NALGENE nunc (Roskilde, Dänemark)

(Nunc-Immuno TM Plate MaxiSorp TM Surface)

Küvetten (Eppendorf UVette)

Eppendorf (Hamburg)

MicroAmp ${ }^{\mathrm{TM}}$ Fast Optical 96-well

Reaction Plate

Applied Biosystems (Darmstadt)

Optical Adhesive Covers

(DNA / RNA / RNase Free )

Applied Biosystems (Darmstadt)

PCR- / Reaktions-Gefäße

Eppendorf (Hamburg)

(steril, RNase / DNase frei):

$$
\begin{aligned}
& 0,2 \mathrm{ml} \\
& 0,5 \mathrm{ml} \\
& 1,5 \mathrm{ml}
\end{aligned}
$$


Pipettenspitzen

(steril, RNase / DNase frei)

Reaktionsgefäße (steril, RNase / DNase frei) $50 \mathrm{ml}$

\subsubsection{Geräte}

Agilent 2100 Bioanalyzer

Biophotometer

Brutschrank

Elektrophoresegerät

Mikrowelle

PCR Thermo-Cycler:

Hybaid Omnigene

GeneAMP 9600 PCR System

FlexCycler

Pipetten

Pipettus-akku

Sequence detection systems:

ABI prism 7000

StepOnePlus

Spannungsquelle POWER PAC 300

Sterilbank LaminAir

Vortex

Waage

Zentrifugen:

Centrifuge $5415 \mathrm{D}$

Megafuge 1.0R

Rotixa/A
Biozym (Oldendorf)

FALCON (New Jersey)
Agilent Technologies (Böblingen)

Eppendorf (Hamburg)

Heraeus (Hanau)

Life Technologies Gibco BRL Horizon

11-14 (Eggenstein)

Whirlpool Philips (Schweden)

MWG Biotech (Ebersberg)

PerkinElmer (Weiterstadt)

Analytik Jena (Jena)

Eppendorf (Hamburg)

Hirschmann Laborgeräte (Eberstadt)

Applied Biosystems (Darmstadt)

Bio-Rad (München)

Heraeus (Hanau)

Heidolph (Kelheim)

Sartorius (Göttingen)

Eppendorf (Hamburg)

Heraeus (Hanau)

Hettich (Kirchlengern) 


\subsection{Methoden}

\subsubsection{Isolierung der PBMC}

Für die Isolierung der PBMC wurden $20 \mathrm{ml}$ Ficoll in 50-ml-Falconröhrchen vorgelegt und mit $30 \mathrm{ml}$ Heparinat-Blut vorsichtig überschichtet. Es folgte eine Zentrifugation für 30 Min bei $21{ }^{\circ} \mathrm{C}$ und $700 \mathrm{x}$ g (ohne Bremse). Während der Zentrifugation bildet sich ein Dichtegradient aus: Im Sediment sammeln sich Granulozyten / Erythrozyten, auf dem FicollKissen bildet sich eine Schicht mit mononukleären Zellen / Thrombozyten und ganz oben Plasma. Das Plasma wurde abgenommen, PBMC wurden in ein neues 50-ml-Falconröhrchen überführt und insgesamt dreimal in PBS-Lösung gewaschen (Zentrifugation für 10 Min bei $4{ }^{\circ} \mathrm{C}, 250 \mathrm{x} \mathrm{g}$, mit Bremse). Vor dem 3. Waschvorgang erfolgte die Zellzählung: Die Zellen wurden in $10 \mathrm{ml}$ PBS suspendiert, $50 \mu$ Zellsuspension wurden entnommen und mit $50 \mu \mathrm{l}$ Trypan-Blau gemischt. Die Zellzahl wurde mit Hilfe einer NeubauerZählkammer mikroskopisch bestimmt.

Nach dem 3. Waschvorgang wurden die Zellen in $2 \mathrm{ml}$ PBS-Lösung aufgenommen und auf zwei 1,5-ml-Reaktionsgefäße aufgeteilt. Es folgte eine Zentrifugation für 10 Min bei $4{ }^{\circ} \mathrm{C}$ und $250 \mathrm{x}$ g. Das Zellsediment wurde bei $-80^{\circ} \mathrm{C}$ bis zur weiteren Verarbeitung aufbewahrt.

\subsubsection{Extraktion der genomischen DNA (gDNA) aus dem Vollblut}

Die Extraktion der gDNA aus dem Vollblut wurde mit dem QIAamp DNA Blood Mini Kit gemäß dem Protokoll „Blood and Body Fluid Spin Protocol“, wie folgt, durchgeführt (alle Schritte erfolgten bei Raumtemperatur, RT):

Lyse / Homogenisierung:

Zunächst wurden je $20 \mu \mathrm{l}$ der Proteaselösung in 1,5-ml-Reaktionsgefäße vorgelegt. $200 \mu 1$ heparinisiertes Blut, das bei $-20{ }^{\circ} \mathrm{C}$ eingefroren war, wurde dazugegeben. Dann wurden $200 \mu \mathrm{l}$ Puffer AL hinzugefügt und die Mischung für 15 Sek gevortext. Es folgte eine Inkubation für $10 \mathrm{Min}$ bei $56^{\circ} \mathrm{C}$, die Zugabe von $200 \mu \mathrm{l}$ Ethanol (96-100 \%) und Mischung durch Vortexen für 15 Sek.

DNA-Bindung an der QIAamp Silikagelmembran:

Das Lysat wurde auf eine QIAamp-Säule gegeben und für 1 Min bei 6000 x g zentrifugiert. Die mit der DNA beladene Säule wurde zweimal gewaschen: Zunächst mit $500 \mu 1$ Puffer AW1 (Zentrifugation für 1 Min bei 6000 x g), dann mit $500 \mu$ Puffer AW2 (Zentrifugation für 3 Min bei $16000 \mathrm{x}$ g). Durchflüsse wurden verworfen. 


\section{DNA-Eluierung:}

$200 \mu 1$ Puffer AE wurde in QIAamp-Säulen pipettiert. Nach einer 1-minütigen Inkubation bei RT wurden die Säulen für 1 Min bei $6000 \mathrm{xg}$ zentrifugiert. Das gewonnene Eluat wurde bei $-20{ }^{\circ} \mathrm{C}$ gelagert.

\subsubsection{Extraktion der gDNA und RNA aus PBMC}

Die Extraktion der gDNA und RNA aus PBMC wurde mit dem AllPrep DNA/RNA Mini Kit gemäß dem Protokoll „Simultaneous Purification of Genomic DNA and Total RNA from Animal Cells“, wie folgt, durchgeführt (alle Schritte erfolgten bei RT):

\section{Lyse / Homogenisierung:}

PBMC, die bei $-80{ }^{\circ} \mathrm{C}$ eingefroren waren, wurden kurz auf RT aufgetaut und durch Klopfen vom Reaktionsgefäß gelöst. Dann wurde die entsprechende Menge von Puffer RLT Plus dazugegeben (für Proben, die $<5 \times 10^{6}$ Zellen enthielten, wurde $350 \mu 1$ Puffer RLT Plus, für die Zellzahl von $5 \times 10^{6}$ bis $1 \times 10^{7} 600 \mu$ von demselben Puffer gebraucht). Die Lösung wurde durch ein kurzes Vortexen gemischt und zur Homogenisierung direkt in die QIAshredder-Säule pipettiert. Es folgte eine Zentrifugation für 2 Min bei 16000 x g.

DNA-Bindung an eine Matrix:

Das homogenisierte Lysat wurde auf die AllPrep DNA-Säule überführt und für 30 Sek bei 8000 x g zentrifugiert. Während dieses Vorgangs wird DNA durch die Membran adsorbiert. Der DNA-freie Durchfluss ist das Ausgangsmaterial für die Isolierung der RNA.

Reinigung der zellulären RNA:

Der Durchfluss aus dem vorangegangenen Schritt wurde mit 1 Volumen $(350$ bzw. $600 \mu \mathrm{l}) 70$ \% Ethanol versetzt. Dann wurde bis zu $700 \mu \mathrm{l}$ von der Probe auf die RNeasy-Säule überführt und für 15 Sek bei 8000 x g zentrifugiert. Falls das Probenvolumen mehr als $700 \mu 1$ betrug, wurden die Aliquote nacheinander in einer und derselben RNeasy-Säule zentrifugiert. Dann folgten drei Waschschritte für die RNeasy-Säule: Zunächst mit $700 \mu$ l Puffer RW1 (Zentrifugation für 15 Sek bei 8000 x g), dann mit $500 \mu$ l Puffer RPE (Zentrifugation für 15 Sek bei $8000 \mathrm{x}$ g) und zum dritten Mal wieder mit $500 \mu \mathrm{l}$ Puffer RPE, aber diesmal länger zentrifugiert (2 Min bei 8000 x g). Um sicher zu gehen, dass der Puffer RPE vollständig eliminiert wurde, zentrifugierte man die RNeasy-Säule nochmals für 1 Min bei $16000 \mathrm{x}$ g. Anschließend, zur Freisetzung der RNA vom Säulenmaterial, wurden die Säulen in neue 1,5-ml-Gefäße gesetzt und 30-50 $\mu$ l RNase-freies Wasser direkt auf die Säulemembran pipettiert. Es folgte eine Zentrifugation für $1 \mathrm{Min}$ bei $8000 \mathrm{x}$ g für die Eluierung der RNA. RNA-Eluate wurden bei $-80{ }^{\circ} \mathrm{C}$ gelagert. 


\section{Reinigung der genomischen DNA:}

Zunächst wurden zwei Waschschritte für AllPrep DNA-Säulen unternommen: 1) Mit $500 \mu 1$ Puffer AW1 (Zentrifugation für 15 Sek bei 8000 x g); 2) Mit $500 \mu$ l Puffer AW2 (Zentrifugation für 2 Min bei $16000 \mathrm{xg}$ ).

Anschließend, zur Freisetzung der gDNA, wurden AllPrep DNA-Säulen in neue 1,5-ml-Gefäße gesetzt und $100 \mu \mathrm{l}$ Puffer EB direkt auf die Säulenmembran pipettiert. Die Säulen wurden für 1 Min bei RT inkubiert und danach zur Eluierung der gDNA für 1 Min bei $8000 \mathrm{xg}$ zentrifugiert. DNA-Eluate wurden bei $-20^{\circ} \mathrm{C}$ gelagert.

\subsubsection{Bestimmung der DNA- / RNA-Konzentration und -Reinheit und Nachweis der DNA- / RNA-Integrität}

Die Absorption der extrahierten DNA / RNA wurde im Photometer bei $260 \mathrm{~nm}$ und $280 \mathrm{~nm}$ gemessen. Zur Messung wurde die DNA bzw. die RNA mit Ampuwa 1:100 verdünnt. Die Konzentration der Nukleinsaüren wurde aus der Extinktion bei $260 \mathrm{~nm}$ errechnet. Da Proteine ihr Absorptionsmaximum bei $280 \mathrm{~nm}$ aufweisen, lässt das Verhältnis der Extinktion bei 260 nm und 280 nm Rückschlüsse auf die Reinheit der Nukleinsäuren zu. Gereinigte DNA, die frei von Proteinen ist, sollte Werte von 1,7-1,9 haben, gereinigte RNA 1,9-2,1.

Für unsere Untersuchungen benötigten wir DNA-Proben mit einer Konzentration von $10 \mathrm{ng} / 5 \mu \mathrm{l}$. Dementsprechend wurde die extrahierte DNA mit Ampuwa verdünnt und bei $-20{ }^{\circ} \mathrm{C}$ gelagert.

RNA-Proben wurden nach der Messung der Konzentration und Reinheitsbestimmung bei $-80{ }^{\circ} \mathrm{C}$ gelagert.

Die Integrität der DNA / RNA wurde über ein 1,5 \% Agarose / Ethidiumbromid-Gel geprüft.

Herstellung des Agarose-Gels:

Zunächst wurden 1,88 g Agarose abgewogen und diese in $125 \mathrm{ml}$ Tris-Borat-EDTA (TBE) Puffer* gelöst. Anschließend wurde das Gemisch in der Mikrowelle erhitzt bis eine klare Lösung entstand (ca. 3 Min). Nachdem die Lösung auf ca. $70{ }^{\circ} \mathrm{C}$ abgekühlt war, wurden $5 \mu 1$ Ethidiumbromidlösung $(10 \mu \mathrm{g} / \mu \mathrm{l})$ zugemischt, die flüssige Agarose auf einen Gelträger gegossen und abgewartet, bis sie erhärtete.

* TBE-Puffer: 108 g Tris Base, 55 g Borsäure und 7,44 g EDTA wurden in 600 ml Ampuwa gelöst, der $\mathrm{pH}$ muss auf 8,2 äquilibriert werden. Mit Ampuwa wurde ein Volumen von 1000 ml eingestellt.

Der Längenstandard ( $O^{\prime}$ GeneRuler low range DNA ladder) und die Proben wurden auf das Gel aufgetragen. Je $10 \mu \mathrm{l}(1 \mu \mathrm{g})$ Längenstandard sowie 100 ng DNA bzw. RNA in $10 \mu 1$ 
Lösung wurden mit $3 \mu \mathrm{l}$ Ladepuffer versehen. Anschließend erfolgte eine elektrophoretische Auftrennung (60 Min bei $400 \mathrm{~mA}$ und $85 \mathrm{~V}$ ). Die Nukleinsäuren wurden im ultravioletten (UV) Licht sichtbar gemacht und zu Dokumentationszwecken fotografiert.

\title{
2.3.5 cDNA(complementary DNA)-Synthese (reverse Transkription, RT)
}

Zur Herstellung der cDNA wurde jeweils $1 \mu \mathrm{g}$ RNA eingesetzt. Die cDNA-Synthese erfolgte mit Primer random $\mathrm{p}(\mathrm{dN}) 6$. Zunächst wurde Primer random $\mathrm{p}(\mathrm{dN}) 6$ von $1000 \mathrm{nmol} / \mathrm{ml}$ auf $150 \mathrm{pmol} / 2 \mu \mathrm{l}$ mit Ampuwa verdünnt. Dann wurde der Reaktionsansatz

$10 \mu 1$ RNA-Lösung entsprechend $1 \mu \mathrm{g}$ RNA

$+\quad 2 \mu 1$ Primer random $\mathrm{p}(\mathrm{dN}) 6$ entsprechend $150 \mathrm{pmol}$

für 10 Min bei $70{ }^{\circ} \mathrm{C}$ denaturiert, für 5 Min abgekühlt, $13 \mu \mathrm{RT}$-Mix dazugegeben und das Ganze für 60 Min bei $42{ }^{\circ} \mathrm{C}$ inkubiert. Um die erwünschte Endkonzentration der cDNALösung, $8 \mathrm{ng} / 2,5 \mu \mathrm{l}$, zu erreichen, wurde der Ansatz mit Ampuwa auf ein Volumen von 312 $\mu l$ aufgefüllt.

RT-Mix pro Reaktionsansatz $(13 \mu \mathrm{l})$ :

\author{
2,5 $\mu 140 \mathrm{mM}$ dNTP \\ $5,0 \mu \mathrm{l} 5 \mathrm{x}$ RT Puffer \\ $2,5 \mu 10,1$ M DTT \\ $1,0 \mu \mathrm{l}$ MMLV reverse transcriptase (200 U) \\ $0,4 \mu \mathrm{R} \operatorname{Rasin}(0,4 \mathrm{U})$ \\ 1,6 $\mu$ l Ampuwa.
}

\subsubsection{Genotypisierung genetischer Polymorphismen mittels allelischer Diskriminierung}

Mithilfe allelischer Diskriminierung können polymorphe Positionen in einer DNA-Probe genotypisiert werden. Die Methode beruht auf der 5 ' $\rightarrow 3^{\prime}$ '-Exonukleaseaktivität der DNAPolymerase (Holland et al. 1991) und auf dem Einsatz fluoreszierender farbmarkierter Oligonukloetide (Sonden) (Lee et al. 1993). Der PCR-Ansatz beinhaltet zwei Primer, die den DNA-Abschnitt, der den interessierenden SNP enthält, flankieren und zwei Sonden (falls es sich um einen bi-allelischen Polymorphismus handelt), die in Bezug auf die polymorphe Position Allel-spezifisch sind. Die Sonden besitzen am 5'-Terminus ein fluorogenes Farbstoffmolekül und am 3'-Terminus einen nicht-fluoreszierenden Quencher (to quench engl. - auffangen). Solange die Sonde intakt ist und sich der Reporter-Farbstoff und Quencher in unmittelbarer Nähe zueinander befinden, wird die fluoreszierende Aktivität des Reporter- 
Farbstoffs gemäß dem Gesetz von fluorescence resonance energy transfer (FRET) durch den Quencher unterdrückt (Cardullo et al. 1988). Während der PCR binden die Sonden jeweils an die komplementäre DNA-Sequenz. Die DNA-Polymerase aber, die ausgehend vom Vorwärtsprimer einen neuen komplementären Strang synthetisiert, spaltet durch ihre 5'-3'Exonukleaseaktivität die gebundene Sonde. Das führt zur Freisetzung des ReporterFarbstoffs, wodurch er sich dem unterdrückenden Einfluss des Quencher-Moleküls entzieht und Fluoreszenz freisetzt. In der linearen Phase der Reaktion steigt die Fluoreszenz nach jedem PCR-Zyklus exponentiell an und ist direktproportional der Menge des freigesetzten Reporter-Farbstoffs bzw. der eingesetzten Menge an DNA. Der oben beschriebene Vorgang trifft für den Fall zu, wenn Sonde und DNA-Sequenz vollständig komplementär gepaart (matched) sind. Bei nicht vollständig gepaarten (mismatched) Sonden kommt es eher zur Loslösung von der DNA-Sequenz durch das „Voranschreiten“ der DNA-Polymerase, ohne dass sie dabei gespalten werden. Deswegen ergibt sich in diesem Fall keine Fluoreszenz (s. Abb. 2.1). Diese Art von Sonden werden als Sequenz-spezifische Hydrolisierungssonden bezeichnet.

Um zwischen verschiedenen Allelen unterscheiden zu können, sind die Sonden am 5'-Ende mit unterschiedlichen Fluoreszenzfarbstoffen (FAM- und VIC-Farben) markiert. TaqMan-Sonden besitzen auch ein MGB-(minor groove binder)-Molekül am 3'-Ende. Diese Moleküle binden an die engeren Windungen der DNA-Helix und stabilisieren damit den Sonden/template-Komplex. Dadurch steigt die Schmelztemperatur (melting temperature, Tm) des Komplexes an, was das Entwerfen kürzerer Sonden ermöglicht (Afonina et al. 1997; Kutyavin et al. 2000). Das ist doppelt günstig: Einerseits steigt das Tm-Fenster zwischen gepaarten und fehlgepaarten Sonden/template-Komplexen, was zu besserer Differenzierung der Allele beiträgt, und andererseits sind kürzere Sonden Fehlpaarungen gegenüber sensibler. Ziel der allelischen Diskriminierung ist es, Proben als homozygot für Allel 1, homozygot für Allel 2 oder heterozygot zu klassifizieren. Der gesamte Vorgang besteht in der Regel aus 3 Schritten: pre-read run, amplification run und post-read run. Pre-read run detektiert die Hintergrundsfluoreszenz (background fluorescence) von jedem well vor der PCR. Während der Amplifizierung (amplification run) werden die Fluoreszenzsignale von jeder ReporterFarbe durch das PCR-Gerät detektiert und als Funktion der PCR-Zyklenzahl dargestellt (Abb. 2.2). Bei dem post-read run wird pre-read Fluoreszenz von der post-read Fluoreszenz abgezogen um die Hintergrundsfluoreszenz vor der Amplifikation zu berücksichtigen und genaue Ergebnisse zu erzielen. 


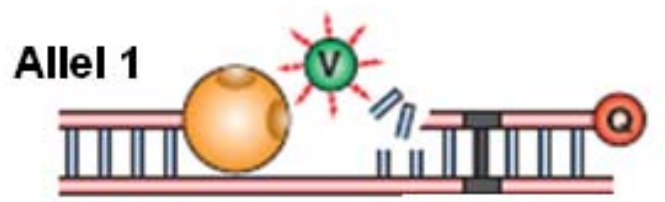

gepaart

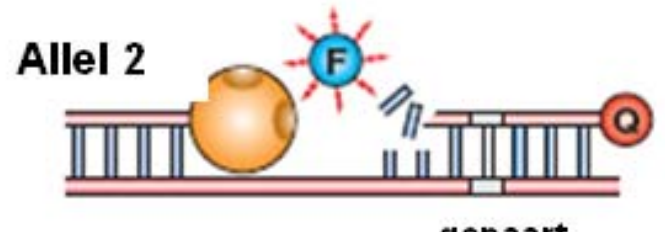

gepaart

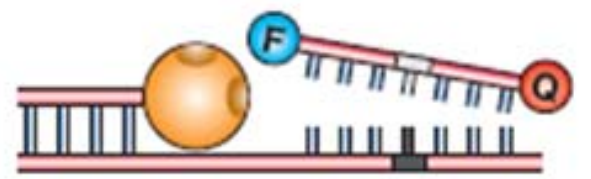

nicht gepaart

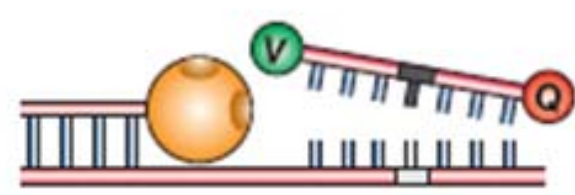

nicht gepaart

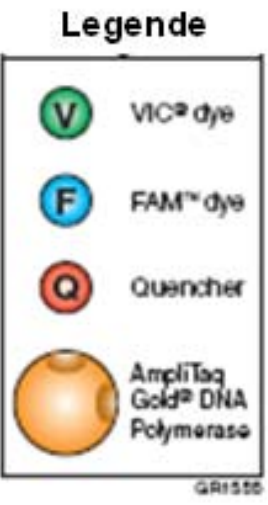

Garst:

\begin{tabular}{|l|l|}
\hline Fluoreszenz-Messung & \multicolumn{1}{|c|}{ Bedeutung } \\
\hline Nur VIC-Fluoreszenz & Homozygot für Allel 1 \\
\hline Nur FAM-Fluoreszenz & Homozygot für Allel 2 \\
\hline Beide & Heterozygot \\
\hline
\end{tabular}

\section{Abb. 2.1: Allelische Diskriminierung}

Eine VIC-markierte Sonde ist für Allel 1 und eine FAM-markierte Sonde für Allel 2 spezifisch. Beide Sonden sind mit jeweils entsprechender DNA-Sequenz vollständig gepaart. Deswegen werden sie durch die 5'-3'Exonukleaseaktivität der DNA-Polymerase gespalten. Infolge dessen wird die VIC- bzw. FAM-Fluoreszenz freigesetzt. Beide Sonden weisen eine nicht vollständige Paarung mit DNA-Sequenzen auf, für die sie nicht spezifisch sind. Das Vorwärtskommen der DNA-Polymerase führt zur Loslösung der nicht vollständig gepaarten Sonden von der DNA-Sequenz, die Sonden bleiben intakt und es kommt nicht zur Freisetzung der Fluoreszenz.

(modifiziert nach Applied Biosystems, www.bio.tamu.edu/bsif/pdfs/Allelic\%20discrimination\%20guide.pdf)

Nach dem post-read run werden die Ergebnisse der allelischen Diskriminierung in einem Koordinatensystem graphisch - Allel X versus Allel Y - dargestellt. Wenn die Reaktion erfolgreich war, entstehen drei Gruppen (clusters) von Signalen: An der vertikalen (homozygot für Allel Y), an dem horizontalen (homozygot für Allel X) und an der diagonalen Achse (heterozygot Allel X / Allel Y). Die tatsächliche Bezeichnungen der Allele (z. B. C und G) sind zu Allel X oder Y vorher zugeordnet (Abb. 2.3). 


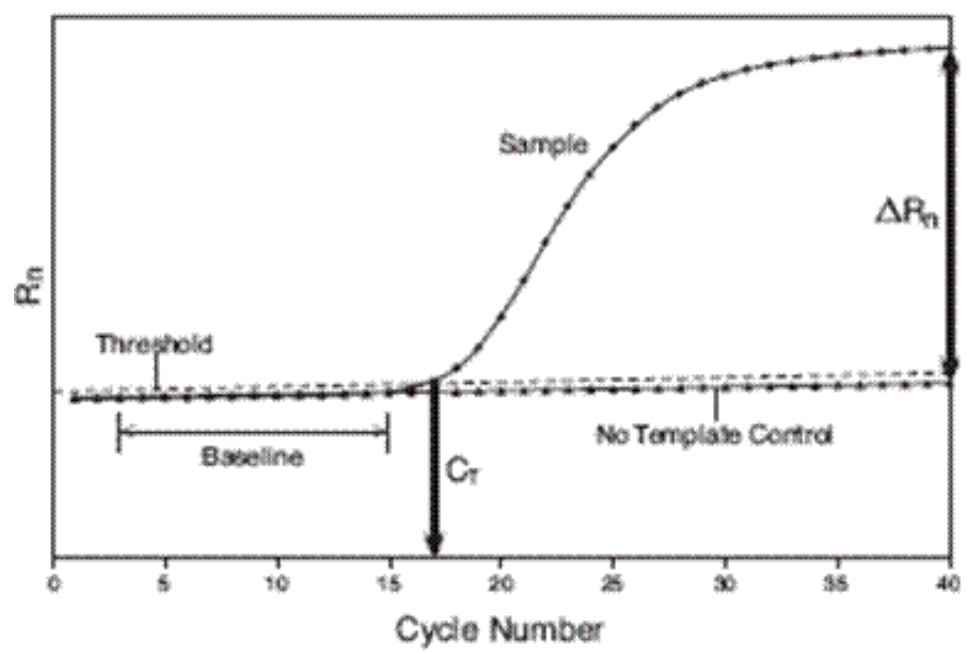

\begin{tabular}{|c|c|}
\hline Begriff & Definition \\
\hline Baseline & $\begin{array}{l}\text { Entspricht den Fluoreszenzwerten der frühen PCR-Zyklen (in der Regel 3.- } \\
\text { 15. Zyklen), bei denen noch kein detektierbarer Anstieg der Fluoreszenz zu } \\
\text { beobachten ist. Baseline wird von der Fluoreszenz der PCR-Produkte } \\
\text { abgezogen }\end{array}$ \\
\hline Template & Nukleotidensequenz, die zu amplifizieren ist \\
\hline $\begin{array}{l}\text { No Template Control } \\
\text { (NTC) }\end{array}$ & $\begin{array}{l}\text { Eine Probe, die kein template enthält. Sie zeigt nur Hintergrundssignal und } \\
\text { wird als negative Kontrolle benutzt, was die Messung der Kontaminierung, } \\
\text { die ein falsch-positives Signal liefern könnte, ermöglicht }\end{array}$ \\
\hline Threshold & $\begin{array}{l}\text { Wird oberhalb der baseline gesetzt, aber immer innerhalb der Phase des } \\
\text { linearen Anstiegs der Kurve (nicht in der Plateau-Phase) }\end{array}$ \\
\hline Threshold cycle (CT) & $\begin{array}{l}\text { Die Zykluszahl, bei der die Fluoreszenzintensität der Probe den threshold } \\
\text { überschreitet, s. o. }\end{array}$ \\
\hline Passive reference & $\begin{array}{l}\text { Ein Farbstoff, der eine interne Fluoreszenzreferenz liefert, auf die während } \\
\text { der Datenanalyse das Signal einer Reporter-Farbe genormt werden kann. } \\
\text { Diese Normierung ist notwendig, um für Fluoreszenzschwankungen } \\
\text { aufgrund von Konzentrations- oder Volumensvariationen zu korrigieren }\end{array}$ \\
\hline Reporter dye & $\begin{array}{l}\text { Der Farbstoff, gebunden am 5'-Ende einer TaqMan-Sonde. Er liefert ein } \\
\text { Signal, das spezifische Amplifizierung anzeigt }\end{array}$ \\
\hline Normalized reporter $(R n)$ & $\begin{array}{l}\text { Das Verhältnis der Fluoreszenzintensität des Reporter-Farbstoffsignals zur } \\
\text { Fluoreszenzintensität des Signals von Passivreferenz-Farbstoffsignal }\end{array}$ \\
\hline Delta $R n(\Delta R n)$ & $\begin{array}{l}\text { Entspricht der Signalgröße, die durch die PCR erzeugt wird }(\Delta \mathrm{Rn}=\mathrm{Rn}- \\
\text { baseline })\end{array}$ \\
\hline
\end{tabular}

Abb.2.2: Amplification plot

(modifiziert nach Applied Biosystems, www.bio.tamu.edu/bsif/pdfs/Allelic\%20discrimination\%20guide.pdf) 


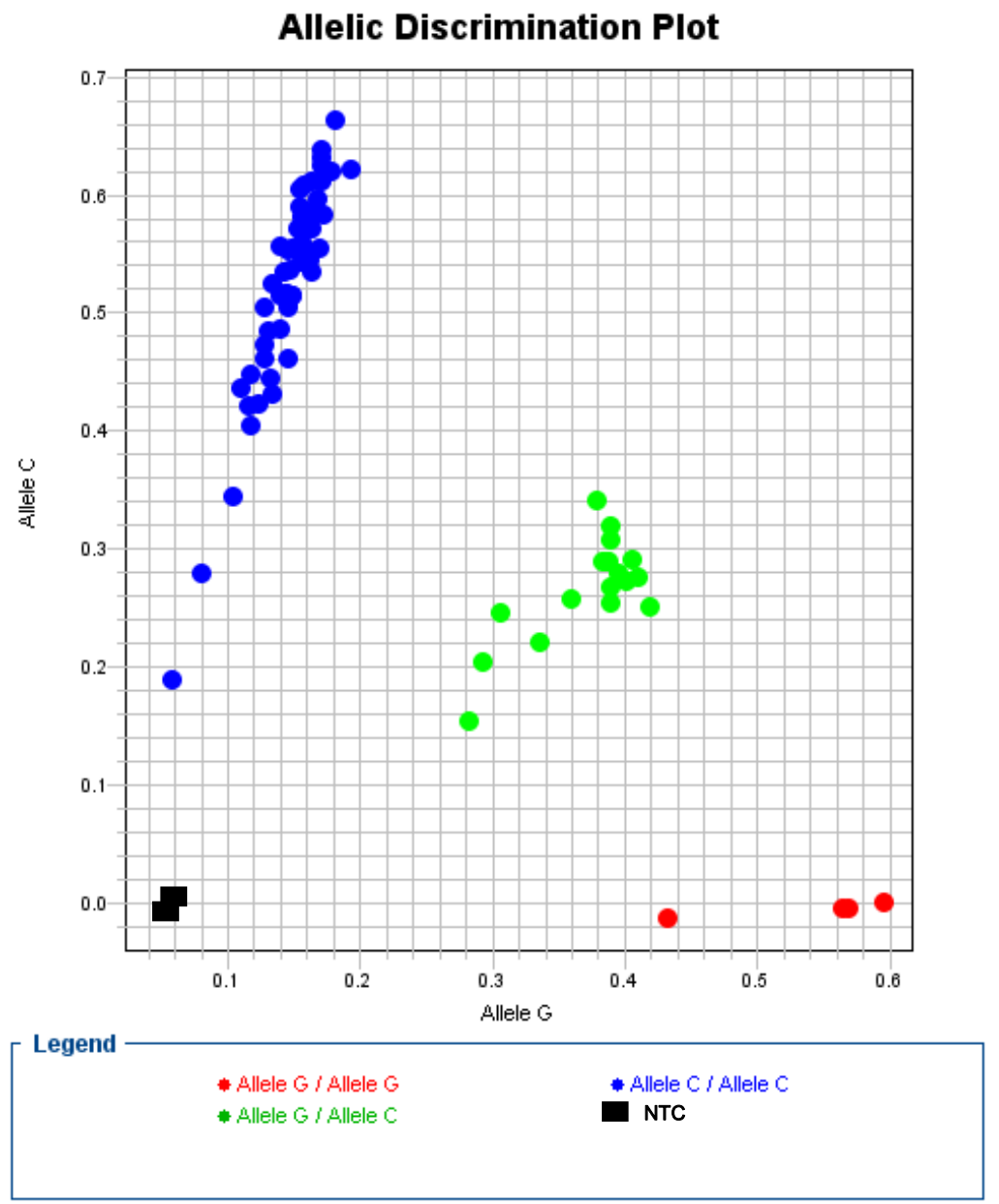

Abb. 2.3: Ergebnisse einer allelischen Diskriminierung

Auf der vertikalen (Y) Achse sind FAM-Fluoreszenzwerte und an der horizontalen (X) VIC-Fluoreszenzwerte dargestellt. Die Proben, die überwiegend FAM-Fluoreszenz aufweisen, sind homozygot für das Allel, das durch die FAM-markierte Sonde erkannt wird (in diesem Fall Allel C). Bei den überwiegend VIC-fluoreszierenden Proben handelt es sich um Homozygote für das durch die VIC-Sonde erkannte Allel (in diesem Fall Allel G). An der diagonalen Achse reihen sich heterozygote Proben, die die beiden (FAM- und VIC-)Fluoreszenzen etwa gleichermaßen aufweisen. Bei den NTC-Proben, die keine DNA-Sequenz enthalten, ist fast keine Fluoreszenz festzustellen, deswegen befinden sie sich in der Nähe des Nullpunkts. 


\subsubsection{Genotypisierung am SNP rs2569190 / C-159T}

Die Diskriminierung der Allele des SNPs rs2569190 / C-159T erfolgte mit einem Assay-byDesign aus Primern und Sonden, der im Rahmen einer vorangegangenen Doktorarbeit etabliert worden war (Maouzi 2007) (Abb. 2.4).

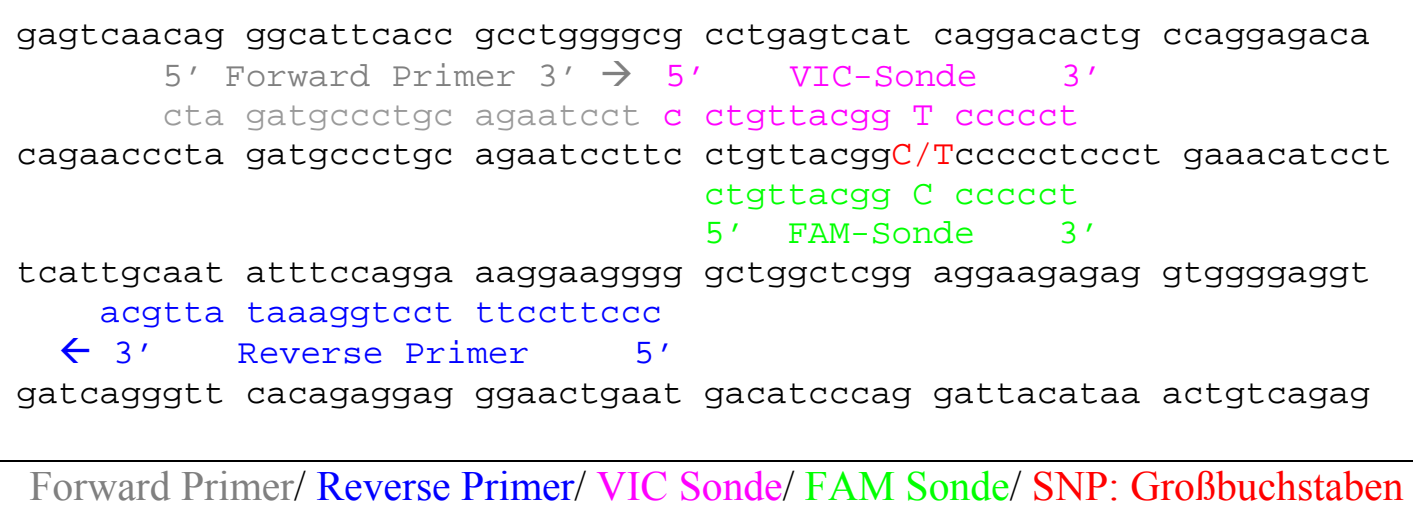

Abb. 2.4: Die relevante Nukleotidsequenz im Bereich des Polymorphismus rs2569190 / C-159T und die für die Genotypisierung eingesetzten Primer und Sonden

(Nukleotidensequenz entnommen von Ensemble, http://www.ensembl.org/Homo_sapiens/Gene/Sequence?g=ENSG00000170458)

Reaktionsansatz für die Genotypisierung einer gDNA-Probe, die aus PBMC oder Serum extrahiert wurde:

Ansatz für PCR $(20 \mu 1)$ :

$\begin{array}{rrl}10,0 & \mu 1 & \text { 2x TaqMan Genotyping PCR Master Mix } \\ 0,5 & \mu 1 & \text { 40x Assay Mix (Primer + Sonden) } \\ 4,5 / 7,0 \mu 1 & \text { Ampuwa } \\ 5,0 / 2,5 \mu 1 & \text { gDNA aus PBMC }(10 \mathrm{ng} / 5 \mu 1) / \text { aus Serum }\end{array}$

Die Reaktionsgemische wurden auf eine 96-well-Mikrotiterplatte pipettiert. Für jede Probe wurde Doppelbestimmung durchgeführt. Um Fehler zu vermeiden, wurden zusätzlich zwei negative Kontrollen (NTC) (5 $\mu$ l Ampuwa statt DNA) auf jede Platte eingesetzt.

Die PCR als real time PCR wurde mit dem Sequence detection system ABI prism 7000 durchgeführt:

$\begin{array}{rrl}95{ }^{\circ} \mathrm{C} & 10 \mathrm{Min} & \text { Vordenaturierung } \\ 95^{\circ} \mathrm{C} & 15 \mathrm{Sek} & \text { Denaturierung } \\ 60^{\circ} \mathrm{C} & 1 \mathrm{Min} & \begin{array}{l}\text { Primer-/ Sonden-Anlagerung, } \\ \text { Kettenverlängerung }\end{array}\end{array}$


Die freigewordene Fluoreszenz wurde im Anschluss an die PCR im Sequence detection system ABI prism 7000 im Modus ,plate read“" bei einer Temperatur von $60{ }^{\circ} \mathrm{C}$ gemessen.

\subsubsection{Genotypisierung am SNP rs4914}

Die Genotypisierung an der polymorphen Position rs4914 erfolgte teils mit dem kommerziell erhältlichen TaqMan-Genotypisierungs-Assay (Assay-on-Demand C_8724832_10) entsprechend den Anweisungen des Herstellers, und teils mit Sonden und Primern, die im Rahmen einer vorangegangenen Doktorarbeit etabliert waren (Mansur 2008) (Tab. 2.1).

Tab. 2.1: Primer und Sonden für Genotypisierung an der Position rs4914

\section{Sequenz}

\begin{tabular}{ll}
\hline $\begin{array}{l}\text { Primer } \\
\text { CD14exon1forward }\end{array}$ & 5' TCC CAG CCT GTG CAC GTT 3' \\
CD14exon1reverse & 5' CTG AAG CCA AGG CAG TTT GAG T 3' \\
\hline Sonden & \\
CD14exon1-G & VIC 5' CCT TGG AGG AGC AC MGB 3' (erkennt das G-Allel) \\
CD14exon1-C & FAM 5' CTT GGA G $\underline{\text { CA GCA CC MGB 3' (erkennt das C-Allel) }}$ \\
\hline
\end{tabular}

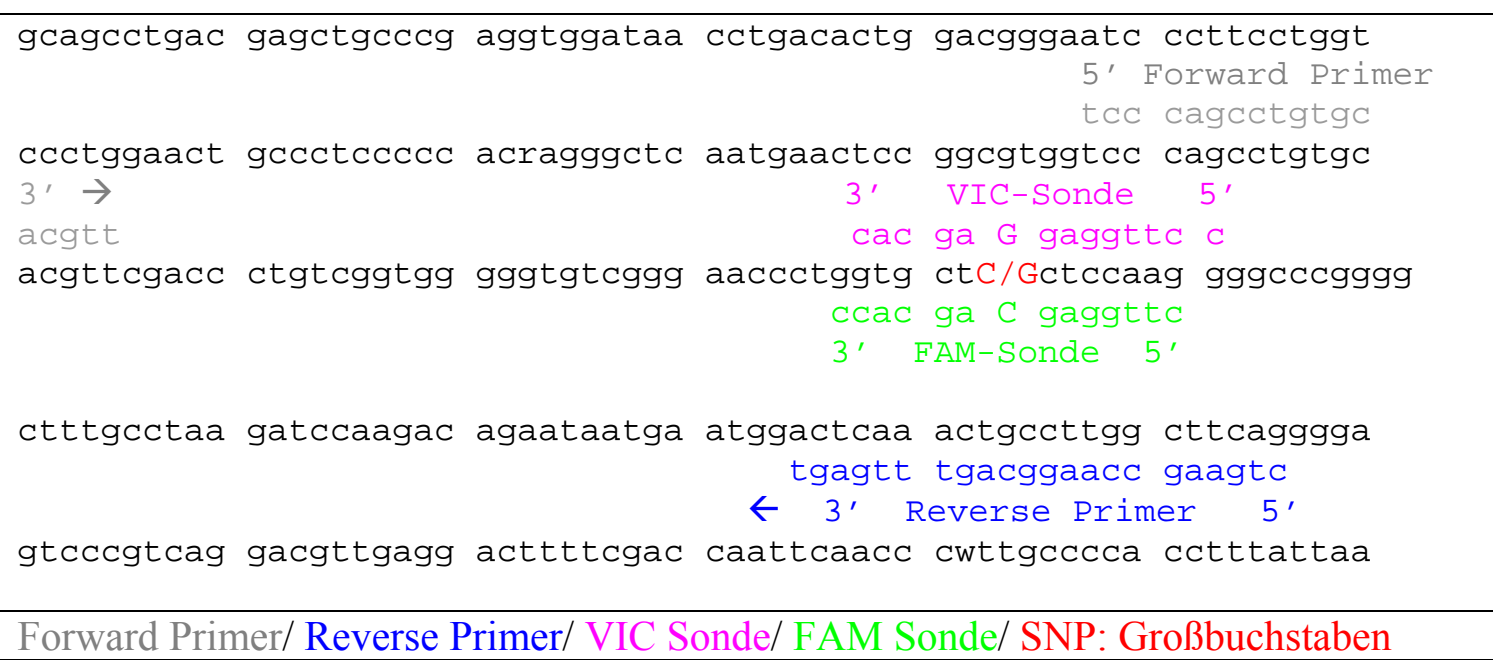

Abb. 2.5: Die relevante Nukleotidsequenz im Bereich des untersuchten SNPs rs4914 und die für die Genotypisierung eingesetzten Primer und Sonden

(Nukleotidensequenz entnommen von Ensemble, http://www.ensembl.org/Homo_sapiens/Gene/Sequence?g=ENSG00000170458) 
Für die real time PCR gab es folgende Bedingungen:

Reaktionsansatz für gDNA-Proben, die aus PBMC oder Serum extrahiert wurden:

Ansatz für PCR $(10 \mu l)$ :

$\begin{array}{lll}5,0 & \mu 1 & \text { 2x TaqMan Genotyping Master Mix } \\ 1,0 / 0,125 & \mu \mathrm{l} & \text { Primer forward } 6 / 48 \mu \mathrm{M} \\ 1,0 / 0,125 & \mu \mathrm{l} & \text { Primer reverse } 6 / 48 \mu \mathrm{M} \\ 1,0 / 0,5 & \mu \mathrm{l} & \text { Sonde „Allel 1“2 } / 4 \mu \mathrm{M} \\ 1,0 / 0,5 & \mu \mathrm{l} & \text { Sonde „Allel 2“2 } / 4 \mu \mathrm{M} \\ 1,0 / 3,75 & \mu \mathrm{l} & \text { gDNA aus PBMC }(10 \mathrm{ng} / 5 \mu \mathrm{l}) / \text { aus Serum }\end{array}$

Thermoprofil (StepOnePlus):

$95^{\circ} \mathrm{C} \quad 10 \mathrm{Min}$

$95^{\circ} \mathrm{C} 15$ Sek

$65^{\circ} \mathrm{C} \quad 1 \mathrm{Min}$ $\left.\begin{array}{l}\text { Vordenaturierung } \\ \text { Denaturierung } \\ \text { Primer- / Sonden-Anlagerung, } \\ \text { Kettenverlängerung }\end{array}\right\}$

1-malig

45 Zyklen (für gDNA aus PBMC) /

50 Zyklen (für gDNA aus Serum)

\subsubsection{Genotypisierung genetischer Polymorphismen mittels tetra-Primer- ARMS(Amplification Refractory Mutation System) -PCR}

Die Genotypisierung an der Positionen rs5744455 und rs2563298 haben wir mithilfe tetraPrimer-ARMS-PCR (Ye et al. 2001) durchgeführt. Diese Methode benutzt zwei Primerpaare (innere Primer und äußere Primer), um zwei verschiedene Allele eines SNPs in einer einzigen PCR zu amplifizieren. Die Produkte werden anschließend in einem Agarosegel aufgetrennt und die Genotypen können anhand des Größenmusters der entstandenen Produkte abgelesen werden. Die inneren Primer sind so entworfen, dass sie sich an die polymorphe Position mit ihrem letzten Nukleotid am 3'-Ende anlagern. Außerdem enthalten sie eine absichtlich gesetzte Fehlpaarung an der Position -3 am 3'-Terminus, wodurch eine unspezifische Anlagerung der Primer effektiv verhindert wird (Ye et al. 2001). Die Tm der Primer, wie üblich, müssen annähernd gleich sein (Unterschied $<2{ }^{\circ} \mathrm{C}$ ).

Für das Entwerfen der Primer haben die Autoren ein Computerprogramm entwickelt und zur Verfügung gestellt (http://cedar.genetics.soton.ac.uk/public-html/primer1.html).

\subsubsection{Genotypisierung am SNP rs5744455}

Für die Genotypisierung am SNP rs5744455 wurden tetra-Primer mithilfe des obengenannten Computerprogramms entworfen (Tab. 2.2, Abb. 2.6). Die Amplifikation mit den Primern (siehe unten) führt zur Bildung von Produkten unterschiedlicher Größe (Tab. 2.3), die 
gelelektrophoretisch in einem $2 \%$-igen Agarosegel (120 V, $400 \mathrm{~mA}, 40$ Min) aufgetrennt werden können (Abb. 2.7).

Tab. 2.2: Tetra-Primer für die Genotypisierung des SNPs rs5744455

\begin{tabular}{lcc}
\hline Primer & \multicolumn{1}{c}{ Sequenz } & Tm [ $\left.{ }^{\circ} \mathrm{C}\right]$ \\
\hline rs574 tetra T f & 5' AAG GAA GGG GGA ATT TTT CTT TAG CCT 3' & 61,9 \\
rs574 tetra C r & 5' GGT AGA ATT AGG TTC AAG AAA AGG AAG GTG 3' & 64,0 \\
rs574 tetra for & 5' CTG AGC AAC AGA GCA AGA CTC TAT CTC A 3' & 65,1 \\
rs574 tetra rev & 5' CAT TTC TTT GAC TTC TTC CTT GTC TTG G 3' & 62,2 \\
\hline
\end{tabular}

gaggcagaga attgcttgaa cccaggaggc ggaggttgca gtgagccgag atcatggcac

$5^{\prime}$ Forward outer primer $3^{\prime} \rightarrow$

ctgagcaac agagcaagac tctatctca

tctactccag cctgagcaac agagcaagac tctatctcaa aaaaaaaaaa aaaaaagaaa 5' Forward inner primer aag gaagggggaa tttttcttta gaaagttatt acttaatcaa aggagcaagg aaaaaaaag gaagggggaa ttttcttta $3^{\prime} \rightarrow$ gcc $\mathrm{t}$

gacc/Taacttc cttttcttga acctaattct acccccettg gtgccaacag atgaggttca g tggaag gaaaagaact tggattaaga tgg

$\leftarrow 3^{\prime}$ Reverse inner primer $5^{\prime}$

caatctcttc cacaaaacat gcagttaaat atctgaggat attcagggac ttggatttgg

tggcaggaga tcaacataaa ccaagacaag gaagaagtca aagaaatgaa tcaagtagat ggttctgttc cttcttcagt ttctttac $\leftarrow 3^{\prime}$ Reverse outer primer $5^{\prime}$

tctctgggat ataaggtagg gggattgggg ggttggatag tgcagagtat ggtactggcc taaggcactg aggatcatcc ttttcccaca cccaccagag aaggcttagg ctcccgagtc

Forward outer primer/Reverse outer primer/Forward inner primer/Reverse inner primer/SNP: Großbuchstaben

Abb. 2.6: Die relevante Nukleotidsequenz im Bereich des Polymorphismus rs5744455 und die für die Genotypisierung verwendeten tetra-Primer

(Nukleotidensequenz entnommen von Ensemble, http://www.ensembl.org/Homo_sapiens/Gene/Sequence? $g=E N S G 00000170458$ ) 
Tab. 2.3: Produkte der tetra-Primer-ARMS-PCR-Genotypisierung am SNP rs5744455

\begin{tabular}{lcc}
\hline Primer & PCR-Produkt & Länge des PCR-Produkts \\
\hline $\begin{array}{l}\text { Forward outer Primer (rs574 tetra for) } \\
\text { Reverse outer Primer (rs574 tetra rev) }\end{array}$ & Outer Produkt & $277 \mathrm{bp}$ \\
\hline $\begin{array}{l}\text { Forward outer Primer (rs574 tetra for) } \\
\text { Reverse inner Primer (rs574 tetra C r) }\end{array}$ & C-Allel-Produkt & $142 \mathrm{bp}$ \\
\hline $\begin{array}{l}\text { Forward inner Primer (rs574 tetra T f) } \\
\text { Reverse outer Primer (rs574 tetra rev) }\end{array}$ & T-Allel-Produkt & $192 \mathrm{bp}$ \\
\hline
\end{tabular}

Für konventionelle PCR gab es folgende Bedingungen:

Ansatz für PCR $(25 \mu l)$ :

$\begin{aligned} 12,5 \mu \mathrm{l} & \text { GoTaq Colorless-/Green-master-Mix } \\ 1,5 \mu \mathrm{l} & \text { Primer rs574 tetra T f } 3 \mu \mathrm{M} \\ 1,5 \mu \mathrm{l} & \text { Primer rs574 tetra C r } 3 \mu \mathrm{M} \\ 1,5 \mu \mathrm{l} & \text { Primer rs574 tetra for } 3 \mu \mathrm{M} \\ 1,5 \mu \mathrm{l} & \text { Primer rs574 tetra rev } 3 \mu \mathrm{M} \\ 4,5 \mu \mathrm{l} & \mathrm{H}_{2} \mathrm{O} \text { (Ampuwa) } \\ 2,0 \mu \mathrm{l} & \text { gDNA-Lösung (entspr. 10-20 ng gDNA) }\end{aligned}$

Thermoprofil (Perkin Elmer, GeneAmp PCR System 9600):

\begin{tabular}{|c|c|c|c|}
\hline $94^{\circ} \mathrm{C}$ & $3 \mathrm{Min}$ & Vordenaturierung & 1-malig \\
\hline $94^{\circ} \mathrm{C}$ & $1 \mathrm{Min}$ & Denaturierung & \\
\hline $62^{\circ} \mathrm{C}$ & $1 \mathrm{Min}$ & Primeranlagerung & 40 Zyklen \\
\hline $72{ }^{\circ} \mathrm{C}$ & $1 \mathrm{Min}$ & Kettenverlängerung & \\
\hline$\circ$ & & & hold \\
\hline
\end{tabular}




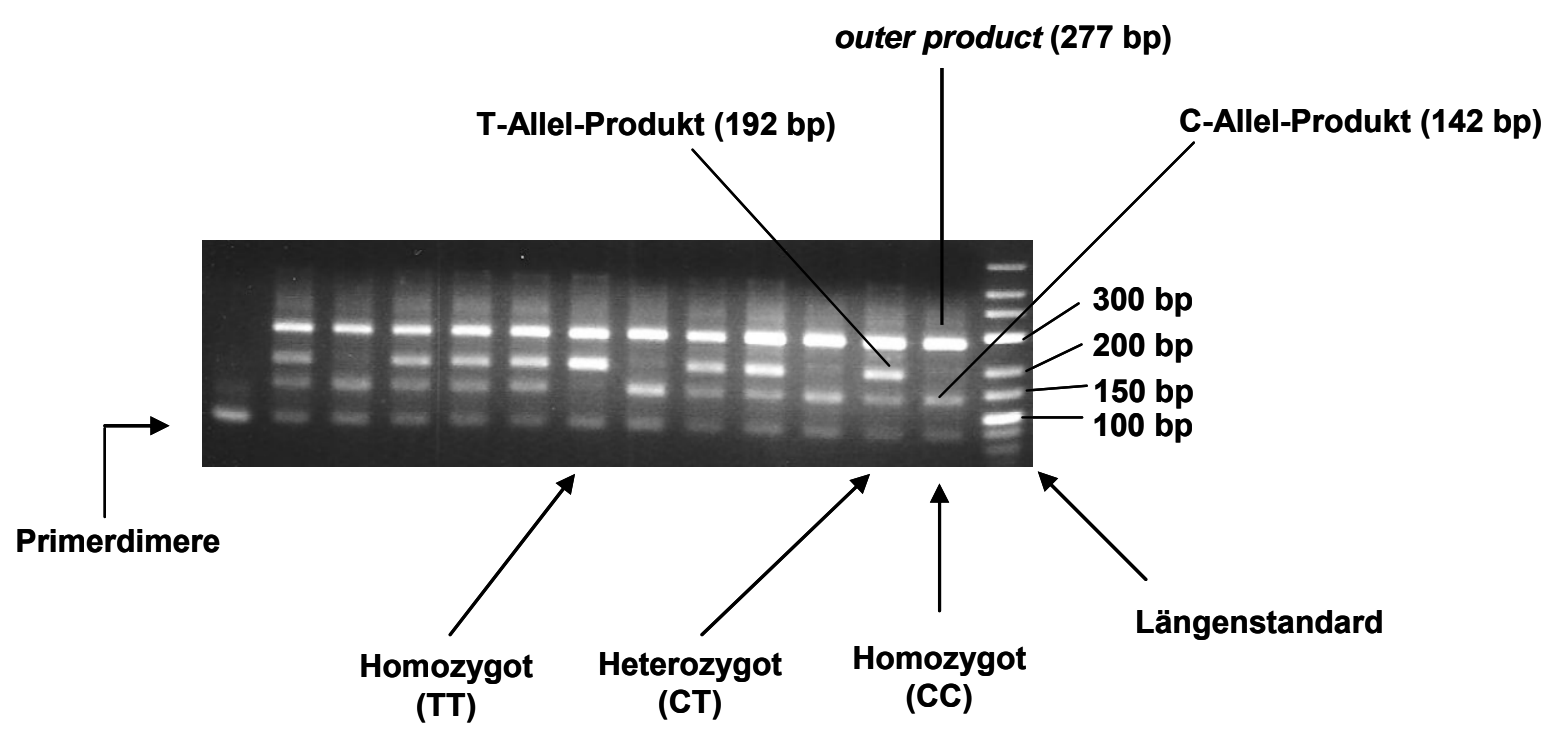

Abb. 2.7: Tetra-Primer-ARMS-PCR zur Genotypisierung am SNP rs5744455

Die Amplifikate der tetra-Primer-ARMS-PCR wurden gelelektrophoretisch separiert und unter UV-Licht photographiert. Ein PCR-Produkt der beiden äußeren (outer) Primer (277 bp) entsteht in allen Fällen. Außerdem, je nach Genotyp, entstehen PCR-Produkte mit folgenden Größen: 142 bp bei C-homozygoten Proben, 192 bp bei T-homozygoten Proben, 142 bp und 192 bp bei heterozygoten Proben.

\subsubsection{Genotypisierung am SNP rs2563298}

Die Genotypisierung am SNP rs2563298 erfolgte analog zur Genotypisierung am SNP rs5744455 mit Hilfe einer tetra-Primer-ARMS-PCR (Abb. 2.8). Entsprechend der Tm der Primer (Tab. 2.4) erfolgte die Primeranlagerung bei $60{ }^{\circ} \mathrm{C}$. Die Amplifikaten hatten Größen von $247 \mathrm{bp}, 143 \mathrm{bp}$ und $163 \mathrm{bp}$ (Tab. 2.5) und wurden ebenfalls nach gelelektrophoretischer Auftrennung in einem 4 \%-igen Agarosegel unter UV-Licht dargestellt (Abb. 2.9).

Tab. 2.4:Tetra-Primer für Genotypisierung an der Position rs2563298

\begin{tabular}{llc}
\hline Primer & \multicolumn{1}{c}{ Sequenz } & Tm [ $\left.{ }^{\circ} \mathrm{C}\right]$ \\
\hline rs2563 tetra G f & 5' CCC ACC TTT ATT AAA ATC TTA AAG AAC AGG 3' & 61,3 \\
rs2563 tetra T r & 5' TAA AGG TCT GTT AAA TGA ATG ACA CGA AA 3' & 59,6 \\
rs2563 tetra for & 5' TTT GCC TAA GAT CCA AGA CAG AAT AAT G 3' & 60,7 \\
rs2563 tetra rev & 5' TTT CTT AGG GAG TTA GGA TGA AGA AAG C 3' & 62,2 \\
\hline
\end{tabular}




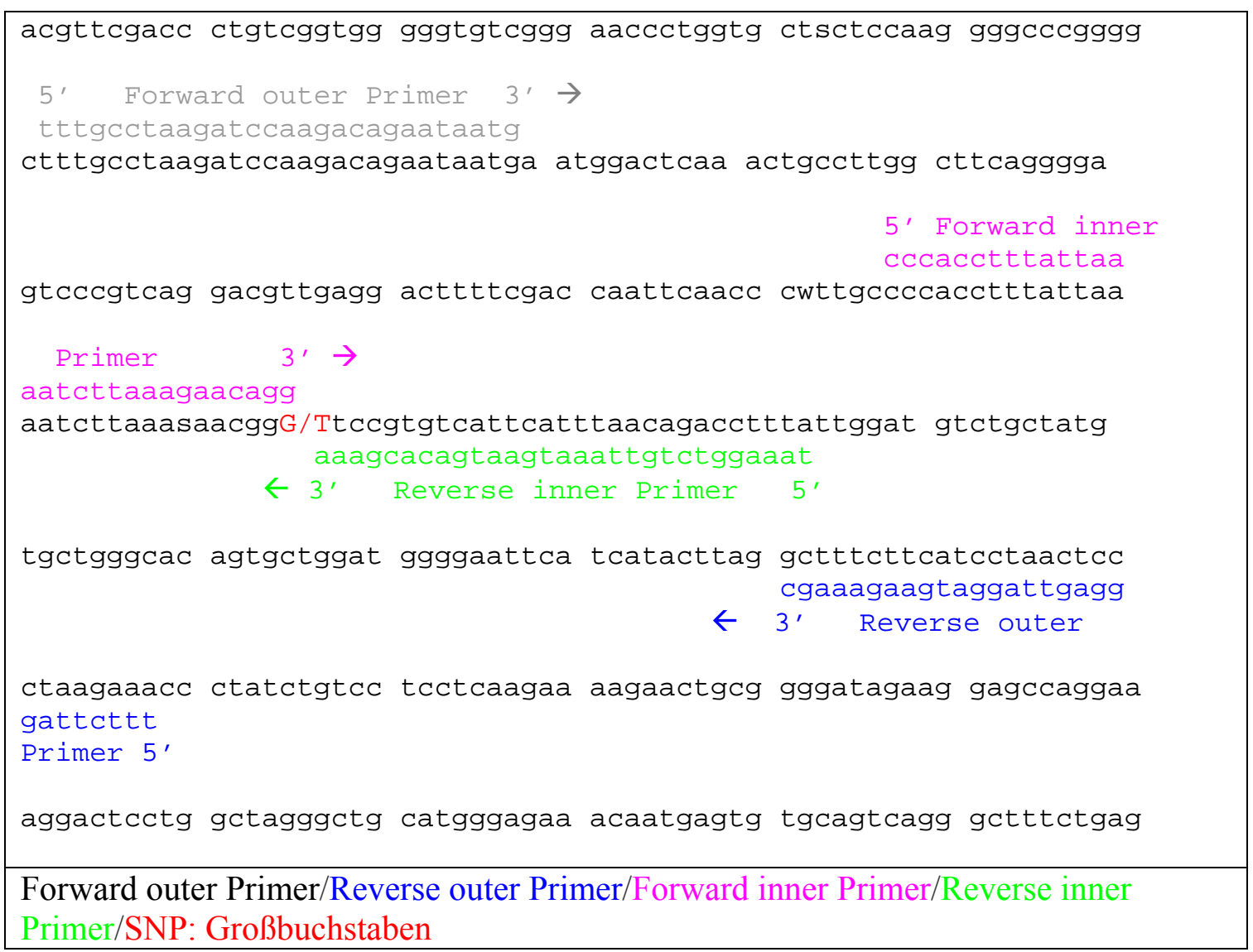

Abb. 2.8: Die relevante Nukleotidsequenz im Bereich des Polymorphismus rs2563298 und die für die Genotypisierung verwendeten tetra-Primer

(Nukleotidensequenz entnommen von Ensemble, http://www.ensembl.org/Homo_sapiens/Gene/Sequence?g=ENSG00000170458)

Tab. 2.5: Produkte der tetra-Primer-ARMS-PCR-Genotypisierung am SNP rs2563298

\begin{tabular}{llc}
\hline Primer & PCR-Produkt & Länge des PCR-Produkts \\
\hline $\begin{array}{l}\text { Forward outer Primer (rs2563 tetra for) } \\
\text { Reverse outer Primer (rs2563 tetra rev) }\end{array}$ & Outer Produkt & $247 \mathrm{bp}$ \\
\hline $\begin{array}{l}\text { Forward inner Primer (rs2563 tetra G f) } \\
\text { Reverse outer Primer (rs2563 tetra rev) }\end{array}$ & G-Allel-Produkt & $143 \mathrm{bp}$ \\
\hline $\begin{array}{l}\text { Forward outer Primer (rs2563 tetra for) } \\
\text { Reverse inner Primer (rs2563 tetra T r) }\end{array}$ & T-Allel-Produkt & $163 \mathrm{bp}$ \\
\hline
\end{tabular}




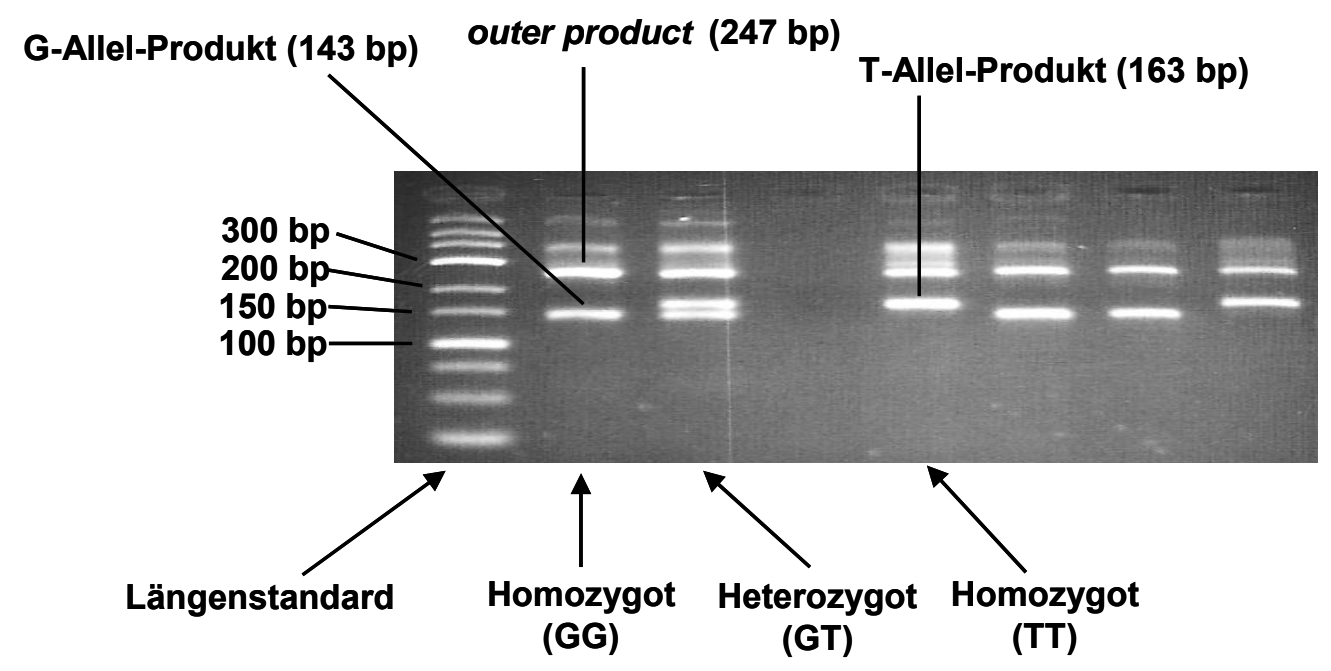

Abb. 2.9: Tetra-Primer-ARMS-PCR zur Genotypisierung am SNP rs2563298

Ein PCR-Produkt der beiden äußeren (outer) Primer (247 bp) entsteht in allen Fällen. Außerdem, je nach Genotyp, entstehen PCR-Produkte mit folgenden Größen: 143 bp bei G-homozygoten Proben, 163 bp bei Thomozygoten Proben, 143 bp und 163 bp bei heterozygoten Proben.

Die meisten Proben wurden jedoch im Rahmen der Haplotypisierung genotypisiert (s. unten 2.3.8).

\subsubsection{Haplotypisierung}

Um den Einfluss einer Kombination von SNPs auf die Genexpression oder auf phänotypische Merkmale eines Organismus zu untersuchen, muss der Haplo(geno)typ bestimmt werden. Das Prinzip, dem wir bei Haplotypisierung unseres Materials gefolgt sind, besteht darin, dass ausgehend von einer terminalen der 4 polymorphen Positionen, die genotypisiert wurden, Allel-spezifische Amplifikate hergestellt werden, die weitere SNPs enthalten. Diese für einen SNP Allel-spezifischen Amplifikate werden dann an weiteren Positionen genotypisiert (Abb. 2.10).

Proben, die heterozygot am SNP rs5744455 und auch heterozygot am SNP rs2569190 oder rs4914 waren, wurden mit Allel-spezifischen Primern (Tab. 2.6), entworfen nach dem ARMS-Prinzip (siehe oben), für den SNP rs5744455 amplifiziert, so dass etwa 2000 nukleotidlange Fragmente entstanden, die alle 4 Positionen von Interesse enthielten. Da wir die rs5744455-heterozygoten Proben in verschiedenen Reaktionsgefäßen mit jeweils einem Allel-spezifischen Primer (für Allel C bzw. Allel T) amplifiziert haben, standen nach der PCR Allel-spezifische Amplifikate separat zur Verfügung. 
A

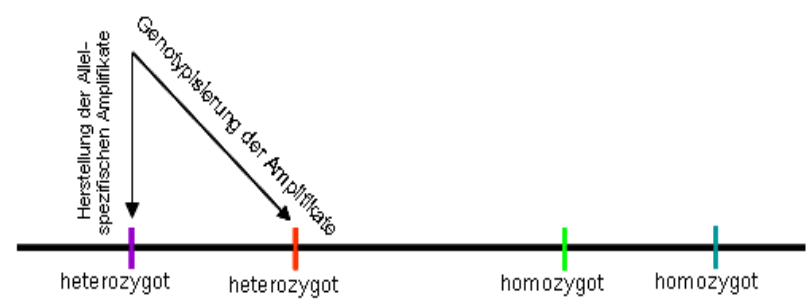

B

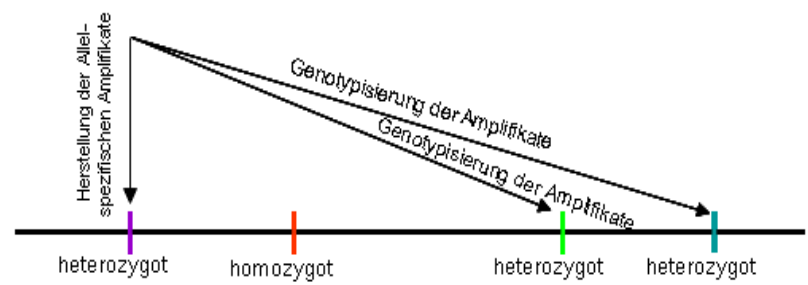

C

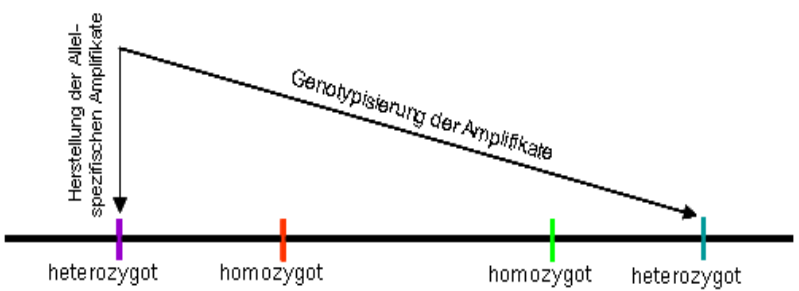

D

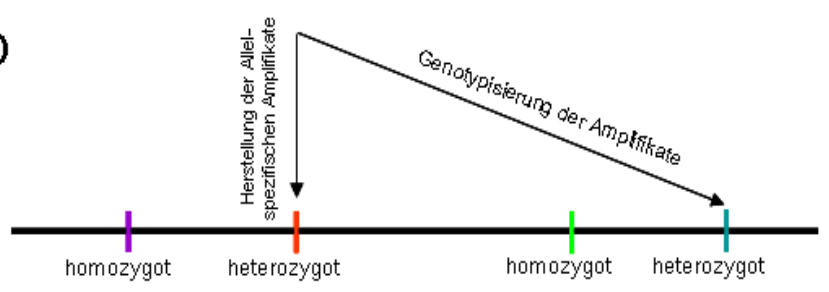

E

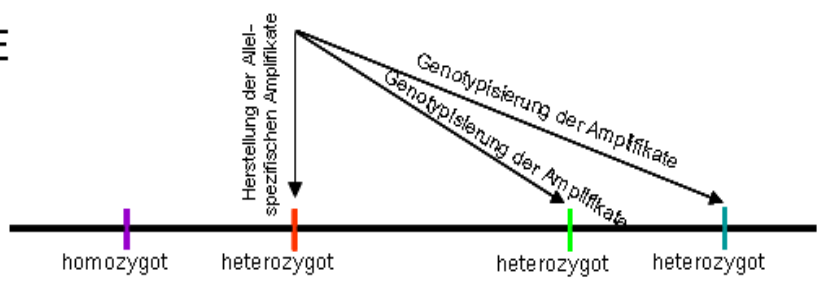

$\mathrm{F}$

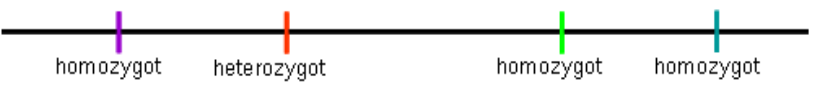

G

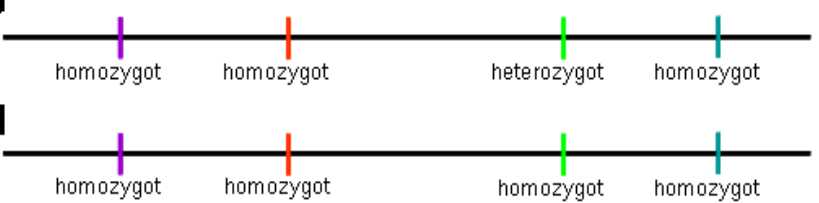

Abb. 2.10: Haplotypisierung der polymorphen Positionen im CD14-Gen (rs5744455, rs2569190, rs4914, rs2563298)

Die Genotypisierung des Materials an den 4 SNPs ergab eine begrenzte Anzahl von Kombinationen von homound heterozygoten Positionen (A-H). Die Vorgehensweise der Haplotypisierung orientierte sich an dem jeweiligen Muster. Von den Proben, die am SNP rs5744455 heterozygot waren, wurden rs57444455 Allelspezifische Amplifikate hergestellt und diese an den heterozygoten Positionen genotypisiert (A-D). Von den Proben, die am rs5744455 homozygot, aber am rs2569190 heterozygot waren, wurden rs2569190 Allelspezifische Amplifikate erzeugt, die ebenfalls an den verbleibenden heterozygoten Positionen genotypisiert wurden (D, E). Eine exprerimentelle Haplotypisierung war für die Proben, die an nur auf einer oder keiner Position heterozygot waren, nicht erforderlich (F-H).

Tab. 2.6: Allel-spezifische Primer für den SNP rs5744455

\begin{tabular}{lcc}
\hline Primer & \multicolumn{1}{c}{ Sequenz } & Tm [ $\left.{ }^{\circ} \mathrm{C}\right]$ \\
\hline rs574 tetra C f & 5' AAG GAA GGG GGA ATT TTT CTT TAG CCC 3' & 61,9 \\
rs574 tetra T f & 5' AAG GAA GGG GGA ATT TTT CTT TAG CCT 3' & 63,4 \\
CD14 tetra 3-rev & 5' TTT TCT TGA GGA GGA CAG ATA GGG TTT C 3' & 63,7 \\
\hline
\end{tabular}


Für die konventionelle PCR gab es folgende Bedingungen:

Ansatz-PCR $(25 \mu \mathrm{l})$ :

$\begin{array}{rl}0,50 \mu \mathrm{l} & 10 \mathrm{mM} \text { dNTP } \\ 2,50 \mu \mathrm{l} & 6 \mu \mathrm{M} \text { Primer forward (rs574 tetra C f bzw. rs574 tetra T f) } \\ 2,50 \mu \mathrm{l} & 6 \mu \mathrm{M} \text { Primer reverse (CD14 tetra 3-rev) } \\ 3,25 \mu \mathrm{l} & \text { Puffer (10x mit Magnesium) } \\ \mathrm{x} \mu \mathrm{l} & \text { Probe entsprechend 20-30 ng gDNA } \\ \operatorname{ad} 23 \mu \mathrm{l} & \text { Ampuwa } \\ 2,00 \mu \mathrm{l} & 0,625 \mathrm{U} \text { Taq Polymerase }\end{array}$

Thermoprofil (FlexCycler analytikjena):

\begin{tabular}{|c|c|c|}
\hline $\begin{array}{l}94^{\circ} \mathrm{C} 5 \mathrm{Min} \\
\text { hot start manuell }\end{array}$ & Vordenaturierung & 1-malig \\
\hline $94{ }^{\circ} \mathrm{C} 50 \mathrm{Sek}$ & Denaturierung & \\
\hline $60^{\circ} \mathrm{C} 50 \mathrm{Sek}$ & Primeranlagerung & 45 Zyklen \\
\hline $72^{\circ} \mathrm{C} 2 \mathrm{Min} 30 \mathrm{Sek}$ & Kettenverlängerung & \\
\hline $94^{\circ} \mathrm{C} 50 \mathrm{Sek}$ & Denaturierung & \\
\hline $60^{\circ} \mathrm{C} 50 \mathrm{Sek}$ & Primeranlagerung & 1-malig \\
\hline $72^{\circ} \mathrm{C} \quad 10 \mathrm{Min}$ & Kettenverlängerung & \\
\hline $12^{\circ} \mathrm{C}$ & & hold \\
\hline
\end{tabular}

Anschließend wurden die Produkte in einem 0,9\%-igen Agarosegel dargestellt.

Die rs5744455 Allel-spezifischen Amplifikate sollten an weiteren heterozygoten Positionen genotypisiert werden (Abb. 2.10, A-C).

Für die Haplotypisierung wurden mindestens 1:500 verdünnte Produkte, die mit Allel C- oder Allel T-spezifischen Primern generiert worden waren, am SNP rs2569190 oder am SNP rs4914 genotypisiert (siehe 2.3.6 im Material und Methoden). Liefert z. B. ein rs5744455-CAllel-spezifisches Amplifikat in der Genotypisierung für den SNP rs4914 ein C-Signal, so befinden sich das C-Allel von rs5744455 und das C-Allel von rs4914 auf einem Haplotyp (Abb. 2.11). 


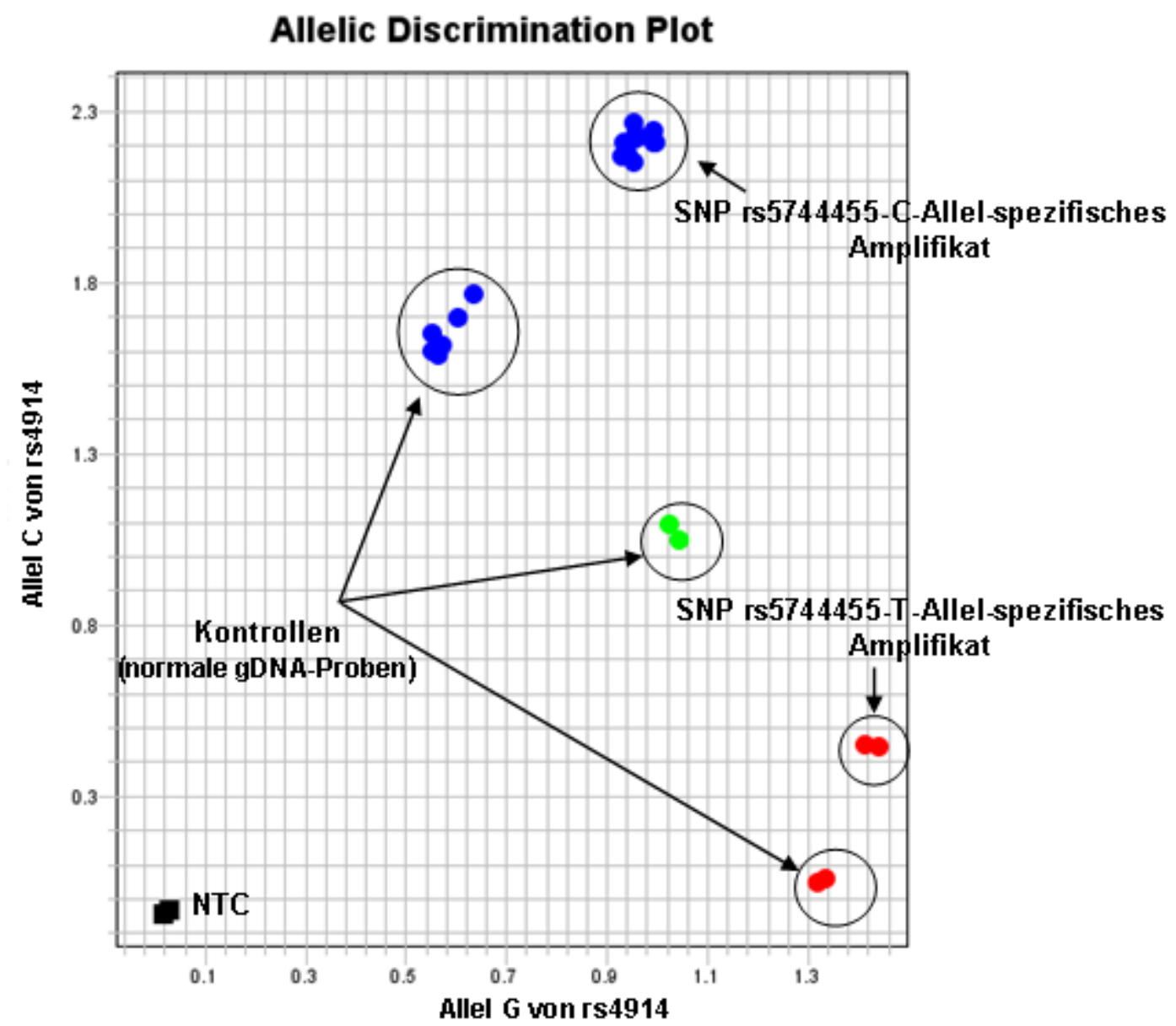

Abb. 2. 11: Haplotypisierung unter Verwendung eines TaqMan-Genotypisierungs-Assays

Für die Haplotypisierung der beiden Loci rs5744455 und rs4914 wurden Proben zunächst mit Allel-spezifischen Primern für rs5744455 amplifiziert, um dann die Allel-spezifischen Amplifikate in den TaqManGenotypisierungs-Assay für den SNP rs4914 einzusetzen. Im dargestellten Beispiel weist das C-Allelspezifische Amplifikat im Genotypisierungs-Assay für SNP rs4914 nur ein C-Signal und das T-Allel-spezifische Amplifikat nur ein G-Signal auf (wie die gleichzeitig eingesetzten rs4914-C- bzw. G-homozygoten gDNAProben). Es bedeutet, dass das C-Allel des SNPs rs57444455 und das C-Allel des SNPs rs4914 sowie das T-Allel des SNPs rs5744455 und das G-Allel des SNPs rs4914 jeweils einen Haplotypen bilden.

Für die Proben, die am SNP rs5744455 homozygot, aber an rs2569190 und rs4914 bzw. rs2563298 heterozygot waren, wurden Allel-spezifische Primer für die Position rs2569190 entworfen (Tab. 2.7). Als reverse Primer wurde auch hier CD14 tetra 3-rev (siehe Tab. 2.6) benutzt. Die rs2569190 Allel-spezifischen Amplifikate sollten dann an verbleibenden heterozygoten Positionen genotypisiert werden (Abb. 2.10, D, E). 
Tab. 2.7: Allel-spezifische Primer für den SNP rs2569190

\begin{tabular}{lcc}
\hline Primer & Sequenz & Tm [ $\left.{ }^{\circ} \mathrm{C}\right]$ \\
\hline rs2569190 C f & 5' AAG GAA GGG GGA ATT TTT CTT TAG CCC 3' & 64,6 \\
rs2569190 T f & 5' AAG GAA GGG GGA ATT TTT CTT TAG CCT 3' & 64,8
\end{tabular}

Die konventionelle PCR mit diesen Primern sowie die weitere Vorgehensweise (Auftrennung der PCR-Produkte im Gel, Verdünnung der Produkte, real time PCR mit TaqMan-Sonden) erfolgte analog der Haplotypisierung der Positionen rs5744455 und rs2569190 bzw. rs5744455 und rs4914 (siehe oben).

Da es für den SNP rs2563298 kein fertiges, erhältliches TaqMan-Genotypisierungs-Assay gibt, haben wir tetra-Primer für die Genotypisierung an der Position rs2563298 (Tab. 2.4) in einer real time PCR mit SYBR Green chemistry benutzt, um auch diesen SNP in die Haplotypisierung miteinzubeziehen. Die Haplotypisierung erfolgte wie auf der Abbildung 2.12 dargestellt.

Real time PCR mit SYBR Green chemistry wurde unter folgenden Bedingungen durchgeführt: Ansatz-PCR (10 $\mu \mathrm{l})$ :

$\begin{array}{ll}5,00 \mu \mathrm{l} & \text { 2x Platinium SYBR Green qPCR Super Mix UDG } \\ 0,20 \mu \mathrm{l} & 50 \mathrm{x} \text { ROX Reference Dye } \\ 0,33 \mu \mathrm{l} & 3 \mu \mathrm{M} \text { Primer forward (rs2563 tetra G f bzw. rs2563 tetra for) } \\ 0,33 \mu \mathrm{l} & 3 \mu \mathrm{M} \text { Primer reverse (rs2563 tetra rev bzw. rs2563 tetra T rev) } \\ 3,14 \mu \mathrm{l} & \text { Ampuwa } \\ 1,00 \mu \mathrm{l} & \text { Probe (PCR-Produkt, verdünnt 1:5000 oder 1:50000) }\end{array}$

Thermoprofil (StepOnePlus):

\begin{tabular}{|c|c|c|c|}
\hline $50{ }^{\circ} \mathrm{C}$ & 2 Min & Inkubation der Uracil-DNA-Glycosylase (UDG) & 1-malig \\
\hline $95^{\circ} \mathrm{C}$ & $2 \mathrm{Min}$ & Vordenaturierung & 1-malig \\
\hline $95^{\circ} \mathrm{C}$ & $15 \mathrm{Sek}$ & Denaturierung & \\
\hline $60^{\circ} \mathrm{C}$ & 30 Sek & Primeranlagerung / Kettenverlängerung & 45 Zyklen \\
\hline $\begin{array}{l}95^{\circ} \mathrm{C} \\
60^{\circ} \mathrm{C} \\
95^{\circ} \mathrm{C}\end{array}$ & $\begin{array}{r}15 \mathrm{Sek} \\
1 \mathrm{Min} \\
15 \mathrm{Sek}\end{array}$ & Dissoziationsprotokoll & \\
\hline
\end{tabular}



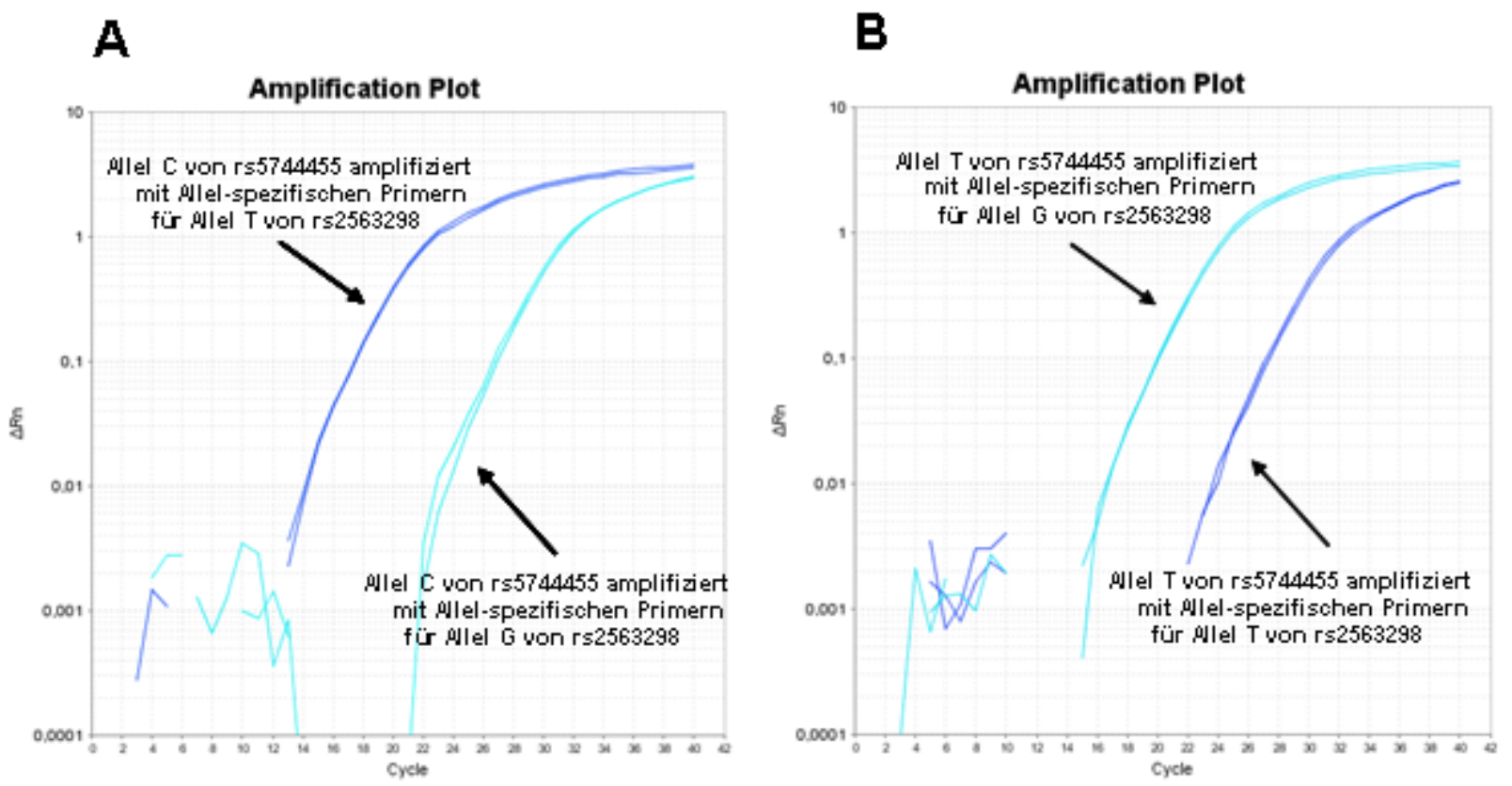

Abb. 2.12: Haplotypisierung unter Verwendung von tetra-Primern

Panel A: Produkte, die mit dem rs5744455 C-Allel-spezifischen Primer generiert wurden, lassen sich mit einem rs2563298 T-Allel-, nicht aber G-Allel-spezifischen Primer amplifizieren. Das mit dem rs2563298 G-Allelspezifischen Primer generierte schwache Signal ist auf eine unspezifische Bindung dieses Primers zurückzuführen. Wir schließen aus diesem Ergebnis, dass das rs5744455 C-Allel auf demselben Chromosom lokalisiert ist, wie das rs2563298 T-Allel.

Panel B: Produkte, die mit dem rs5744455 T-Allel-spezifischen Primer generiert wurden, lassen sich mit einem rs2563298 G-Allel-, nicht aber T-Allel-spezifischen Primer amplifizieren. Das mit dem rs2563298 T-Allelspezifischen Primer generierte schwache Signal ist auf eine unspezifische Bindung dieses Primers zurückzuführen. Wir schließen aus diesem Ergebnis, dass das rs5744455 T-Allel auf demselben Chromosom lokalisiert ist, wie das rs2563298 G-Allel.

Bei der Haplotypisierung ergaben sich auch die rs2563298-Genotypen.

\subsubsection{Quantifizierung der CD14-Genexpression}

Die Menge der CD14-Transkripte wurde nach reverser Transkription der zellulären RNA (siehe 2.3.5 im Material und Methoden) mithilfe kommerziell erhältlicher TaqMan Gene Expression Assays relativ, d. h. bezogen auf die Menge von Referenztranskripten, quantifiziert.

Der Assay enthält neben 2 Sequenz-spezifischen Primern eine spezifische FAM-markierte MGB-Sonde. Als Referenzen dienten GAPDH (glyceraldehyde-3-phosphate dehydrogenase), ein konstitutiv exprimierter Gen aus der Glykolyse, sowie CD11b zur Normierung für die Menge bzw. für den Aktivierungstatus von Monozyten / Makrophagen. Die CD14- 
Genexpressionsraten wurden als Expressionsunterschiede (Ratio) zwischen CD14- und dem jeweiligen Referenzgen ausgedrückt. Ratio wurde folgendermassen berechnet:

$\Delta \mathrm{Ct}=\mathrm{Ct}$ Zielgen $-\mathrm{Ct}$ Referenzgen

Ratio $=2^{-\Delta \mathrm{Ct}}$

Als thresholds wurden 0,02 fur CD14 und 0,1 für GAPDH und CD11b angesetzt.

Die Abbildung 2.13 veranschaulicht ein typisches amplification plot und das Prinzip der Genexpressionsquantifizierung.

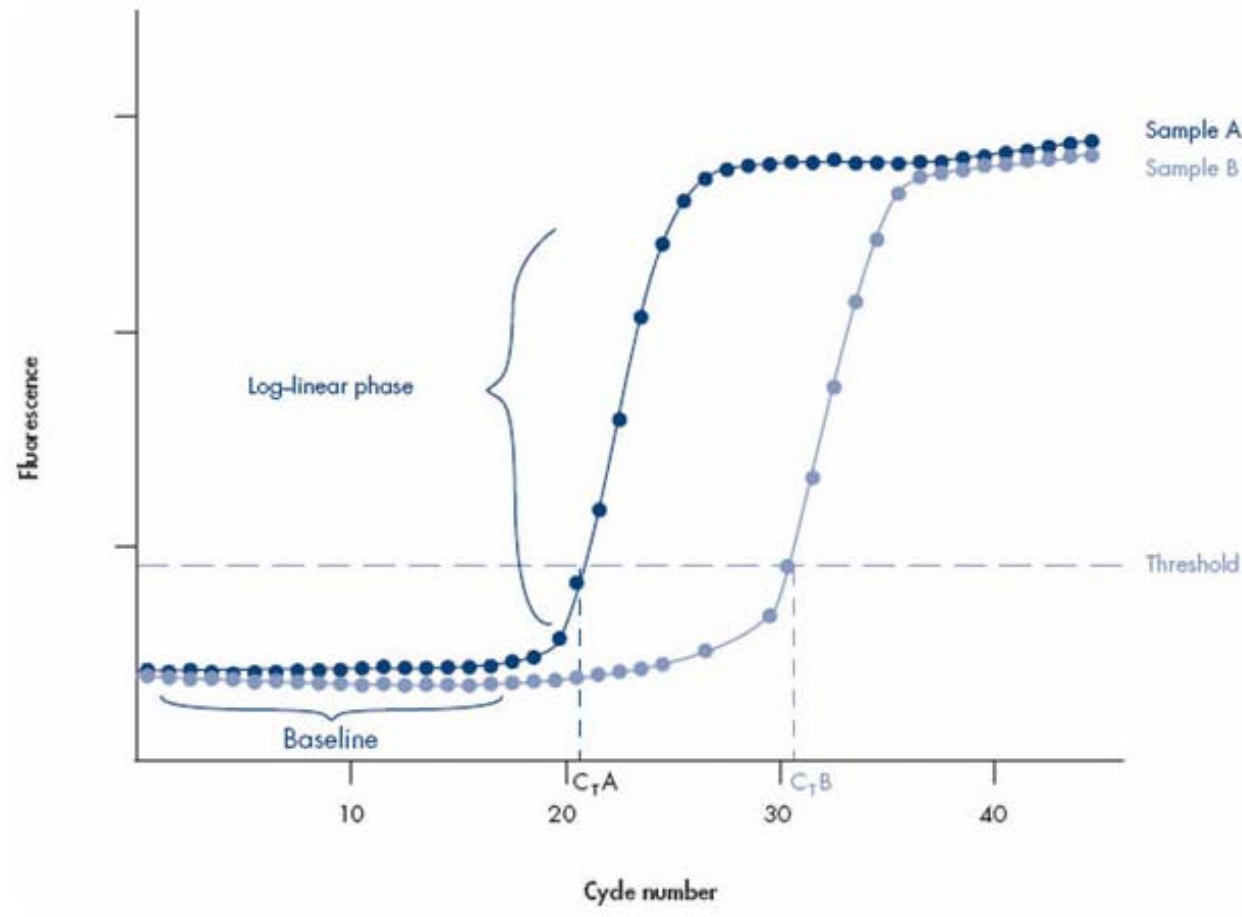

Abb. 2.13: Ein typisches amplification plot

Die Fluoreszenz steigt mit jedem PCR-Zyklus. Die Anreicherung der PCR-Podukte wird anhand der Steigerung der Fluoreszenz detektiert. Die Software des real time PCR-Geräts erstellt einen amplification plot, auf dem die Fluoreszenzintensität gegen die Zykluszahl dargestellt wird. Für die Analyse des PCR-Laufs wird zuerst der amplification plot angesehen und baseline und threshold gesetzt. Threshold ist in der Regel Assay-spezifisch. Zur Quantifizierung muß der Ct(threshold cycle)-Wert der Probe bestimmt werden. Der Ct-Wert ist von der Ausgangskonzentration der DNA in der Probe abhängig: Die Probe mit niedrigerer Ausgangskonzentration (B) der target-DNA braucht mehr Amplifikationszyklen, um den threshold zu erreichen, während die Probe mit höherer Konzentration (A) weniger Zyklen benötigt.

(QIAGEN, http://www1.qiagen.com/resources/info/Guidelines_RTPCR/DataAnalysis_SYBR.aspx) 
Bei der Transkriptquantifizierung wurde unter folgenden Bedingungen gearbeitet:

Ansatz PCR $(25 \mu \mathrm{l})$ :

$\begin{array}{rl}12,50 \mu \mathrm{l} & 2 \mathrm{x} \text { Universal PCR Master Mix } \\ 1,25 \mu \mathrm{l} & 20 \mathrm{x} \text { Assay-on-Demand } \\ 8,75 \mu \mathrm{l} & \mathrm{H}_{2} \mathrm{O} \\ 2,50 \mu \mathrm{l} & \text { Probe (8 ng cDNA) }\end{array}$

Thermoprofil (ABI prism 7000):

$\left.\begin{array}{rrl}95^{\circ} \mathrm{C} & 10 \mathrm{Min} & \text { Vordenaturierung } \\ 95^{\circ} \mathrm{C} & 15 \mathrm{Sek} & \begin{array}{l}\text { Denaturierung } \\ 60^{\circ} \mathrm{C}\end{array} \\ 1 \mathrm{Min} & \text { Primer-/ Sonde-Anlagerung, Kettenverlängerung }\end{array}\right\} 45$ Zyklen

\subsubsection{Ermittlung der CD14-mRNA-splice-Variante}

Um herauszufinden, welche die beiden CD14-mRNA-splice-Varianten im Probenmaterial vorliegt (Variante 1 - NM_000591.2, bei der SNP rs2569190 im transkribierten Bereich liegt oder Variante 2 - NM_001040021.1, bei der SNP im Intron liegt), wurden die cDNA-Proben mit 4 verschiedenen Assays amplifiziert: 1) mit Allel-spezifischen Sonden für den SNP CD14 rs2569190; 2) mit Allel-spezifischen Sonden für den SNP CD14 rs4914 (liegt im Transkriptbereich); 3) mit Allel-spezifischen Sonden für den SNP IRF-1 rs254909 (liegt im Promotor des IRF-1-Gens); 4) mit dem Genexpressions-Assay für CD14-mRNA.

Zur Kontrolle wurden neben cDNA- auch einige gDNA-Proben unter identischen Bedingungen amplifiziert.

Real time PCR wurde unter folgenden Bedingungen durchgeführt:

Ansatz (10 $\mu \mathrm{l})$ für die Quantifizierung der zellulären CD14-mRNA:

$\begin{array}{ll}5,0 \mu \mathrm{l} & 2 \mathrm{x} \text { Universal PCR Master Mix } \\ 0,5 \mu \mathrm{l} & \text { 20x Assay on Demand (CD14) } \\ 3,5 \mu \mathrm{l} & \mathrm{H}_{2} \mathrm{O} \\ 1,0 \mu \mathrm{l} & \text { Probe (3,2 ng cDNA bzw. 2 ng gDNA) }\end{array}$

Ansatz (10 $\mu$ l) für den SNP CD14 rs4914:
$5,0 \mu 1$
2x Universal PCR Master Mix
$1,0 \mu \mathrm{l}$
Primer forward $6 \mu \mathrm{M}$
$1,0 \mu 1$
Primer reverse $6 \mu \mathrm{M}$
$1,0 \mu 1$
$1,0 \mu 1$
Sonde ,Allel 1" $2 \mu \mathrm{M}$
$1,0 \mu 1$
Sonde „Allel 2" $2 \mu \mathrm{M}$
Probe (2 ng cDNA bzw. 2 ng gDNA) 
Ansatz (10 $\mu$ l) für SNPs CD14 rs2569190 bzw. IRF-1 rs254909:

$\begin{array}{ll}5,00 \mu 1 & 2 x \text { Universal PCR Master Mix } \\ 0,25 \mu 1 & \text { 40x Assay-by-design für CD14 rs2569190 } \\ 3,75 \mu 1 & \text { bzw. für IRF-1 rs254909 } \\ 1,00 \mu 1 & \mathrm{H}_{2} \mathrm{O}\end{array}$

Thermoprofil (StepOnePlus):

\begin{tabular}{|c|c|c|c|}
\hline $95^{\circ} \mathrm{C}$ & $10 \mathrm{Min}$ & Vordenaturierung & 1-malig \\
\hline $95^{\circ} \mathrm{C}$ & $15 \mathrm{Sek}$ & Denaturierung & \\
\hline $60^{\circ} \mathrm{C}$ & $1 \mathrm{Min}$ & $\begin{array}{c}\text { Primer- / Sonden-Anlagerung, } \\
\text { Kettenverlängerung }\end{array}$ & 45 Zyklen \\
\hline
\end{tabular}

\subsubsection{Bestimmung der Konzentration des löslichen CD14 (sCD14) im Serum / Plasma mithilfe von ELISA}

Die Konzentration des sCD14 wurde in Serum / Plasma-Proben von 42 gesunden Probanden und 41 Hepatitis-C-Patienten mithilfe eines kommerziell erhältlichen ELISA bestimmt (Enzyme Immunoassay for Determination of soluble human CD14 with matched antibody pairs).

Es handelt sich um einen Festphasen-sandwich ELISA. Eine Mikrotiterplatte wird mit zwei für sCD14 spezifischen monoklonalen Antikörpern beschichtet. Nach dem Blockieren freier Bindungstellen werden Standardlösungen und Proben aufgetragen. Während der Inkubation wird CD14 durch die an die Platte gebundenen Antikörper festgehalten. Ungebundenes Material wird durch Waschen entfernt. Es folgt eine Inkubation mit einem sCD14 spezifischen POD(Enzym)-markierten monoklonalen Antikörper (Detektionsantikörper). Im Nachweisschritt wird TMB (3,3', 5,5'-tetramethylbenzidine) als Chromogen benutzt. Die enzymatische Reaktion wird durch Zugabe von Schwefelsäure gestoppt und die optische Dichte bei $450 \mathrm{~nm}$ im Spectrophotometer gemessen.

Für die Gewinnung der Serumproben wurden ca. $10 \mathrm{ml}$ nicht-heparinisiertes Blut für $10 \mathrm{Min}$ zentrifugiert. Nach der Zentrifugation wurde der Überstand in drei 1,5-ml-Reaktionsgefäße aufgeteilt (je $1 \mathrm{ml}$ pro Gefäß) und bei $-20{ }^{\circ} \mathrm{C}$ aufbewahrt. Die für die Durchführung des ELISA notwendigen Reagenzien wurden gemäß der Angaben des Herstellers vorbereitet.

Für die Standardkurve wurden aus einem mitgelieferten CD14-Standard 6 verschiedene Verdünnungen in 2-er Schritten beginnend bei $50 \mathrm{ng} / \mathrm{ml}$ unmittelbar vor der Anwendung hergestellt. Die Serumproben wurden bei RT aufgetaut, kurz gevortext und in 
Verdünnungspuffer 1:200 verdünnt. Eingesetzt wurde außerdem ein Referenzserum. Als Normbereich für die Konzentration von sCD14 im Serum gelten 1,79 bis 3,68 $\mu \mathrm{g} / \mathrm{ml}$.

Der ELISA wurde bei RT gemäß der Angaben des Herstellers durchgeführt. Von allen Proben wurden Doppelbestimmungen durchgeführt (alle Proben wurden doppelt eingesetzt). Die Absorption bei $450 \mathrm{~nm}$ mit der Referenzwellenlänge $620 \mathrm{~nm}$ wurde aufgenommen. Anhand der Standardkurve wurden die Serumkonzentrationen für sCD14 berechnet.

\subsubsection{Allel-spezifische Transkriptquantifizierung (ASTQ)}

Die ASTQ ist eine Methode, mit der die Funktionalität eines SNPs hinsichtlich der transkriptionellen Aktivität überprüft werden kann. Diese Methode ermöglicht eine ggf. Allelspezifische Expression eines Gens in bzw. ex vivo zu ermitteln (Buckland 2004). Liegt der SNP von Interesse im Transkript, so können bei Heterozygoten die Genprodukte eines elterlichen Chromosoms von denen des anderen unterschieden und die relativen Mengen quantifiziert werden. Falls der zu untersuchende SNP nicht im Transkript liegt, kann ein zweiter SNP im Transkriptbereich als Surrogat herangezogen werden. Mit doppeltheterozygoten Proben wären dann ASTQ Analysen möglich. Die Diskriminierung und Quantifizierung der Allele kann z. B. durch Einsatz markierter Sonden (in real time TaqManPCR), Pyrosequenzierung oder Restriktions-Fragmentlängen-Analyse (RFLP) (Kochi et al. 2005) erfolgen.

\subsubsection{ASTQ mittels real time TaqMan-RT-PCR}

Wir haben die allelische Diskriminierung mithilfe von TaqMan-Sonden in einer real time RTPCR, wie unter dem Punkt 2.3.6.2 beschrieben, unternommen. Als Proben wurden 3,2 ng cDNA bzw. 2 oder 3,8 ng gDNA eingesetzt.

\subsubsection{ASTQ mittels RFLP}

Für die ASTQ mittels RFLP-Analyse wurde zunächst ein Abschnitt der cDNA / gDNA, der den SNP von Interesse enthält, konventionell amplifiziert. Neben den zu analysierenden Proben heterozygoter Spender wurden zu Kontrollzwecken auch cDNA- und gDNA-Proben CC- und GG-Homozygoter eingesetzt. Primer für die konventionelle PCR sind in der Tabelle 2.8 aufgeführt. 
Tab. 2.8: Primer für die ASTQ mittels RFLP

\begin{tabular}{ccc}
\hline Primerbezeichnung & Sequenz & Tm [ $\left.{ }^{\circ} \mathrm{C}\right]$ \\
\hline CD14 exon 2 for & 5' GCC CGA GGT GGA TAA CCT G 3' & 61,0 \\
CD14 exon 2 rev & 5' GTC CAT TCA TTA TTC TGT CTT GGA TC 3' & 60,0 \\
\hline
\end{tabular}

Ansatz PCR $(50 \mu \mathrm{l})$ :

$\begin{array}{rl}1,0 \mu \mathrm{l} & 10 \mathrm{mM} \text { dNTP } \\ 6,5 \mu \mathrm{l} & \text { PCR-Puffer }+\mathrm{MgCl}_{2} \\ 10,0 \mu \mathrm{l} & 3 \mu \mathrm{M} \text { Primer forward (CD14 exon } 2 \text { for }) \\ 10,0 \mu \mathrm{l} & 3 \mu \mathrm{M} \text { Primer reverse }(\mathrm{CD} 14 \text { exon } 2 \mathrm{rev}) \\ 4,0 \mu \mathrm{l} & 1,25 \mathrm{U} \text { Taq Polymerase } \\ 13,5 \mu \mathrm{l} & \text { Ampuwa } \\ 5,0 \mu \mathrm{l} & \text { gDNA }(10 \mathrm{ng}) \text { bzw. cDNA }(16 \mathrm{ng})\end{array}$

Thermoprofil (FlexCycler analytikjena):

\begin{tabular}{|c|c|c|}
\hline $\begin{array}{l}94{ }^{\circ} \mathrm{C} 5 \mathrm{Min} \\
\text { hot start manuell }\end{array}$ & Vordenaturierung & 1-malig \\
\hline $94^{\circ} \mathrm{C} 50 \mathrm{Sek}$ & Denaturierung & \\
\hline $60{ }^{\circ} \mathrm{C} 50 \mathrm{Sek}$ & Primeranlagerung & 45 Zyklen \\
\hline $72{ }^{\circ} \mathrm{C} 50$ Sek & Kettenverlängerung & \\
\hline $94{ }^{\circ} \mathrm{C} 50$ Sek & Denaturierung & \\
\hline $60{ }^{\circ} \mathrm{C} 50$ Sek & Primeranlagerung & 1-malig \\
\hline $72^{\circ} \mathrm{C} \quad 10 \mathrm{Min}$ & Kettenverlängerung & \\
\hline $14^{\circ} \mathrm{C}$ & & hold \\
\hline
\end{tabular}

Die Generierung von Produkten der erwarteten Größe wurde gelelektrophoretisch überprüft.

Das Material aus zwei $50 \mu 1$-Ansätzen wurde vereinigt, gereinigt und konzentriert.

Reinigung und Konzentrierung wurden mithilfe des PrepEase Gel Extraction Kit durchgeführt: Die Probe wurde zunächst mit 2 Volumina des NT-Puffers verdünnt und dann direkt ins Zentrum der clean-up Säule aufgetragen. Es folgte eine 1-minütige Zentrifugation bei $11000 \mathrm{x}$ g, bei der die DNA an der Säule gebunden bleibt. Nach einem Waschschritt und dem Trocknen der Säule wurde die DNA in $20 \mu \mathrm{l}$ Puffer NE eluiert. Dies entspricht einer Konzentrierung in etwa von Faktor 5.

Dann folgt ein enzymatischer Verdau der gereinigten und konzentrierten PCR-Produkte mit Restriktionsenzymen, die spezifisch das eine oder andere Allel erkennen (Tab. 2.9), nach folgendem Protokoll: 
Verdau mit Allel-spezifischen Restriktionsenzymen (2 Stunden bei $37{ }^{\circ} \mathrm{C}$ ):

$\begin{array}{ll}4,5 \mu 1 & \text { gereinigtes PCR-Produkt } \\ 1,0 \mu \mathrm{l} & 10 \mathrm{x} \text { Puffer (Puffer G für SatI und Puffer O für Alw21I) } \\ 4,0 \mu 1 & \text { Ampuwa } \\ 0,5 \mu 1 & 5 \text { U Enzym (SatI oder Alw21I) }\end{array}$

Tab. 2.9: SNP-rs4914-spezifische relevante Restriktionsendonukleasen und deren Erkennungssequenzen

\begin{tabular}{|c|c|c|}
\hline Restriktionsenzym & Allel & Erkennungssequenzen* \\
\hline \multirow{2}{*}{ Satl } & \multirow{2}{*}{ Allel C } & 5'-CTTGGAG $\downarrow \underline{C} A \quad$ GCACC-3' \\
\hline & & 3'-GAACCTC GT个CGTGG-5' \\
\hline \multirow{2}{*}{ Alw21I } & \multirow{2}{*}{ Allel G } & 5'-CTTGGAGG AGCA $\downarrow C C-3$ ' \\
\hline & & 3'-GAACCTCĈ个TCGT GG-5' \\
\hline
\end{tabular}

*Erkennungssequenzen der Enzyme (nur für die Erkennung relevante Nukleotide) sind farbig hinterlegt. Schneidestellen sind mit Pfeilen ( $\uparrow \downarrow$ ) gekennzeichnet

Die 201 bp Amplifikate werden von Alw21I in Fragmente der Größen 95bp und 106 bp geschnitten. G-Allel Amplifikate enthalten eine zusätzliche Schnittstelle, so dass 95 bp Fragment nochmals in 2 Fragmente der Größen 55 und 40 bp geschnitten wird. Die Endonuklease SatI erkennt ausschließlich ein Motiv in C-Allel Amplifikat, so dass nur dieses in der Reaktion um 55 bp verkürzt wird (Tab. 2.10).

Tab. 2.10: DNA-Fragmente nach dem Verdau

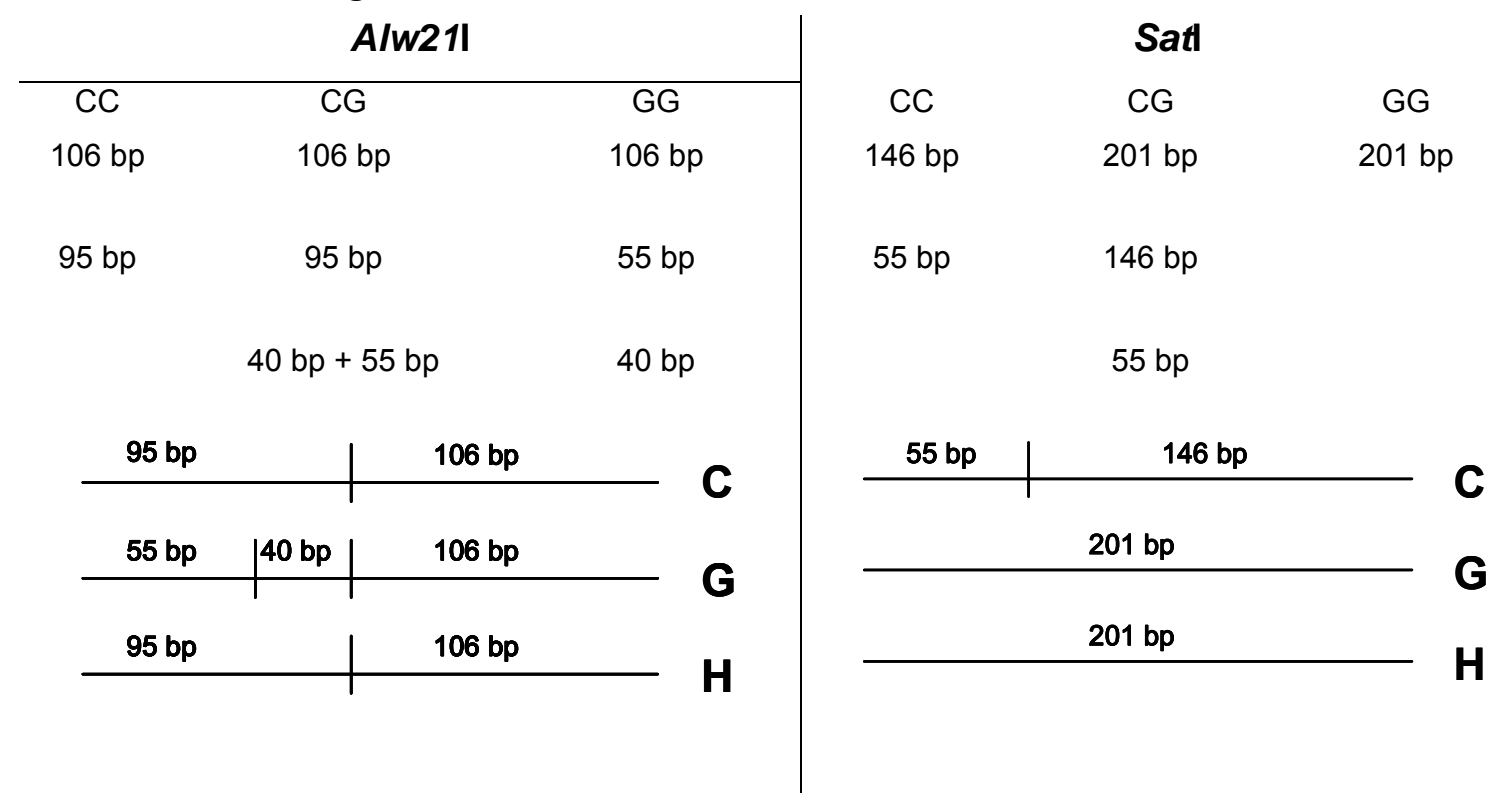

Im nächsten Schritt werden die Fragmente im Agilent Bioanalyser 2100 mithilfe des Agilent DNA 1000 Kit entsprechend ihrer Größen aufgetrennt und quantifiziert. 
Der Agilent Bioanalyser 2100 ist das erste verfügbare System mit chip-basierter Technologie für die Auftrennung von Nukleinsäuren. Die Software des Agilent Bioanalyzer berechnet die Längen der Fragmente und deren Konzentration bzw. Molarität (Abb. 2.14). Aus diesen Angaben haben wir das Verhältnis der Allelvarianten zueinander folgendermassen berechnet: Für Proben, die mit SatI verdaut wurden, gilt im dargestellten Beispiel (Abb. 2.14 A): $(\mathrm{G}+\mathrm{H}): \mathrm{C}=169,7: 85,5=2,0$.

Außerdem gilt

$\mathrm{G}=100 \%-\mathrm{C}-\mathrm{H}$.

Daraus ergibt sich ein Anteil des C-Allels im Amplifikat von 33,3 \%.

Die restlichen 66,7\% des Amplifikats setzen sich sowohl aus dem G-Allel, als auch aus Hybriden $(\mathrm{H})$, die sich während der De- und Renaturierung bilden, zusammen.

Für Proben, die mit Alw21I verdaut wurden, gilt in diesem Beispiel (Abb. 2.14 B):

$(\mathrm{C}+\mathrm{H}+1 / 2 \mathrm{G}): 1 / 2 \mathrm{G}=447,2: 74,3=6$

Daraus folgt, dass $\mathrm{H}=29,6 \%$ und $\mathrm{G}=37,1 \%$.

Also,

$\mathrm{C}=33,3 \% \quad \mathrm{G}=37,1 \% \quad \mathrm{H}=29,6 \%$.

Da Hybride zu gleichen Teilen aus C- und G-Allelen bestehen, wird eine Hälfte des Hybridanteils den C- und die andere Hälfte den G-Allel-Fragmenten hinzugerechnet. Die analysierende Probe enthält also C- und G-Allel-Amplifikate im Verhältnis von 48,1 : 51,9 oder 0,93 .

Auf diese Weise können die Anteile der beiden Allele sowohl in gDNA- als auch in cDNAProben berechnet werden.

Als Schneidekontrollen wurden jeweils eine C- und eine G-homozygote Proben eingesetzt. Die C-homozygote Probe wird durch SatI komplett geschnitten, die G-homozygote Probe dagegen gar nicht. Das umgekehrte geschieht bei Alw21I. 

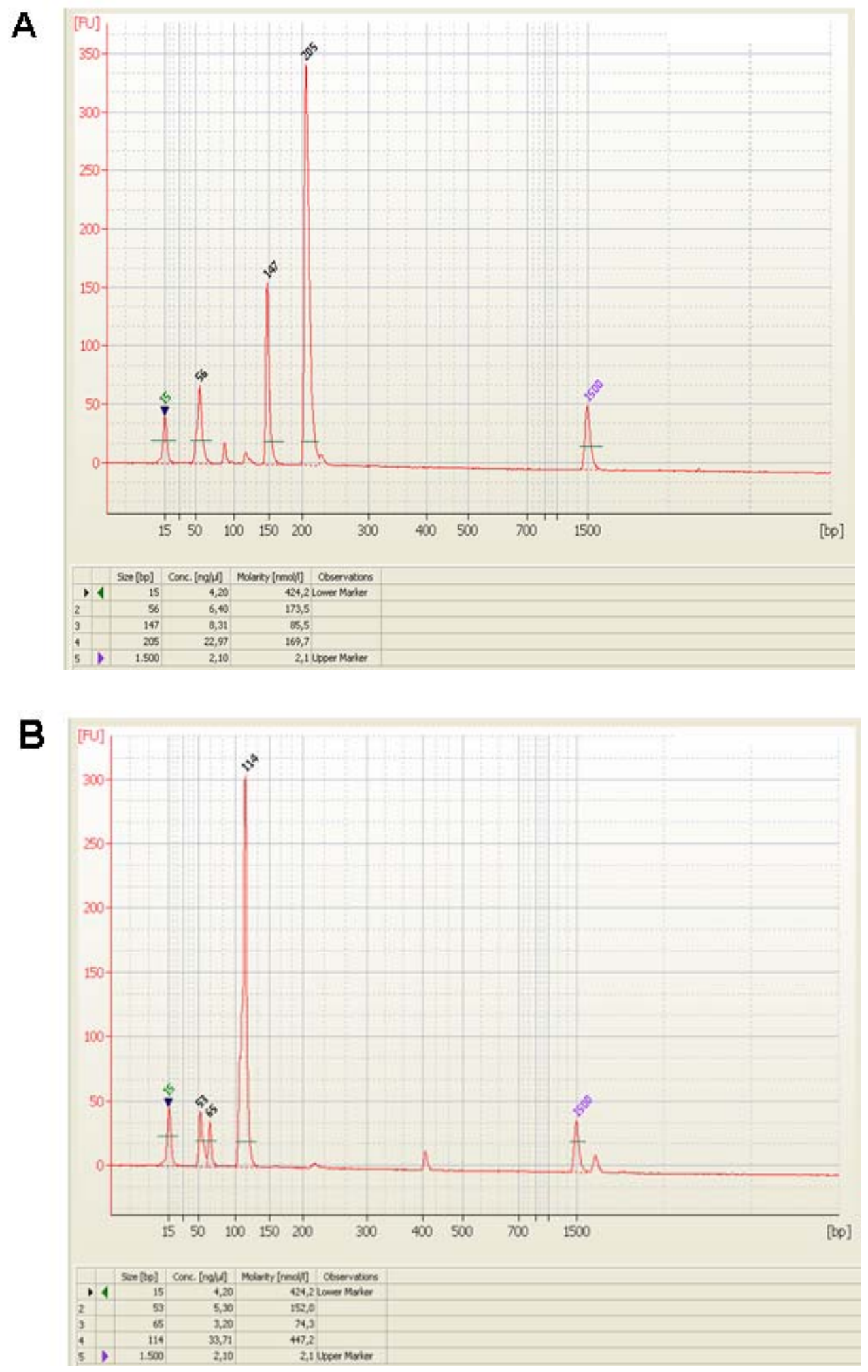

Abb. 2.14: Quantitative RFLP-Analyse einer mit SatI (A) und Alw21I (B) geschnittenen gDNA-Probe Im Agilent Bioanalyzer werden die Produkte des enzymatischen Verdaus zusammen mit zwei Größenmarkern (15 bp und 1500 bp) aufgetrennt und anhand der berechneten Menge der beiden Marker quantifiziert. 


\subsubsection{Auswertung und Statistik}

Das Datenmaterial wurde zum einen mithilfe des Programms GraphPad Prism (Version 4.00 for Windows, GraphPad Software, San Diego California USA, www.graphpad.com) und zum anderen mit einem Online-Statistikprogramm (http://ihg2.helmholtz-muenchen.de) analysiert. CD14-Expressionsparameter (CD14-mRNA in PBMC und sCD14-Serumkonzentration) bei gesunden Probanden und Patienten mit chronischer Hepatitis C wurden durch den Student's $t$ Test (zweiseitig) für unabhängige Stichproben miteinander verglichen. $\mathrm{p}<0,05$ galt als Grenze für statistische Signifikanz.

Bei der Analyse der Auswirkung von varianten Allelen auf die CD14-Expressionsparameter bei Gesunden bzw. bei Patienten wurden zunächst für einzelnen zu untersuchenden SNP alle drei Genotypgruppen (Wildtypallel-Homozygote, Heterozygote, Variantallel-Homozygote) durch one-way ANOVA (analysis of variance) miteinander verglichen (nonparametric, Kruskal-Wallis-Test). Im Falle eines signifikanten Unterschieds $(p<0,05)$ wurden weitere Analysen vorgenommen, indem sowohl Variantallelträger Wildtypallel-Homozygoten als auch Wildtypallelträger Variantallel-Homozygoten gegenübergestellt und durch den Student's $t$-Test (s. oben) miteinander verglichen wurden. Bei $\mathrm{p}<0,05$ wurde ein Unterschied zwischen Mittelwerten als statistisch signifikant angenommen. Ähnlich wurde die Analyse der Auswirkung verschiedener Haplotypen auf die Genexpressionsparameter durchgeführt. Ergebnisse sind als Mittelwert \pm Standardabweichung aufgeführt.

Die Grade des paarweisen Kopplungsungleichgewichts (D' und $r^{2}$ ) zwischen 4 untersuchten SNPs, sowohl für gesunde Probanden als auch für die Patientengruppe, wurde mithilfe des Programms Haploview (Version 4.1, 29 April, 2008, Daly Lab at the Broad Institute, Cambridge, MA 02141, USA; www.broad.mit.edu/mpg/haploview/) berechnet.

Um Unterschiede in CD14-Expressionsparametern zwischen verschiedenen Haplogenotypgruppen zu analysieren, wurde one-way ANOVA verwendet. Als die Grenze der statistischen Signifikanz wurde auch hier $\mathrm{p}<0,05$ genommmen.

Um den Grad der Abhängigkeit zwischen den untersuchten Variablen zu quantifizieren bzw. um herauszufinden, ob eine Korrelation besteht oder nicht, wurde der lineare Korrelationskoeffizient $\left(\mathrm{r}^{2}\right)$ errechnet.

Um bei Genotypverteilungen die Abweichungen vom HWE zu überprüfen, verwendeten wir den Exakt-Test im oben genannten Online-Statistikprogramm. Bei $\mathrm{p}>0,05$ gilt die Abweichung nicht-signifikant, d. h. die aktuelle Verteilung entspricht dem HWE. 


\section{Ergebnisse}

\subsection{Untersuchung zur Assoziation des SNPs rs2569190 mit der CD14-Genexpression}

Probanden (42 Gesunden und 42 Patienten mit chronischer Hepatitis C) wurden an der polymorphen Position rs2569190 im CD14-Gen genotypisiert. Für beide Kollektive wurden CD14-Transkripte aus PBMC quantifiziert und die Konzentration des sCD14 in Serumproben bestimmt. Die Daten der gesunden Probanden wurden denen der Patienten gegenübergestellt. Des Weiteren wurden Ergebnisse hinsichtlich der Genotypen am SNP rs2569190 analysiert.

\subsubsection{Genotypisierung am SNP rs2569190}

Die Genotypisierung am SNP rs2569190 mittels allelischer Diskriminierung im 5'-NukleaseAssay ergab die in Tab. 3.1 zusammengefassten Verteilungen, die einer erwarteten Verteilung nach HWE entsprechen. Die Häufigkeit des varianten T-Allels (MAF) lag mit 0,44 für Gesunden und 0,51 für Patienten im Bereich der für eine kaukasische Population erwarteten.

Tab. 3.1: Genotypisierungsergebnisse für den SNP rs2569190

\begin{tabular}{|c|c|c|c|c|c|}
\hline & \multicolumn{3}{|c|}{ Genotyp rs2569190 $(C \rightarrow T)$} & \multirow{2}{*}{ MAF } & \multirow{2}{*}{$p^{1}$} \\
\hline & CC & CT & TT & & \\
\hline Gesunden $(n=42)$ & $10(23,8 \%)$ & 27 (64,3\%) & $5(11,9 \%)$ & 0,44 & 0,07 \\
\hline Patienten $(n=42)$ & $10(23,8 \%)$ & $21(50,0 \%)$ & $11(26,2 \%)$ & 0,51 & 1,00 \\
\hline
\end{tabular}

${ }^{1}$ Exakt-Test für HWE

\subsubsection{CD14-mRNA-Expression in PBMC bei gesunden Probanden vs Patienten und in} Abhängigkeit des SNP-rs2569190-Genotyps

Die Menge der CD14-mRNA aus PBMC wurde relativ, d. h. bezogen auf die Menge zweier Referenztranskripte, quantifiziert. Als Referenzen wurden zum einen die GAPDH, zum anderen CD11b herangezogen. CD11b, das als Monozyten / Makrophagen-Antigen gilt, wurde benutzt, um für den Aktivierungstatus von Monozyten / Makrophagen zu normieren. Laut unserer Daten ist die CD14-mRNA-Expression zwischen Gesunden und Patienten nicht signifikant unterschiedlich (Abb. 3.1). Wir haben auch keinen signifikanten Unterschied in der CD14-Genexpression zwischen verschiedenen Genotypgruppen (CC, CT, TT) gefunden, weder bei gesunden Probanden, noch bei Patienten (Abb. 3.2). 
A

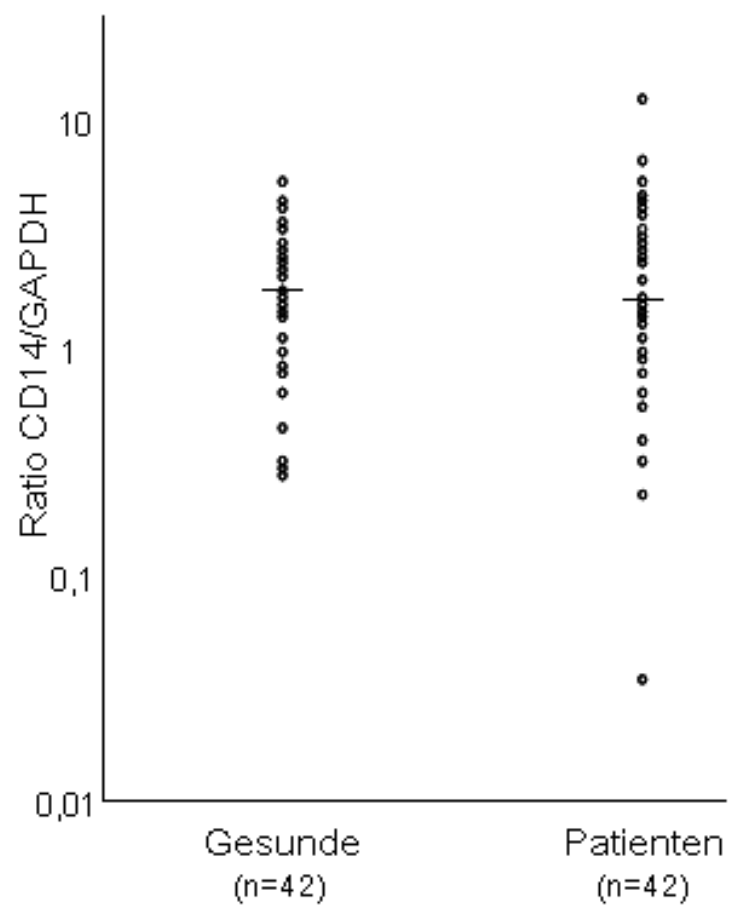

B

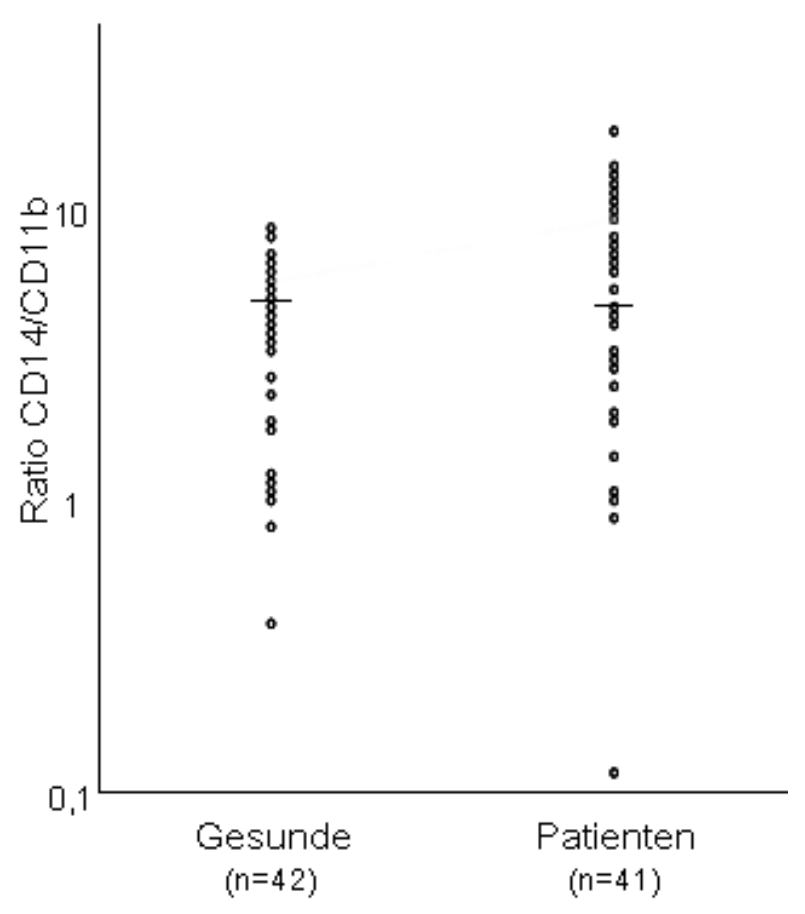

Abb. 3.1: CD14-mRNA-Expression in PBMC von gesunden Probanden und Patienten mit chronischer Hepatitis C

Die CD14-mRNA-Expression wurde in frisch isolierten PBMC von gesunden Spendern und Patienten mit chronischer HCV-Infektion bezogen auf GAPDH (A) und CD11b (B) als Referenz quantifiziert. Die Mediane sind gekennzeichnet. Es ergab sich kein statistisch signifikanter Unterschied in der CD14-mRNA-Expression der beiden Gruppen. 


\section{Gesunde}

A

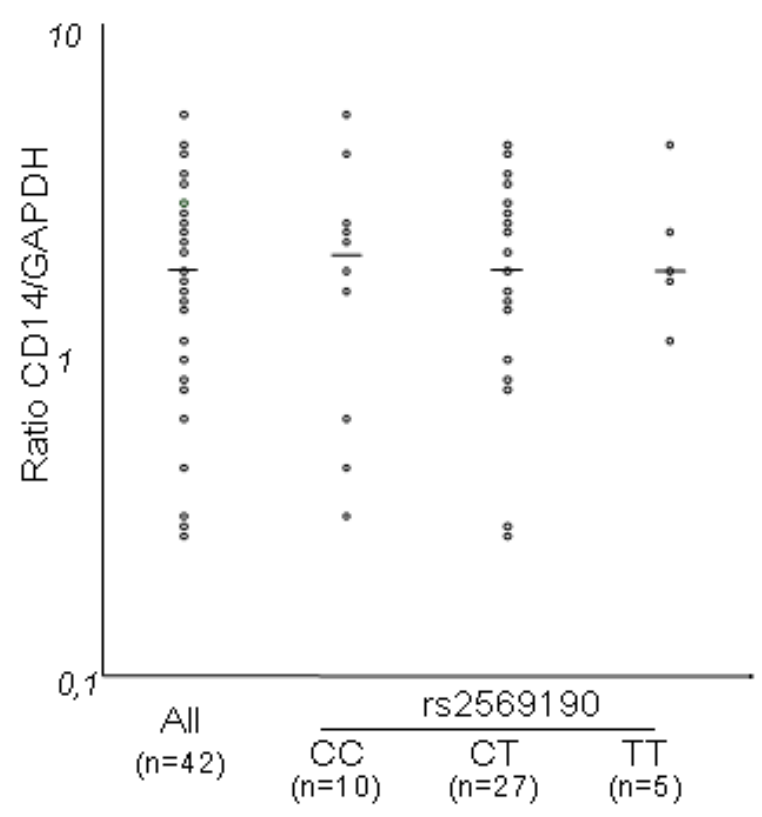

B

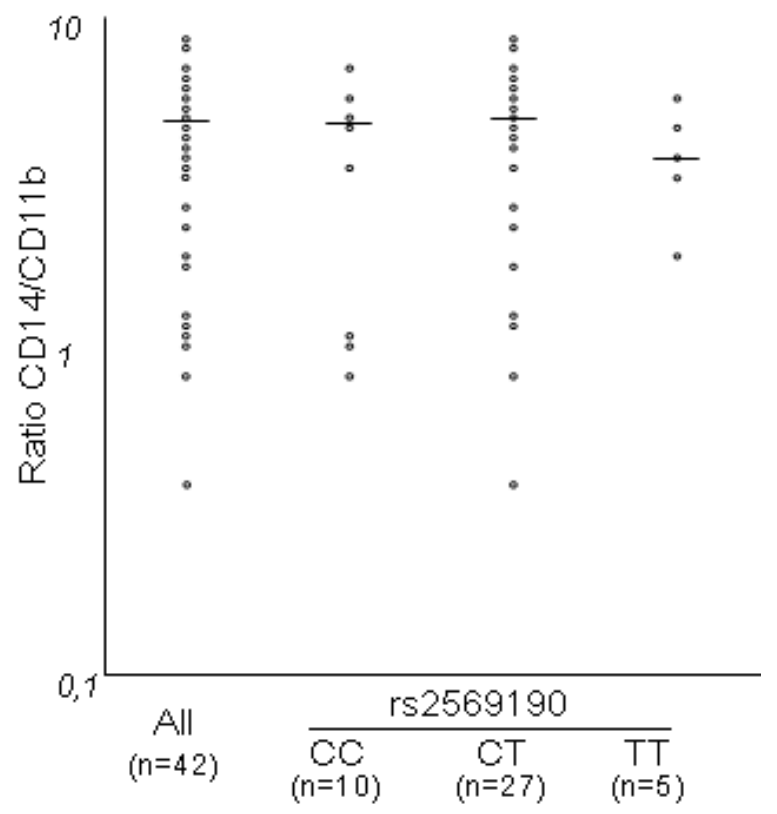

\section{Patienten}

A

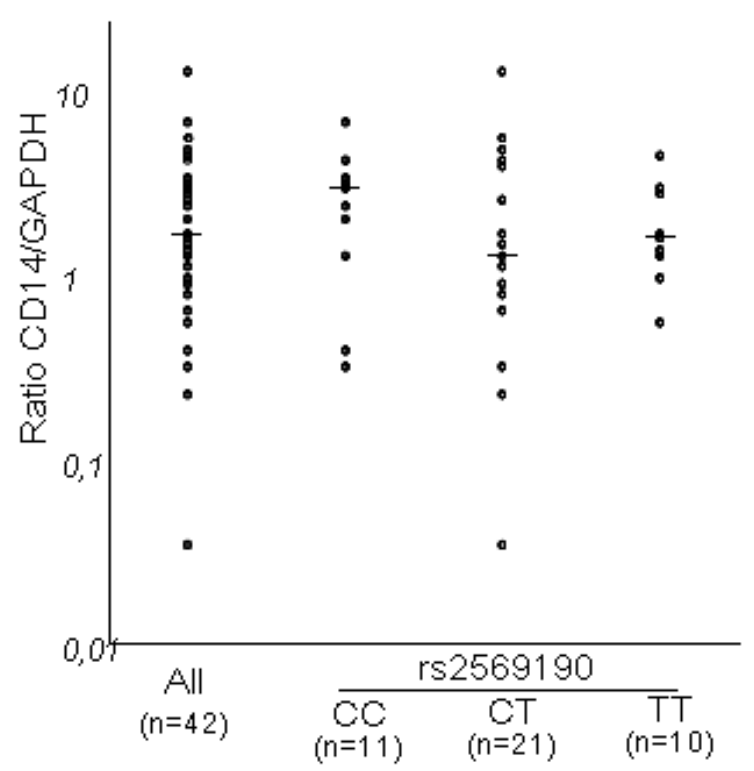

B

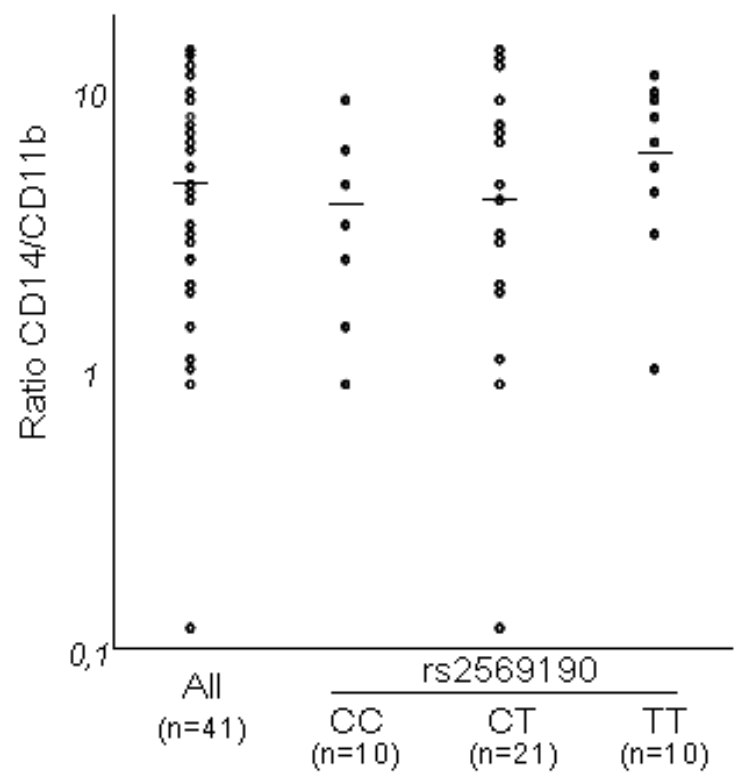

Abb. 3.2: CD14-mRNA-Expression in PBMC von gesunden Probanden und Patienten mit chronischer

Hepatitis C in Bezug auf den Genotyp am SNP rs2569190

Die Daten zur CD14-mRNA-Expression in frisch isolierten PBMC von gesunden Spendern und Patienten mit chronischer HCV-Infektion wurde in Abhängigkeit des Genotyps am SNP rs2569190 sowohl in Bezug auf die Referenz GAPDH (A) als auch CD11b (B) analysiert. Die Mediane sind gekennzeichnet. Es wurde kein statistisch signifikanter Unterschied erkennbar. 


\subsubsection{Konzentration des SCD14 im Serum und Analyse der Daten in Bezug auf den SNP rs2569190}

Die Messung der Konzentration des sCD14 im Serum von gesunden Probanden ergab eine mittlere Konzentration von 4,66 $\pm 0,29 \mu \mathrm{g} / \mathrm{ml}$. Dieser Wert befindet sich etwas oberhalb der oberen Grenze der Norm, die von der Herstellerfirma des verwendeten ELISA angegeben ist (1,79-3,68 $\mu \mathrm{g} / \mathrm{ml})$. Patienten mit chronischer Hepatitis $\mathrm{C}$ weisen eine im Mittel etwas höhere Konzentration von 5,30 $\pm 0,31 \mu \mathrm{g} / \mathrm{ml}$ auf. Dieser Unterschied erreicht jedoch keine statistische Signifikanz (Abb. 3.3).

Der Vergleich der sCD14-Serumkonzentrationen zwischen verschiedenen rs2569190Genotypgruppen ergab weder für gesunde Probanden noch für Patienten mit chronischer Hepatitis C signifikante Unterschiede (Abb. 3.4).

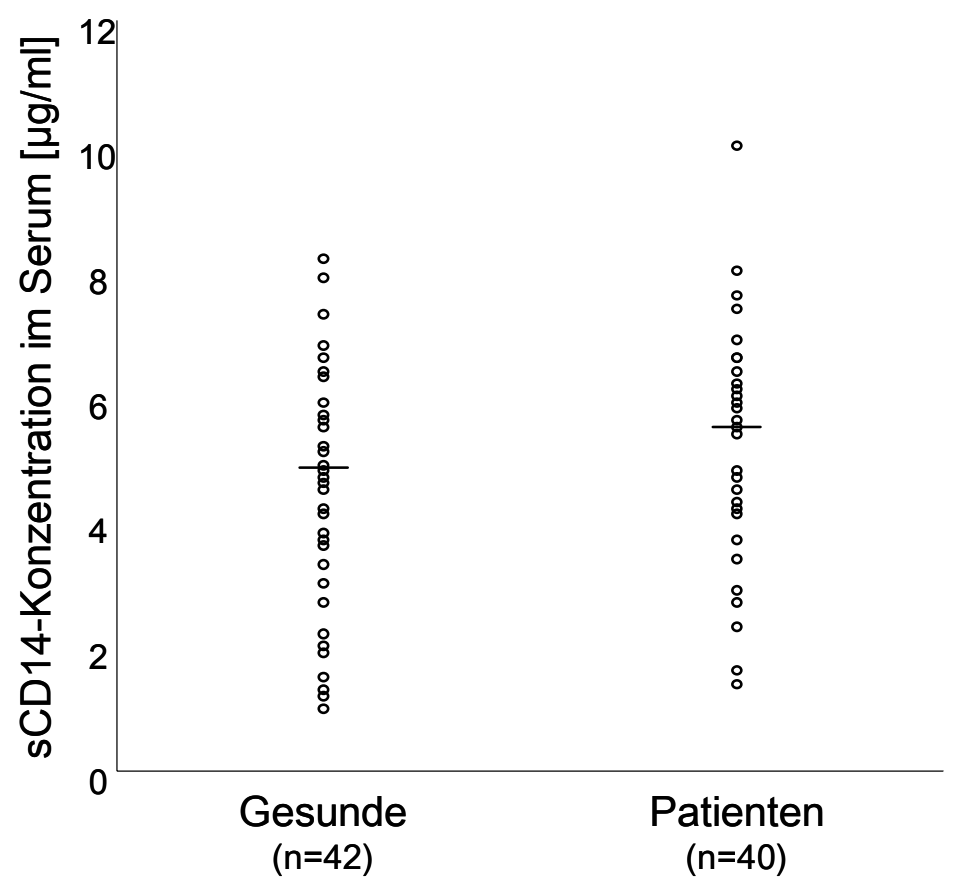

Abb. 3.3: Der Vergleich der sCD14-Serumkonzentrationen zwischen gesunden Probanden und Patienten Die Konzentrationen von sCD14 wurden in Serumproben von gesunden Spendern und Patienten mit chronischer HCV-Infektion mittels ELISA gemäß den Angaben des Herstellers bestimmt. Die Mediane sind gekennzeichnet. Es ergab sich kein statistisch signifikanter Unterschied zwischen beiden Gruppen. 
A

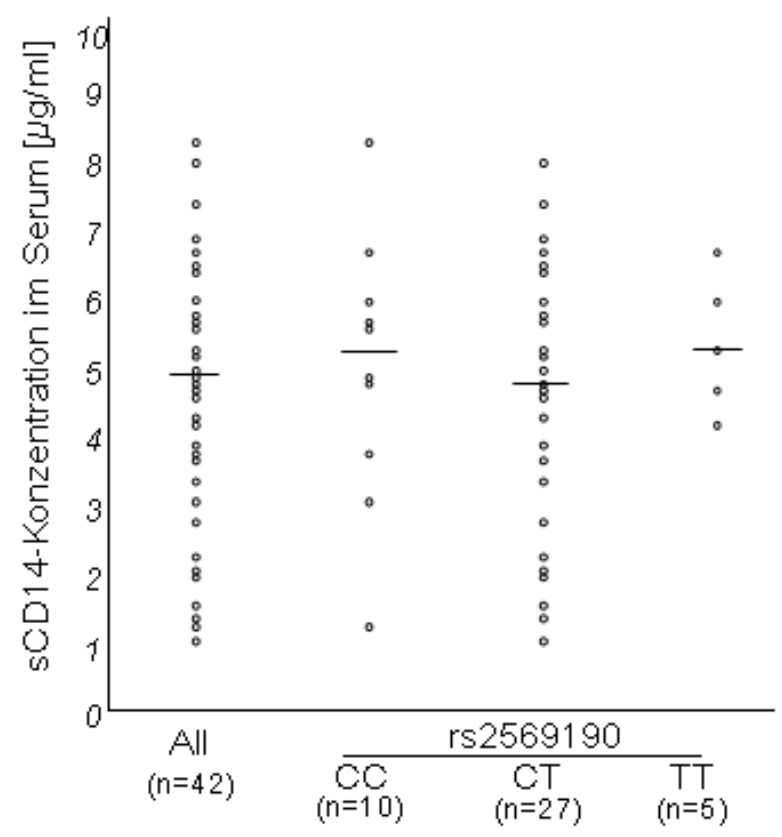

B

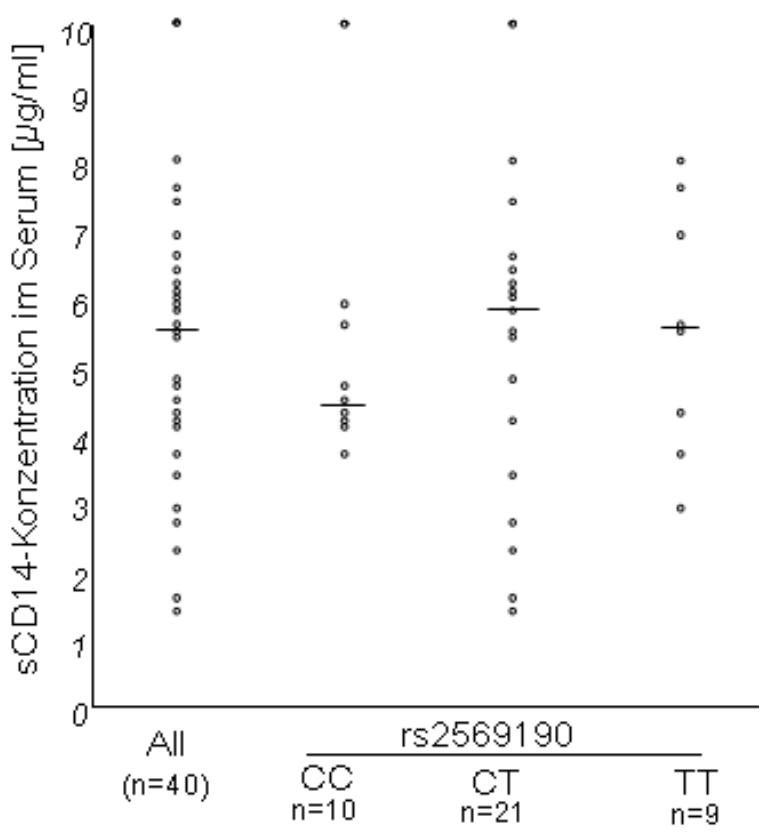

Abb. 3.4: sCD14-Serumkonzentrationen bei gesunden Probanden (A) und Patienten mit chronischer Hepatitis C (B) in Bezug auf den Genotyp am SNP rs2569190

Die Daten zur Konzentrationen von sCD14 in Serumproben von gesunden Spendern (A) und Patienten mit chronischer HCV-Infektion (B) wurden in Abhängigkeit des Genotyps am SNP rs2569190 analysiert. Die Mediane sind gekennzeichnet. Es wurde kein statistisch signifikanter Unterschied erkennbar.

\subsection{Analyse der CD14-Genexpression in Bezug auf weitere SNPs im CD14-Gen}

Da sich keine deutliche Assoziation des rs2569190-SNPs mit der CD14-Genexpression abzeichnete, obwohl Assoziationsstudien mit verschiedenen Erkrankungen und biologischen Parameter sowie in-vitro-Experimente die Funktionalität des SNPs vermuten lassen (siehe 1.4.5 in Einleitung), haben wir die Genexpressionsdaten auch hinsichtlich benachbarter SNPs untersucht. Das könnte uns einen Hinweis darauf geben, ob die in verschiedenen Studien beobachteten Assoziationen auf einen anderen, mit dem SNP rs2569190 im Kopplungsungleichgewicht stehenden SNP zurückzuführen wären.

Laut NCBI-Datenbank befinden sich drei weitere SNPs mit relevanter MAF in direkter Nachbarschaft zum SNP rs2569190 (Tab. 3.2). Ihre relative Position im Gen bzw. Transkript ist von der splice-Variante abhängig. 
Tab. 3.2: Die bekannten SNPs im CD14-Gen mit höchster Heterozygotie

\begin{tabular}{ccccc}
\hline SNP & mRNA-Position & Heterozygotie & Lokalisation & Allele \\
\hline rs5744455 & - & 0,315 & $5^{\prime}$ 'near gene & C/T \\
rs2569190 & $95^{1}$ & 0,488 & $5^{\prime}$ 'TR $^{1} /$ Intron $^{2}$ & $\mathrm{C} / \mathrm{T}$ \\
rs4914 & $1455^{1} / 1362^{2}$ & 0,104 & Exon 2 $^{1} /$ Exon 3 $^{2}$ & $\mathrm{C} / \mathrm{G}$ \\
rs2563298 & - & 0,309 & 3'near gene $^{1+2}$ & $\mathrm{G} / \mathrm{T}$ \\
\hline
\end{tabular}

${ }^{1}$ laut Accession-Nr.: NM_000591, NCBI

2 laut Accession-Nr.: NM_001040021, NCBI

\subsubsection{Genotypisierung an den SNPs rs5744455, rs4914 und rs2563298 und}

\section{Kopplungsungleichgewicht bei den untersuchten SNPs}

Die Genotypisierung an den drei SNPs von 42 gesunden Probanden und 42 Patienten mit chronischer Hepatitis $\mathrm{C}$ wurde wie in Methoden beschrieben mittels allelischer Diskriminierung bzw. tetra-Primer-ARMS-PCR vorgenommen. Die Verteilungen (Tab. 3.3 und 3.4) entsprechen dem Hardy-Weinberg-Gleichgewicht und die MAFs in etwa den Angaben aus NCBI von 0,30 / 0,17, 0,09 und 0,22 für rs5744455, rs4914 und rs2563298 für eine kaukasische Bevölkerung.

Tab. 3.3: Genotypverteilungen an 3 relevanten SNPs im Kollektiv der gesunden Probanden

\begin{tabular}{|c|c|c|c|c|c|c|}
\hline \multirow{2}{*}{ SNP } & \multirow{2}{*}[\mathrm{n}]{} & \multicolumn{3}{|c|}{ Genotypverteilung } & \multirow{2}{*}{ MAF } & \multirow{2}{*}{$p^{2}$} \\
\hline & & wt/wt & $w t / v$ & $\mathbf{v} / \mathbf{v}$ & & \\
\hline rs5744455 $[\mathrm{C} / \mathrm{T}]^{1}$ & 42 & $22(52,4 \%)$ & $18(42,9 \%)$ & $2(4,7 \%)$ & 0,26 & 0,70 \\
\hline rs4914 [C/G $]^{1}$ & 42 & $31(73,8 \%)$ & $9(21,4 \%)$ & $2(4,8 \%)$ & 0,16 & 0,23 \\
\hline rs2563298 [G/T] $]^{1}$ & 42 & $22(52,4 \%)$ & $17(40,5 \%)$ & $3(7,1 \%)$ & 0,27 & 1,00 \\
\hline
\end{tabular}

${ }^{1}$ [Wildtyp (wt)/variant (v)]

2 Exakt-Test für HWE 
Tab. 3.4: Genotypverteilungen an 3 relevanten SNPs im Kollektiv der Patienten mit chronischer Hepatitis C

\begin{tabular}{lcccccc}
\hline \multirow{2}{*}{ SNP } & [n] & \multicolumn{3}{c}{ Genotypverteilung } & MAF & $\mathbf{p}^{2}$ \\
\cline { 3 - 6 } & & wt/wt & wt/v & v/v & & \\
\hline rs5744455 [C/T] & $36^{3}$ & $25(69,4 \%)$ & $10(27,8 \%)$ & $1(2,8 \%)$ & 0,17 & 1,00 \\
rs4914 [C/G $]^{1}$ & $38^{3}$ & $23(60,5 \%)$ & $13(34,2 \%)$ & $2(5,2 \%)$ & 0,22 & 1,00 \\
rs2563298 [G/T] & $36^{3}$ & $18(50,0 \%)$ & $15(41,7 \%)$ & $3(8,3 \%)$ & 0,29 & 1,00 \\
\hline
\end{tabular}

${ }_{2}^{1}$ [Wildtyp (wt)/variant (v)]

2 Exakt-Test für HWE

${ }^{3}$ Die Genotypisierung ergab nicht in allen Fällen ein eindeutiges Ergebnis

Mithilfe von der Software Haploview haben wir die Grade des Kopplungsungleichgewichts (paarweise) zwischen den 4 SNPs (rs5744455, rs2569190, rs4914, rs2563298), sowohl für gesunde Probanden als auch für die Patientengruppe, berechnet. Es ergaben sich folgende Werte (Tab.3.5-6):

Tab. 3.5: Die Grade des paarweisen Kopplungsungleichgewichts zwischen den SNPs rs5744455, rs2569190, rs4914 und rs2563298 im Kollektiv der gesunden Probanden

\begin{tabular}{lcc}
\hline \multicolumn{1}{c}{ SNP-Paar } & D' & $\mathbf{r}^{2}$ \\
\hline rs5744455-rs2569190 & 1,0 & 0,308 \\
rs2569190-rs4914 & 1,0 & 0,144 \\
rs4914-rs2563298 & 1,0 & 0,500 \\
rs5744455-rs4914 & 1,0 & 0,059 \\
rs2569190-rs2563298 & 1,0 & 0,289 \\
rs5744455-rs2563298 & 1,0 & 0,118 \\
\hline
\end{tabular}


Tab. 3.6: Die Grade des paarweisen Kopplungsungleichgewichts zwischen den SNPs rs5744455, rs2569190, rs4914 und rs2563298 im Kollektiv der Patienten mit chronischer Hepatitis C

\begin{tabular}{lcc}
\hline \multicolumn{1}{c}{ SNP-Paar } & D' & r $^{2}$ \\
\hline rs5744455-rs2569190 & 1,0 & 0,211 \\
rs2569190-rs4914 & 1,0 & 0,302 \\
rs4914-rs2563298 & 1,0 & 0,694 \\
rs5744455-rs4914 & 1,0 & 0,057 \\
rs2569190-rs2563298 & 1,0 & 0,435 \\
rs5744455-rs2563298 & 1,0 & 0,082 \\
\hline
\end{tabular}

Für alle SNP-Paare in beiden Gruppen (Gesunde, Patienten) ergab sich also D' = 1, was eine vollständige Kopplung bedeutet.

\subsubsection{CD14-mRNA-Expression und sCD14-Serumkonzentration in Abhängigkeit von} Genotypen an den Positionen rs5744455, rs4914 und rs2563298

Auch aus einer Analyse der CD14-mRNA-Expression in PBMC hinsichtlich der Genotypen an den Positionen rs5744455, rs4914 und rs2563298 ergaben sich keine signifikante Assoziationen (Abb. 3.5-7). Hinsichtlich der sCD14-Konzentration als Genexpressionsparameter jedoch zeichnen sich statistisch signifikante Assoziationen ab (Abb. 3.8, 3.10): Gesunde T-Allel-Träger des SNPs rs5744455 weisen eine im Mittel signifikant geringere sCD14-Serumkonzentration auf als C-Homozygote $(3,93 \pm 1,89 \mu \mathrm{g} / \mathrm{ml}$ vs 5,32 $\pm 1,57 \mu \mathrm{g} / \mathrm{ml} ; \mathrm{p}=0,0128)$. Bei Hepatitis-C-Patienten konnten wir eine gegenläufige Tendenz beobachten, allerdings ohne signifikante Unterschiede: T-Allel-Träger haben im Mittel höhere sCD14-Serumkonzentrationen, als C-Homozygote $(5,81 \pm 1,99 \mu \mathrm{g} / \mathrm{ml}$ vs 4,98 $\pm 1,84 \mu \mathrm{g} / \mathrm{ml} ; \mathrm{p}=0,2531)$. Des Weiteren haben gesunde T-Allel-Träger des SNPs rs2563298 im Mittel höhere sCD14-Werte als G-Homozygote $(5,37 \pm 1,57 \mu \mathrm{g} / \mathrm{ml}$ vs $4,02 \pm 1,88 \mu \mathrm{g} / \mathrm{ml} ; \mathrm{p}=0,0163)$. Auch wenn T-Homozygote den G-Allel-Trägern gegenübergestellt werden, ergibt sich ein statistisch signifikanter Unterschied $(6,77 \pm$ $1,36 \mu \mathrm{g} / \mathrm{ml}$ vs 4,50 $\pm 1,79 ; \mathrm{p}=0,0387)$. Bei Hepatitis-C-Patienten lässt sich wiederum eine gegenläufige Tendenz beobachten, jedoch ohne statistische Signifikanz (Abb. 3.10). 


\section{Gesunde}

A

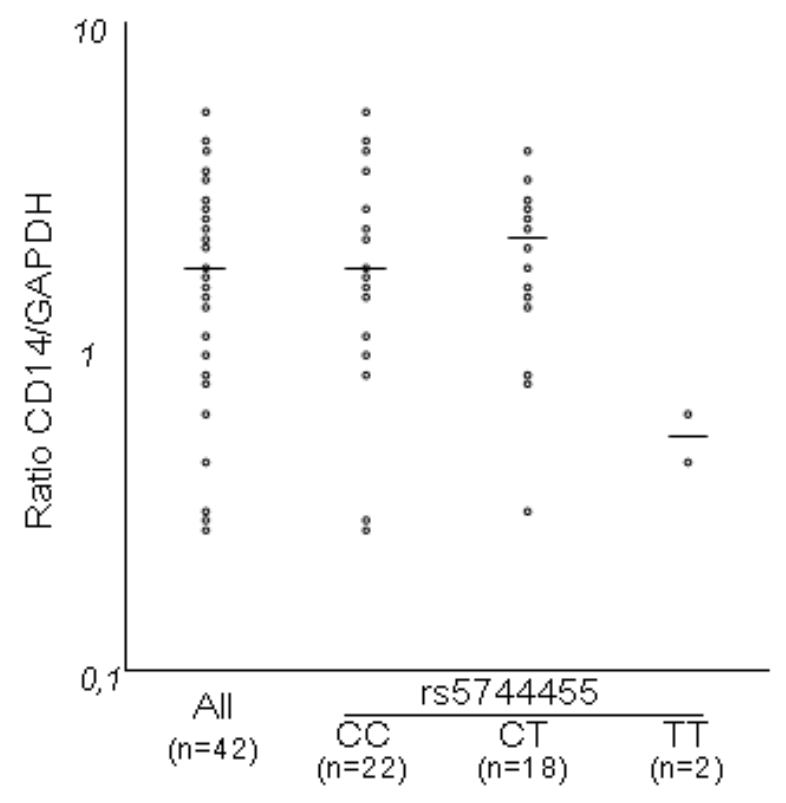

B

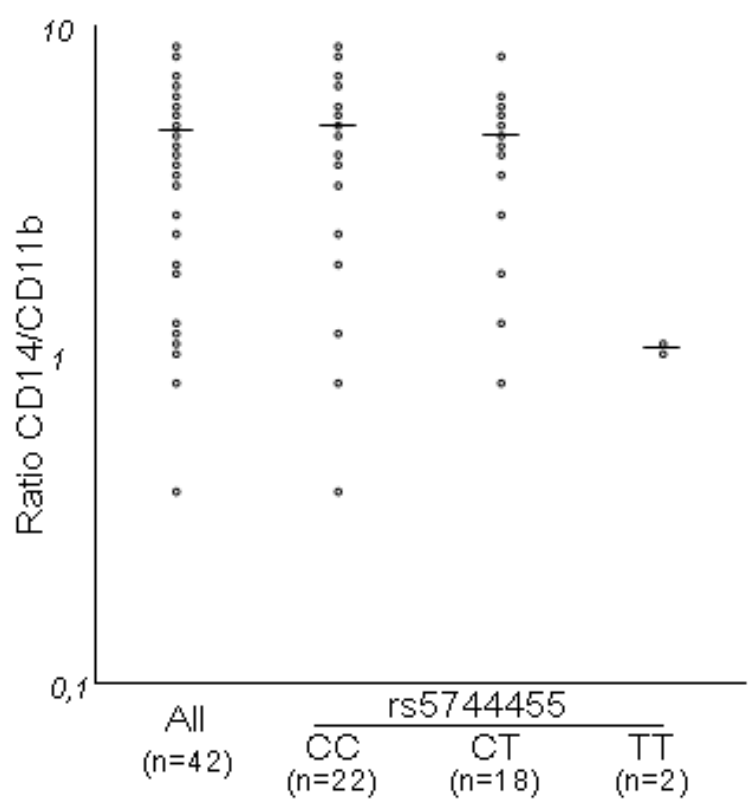

\section{Patienten}

A

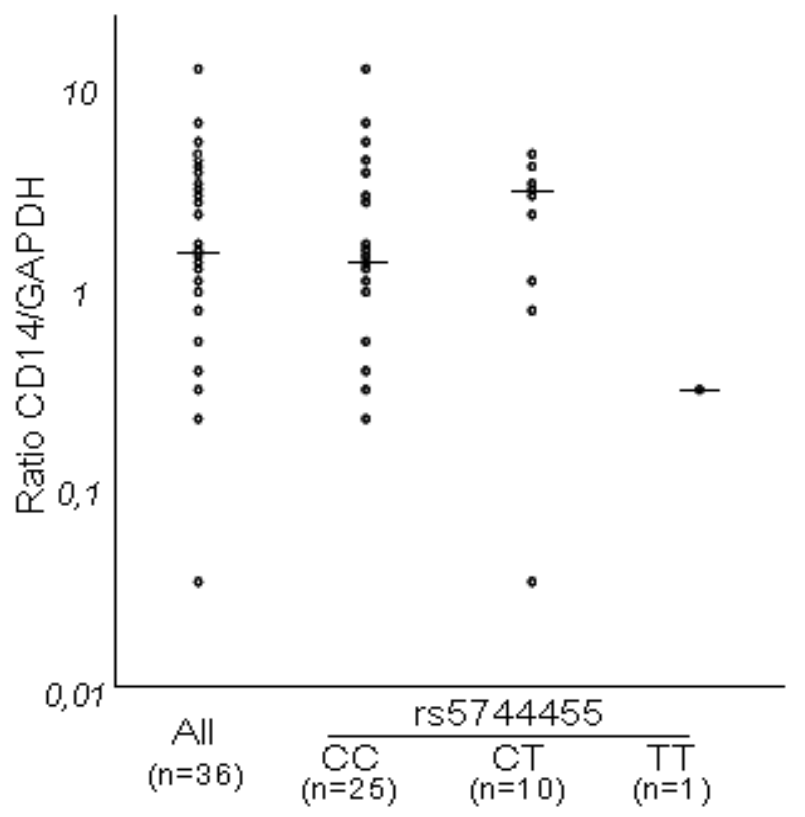

B

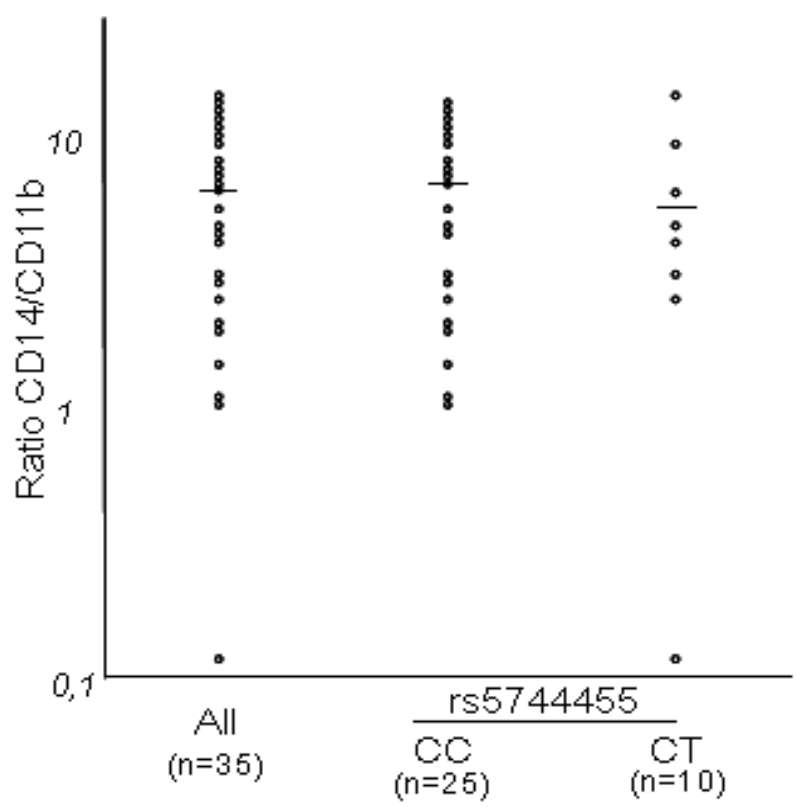

Abb. 3.5: CD14-mRNA-Expression in PBMC von gesunden Probanden und Patienten mit chronischer Hepatitis C in Bezug auf den Genotyp am SNP rs5744455

Die Daten zur CD14-mRNA-Expression in frisch isolierten PBMC von gesunden Spendern und Patienten mit chronischer HCV-Infektion wurden in Abhängigkeit des Genotyps am SNP rs5744455 sowohl in Bezug auf die Referenz GAPDH (A) als auch CD11b (B) analysiert. Die einzige T-homozygote Probe war für CD11b mRNAMessung nicht mehr verfügbar. Die Mediane sind gekennzeichnet. Es wurde kein statistisch signifikanter Unterschied erkennbar. 


\section{Gesunde}

A

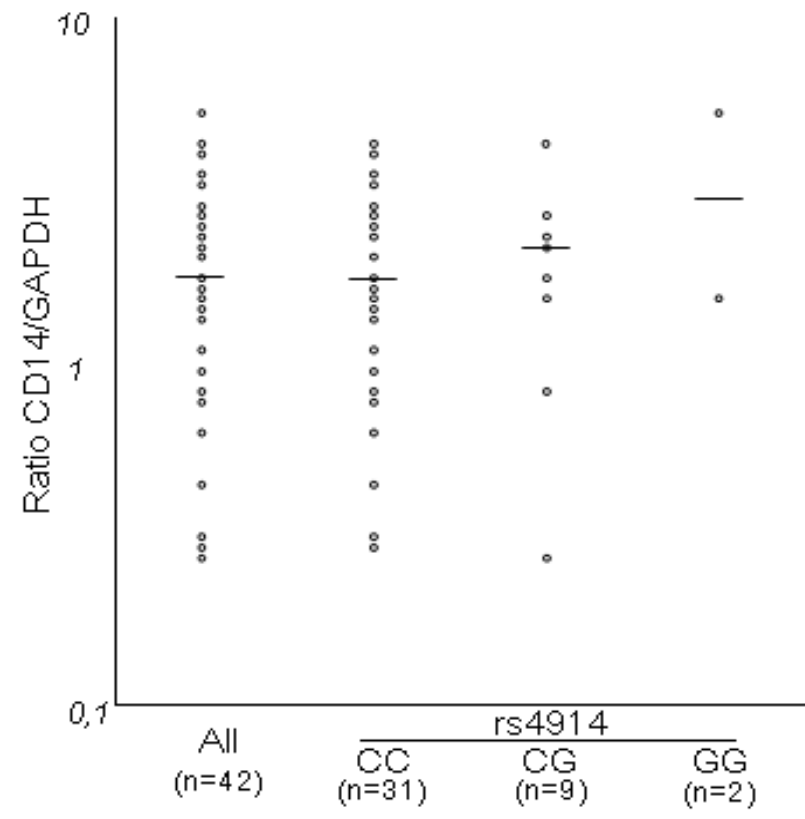

B

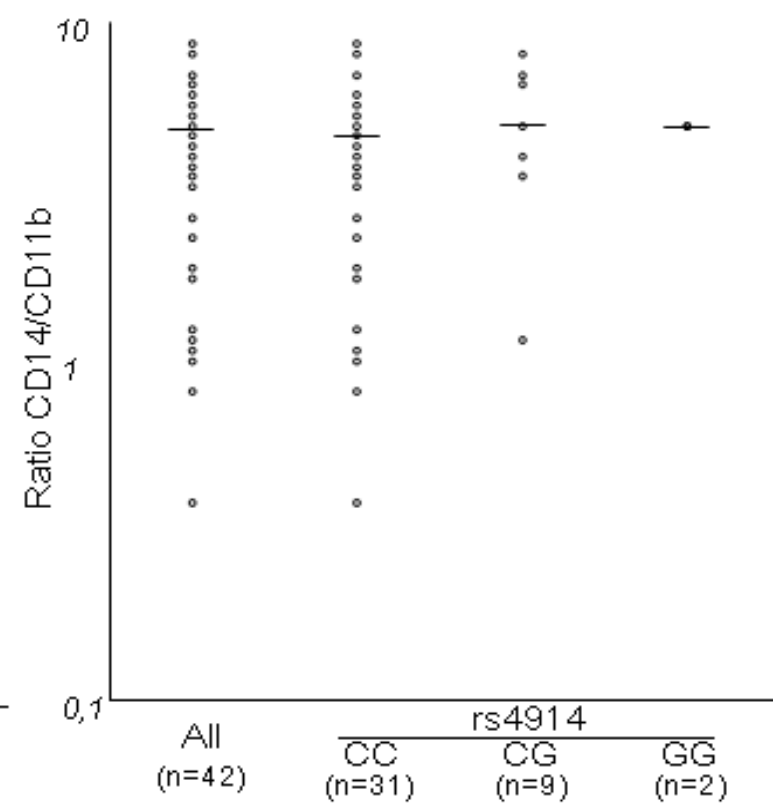

\section{Patienten}

A

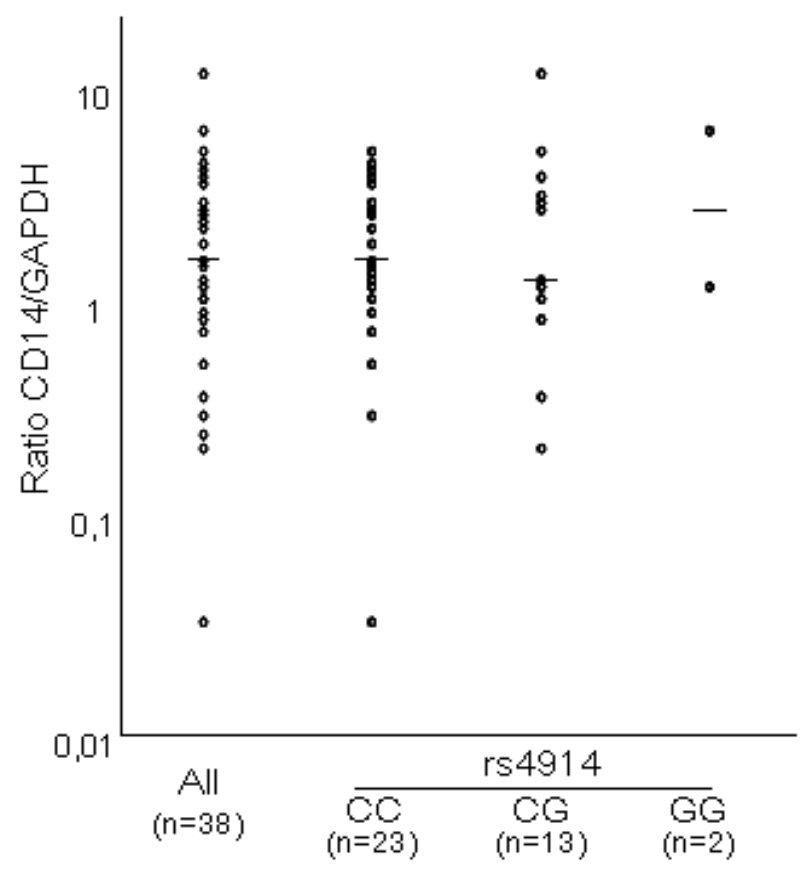

B

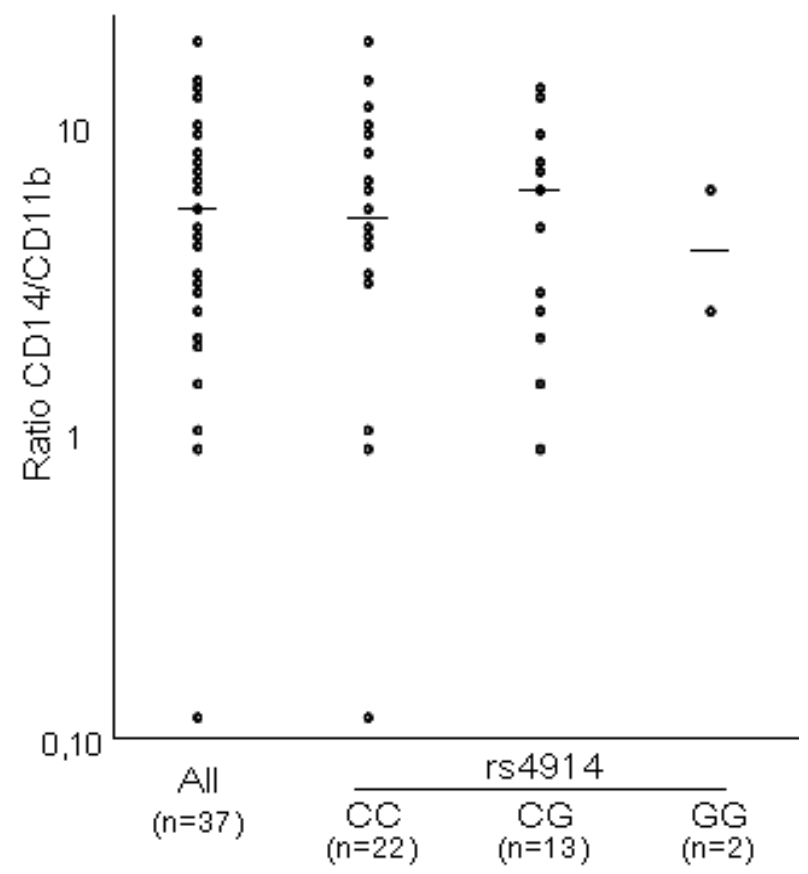

Abb. 3.6: CD14-mRNA-Expression in PBMC von gesunden Probanden und Patienten mit chronischer Hepatitis C in Bezug auf den Genotyp am SNP rs4914

Die Daten zur CD14-mRNA-Expression in frisch isolierten PBMC von gesunden Spendern und Patienten mit chronischer HCV-Infektion wurden in Abhängigkeit des Genotyps am SNP rs4914 sowohl in Bezug auf die Referenz GAPDH (A) als auch CD11b (B) analysiert. Die Mediane sind gekennzeichnet. Es wurde kein statistisch signifikanter Unterschied erkennbar. 


\section{Gesunde}

A

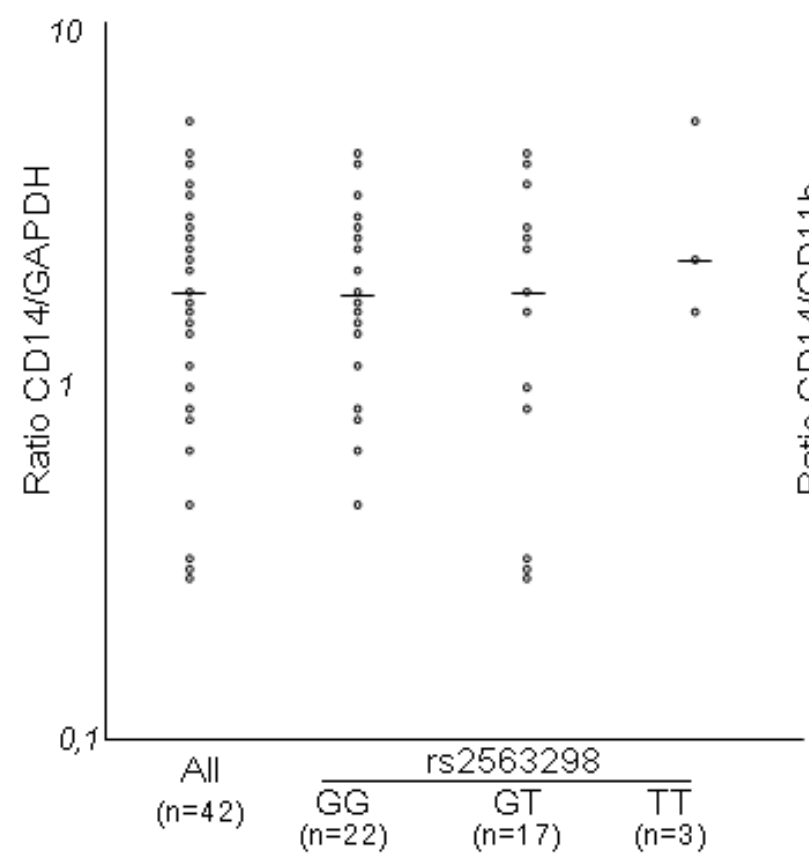

B

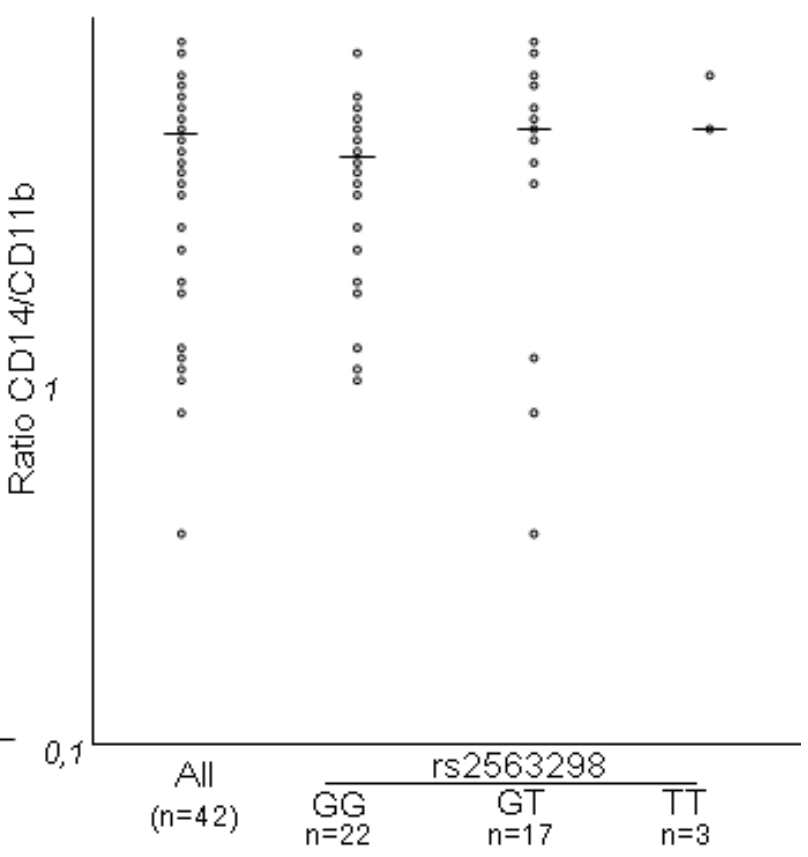

\section{Patienten}

A

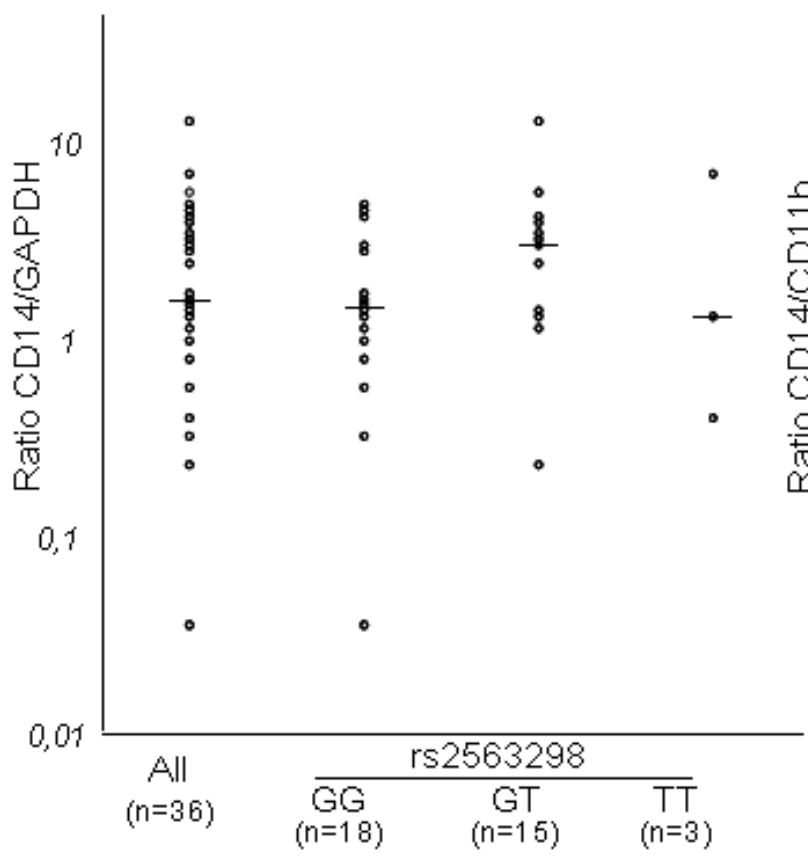

B

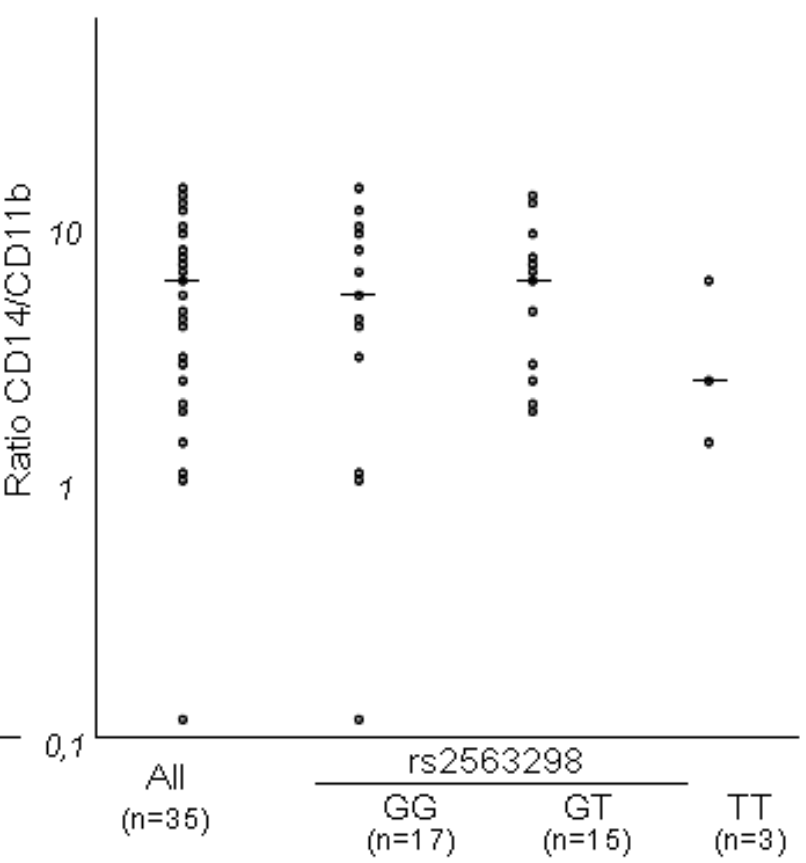

Abb. 3.7: CD14-mRNA-Expression in PBMC von gesunden Probanden und Patienten mit chronischer Hepatitis C in Bezug auf den Genotyp am SNP rs2563298

Die Daten zur CD14-mRNA-Expression in frisch isolierten PBMC von gesunden Spendern und Patienten mit chronischer HCV-Infektion wurden in Abhängigkeit von dem Genotyp am SNP rs2563298 sowohl in Bezug auf die Referenz GAPDH (A) als auch CD11b (B) analysiert. Die Mediane sind gekennzeichnet. Es wurde kein statistisch signifikanter Unterschied erkennbar. 
A

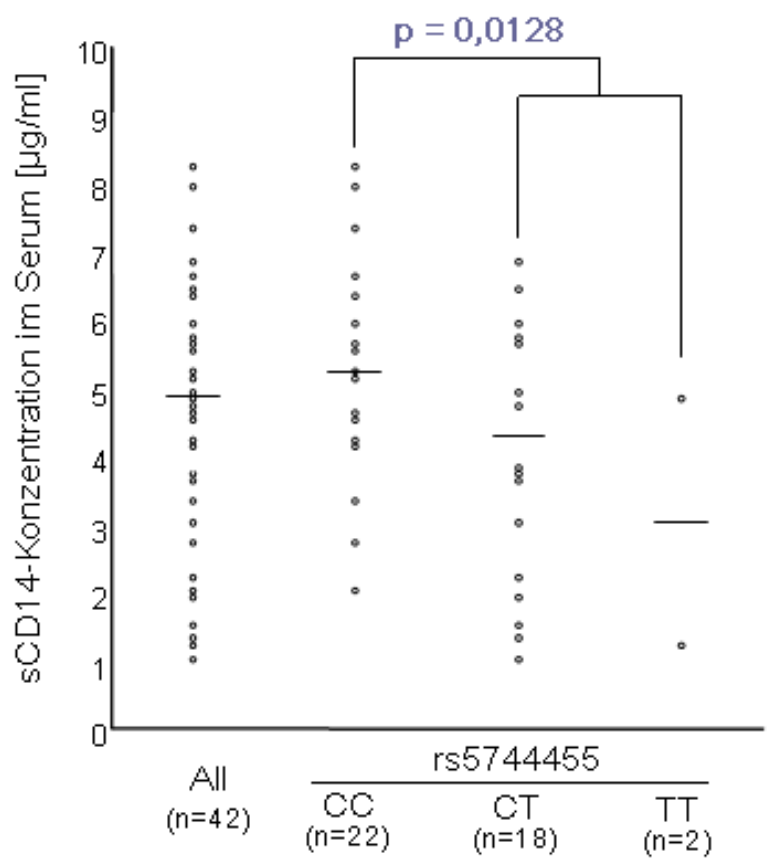

B

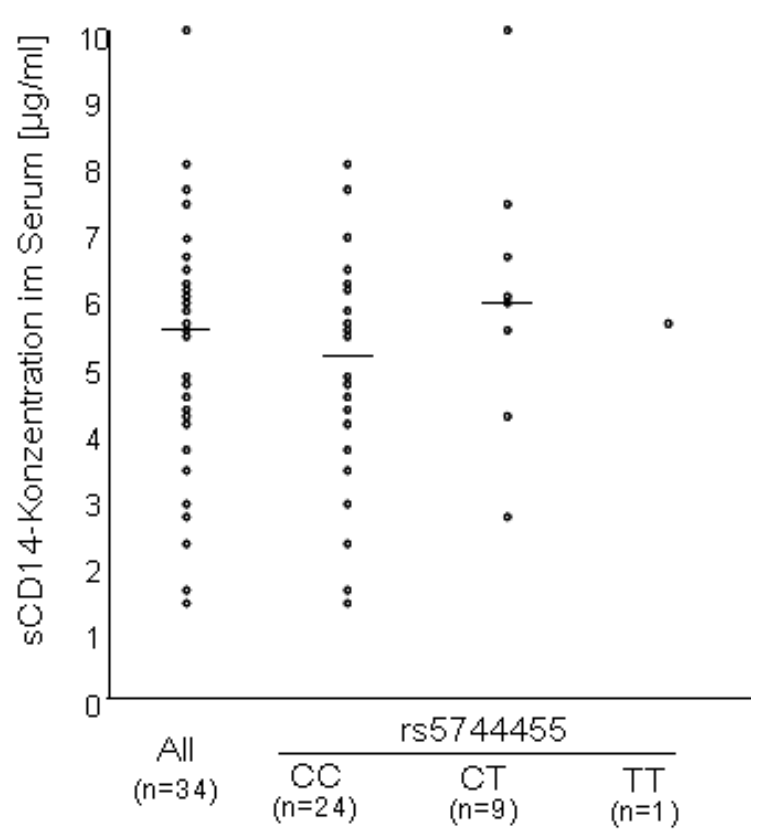

Abb. 3.8: sCD14-Serumkonzentrationen bei gesunden Probanden (A) und Patienten mit chronischer Hepatitis C (B) in Bezug auf den Genotyp am SNP rs5744455

Die Daten zur Konzentration von sCD14 in Serumproben von gesunden Spendern (A) und Patienten mit chronischer HCV-Infektion (B) wurden in Abhängigkeit von dem Genotyp am SNP rs5744455 analysiert. Die Mediane sind gekennzeichnet. Gesunde T-Allel-Träger weisen im Mittel signifikant niedrigere sCD14Serumkonzentrationen auf als C-Homozygote. In der Gruppe der Patienten wurde kein statistisch signifikanter Unterschied erkennbar. 
A

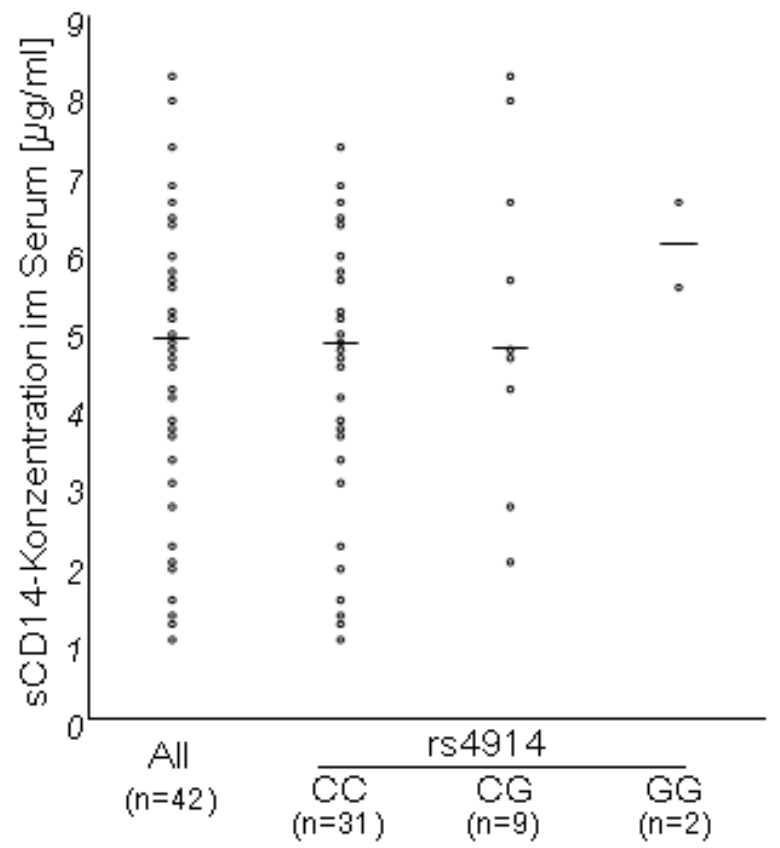

B

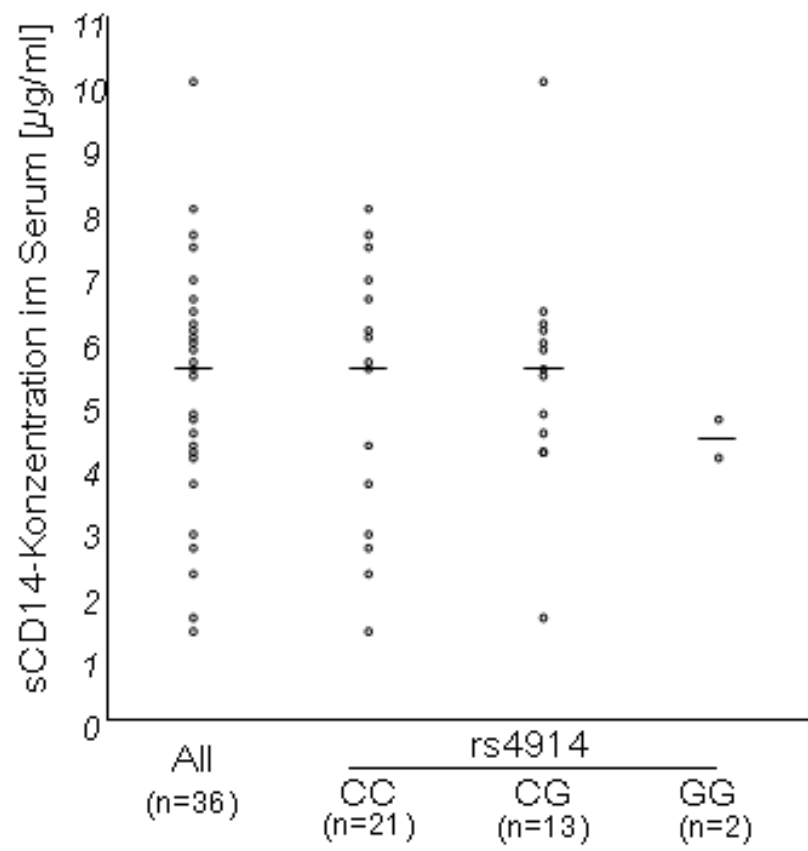

Abb. 3.9: sCD14-Serumkonzentrationen bei gesunden Probanden (A) und Patienten mit chronischer Hepatitis C (B) in Bezug auf den Genotyp am SNP rs4914

Die Daten zur Konzentration von sCD14 in Serumproben von gesunden Spendern (A) und Patienten mit chronischer HCV-Infektion (B) wurden in Abhängigkeit von dem Genotyp am SNP rs4914 analysiert. Die Mediane sind gekennzeichnet. Es wurde kein statistisch signifikanter Unterschied erkennbar. 

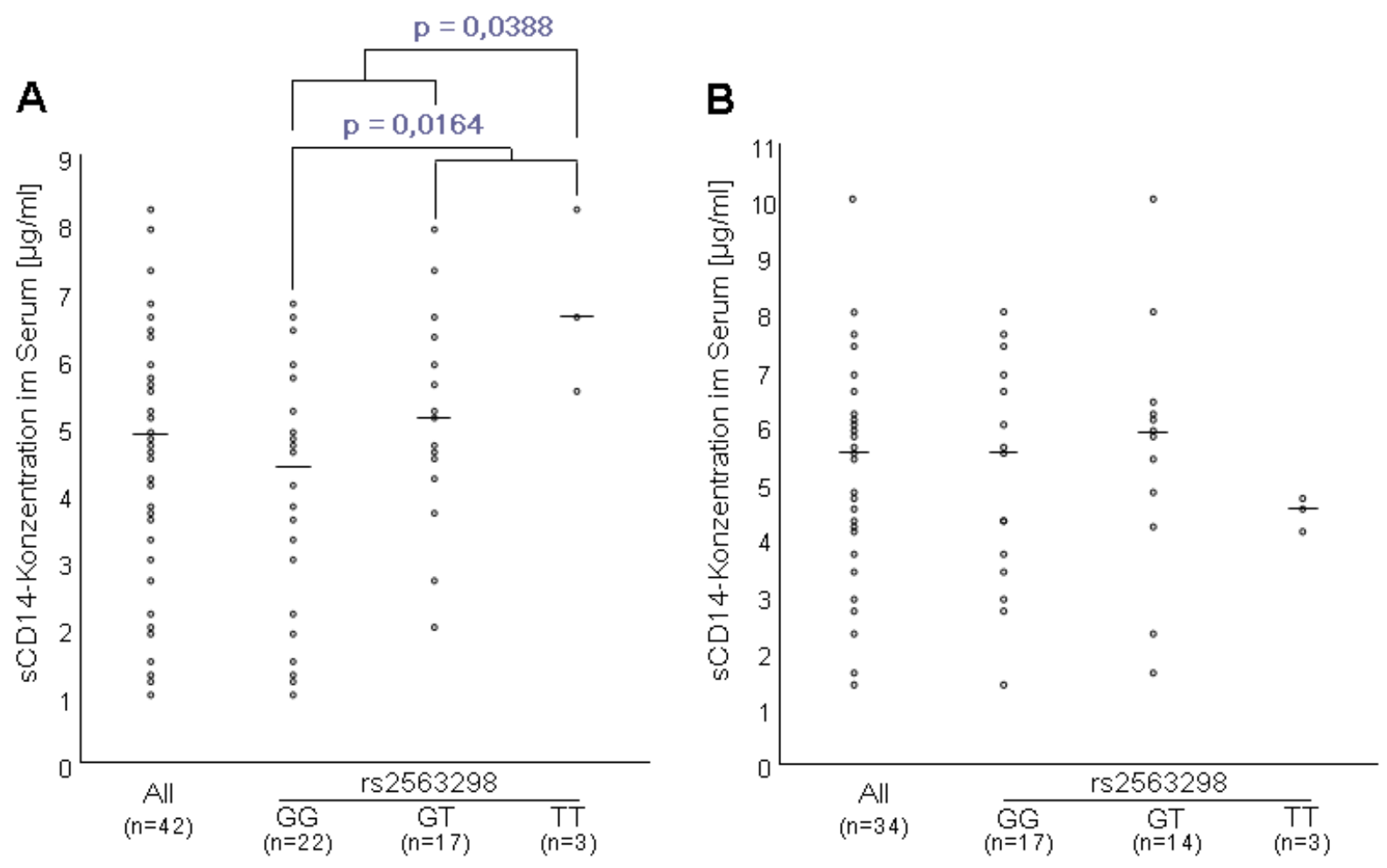

Abb. 3.10: sCD14-Serumkonzentrationen bei gesunden Probanden (A) und Patienten mit chronischer

\section{Hepatitis C (B) in Bezug auf den Genotyp am SNP rs2563298}

Die Daten zur Konzentration von sCD14 in Serumproben von gesunden Spendern (A) und Patienten mit chronischer HCV-Infektion (B) wurden in Abhängigkeit des Genotyps am SNP rs2563298 analysiert. Die Mediane sind gekennzeichnet. Gesunde T-Homozygote gegenüber G-Allel-Trägern sowie T-Allel-Träger gegenüber G-Homozygoten weisen im Mittel signifikant höhere sCD14-Konzentrationen auf. In der Gruppe der Patienten wurde kein statistisch signifikanter Unterschied erkennbar.

Zusammenfassend lässt sich sagen, dass sich kein signifikanter Unterschied zwischen verschiedenen Genotypgrupppen der untersuchten SNPs bezüglich der CD14-mRNAExpression in PBMC nachweisen lässt. Es fällt jedoch auf, dass die Werte für die beiden Thomozygoten Gesunden in Bezug auf den SNP rs5744455 im unteren Bereich liegen (Abb. 3.5 Gesunde A). Bei der sCD14-Serumkonzentration in gesunden Probanden sind signifikante Assoziationen mit SNPs rs5744455 (Abb. 3.8 A) und rs2563298 (Abb.3.10 A) zu erkennen. Es ist auch bemerkenswert, dass mit der sCD14-Serumkonzentration bei Gesunden und Patienten in Bezug auf 3 von 4 untersuchten SNPs immer gegenläufige Tendenzen zu beobachten sind, auch wenn die Unterschiede zwischen den Genotypgruppen nicht immer statistisch signifikant sind.

Allerdings, wenn wir die Bonferroni-Anpassung durchführen, müssen wir die Schwelle der Signifikanz vom p-Wert heruntersetzen: Da insgesamt 4 SNPs untersucht wurden, streng 
genommen gilt es $\mathrm{p}<0,0125$ als ein Schwellenwert von Signifikanz (der übliche Schwellenwert 0,05 muss durch 4 dividert werden). Durch diese Anpassung werden die beobachteten signifikanten Unterschiede in untersuchten Parametern zwischen verschiedenen Genotypgruppen aufgehoben.

\subsection{CD14-mRNA-Expression in der Leber}

Die Regulation der CD14-mRNA-Expression in PBMC unterscheidet sich möglicherweise von der in der Leber. Wir haben deshalb auch die hepatische CD14-Expression in Bezug auf die Genotypen an den 4 relevanten varianten Positionen untersucht. Zur Verfügung standen 41 Lebergewebeproben von Patienten mit chronischer Hepatitis C, deren Genotypverteilung in Tab. 3.7 zusammengefasst ist. Die Verteilungen entsprechen dem Hardy-Weinberg Gleichgewicht und die MAFs in etwa den Angaben aus NCBI von 0,30, 0,47, 0,09 und 0,22 für rs5744455, rs2569190, rs4914 und rs2563298 für die kaukasische Bevölkerung.

Die CD14-Genexpression in der Leber wurde auf die Expression der GAPDH als Referenz bezogen. In Bezug auf die Genotypen an den relevanten Positionen ergaben sich keine signifikanten Unterschiede.

Tab. 3.7: Genotypverteilungen an 4 relevanten SNPs im Kollektiv der Patienten mit Lebergewebeproben

\begin{tabular}{ccccccc}
\hline \multirow{2}{*}{ SNP } & [n] & \multicolumn{3}{c}{ Genotypverteilung } & MAF & $\mathbf{P}^{2}$ \\
\cline { 3 - 6 } & & wt/wt & wt/v & v/v & \\
\hline rs5744455 [C/T] & $25^{3}$ & $16(64,0 \%)$ & $8(32,0 \%)$ & $1(4,0 \%)$ & 0,20 & 1,00 \\
rs2569190 [C/T] & 41 & $8(19,5 \%)$ & $18(43,9 \%)$ & $15(36,6 \%)$ & 0,59 & 0,53 \\
rs4914 [C/G] & 41 & $31(75,6 \%)$ & $8(19,5 \%)$ & $2(4,9 \%)$ & 0,15 & 0,18 \\
rs2563298 [G/T] & $37^{1}$ & $23(62,2 \%)$ & $11(29,7 \%)$ & $3(8,1 \%)$ & 0,23 & 0,35 \\
\hline
\end{tabular}

${ }_{2}^{1}$ [Wildtyp (wt)/variant (v)]

2 Exakt-Test für HWE

${ }^{3}$ Die Genotypisierung ergab nicht in allen Fällen ein eindeutiges Ergebnis 
A

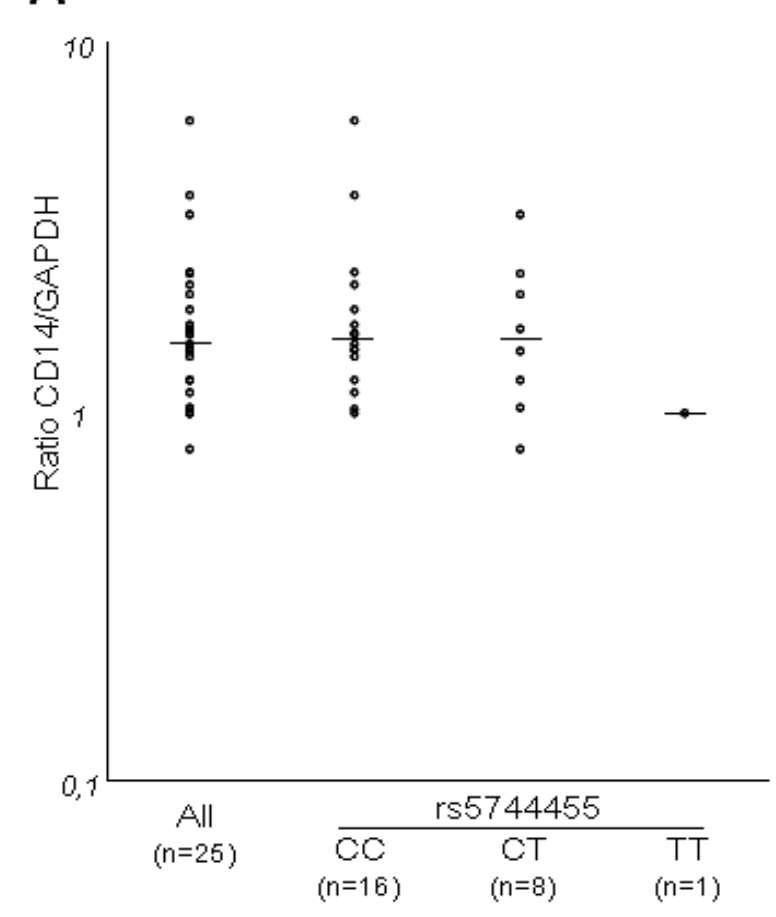

C

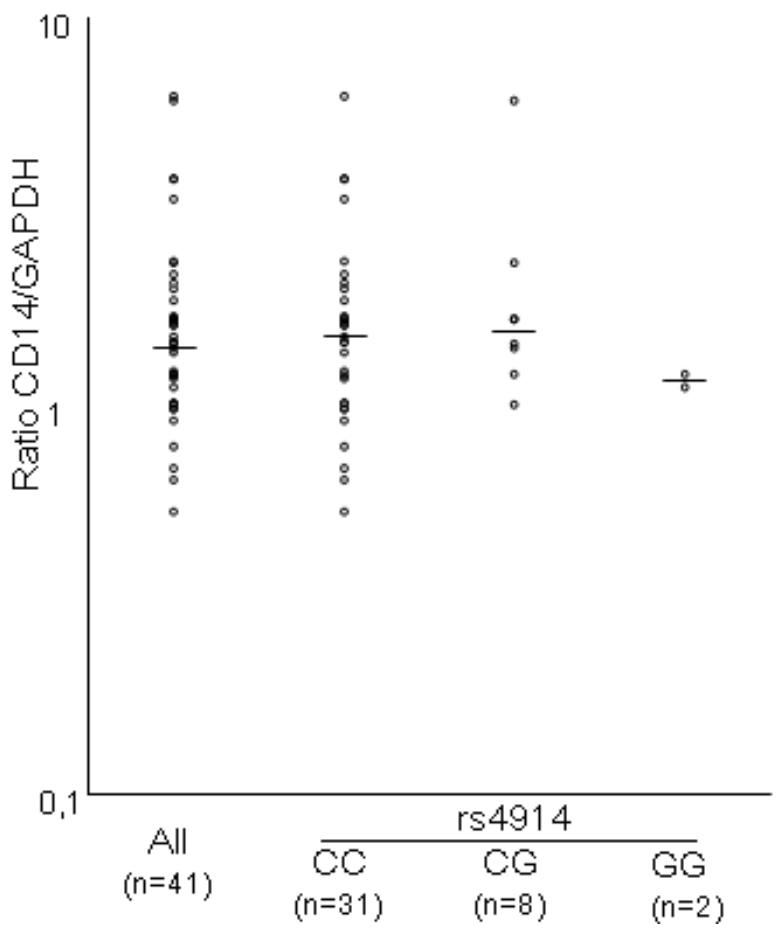

B

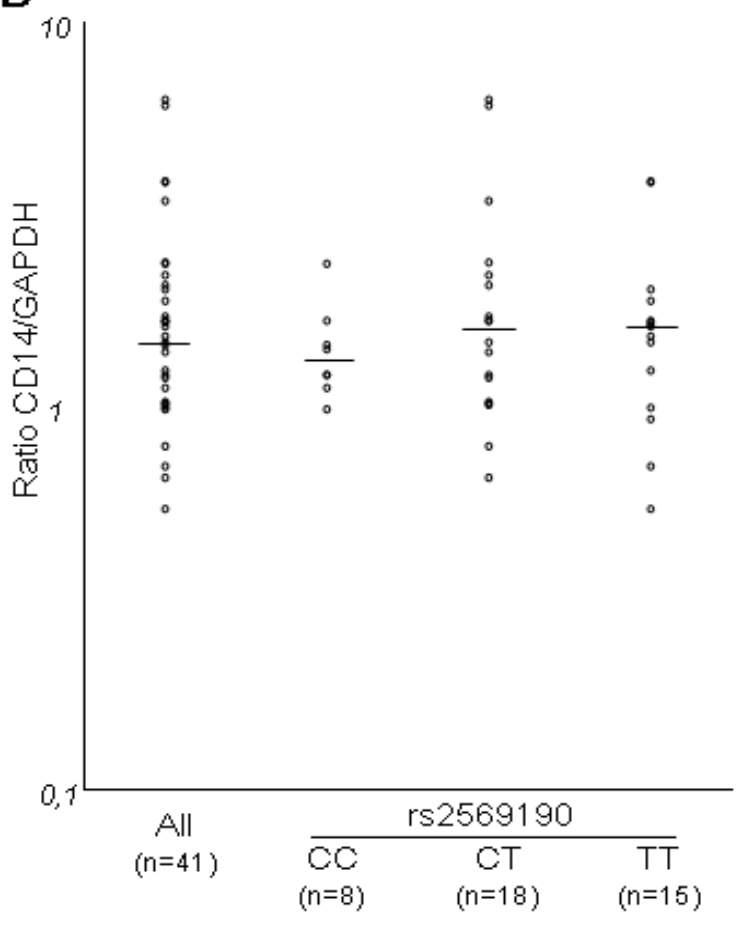

D

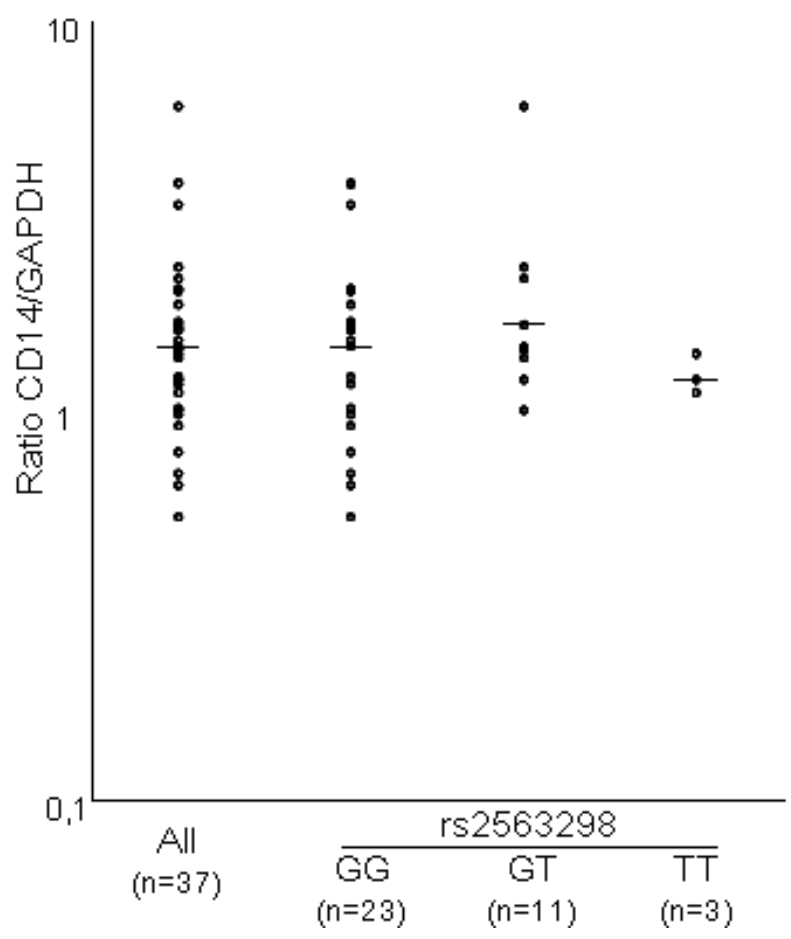

Abb. 3.11: CD14-mRNA-Expression in der Leber von Patienten mit chronischer Hepatitis C in Bezug auf den Genotyp an SNPs rs5744455 (A), rs2569190 (B), rs4914 (C) und rs2563298 (D)

Die Daten zur CD14-mRNA-Expression in Lebergewebeproben von Patienten mit chronischer Hepatitis C wurden in Abhängigkeit der Genotypen an 4 relevanten polymorphen Positionen in Bezug auf die Referenz GAPDH analysiert. Die Mediane sind gekennzeichnet. Die Analyse ergab keine statistisch signifikante Unterschiede. 


\subsection{Haplotypisierung}

Die Haplotypisierung diente einerseits dem Zweck, zu überprüfen, ob sich ggf. Haplotypabhängige Unterschiede in der CD14-Genexpression abzeichnen. Andererseits war sie notwendig, um bei der ASTQ rs4914-Transkriptvarianten den rs2569190-Genvarianten zuordnen zu können (siehe unten).

gDNA von gesunden Probanden und Patienten mit chronischer Hepatitis $C$ wurde für die 4 Positionen (rs5744455, rs2569190, rs4914, rs2563298) wie in Material und Methoden beschrieben (siehe 2.3.8) mit einer Kombination aus tetra-Primer-ARMS-PCR und Genotypisierungs-Techniken haplotypisiert.

Es ergaben sich insgesamt 5 Haplotypen (Tab. 3.8) und daraus insgesamt 11 bzw. 10 Haplogenotypen bei Gesunden und bei Patienten mit chronischer Hepatitis C (Tab. 3.9). Die von uns experimmentell herausgefundene Haplotypen sowie ihre Häufigkeiten stimmen mit den durch die Software Haploview geschätzten Daten überein.

Tab. 3.8: Verteilung der Haplotypen bei gesunden Probanden und Patienten mit chronischer Hepatitis C

\begin{tabular}{ccc}
\hline Haplotyp & $\begin{array}{c}\text { Gesunde Probanden } \\
{[\mathbf{n}](\%)}\end{array}$ & $\begin{array}{c}\text { Patienten mit chronischer Hepatitis C } \\
{[\mathrm{n}](\%)}\end{array}$ \\
\hline C-T-C-G & $37(44 \%)$ & $37(51,4 \%)$ \\
T-C-C-G & $22(26,2 \%)$ & $12(16,7 \%)$ \\
C-C-G-T & $13(15,5 \%)$ & $16(22,2 \%)$ \\
C-C-C-T & $10(11,9 \%)$ & $5(6,9 \%)$ \\
C-C-C-G & $2(2,4 \%)$ & $2(2,8 \%)$ \\
\hline
\end{tabular}

* rs5744455 - rs2569190 - rs4914 - rs2563298 
Tab. 3.9: Verteilung der Haplogenotypen bei gesunden Probanden und Patienten mit chronischer Hepatitis C

\begin{tabular}{ccc}
\hline Haplogenotyp* & $\begin{array}{c}\text { Gesunde Probanden } \\
\text { [n] }\end{array}$ & $\begin{array}{c}\text { Patienten mit chronischer Hepatitis C } \\
{[\mathrm{n}]}\end{array}$ \\
\hline T-C-C-G/C-T-C-G & 13 & 5 \\
C-C-G-T/C-T-C-G & 7 & 7 \\
C-C-C-T/C-T-C-G & 6 & 3 \\
C-T-C-G/C-T-C-G & 5 & 10 \\
C-C-C-T/T-C-C-G & 3 & 1 \\
C-C-G-T/C-C-G-T & 2 & 2 \\
T-C-C-G/T-C-C-G & 2 & 1 \\
C-C-C-T/C-C-G-T & 1 & 1 \\
C-C-C-G/C-T-C-G & 1 & 2 \\
T-C-C-G/C-C-G-T & 1 & 4 \\
C-C-C-G/T-C-C-G & 1 & - \\
\hline
\end{tabular}

* rs5744455-rs2569190-rs4914-rs2563298

Beim Vergleich der CD14-Genexpressionsparameter (CD14-mRNA-Expression in PBMC und ggf. in der Leber und sCD14-Serumkonzentration) zwischen verschiedenen genügend großen Haplogenotypgruppen $(\mathrm{n} \geq 2)$ konnten wir keine signifikante Unterschiede finden, weder bei gesunden Probanden, noch bei Hepatitis-C-Patienten, unabhängig davon, ob CD14mRNA-Mengen auf GAPDH oder CD11b als Referenz bezogen wurden (Daten nicht gezeigt). Es zeichnete sich auch keine Assoziation mit verschiedenen 4-er Haplotypgruppen, z. B. C-T-C-G-Träger vs Nicht-C-T-C-G-Träger usw., ab (Daten nicht gezeigt).

\subsection{Korrelationen zwischen verschiedenen Parametern der CD14-Genexpression}

Die Analyse der Daten ergab keine signifikante Korrelation zwischen CD14-mRNAExpression in $\mathrm{PBMC}$ und $\mathrm{SCD} 14-$ Serumkonzentration bei gesunden Probanden $\left(\mathrm{r}^{2}=0,0530, \mathrm{p}=0,1425, \mathrm{n}=42\right)$, wenn die CD14-mRNA-Mengen auf GAPDH als Referenzgen bezogen wurden. Zwischen den CD14 Mengen bezogen auf CD11b und sCD14-Werten im Serum ergab sich aber eine positive Korrelation $\left(r^{2}=0,1316, p=\right.$ 0,0182, $\mathrm{n}=42$ ). Bei Patienten mit chronischer Hepatitis $\mathrm{C}$ war zwischen denselben Parametern keine signifikante Korrelation zu beobachten, unabhängig davon ob die CD14mRNA-Mengen in PBMC auf GAPDH oder auf CD11b bezogen waren $\left(\mathrm{r}^{2}=0,0158\right.$, 
$\mathrm{p}=0,4390, \mathrm{n}=40$ bzw. $\mathrm{r}^{2}=0,03306, \mathrm{p}=0,2680, \mathrm{n}=39$ ). Es wurde auch keine Korrelation zwischen CD14-mRNA-Expression in der Leber und sCD14-Serumkonzentrationen bei Patienten gesehen $\left(\mathrm{r}^{2}=0,2951, \mathrm{p}=0,1277, \mathrm{n}=28\right)$. Die Gegenüberstellung der CD14mRNA-Expression in PBMC und in der Leber von Patienten mit Hepatitis C ergab aber eine inverse Korrelation, allerdings auch ohne Signifikanz $\left(r^{2}=0,1184, p=0,0730, n=28\right)$ (Daten nicht gezeigt).

\subsection{ASTQ}

Die Technik der ASTQ wird angewendet, um die relative Menge von Transkripten zu erfassen, die von zwei Allelvarianten eines Gens generiert werden. Mit dieser Technik werden intrinsische Fehler, die aus inter-individuellen Vergleichen resultieren können, vermieden, da Eigenschaften zweier Allele innerhalb eines Individuums und nicht zwischen Individuen verglichen werden (Buckland 2004).

Zur Untersuchung des Einflusses von SNPs auf die transkriptionelle Aktivität, die im Gen außerhalb des transkribierten Bereichs lokalisiert sind, ist ein zweiter SNP (Surrogat-SNP) innerhalb des Transkripts erforderlich, mit dessen Hilfe die Genprodukte der beiden elterlichen Chromosomen voneinander unterschieden werden können.

Da der SNP rs2569190 je nach der splice-Variante des CD14-Gens einmal im Transkript, andernmal im Intron liegt (siehe 1.4.4 in Einleitung), mußten wir zunächst herausfinden, welche splice-Variante in PBMC und Leber exprimiert wird.

\subsubsection{Ermittlung der CD14-mRNA-splice-Varianten in PBMC und Leber}

Um zu ermitteln, welche der beiden CD14 splice-Varianten in PBMC und Leber exprimiert wird, wurde cDNA mit zwei verschiedenen Assays amplifiziert, dem CD14 Gene Expression Assay und dem rs2569190 Genotypisierungs-Assay. Für den Fall, dass Transkripte vorliegen, die die variante Position rs2569190 enthalten, sollten cDNA-Proben mit beiden Assays gleicheffektiv amplifiziert werden. Für den Fall, dass Transkripte vorliegen, die die variante Position nicht enthalten, sollte eine Amplifikation mit dem CD14 Gene Expression Assay aber nicht mit dem rs2569190 Genotypisierungs-Assay erfolgen. Zu Kontrollzwecken wurden noch zwei weitere Assays herangezogen, von denen einer den SNP rs4914, der in beiden splice-Varianten vorkommt, erfasst und der andere einen SNP, rs254909, der sicher nicht in cDNA zu erwarten ist. Wir haben also, wie im Material und Methoden beschrieben (siehe 2.3.10), 4 verschiedene Assays für cDNA-Amplifizierung angewendet: GenotypisierungsAssays für SNPs rs4914, rs2569190, rs254909 und Gene Expression Assay für CD14-mRNA. 
Zur Kontrolle der Genotypisierungs-Assays wurden neben cDNA- auch einige gDNA-proben unter identischer Bedingungen amplifiziert (Abb. 3.12).
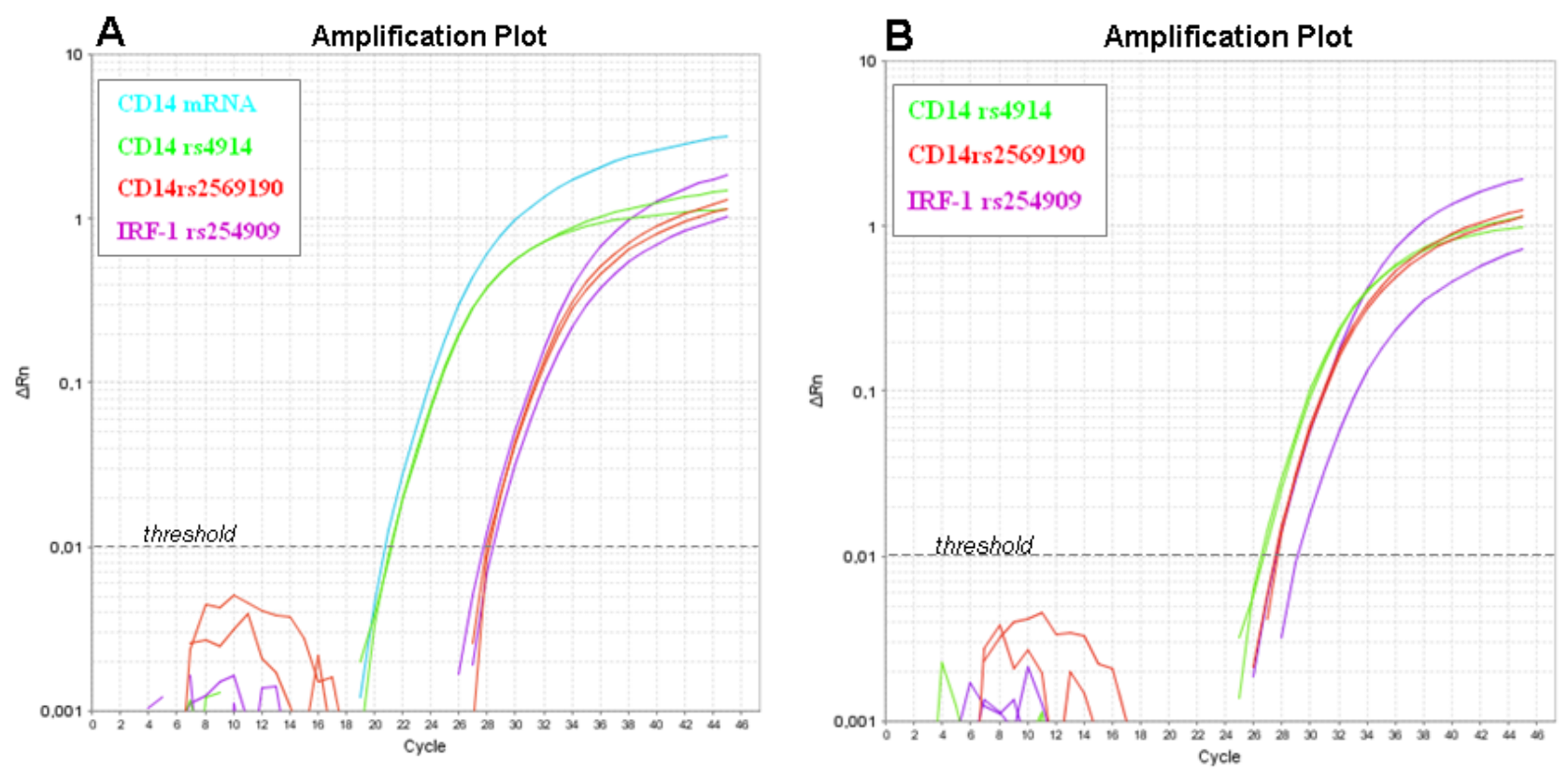

Abb. 3.12: Amplifizierung einer cDNA-Probe mit 4 verschiedenen Assays zur Ermittlung der spliceVariante (A) und eine gDNA-Kontrolle (B)

(A) Die eingesetzte cDNA-Probe wird mit dem Genotypisierungs-Assay für CD14 rs4914 und dem Quantifizierungs-Assay für gesamten CD14-mRNA etwa gleich stark amplifiziert, d. h. alle Transkripte enthalten wie erwartet die variante Position rs4914. Die Menge an Transkripten mit rs2569190 ist um Faktor $2^{8}$ geringer und entspricht in etwa der Menge an gDNA, die mit dem rs254909-spezifischen Assay detektiert wird (der letztere SNP liegt im Promotor vom IRF-1-Gen). Der SNP rs2569190 kommt also nicht in der cDNA-Probe vor, d. h. er befindet sich außerhalb des transkribierten Bereichs des Gens. Die untersuchte Probe enthält die Transkriptvariante 2 ( NM_001040021.1).

(B) Um zu prüfen, ob die Genotypisierung-Assays für alle 3 SNPs (rs4914, rs2569190 und rs254909) funktionieren, wurde eine gDNA-Probe als Kontrolle eingesetzt. Die Amplifikationskurven für alle SNPs liegen fast aufeinander, bis auf eine Kurve für rs254909, was daran liegt, dass die Probe an der entsprechenden Position homozygot, während an beiden anderen Positionen (rs4914 und rs2569190) heterozygot ist.

Wir haben 10 cDNA-Proben aus PBMC sowie 10 cDNA-Proben aus der Leber auf die beschriebene Weise untersucht und festgestellt, dass alle die Transkriptvariante 2 des CD14Gens enthalten, in der der SNP rs2569190 nicht vorkommt. Wir benötigten also einen anderen, im Transkript liegenden Surrogat-SNP, um die ASTQ an der Position rs2569190 sowohl in PBMC als auch in der Leber ausführen zu können. Der SNP sollte eine ausreichende MAF aufweisen, damit die Identifizierung von doppelt-heterozygoten Proben wahrscheinlich würde. 


\subsubsection{Identifizierung eines für ASTQ geeigneten SNPs im transkribierten Bereich des CD14-Gens}

Laut NCBI ist rs4914 der einzige unter den 4 SNPs im CD14-Gen mit ausreichenden MAFs, der sich im Transkript befindet (Abb. 3.13). Dies ließ sich auch von unserer Arbeitsgruppe bestätigen, indem ein die Exone und die angrenzenden 5'- und 3'-Regionen umfassender, 2101 Nukleotiden langer gDNA-Abschnitt des CD14-Gens amplifiziert und sequenziert wurde. Dabei konnten keine weiteren SNPs in diesem Abschnitt identifiziert werden (Mertens et al. 2009). Insofern kam nur der SNP rs4914 als Surrogat für die ASTQ in Frage.

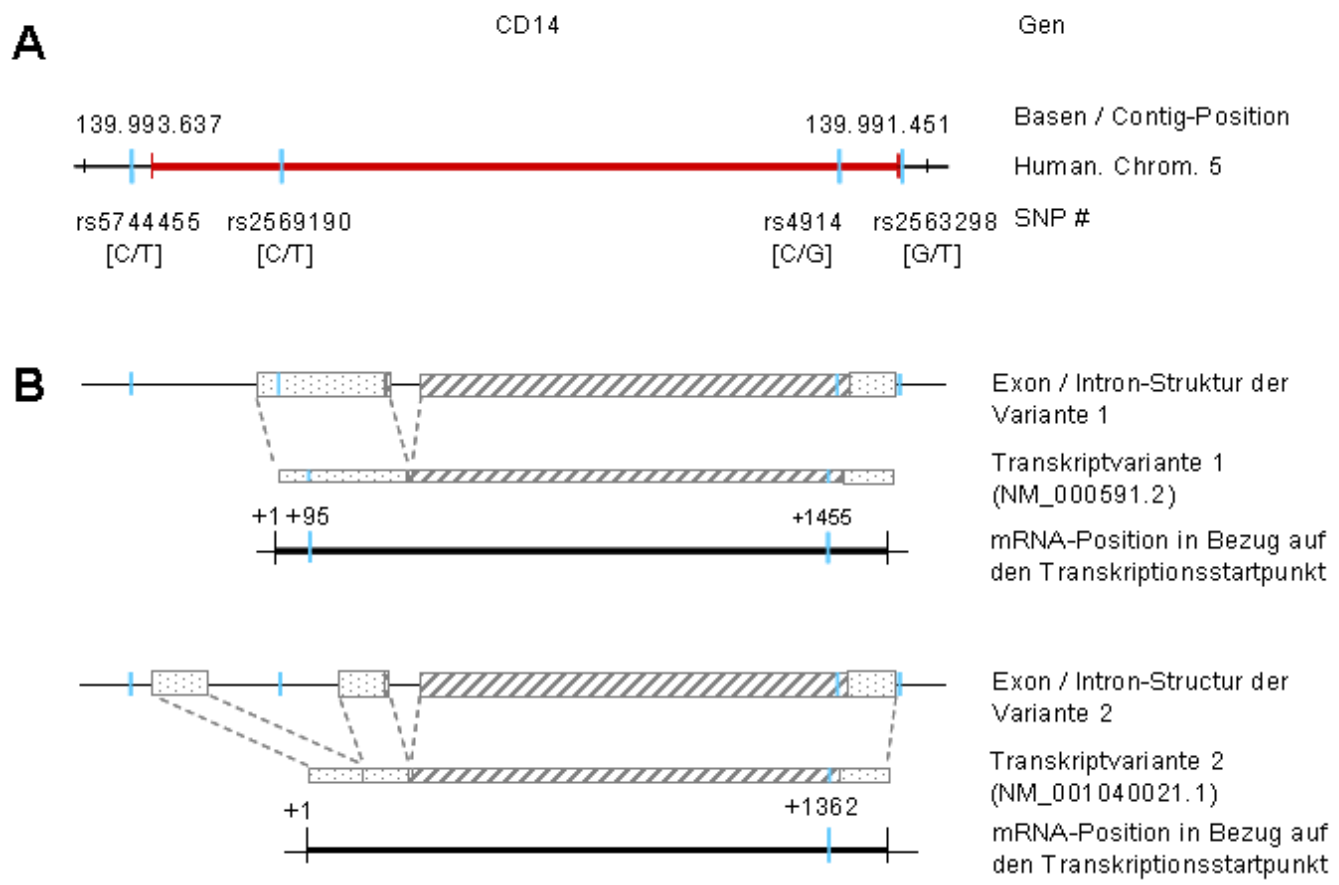

Abb. 3. 13: Schematische Darstellung der Struktur des CD14-Gens und der 2 splice-Varianten

(A) Das CD14-Gen in Menschen ist auf dem 5. Chromosom lokalisiert. Das Gen enthält 4 SNPs, wie gezeigt, mit MAF > 0,1. Die Anwesenheit dieser 4 SNPs bzw. die Abwesenheit weiterer wurde von unserer Arbeitsgruppe durch die Sequenzierung des relevanten gDNA-Abschnitts bestätigt. (B) Unterschiedliches splicing resultiert in 2 Transkriptvarianten. Beide enthalten rs4914, den für ASTQ als Surrogat nutzbaren SNP. In der Transkriptvariante 1 ist rs2569190 in der 5'UTR lokalisiert; Aufgrund der intronischen Lokalisation kommt rs2569190 in der Transkriptvariante 2 nicht vor. 
Unter den gesunden Probanden fanden sich 7, und unter den Patienten 3 an der Positionen rs2569190 und rs4914 Doppelt-Heterozygoten.

Die Haplotypisierung ergab (s. Tab. 3.9), dass die Allele dieser 2 SNPs in doppeltheterozygoten Proben folgendermaßen miteinander gekoppelt sind:

rs2569190

rs4914

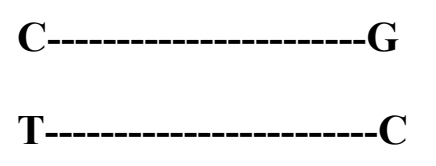

\subsubsection{Ausführung der ASTQ}

Die ASTQ wurde sowohl in PBMC als auch in der Leberproben parallel mit zwei unabhängigen Untersuchungsmethoden, real time TaqMan-RT-PCR und RFLP, durchgeführt. Der SNP rs4914 (C/G) wurde dabei als Surrogat benutzt und allelische Überexpressionen wurden den Allelen des SNPs rs2569190 (C/T) gemäß den Haplotypen zugeordnet.

Die meisten von Proben wurden zwei- bis dreimal analysiert. Für den Ergebnissen wurden Mittelwerte gebildet.

\subsubsection{Allelische Expression des CD14-Gens in PBMC}

\subsubsection{ASTQ mittels real time TaqMan-RT-PCR}

ASTQ mit Sonden in real time PCR lieferte Expressionsraten von beiden Allelen (in CtWerten). Um die mögliche Überexpression eines der Allele in verschiedenen Proben miteinander vergleichen zu können, wurde für jede Probe das Verhältnis zwischen den

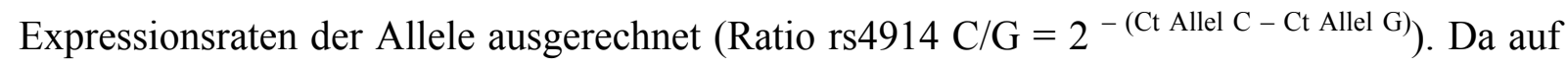
gDNA-Ebene gleiche Expressionsraten von beiden Allelen zu erwarten sind, wurden gDNAProben im gleichen Assay als Kontrollen eingesetzt und die Werte für cDNA mit den Werten für gDNA normiert. Damit konnte der Verzerrungseffekt (bias) in Expressionsraten der Allele, der durch unterschiedliche Bindungseffizienz der farbmarkierten Sonden mit DNASequenz zustande kommen könnte, behoben werden (Abb. 3. 14). rs2569190-Homozygoten dienten als Kontrollen. Von jeder Probe wurden 3-fachbestimmungen durchgeführt und die Expressionsraten gemittelt. 


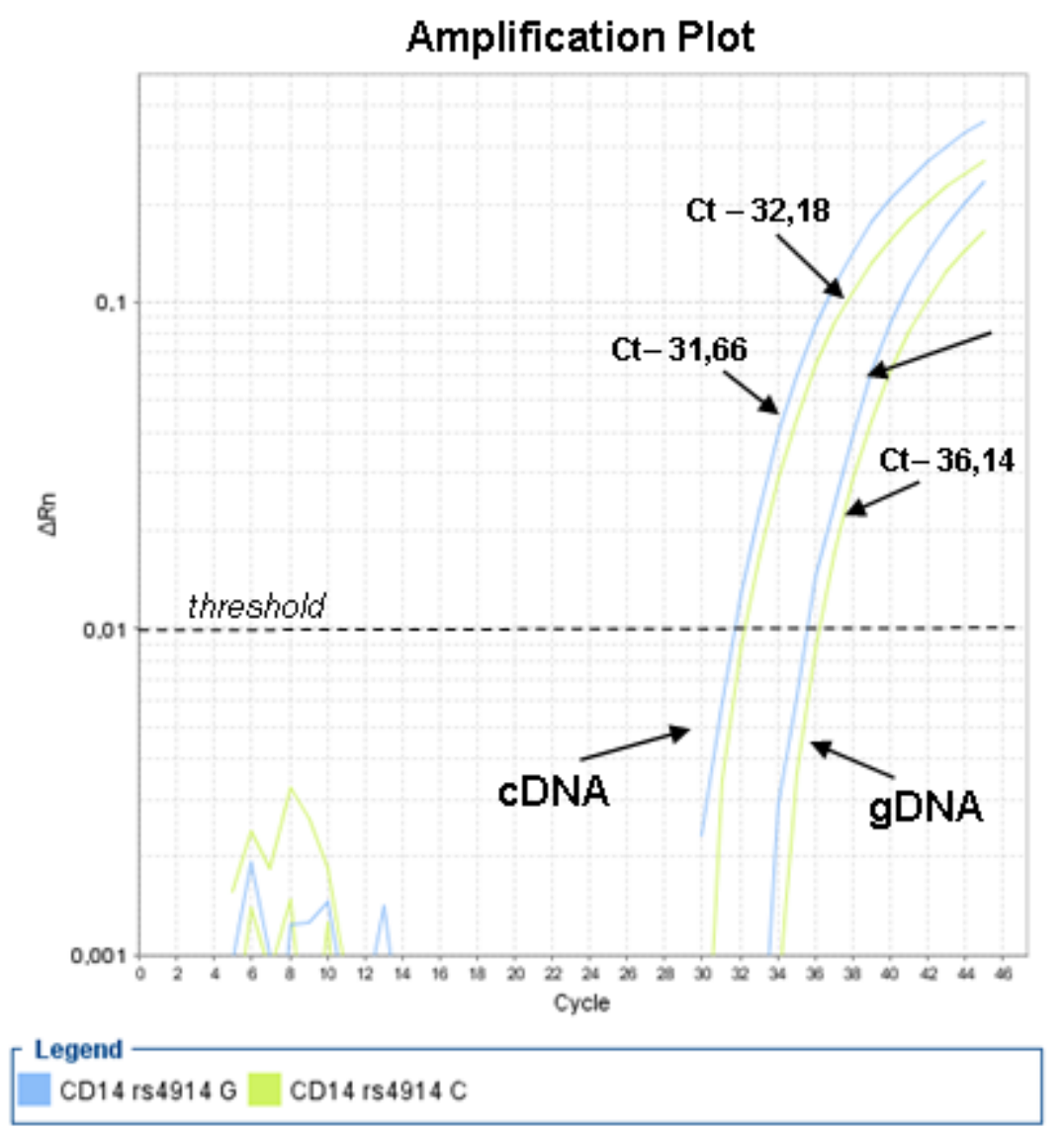

Abb. 3.14: Expression der Allele des SNPs CD14 rs4914 in cDNA- und gDNA-Proben

Um allelische Expression in verschiedenen Proben miteinander vergleichen zu können, wurden für jede Probe das Verhältnis zwischen den Expressionsraten der einzelnen Allele errechnet (Ratio rs4914 C/G $=2^{- \text {(Ct Allel C }-\mathrm{Ct}}$ Allel G) $)$. In diesem Beispiel, weist die cDNA-Probe das Verhältnis rs $4914 \mathrm{C} / \mathrm{G}=2^{-(32,18-31,66)}=2^{-0,52}=0,70$ auf. In der gDNA-Probe von derselben Testperson ergibt sich ein Verhältnis von rs4914 C/G $=2^{-(36,14-35,51)}=2^{-0,63}=$ 0,65. Die Abweichung vom Wert 1 beim Verhältnis der Expressionsraten der Allele in der gDNA wird auf die unterschiedliche Bindungseffizienz der farbmarkierten Sonden zurückgeführt. Um diese Abweichung bei der Auswertung zu beheben, wird die Ratio für cDNA mit der Ratio für gDNA normiert. In dem angeführten Beispiel ist der Unterschied in Ratios C/G für cDNA und gDNA 0,05. Es bedeutet, dass das C-Allel um $5 \%$ mehr transkribiert wird als das G-Allel. 
Tab. 3.10: Quantifizierung der rs4914-CD14-Transkriptvarianten in PBMC mittels TaqManSonden (für gesunde Probanden)

\begin{tabular}{|c|c|c|c|c|c|}
\hline \multirow{2}{*}{$\begin{array}{l}\text { Gesunde } \\
\text { Probanden }\end{array}$} & \multicolumn{3}{|c|}{ Ratio rs4914 C/G } & \multicolumn{2}{|c|}{ Haplogenotyp* } \\
\hline & gDNA & cDNA & $\begin{array}{l}\Delta \text { (Ratio für cDNA - } \\
\text { Ratio für gDNA) }{ }^{\star *}\end{array}$ & Haplotyp* & Haplotyp* \\
\hline$\# 1$ & 0,60 & 0,69 & 0,09 & C-C-G-T & C-T-C-ㅡ \\
\hline$\# 2$ & 0,61 & 0,60 & $-0,01$ & C-C-G-T & C-T-C-ㅡ \\
\hline \#3 & 0,65 & 0,68 & 0,03 & C-C-G-T & C-T-C-ㅡ \\
\hline$\# 4$ & 0,75 & 0,82 & 0,07 & C-C- $\underline{G}-\mathrm{T}$ & C-T- $\underline{-}-\mathrm{G}$ \\
\hline$\# 5$ & 0,74 & 0,72 & $-0,02$ & C-C- $\underline{G}-T$ & C-T- $\underline{-}-\mathrm{G}$ \\
\hline \#6 & 0,67 & 0,73 & 0,06 & C-C-G-T & C-T-C-G \\
\hline$\# 7$ & 1,44 & 0,51 & $-0,93$ & C-C-G-T & C-T- $\underline{C}-\mathrm{G}$ \\
\hline$\# 8$ & 0,71 & 0,69 & $-0,02$ & C-C-G-T & C-C- $\underline{C}-\mathrm{T}$ \\
\hline$\# 9$ & 0,80 & 0,80 & 0 & C-C-G-T & T-C- $\underline{C}-\mathrm{G}$ \\
\hline
\end{tabular}

${ }^{*}$ rs5744455-rs2569190-rs4914-rs2563298

** positives $\Delta$-Wert - Überexpression des rs4914-C-Allels bzw. rs2569190-T-Allels negatives $\Delta$-Wert - Überexpression des rs4914-G-Allels bzw. rs2569190-C-Allels

Tab. 3.11: Quantifizierung der rs4914-CD14-Transkriptvarianten in PBMC mittels TaqManSonden (für Patienten mit chronischer Hepatitis C)

\begin{tabular}{|c|c|c|c|c|c|}
\hline \multirow{2}{*}{$\begin{array}{c}\text { Patienten mit } \\
\text { Hepatitis C }\end{array}$} & \multicolumn{3}{|c|}{ Ratio rs4914 C/G } & \multicolumn{2}{|c|}{ Haplogenotyp* } \\
\hline & gDNA & cDNA & $\begin{array}{c}\Delta \text { (Ratio für cDNA - } \\
\text { Ratio für gDNA })^{* *}\end{array}$ & Haplotyp* & Haplotyp* \\
\hline \#1 & 0,71 & 0,80 & 0,09 & C-C- $\underline{G}-\mathrm{T}$ & C-T- $\underline{C}-\mathrm{G}$ \\
\hline \#2 & 0,60 & 0,64 & 0,04 & C-C-G-T & C-T-C- $-\mathrm{G}$ \\
\hline \#3 & 0,71 & 1,59 & 0,88 & C-C-G-T & C-T-C- $-\mathrm{G}$ \\
\hline$\# 4$ & 0,63 & 0,67 & 0,04 & C-C-G-T & T-C-C- $-\mathrm{G}$ \\
\hline$\# 5$ & 0,66 & 0,72 & 0,06 & C-C- $\underline{G}-T$ & T-C- $\underline{C}-\mathrm{G}$ \\
\hline \#6 & 0,73 & 0,73 & 0 & C-C-G-T & T-C- $\underline{C}-\mathrm{G}$ \\
\hline$\# 7$ & 0,74 & 0,93 & 0,19 & C-C-G-T & T-C-C- $-\mathrm{G}$ \\
\hline
\end{tabular}

* rs5744455-rs2569190-rs4914-rs2563298

** positives $\Delta$-Wert - Überexpression des rs4914-C-Allels bzw. rs2569190-T-Allels negatives $\Delta$-Wert - Überexpression des rs4914-G-Allels bzw. rs2569190-C-Allels 
Bei gesunden Probanden sind nur relativ kleine Unterschiede zwischen Expressionsraten der Allele zu sehen, die sich von denen der Kontrollen nicht unterscheiden. Es ist nur bei dem Proband \#7 eine etwas stärkere allelische Überexpression zu beobachten - C-Allel des SNPs rs 2569190 wird um 93 \% stärker transkribiert als das T-Allel an derselben Position (Tab. 3.10). Bei Patienten sehen die Fälle und die Kontrolle in diesem Zusammenhang auch ähnlich aus. Nur bei der Probe \#3 zeigt sich eine stärkere Überexpression des T-Allels von rs2569190 um $88 \%$ (Tab. 3.11).

\subsubsection{ASTQ mittels RFLP}

Für die Analyse der ASTQ mit RFLP wurden Expressionswerte der Allelvarianten prozentual ausgedrückt. Im Anschluß wurden Verhältnisse (Ratios) zwischen Werten der beiden Allele gerechnet und für jede Probe Ratio für cDNA mit der Ratio für entsprechende gDNA normiert.

Tab. 3.12: Quantifizierung der rs4914-CD14-Transkriptvarianten in PBMC mittels RFLP (für gesunde Probanden)

\begin{tabular}{|c|c|c|c|c|c|}
\hline \multirow{2}{*}{$\begin{array}{c}\text { Gesunde } \\
\text { Probanden }\end{array}$} & \multicolumn{3}{|c|}{ Ratio rs4914 C/G } & \multicolumn{2}{|c|}{ Haplogenotyp* } \\
\hline & gDNA & cDNA & $\begin{array}{l}\Delta \text { (Ratio für cDNA - } \\
\text { Ratio für gDNA)** }\end{array}$ & Haplotyp* & Haplotyp* \\
\hline \#1 & 1,00 & 1,00 & 0,00 & C-C- $\underline{G}-T$ & C-T- $\underline{C}-\mathrm{G}$ \\
\hline \#2 & 0,98 & 1,04 & 0,06 & C-C-G-G & C-T-C- $-\mathrm{G}$ \\
\hline$\# 3$ & 0,94 & 0,96 & 0,02 & C-C-G-T & C-T-C-C-G \\
\hline$\# 4$ & 1,03 & 1,11 & 0,08 & C-C-G- $-T$ & C-T- $\underline{-}-\mathrm{G}$ \\
\hline \#5 & 1,13 & 1,00 & $-0,13$ & C-C-G-G & C-T-C- $-\mathrm{G}$ \\
\hline \#6 & 1,02 & 1,02 & 0,00 & C-C-G-T & C-T-C-C-G \\
\hline$\# 7$ & 1,00 & 0,80 & $-0,20$ & C-C-G-T & C-T-C- $-\mathrm{G}$ \\
\hline$\# 8$ & 1,00 & 1,08 & 0,08 & C-C- $\underline{G}-\mathrm{T}$ & C-C- $\underline{C}-\mathrm{T}$ \\
\hline$\# 9$ & 1,04 & 1,04 & 0,00 & C-C-G-T & $\mathrm{T}-\mathrm{C}-\underline{\mathrm{C}}-\mathrm{G}$ \\
\hline
\end{tabular}

*rs5744455-rs2569190-rs4914-rs2563298

** positives $\Delta$-Wert - Überexpression des rs4914-C-Allels bzw. rs2569190-T-Allels negatives $\Delta$-Wert - Überexpression des rs4914-G-Allels bzw. rs2569190-C-Allels 
Tab. 3.13: Quantifizierung der rs4914-CD14-Transkriptvarianten in PBMC mittels RFLP (für Patienten mit chronischer Hepatitis C)

\begin{tabular}{|c|c|c|c|c|c|}
\hline \multirow{2}{*}{$\begin{array}{c}\text { Patienten mit } \\
\text { Hepatitis C }\end{array}$} & \multicolumn{3}{|c|}{ Ratio rs4914 C/G } & \multicolumn{2}{|c|}{ Haplogenotyp* } \\
\hline & gDNA & cDNA & $\begin{array}{l}\Delta \text { (Ratio für cDNA - } \\
\text { Ratio für gDNA })^{* *}\end{array}$ & Haplotyp* & Haplotyp* \\
\hline$\# 1$ & 1,01 & 1,25 & 0,24 & C-C- $\underline{G}-\mathrm{T}$ & C-T- $\underline{-}-\mathrm{G}$ \\
\hline \#2 & 1,02 & 1,00 & $-0,02$ & C-C-G-T & C-T-C-ㅡ \\
\hline$\# 3$ & 1,05 & 1,90 & 0,85 & C-C-G-T & C-T- $\underline{C}-\mathrm{G}$ \\
\hline$\# 4$ & 1,07 & 1,00 & $-0,07$ & C-C-G-T & T-C- $\underline{C}-\mathrm{G}$ \\
\hline$\# 5$ & 0,97 & 0,97 & 0,00 & C-C-G-T & T-C- $\underline{-}-\mathrm{G}$ \\
\hline \#6 & 1,08 & 1,09 & 0,01 & C-C-G-T & T-C- $\underline{C}-\mathrm{G}$ \\
\hline$\# 7$ & 1,02 & 1,21 & 0,19 & C-C-G-T & T-C-C- $-\mathrm{G}$ \\
\hline
\end{tabular}

* rs5744455-rs2569190-rs4914-rs2563298

** positives $\Delta$-Wert - Überexpression des rs4914-C-Allels bzw. rs2569190-T-Allels negatives $\Delta$-Wert - Überexpression des rs4914-G-Allels bzw. rs2569190-C-Allels

Ähnlich, wie bei ASTQ mit Sonden (s. oben), zeigt sich bei gesunden Probanden meistens nur eine geringfügige allelische Überexpression. Bei Proben \#5 (um 13 \%) und \#7 (um $20 \%$ ) ist relativ größere Überexpression von Allel C des SNPs 2569190 zu beobachten (Tab. 3.12). Bei Patienten, auch wie bei ASTQ mit Sonden, ist eine Überexpression von Allel T des SNPs rs2569190 bei der Probe \#3 zu sehen (um 85 \%). Ansonsten sind die Unterschiede bei Fällen und Kontrollen ziemlich ähnlich (Tab. 3.13).

\subsubsection{Allelische Expression des CD14-Gens in der Leber}

Um zu überprüfen, ob die untersuchten Polymorphismen auf die allelische Expression des CD14-Gens in der Leber Einfluss nehmen, wurde ASTQ auch in Lebergewebeproben durchgeführt. Da, wie bei PBMC, auch in der Leber nur die Transkriptvariante 2 des CD14Gens nachgewiesen werden konnte, musste auch hier auf den SNP rs4914 als Surrogat zurückgegriffen werden. Von den 41 Lebergewebeproben, die zur Verfügung standen, waren 18 heterozygot am SNP rs2569190 (s. Tab. 3.7), von diesen wiederum 3 zusätzlich am SNP rs4914, so dass eine ASTQ-Analyse in der Leber an Material von insgesamt 3 Patienten vorgenommen werden konnte. Unter den 8 Heterozygoten am SNP rs4914 fanden sich 5 am SNP rs2569190 C-Homozygote. Dieses Material konnte zu Kontrollzwecken eingesetzt 
werden. Die Probanden (sowohl Fälle als auch Kontrollen), sind die gleichen, mit denen auch ASTQ in PBMC durchgeführt wurde.

Tab. 3.14: Quantifizierung der rs4914-CD14-Transkriptvarianten in der Leber mittels TaqMan-Sonden

\begin{tabular}{|c|c|c|c|c|c|}
\hline \multirow{2}{*}{$\begin{array}{l}\text { Patienten mit } \\
\text { Hepatitis C }\end{array}$} & \multicolumn{3}{|c|}{ Ratio rs4914 C/G } & \multicolumn{2}{|c|}{ Haplogenotyp* } \\
\hline & gDNA & cDNA & $\begin{array}{l}\Delta(\text { Ratio für cDNA - } \\
\text { Ratio für gDNA })^{* *}\end{array}$ & Haplotyp* & Haplotyp* \\
\hline$\# 1$ & 0,71 & 0,54 & $-0,17$ & C-C- $\underline{-}-T$ & C-T- $\underline{-}-\mathrm{G}$ \\
\hline \#2 & 0,60 & 0,91 & 0,31 & C-C- $\underline{G}-T$ & C-T-C- $-\mathrm{G}$ \\
\hline \#3 & 0,71 & 0,78 & 0,07 & C-C- $\underline{G}-\mathrm{T}$ & C-T- $\underline{C}-\mathrm{G}$ \\
\hline$\# 4$ & 0,63 & 0,64 & 0,01 & C-C- $\underline{\text { G-T }}$ & T-C- $\underline{C}-\mathrm{G}$ \\
\hline \#5 & 0,66 & 0,63 & $-0,03$ & C-C-G- $-T$ & T-C- $\underline{C}-\mathrm{G}$ \\
\hline \#6 & 0,73 & 0,80 & 0,07 & C-C- $\underline{G}-T$ & T-C- $\underline{C}-\mathrm{G}$ \\
\hline$\# 7$ & 0,74 & 0,70 & $-0,04$ & C-C- $\underline{G}-\mathrm{T}$ & T-C-C- $-\mathrm{G}$ \\
\hline
\end{tabular}

${ }^{*}$ rs5744455-rs2569190-rs4914-rs2563298

** positives $\Delta$-Wert - Überexpression des rs4914-C-Allels bzw. rs2569190-T-Allels negatives $\Delta$-Wert - Überexpression des rs4914-G-Allels bzw. rs2569190-C-Allels

Tab. 3.15: Quantifizierung der rs4914-CD14-Transkriptvarianten in der Leber mittels RFLP

\begin{tabular}{|c|c|c|c|c|c|}
\hline \multirow{2}{*}{$\begin{array}{l}\text { Patienten mit } \\
\text { Hepatitis C }\end{array}$} & \multicolumn{3}{|c|}{ Ratio rs4914 C/G } & \multicolumn{2}{|c|}{ Haplogenotyp* } \\
\hline & gDNA & cDNA & $\begin{array}{c}\Delta \text { (Ratio für cDNA - } \\
\text { Ratio für gDNA) }\end{array}$ & Haplotyp* & Haplotyp* \\
\hline \#1 & 1,01 & 0,82 & $-0,19$ & C-C- $\underline{G}-\mathrm{T}$ & C-T- $\underline{C}-\mathrm{G}$ \\
\hline \#2 & 1,02 & 1,27 & 0,25 & C-C- $\underline{G}-\mathrm{T}$ & C-T- $\underline{C}-\mathrm{G}$ \\
\hline \#3 & 1,05 & 1,06 & 0,01 & C-C- $\underline{G}-\mathrm{T}$ & C-T- $\underline{C}-\mathrm{G}$ \\
\hline$\# 4$ & 1,07 & 0,95 & $-0,12$ & C-C- $\underline{G}-\mathrm{T}$ & T-C- $\underline{C}-\mathrm{G}$ \\
\hline$\# 5$ & 0,97 & 0,93 & $-0,04$ & C-C- $\underline{\text { G-T }}$ & T-C- $\underline{C}-\mathrm{G}$ \\
\hline$\# 6$ & 1,08 & 1,02 & $-0,06$ & C-C- $\underline{G}-\mathrm{T}$ & T-C-C- $-\mathrm{G}$ \\
\hline$\# 7$ & 1,02 & 1,03 & 0,01 & C-C-G-T & T-C-C- $-\mathrm{G}$ \\
\hline
\end{tabular}

${ }^{*}$ rs5744455-rs2569190-rs4914-rs2563298

** positives $\Delta$-Wert - Überexpression des rs4914-C-Allels bzw. rs2569190-T-Allels negatives $\Delta$-Wert - Überexpression des rs4914-G-Allels bzw. rs2569190-C-Allels 
Sowohl bei der Diskriminierung der Transkriptvarianten mittels TaqMan-Sonden als auch mittels RFLP fanden sich in der Probe \#1 mehr C-Allel des SNPs rs2569190 (um 17 bzw. 19 \%) und in der Probe \#2 mehr T-Allel desselben SNPs (um 31 bzw. 25 \%). In der Probe \#3 war das Verhältnis der allelischen Transkriptvarianten zueinander in etwa ausgeglichen (Tab. 3.14-15). Bei den Kontrollen (Tab. 3.14-15, \#4-8) fielen die Unterschiede geringfügiger aus. 


\section{Diskussion}

Die Berichte über eine Assoziation des SNPs rs2569190 mit verschiedenen physiologischen und pathophysiologischen Parametern sind zahlreich und zum großen Teil widersprüchlich (siehe1.4.5 in Einleitung).

Unsere Daten, die keine Assoziation des Genotyps am SNP rs2569190 mit der CD14-mRNAExpression in PBMC und in der Leber bei Patienten mit chronischer Hepatitis C zeigen (Abb. 3.2 Patienten und 3.11 B), sind im Einklang mit den Ergebnissen von Studien, die keine Assoziation zwischen diesem SNP und dem Schweregrad der Leberfibrose bei chronischer Hepatitis C finden (Meiler et al. 2005; Von Hahn et al. 2008; Askar et al. 2009). Auch die Ergebnisse der sCD14-Serumkonzentrationen bei dieser Patientengruppe (Abb. 3.4 B) lassen sich mit denen von Meiler et al. vereinbaren, obwohl wir im Unterschied zu den Autoren bei diesem Parameter keine signifikante Assoziation mit dem Genotyp finden: Es könnte auf die relativ kleinere Anzahl unserer Probanden $(n=40)$ zurückgeführt werden. Meiler et al. haben 97 Patienten mit chronischer HCV-Infektion untersucht, von denen T-Homozygoten $(\mathrm{n}=20)$ höhere sCD14-Serumkonzentrationen zeigen als Patienten mit CT- oder CC-Genotypen ( $\mathrm{n}=$ 77) $(3,7 \pm 0,7 \mu \mathrm{g} / \mathrm{ml} v s 3,5 \pm 0,4 \mu \mathrm{g} / \mathrm{ml})$. Die Daten ergeben einen statistisch signifikanten Unterschied $(\mathrm{p}=0,012)$. Bei uns weisen T-homozygote Patienten $(\mathrm{n}=9)$ im Mittel auch höhere sCD14-Serumkonzentrationen auf als Patienten mit CT- oder CC-Genotypen $(\mathrm{n}=31)$ $(5,42 \pm 1,78 \mu \mathrm{g} / \mathrm{ml}$ vs 5,26 $\pm 2,02 \mu \mathrm{g} / \mathrm{ml})$. Es ist nicht auszuschließen, dass bei höherer Anzahl der Probanden der Unterschied auch bei uns statistische Signifikanz erreichen könnte. Dass wir bei gesunden Probanden keine signifikante Assoziation des rs2569190-Genotyps mit der CD14-mRNA-Expression in PBMC oder mit der Konzentration des sCD14 im Serum gesehen haben (Abb. 3.2 Gesunde und 3.4 A), unterstützt zwar die Studien mit fehlender Assoziation, aber spricht nicht unbedingt gegen die positiven Assoziationen, die zwischen dem SNP rs2569190 und verschiedenen Parametern bestimmter Erkrankungen von anderen Autoren gezeigt worden sind. Bei uns, wie in der Studie von Heesen et al. (2001), geht es um nicht-stimulierte PBMC von gesunden Probanden und nicht um aktivierte Monozyten / Makrophagen im Gewebe, die möglicherweise in einer pathophysiologischen Situation eine Genotyp-assoziierte CD14-mRNA-Expression zeigen könnten. Laut des Konzepts der Wechselwirkung zwischen Genen und Umweltfaktoren (gene-environment interaction) sind die Einflüsse der Gene auf den Phänotyp meistens bedingt, von verschiedenen Umweltfaktoren abhängig (Virta et al. 2008). Selbst in Studien, in denen eine signifikante Assoziation zwischen rs2569190-Genotypen und dem Schweregrad der Lebererkrankung gezeigt werden konnte (Järveläinen et al. 2001; Meiler et al. 2005), galt 
es nur für fortgeschrittene Stadien der Leberfibrose (Zirrhose). Bei niedrigerem Fibrosegrad wurde keine Assoziation gefunden. Meiler et al. berichten außerdem, dass sie bei Personen mit Alkoholmissbrauch ohne Leberzirrhose keinen signifikanten Genotyp-assoziierten Unterschied im Serumspiegel von Aminotransferasen (Enzyme, deren Konzentration im Serum unter anderem auf die Intensität der Leberentzündung hinweist) finden konnten. Diese Tatsache könnte auf folgende Weise erklärt werden: Es ist bekannt, dass bei Lebererkrankungen, insbesondere bei fortgeschrittenen, LPS-Spiegel im Serum erhöht ist (Lin RS et al. 1995; Chan et al. 1997). LPS seinerseits verstärkt die Bindungsaktivität des Transkriptionsfaktors SP-1 in Monozyten (Sakuta et al. 2001). Da der rs2569190 Polymorphismus die Bindungsaktivität von SP-1 beeinflusst, könnte es sein, dass die erhöhte LPS-Serumkonzentration bei fortgeschrittener Lebererkrankung die CD14-Expression insbesondere in T-Allelträgern steigert (Meiler et al. 2005). Hier sei auch das Konzept der genetischen Kanalisation zu erwähnen, laut dessen ein durchgesetzter (kanalisierter) Phänotyp trotz unterschiedlicher genetischer Hintergründe und / oder Umwelteinflüsse unverändert bleibt, bevor die phänotypisch versteckten genetischen Variationen durch ein „dekanalisierendes“ Ereignis freigesetzt werden (Flatt 2005; Gibson 2009).

Die fehlende Signifikanz in der Assoziation zwischen dem SNP rs2569190 und der Konzentration des sCD14 im Serum bei gesunden Probanden, im Gegensatz zu mehreren anderen Studien, könnte ebenfalls durch die geringere Anzahl $(n=42)$ von Probanden bedingt sein. Bei uns, wie auch in anderen Studien, zeigen T-Homozygoten $(\mathrm{n}=5)$ im Mittel höhere sCD14-Serumkonzentrationen als C-Allelträger $(\mathrm{n}=37)(5,28 \pm 1 \mu \mathrm{g} / \mathrm{ml}$ vs $4,58 \pm 1,93$ $\mu \mathrm{g} / \mathrm{ml})$.

Die Tatsache, dass die rs2569190-T-Allelträger im Mittel höhere sCD14-Werte aufweisen und dass die T-Allel-Genvariante mit verschiedenen Parametern von Erkrankungen, die eine Entzündungkomponente beinhalten, assoziiert ist, passt zu der Hypothese, nach der höhere sCD14-Konzentrationen Entzündungreaktionen in Geweben begünstigen (Kitchens und Thompson 2005). Aber gleichzeitig ist zu bemerken, dass selbst in Studien, die eine signifikante Assoziation zwischen dem SNP rs2569190 und der sCD14-Serumkonzentration belegen, die Unterschiede der sCD14-Werte zwischen verschiedenen Genotypgruppen meistens gering sind $(0,2-0,5 \mu \mathrm{g} / \mathrm{ml})$. Möglicherweise sind diese geringen Unterschiede bereits biologisch relevant.

Wir wollten weiterhin mithilfe der Methodik der ASTQ untersuchen, ob das CD14-Gen in Bezug auf den SNP rs2569190 eine Allel-abhängige Expression zeigt. In PBMC von gesunden heterozygoten Probanden haben wir nur geringe Unterschiede in der Menge der 
allelischen Transkriptvarianten beobachtet (bis $\pm \approx 10 \%$, mit Ausnahme eines einzigen Falls), deren Spannweite sich nicht von der bei entsprechenden homozygoten Kontrollen unterscheidet (Tab. 3.10 und 3.12). In PBMC von Patienten mit chronischer Hepatitis $\mathrm{C}$ sind bei 2 Proben von 3 größere Unterschiede in der Menge der allelischen Transkriptvarianten $(\approx 10 / 25$ und $\approx 85 \%$ ) zugunsten der T-Allelgenvariante zu sehen (Tab. 3.11 und 3.13). In 2 Lebergewebeproben von 3 rs2569190-heterozygoten Patienten sind zwar auch relativ beträchtliche Unterschiede in der Menge der allelischen Transkriptvarianten zu beobachten, aber einmal zurückzuführen auf die C-Allel-Genvariante $(\approx 20 \%)$ und andernmal zurückzuführen auf die T-Allel-Genvariante $(\approx 30 / 25 \%$ ) (Tab. 3.14 und 3.15). Die Ergebnisse an Material von gesunden Probanden (praktisch kein Unterschied in der allelischen Expression zwischen rs2569190-Hetero- und -Homozygoten) sind im Einklang mit unseren Daten, die keine signifikante Assoziation des SNPs mit der CD14-Genexpression auf mRNA- und auf Proteinebene zeigen. Die Ergebnisse der stärkeren allelischen Expression der rs2569190-T-Allel-Genvariante in PBMC von Patienten mit chronischer Hepatitis C unterstützen die positive Assoziation des T-Allels mit der sCD14-Serumkonzentration als Expressionsparameter des CD14-Gens, die in der Studie von Meiler et al. gezeigt werden konnte. Die differenten Ergebnisse zur allelischen Expression in PBMC und Lebergewebeproben einzelner Patienten könnten ein Hinweis darauf sein, dass die CD14Genexpression in Patienten mit chronischer Hepatitis C zwar Allel-spezifisch, aber in PBMC und Hepatozyten unterschiedlich reguliert wird (Pan et al. 2000). Außerdem könnte eine allelische Expression weitgehend Kontext-spezifisch sein. Es kann in verschiedenen Geweben, sogar in verschiedenen Teilen eines Gewebes unterschiedlich ausfallen (Wilkins et al. 2007). Unsere Daten, die eine inverse Korrelation (allerdings ohne Signifikanz) zwischen CD14-mRNA-Expressionsdaten in PBMC und in der Leber bei Patienten mit chronischer Hepatitis C zeigen, sprechen auch für eine unterschiedliche Regulation der CD14Genexpression in PBMC und Hepatozyten (siehe 3.5 in Ergebnissen).

Eine Assoziation des SNPs rs2569190 mit den o. g. Phänotypen, z. B. verschiedenen Krankheiten und biologischen Daten, die sich in einem Teil der Studien belegen lässt, könnte einem anderen, mit dem genannten im Kopplungsungleichgewicht stehenden SNP im CD14Gen zugeschrieben werden. Im CD14-Gen und seiner unmittelbaren Nachbarschaft befinden sich drei weitere SNPs mit relevanter Heterozygotie (Mertens et al. 2009). Alle könnten theoretisch die Genexpression beeinflussen (siehe 1.4.1 in Einleitung).

Das C-Allel an der Position rs5744455 (CD14 / C-550T) ist mit höheren sCD14-Werten bei unseren gesunden Probanden assoziiert $(\mathrm{CC}>\mathrm{CT}+\mathrm{TT}, \mathrm{p}=0,0128)$ (Abb. 3.8 A). Diese 
Ergebnisse stimmen mit den Daten von zwei anderen Studien überein: Guerra et al. finden eine signifikante Assoziation des C-Allels an der genannten polymorphen Position mit höheren sCD14-Serumkonzentrationen bei schwangeren Frauen; Die Assoziation des SNPs rs2569190 mit demselben Parameter weist aber eine grenzwertige Signifikanz auf (Guerra et al. 2004). Weiterhin berichtet eine japanische Studie über eine signifikante Assoziation zwischen CC-Genotyp an der polymorphen Position rs5744455 und höheren sCD14-Werten im peripherem Blut von 6-jährigen Kindern und in Blutproben aus der Nabelvene (cord blood specimen) (Inoue et al. 2007). Die Autoren finden keine Assoziation mit dem SNP rs2569190. Bei unseren Patienten mit chronischer Hepatitis C sieht man in Bezug auf den SNP rs5744455 eine entgegengerichtete Tendenz, die allerdings nicht signifikant ist: T-Allel-Träger an der Position rs5744455 haben etwas höhere sCD14-Werte im Vergleich zu C-Homozygoten (Abb. 3.8 B).

Ein weiterer SNP, mit dem sCD14-Serumkonzentration assoziiert zu sein scheint, ist rs2563298. Dieser SNP ist unseres Wissens wenig untersucht. Reijmerink et al. finden eine Assoziation des AA-Genotyps (respektive TT) von diesem SNP mit niedrigerem IgESerumspiegel bei 4-jährigen Kindern, die Umwelttabakrauch ausgesetzt waren, während bei nicht ausgesetzten Kindern das Umgekehrte zu beobachten war (Reijmerink et al. 2007). Da CD14 die Entwicklung der atopischen Reaktionen beeinflussen kann (siehe 1.1.1.6 in Einleitung), wären die Ergebnisse von obengenannter Studie ein Hinweis darauf, dass der SNP rs2563298 auch für die CD14-Genexpression von Bedeutung sein könnte. Bei unseren gesunden Probanden zeigen T-Allelträger vs G-Homozygoten signifikant höhere sCD14Serumspiegel ( $\mathrm{p}=0,0164)$ (Abb. 3.10 A).

Allerdings diese Assoziationen, die einzeln genommen signifikant erscheinen $(\mathrm{p}<0,05)$, büßen ihre Signifikanz nach Bonferroni-Anpassung ein $(\mathrm{p}<0,0125)$.

Es stellt sich die Frage, ob die SNPs, die mit sCD14-Werten stärker assoziiert zu sein scheinen als der SNP rs2569190, ausschlaggebend für die CD14-Genexpression sind. Anhand unserer Daten ist diese Frage eher negativ zu beantworten, da die Probanden (sowohl Gesunde als auch Patienten mit chronischer Hepatitis C), die durch ASTQ untersucht wurden, sind alle (bis auf eine Kontrolle) auch rs2563298-heterozygot und bei denen finden wir meistens nur geringe, und noch dazu zum Teil unterschiedlich gerichtete allelische Überexpression (Tab. 3.10-15). Was den SNP rs5744455 angeht, der bei Gesunden mit der sCD14-Konzentration assoziiert ist, können wir dessen allelische Expression nur anhand eines gesunden Probanden beobachten, der ursprünglich als eine Kontrolle herangezogen wurde. Da sind beide Allele genau gleichermassen exprimiert (Tab. 3.10 und 3.12 \#9). 
Zusammenfassend sprechen unsere Daten dafür, dass der SNP rs2569190 auf die Parameter der CD14-Genexpression (gemessen an CD14-mRNA in PBMC und in der Leber und an der Serumkonzentration des sCD14), wie zu erwarten, nur einen geringen Einfluss ausübt und dieser Einfluss von anderen Faktoren entsprechend dem Konzept der gene-environment interaction moduliert werden kann (Zhang $G$ et al. 2008). Auch die Tatsache, dass die Analyse der CD14-Genexpression im Bezug auf verschiedenen SNPs bei unseren gesunden Probanden und Patienten mit chronischer Hepatitis $\mathrm{C}$ oft entgegengerichtete Tendenzen zeigt, ist noch ein Hinweis darauf, dass Umweltfaktoren (in diesem Fall HCV-Infektion) die Bedeutung der genetischen Polymorphismen aufheben oder verändern können (Virta et al. 2008). Laut unseren Daten sind außerdem die SNPs rs5744455 und rs2563298 häufiger mit der CD14-Genexpression assoziiert als rs2569190 oder rs4914. Wir finden jedoch keinen Hinweis darauf, dass einer der untersuchten 4 SNPs an sich auf die allelische Expression des CD14-Gens Einfluss nimmt. Es wäre trotzdem interessant, die beiden SNPs auf eine Assoziation mit verschiedenen Krankheitsparameterm (darunter auch Lebererkrankungen) zu prüfen. Möglicherweise wären deutlichere Assoziationen zu beobachten als mit dem SNP rs2569190, analog der obengenannten Studie von Inoue et al., in der der CC-Genotyp und das C-Allel an der Position rs5744455, die mit höheren sCD14-Werten assoziiert waren, sich auch mit RSV(Respiratory Syncytial Virus)-Bronchiolitis bei Kleinkindern assoziiert erwiesen haben (Inoue et al. 2007). 


\section{Zusammenfassung}

Assoziationen des SNPs rs2569190 im CD14-Endotoxinrezeptorgen mit dem Risiko für verschiedene Erkrankungen, die mit einer Entzündungskomponente einhergehen, und weitere in-vitro-Experimente mit transfizierten Zelllinien lassen vermuten, dass das T-Allel der polymorphen Position über eine erhöhte transkriptionelle Aktivität CD14-exprimierende Zellen für endogenes oder exogenes LPS sensibilisiert.

Das Ziel der vorliegenden Arbeit bestand darin, die Assoziation des SNPs mit der CD14Genexpressionsrate in frisch isoliertem humanen Material ex vivo zu überprüfen. Als Parameter für die transkriptionelle Aktivität des CD14-Gens wurden die CD14-mRNAMenge in PBMC und die sCD14-Serumkonzentration herangezogen. Als Ausgangsmaterial dienten Blutproben von 42 gesunden Probanden und 42 Patienten mit chronischer Hepatitis C. Des Weiteren standen Lebergewebeproben von 41 chronisch HCV-infizierten Patienten zur Verfügung. Mithilfe der Technik ASTQ sollte herausgefunden werden, ob das CD14-Gen in Bezug auf den SNP rs2569190 Allel-spezifisch exprimiert wird (allelische Imbalanz).

Obwohl T-homozygote Personen im Mittel höhere sCD14-Konzentration im Serum aufweisen, unterscheiden sich die CD14-Expression in PBMC und Leberproben als auch die sCD14-Konzentration im Serum zwischen den rs2569190-Genotypgruppen nicht signifikant, weder bei Gesunden noch bei Patienten mit chronischer Hepatitis C.

Auf der Suche nach einem ggf. anderen, mit in-vivo-CD14-Expressionsparametern assoziierten SNP, wurden weitere SNPs im CD14-Gen mit relevanter Heterozygotie auf die Assoziation geprüft. Zunächst die signifikante Assoziation, die jedoch nach der BonferroniAnpassung ihre Signifikanz verlor, umfasste bei gesunden rs5744455-T-Allelträgern niedrigere sCD14-Serumkonzentrationen im Vergleich zu C-Homozygoten und bei ebenso gesunden rs2563298-T-Allelträgern erhöhte sCD14-Werte im Vergleich zu G-Homozygoten. Was die allelische Expression des CD14-Gens angeht, so sind in PBMC von Gesunden zum größten Teil nur geringe Unterschiede in der Menge der allelischen Transkriptvarianten zu beobachten (bis $\pm 10 \%$ ). In PBMC von rs2569190-heterozygoten Patienten mit chronischer Hepatitis C ist die allelische Expression stärker ausgeprägt und zwar zugunsten des T-Allels, aber eine gewisse allelische Imbalanz ist auch in entsprechenden rs2569190-homozygoten Kontrollen zu sehen. In Leberproben von denselben heterozygoten Patienten überwiegt mal die eine und mal die andere Alleltranskriptvariante. Die Ergebnisse liefern also zwar Hinweise auf eine allelische Imbalanz in der Expression des CD14-Gens in vivo, sie stützen aber nicht die Annahme, dass allein das T-Allel des SNPs rs2569190 eine stärkere transkriptionelle Aktivität vermittelt. Die Allel-spezifische Expression lässt sich auch nicht 
auf eines der Allele an den 3 anderen untersuchten polymorphen Positionen (rs5744455, rs4914, rs2563298) zurückführen. Möglicherweise wird eine allelische Imbalanz nicht nur von den untersuchten SNPs bestimmt, sondern auch von anderen, nicht-genetischen Faktoren. Dies würde einerseits die Eindeutigkeit der Zuordnung des T-Allels mit einer stärkeren transkriptionellen Aktivität bei zellbiologischen Experimenten mit transfizierten Zelllinien (die unter standardisierten Bedingungen durchgeführt werden) und andererseits die Unterschiede bei ex vivo gewonnenem Material erklären. 


\section{Literaturverzeichnis:}

Abbas A und Lichtman A: Basic Immunology: Functions and Disorders of the Immune System. 2-nd Edition; Saunders Elsevier, Philadelphia 2006-2007.

Afonina I, Zivarts M, Kutyavin I, Lukhtanov E, Gamper H und Meyer RB (1997): Efficient priming of PCR with short oligonucleotides conjugated to a minor groove binder. Nucleic Acids Res $\underline{25}$, 2657-2660.

Akira S und Takeda K (2004): Toll-like receptor signalling. Nat Rev Immunol $\underline{4}$, 499-511.

Akira S, Uematsu S und Takeuchi O (2006): Pathogen recognition and innate immunity. Cell $\underline{124}, 783-801$.

Alexopoulou L, Holt AC, Medzhitov R und Flavell RA (2001): Recognition of doublestranded RNA and activation of NF-kappaB by Toll-like receptor 3. Nature $\underline{413}$, 732-738.

Alvarez G (2008): Deviations from Hardy-Weinberg proportions for multiple alleles under viability selection. Genet Res $\underline{90}, 209-216$.

Amar J, Ruidavets JB, Bal dit Sollier C, Bongard V, Boccalon H, Chamontin B, Drouet L und Ferrieres J (2004): CD14 C(-260)T gene polymorphism, circulating soluble CD14 levels and arteriosclerosis. J Hypertens 22, 1523-1528.

Antal-Szalmas P, Strijp JA, Weersink AJ, Verhoef J und Van Kessel KP (1997): Quantitation of surface CD14 on human monocytes and neutrophils. J Leukoc Biol $\underline{61}, 721$ 728.

Armant MA und Fenton MJ (2002): Toll-like receptors: a family of pattern-recognition receptors in mammals. Genome Biol $\underline{3}$, 3011.1-3011.6

Askar E, Ramadori G und Mihm S (2009): Endotoxin Receptor CD14 rs2569190/C-159T Gene Variants and Histological Features in Chronic Hepatitis C Virus Infection. World J Gastroenterol 3, 3884-3890.

Baldini M, Lohman IC, Halonen M, Erickson RP, Holt PG und Martinez FD (1999): A Polymorphism* in the 5' flanking region of the CD14 gene is associated with circulating soluble CD14 levels and with total serum immunoglobulin E. Am J Respir Cell Mol Biol 20, 976-983.

Bartenschlager R, Frese M und Pietschmann T (2004): Novel insights into hepatitis C virus replication and persistence. Adv Virus Res $\underline{63}, 71-180$.

Bataller R und Brenner DA (2005): Liver fibrosis. J Clin Invest 115, 209-218.

Bataller R, North KE und Brenner DA (2003): Genetic polymorphsims and the progression of liver fibrosis: a critical appraisal. Hepatology $\underline{37}, 493-503$.

Bazil V, Horejsi V, Baudys M, Kristofova H, Strominger JL, Kostka W und Hilgert I (1986): Biochemical characterization of a soluble form of the 53-kDa monocyte surface antigen. Eur J Immunol 16, 1583-1589. 
Bazil V, Baudys M, Hilgert I, Stefanova I, Low MG, Zbrozek J und Horejsi V (1989): Structural relationship between the soluble and membrane-bound forms of human monocyte surface glycoprotein CD14. Mol Immunol 26, 657-662.

Bell JK, Mullen GE, Leifer CA, Mazzoni A, Davies DR und Segal DM (2003): Leucinerich repeats and pathogen recognition in Toll-like receptors. Trends Immunol 24, 528-533.

Beutler B und Rietschel ET (2003): Innate immune sensing and its roots: the story of endotoxin. Nat Rev Immunol $\underline{3}, 169-176$.

Beutler B, Jiang Z, Georgel P, Crozat K, Croker B, Rutschmann S, Du X und Hoebe K (2006): Genetic analysis of host resistance: Toll-like receptor signaling and immunity at large. Annu Rev Immunol 24, 353-389.

Botstein D und Risch N (2003): Discovering genotypes underlying human phenotypes: past successes for mendelian disease, future approaches for complex disease. Nat Genet $\underline{33}$, 228237.

Buckland PR (2004): Allel-specific gene expression differences in humans. Hum Mol Genet $\underline{13}, 255-260$.

Bufler P, Stiegler G, Schuchmann M, Hess S, Kruger C, Stelter F, Eckerskorn C, Schutt C und Engelmann H (1995): Soluble lipopolysaccharide receptor (CD14) is released via two different mechanisms from human monocytes and CD14 transfectants. Eur J Immunol $\underline{25}$, 604-610.

Burgmann H, Winkler S, Locker GJ, Presterl E, Laczika K, Staudinger T, Knapp S, Thalhammer F, Wenisch C, Zedwitz-Liebenstein et al. (1996): Increased serum concentration of soluble CD14 is a prognostic marker in gram-positive sepsis. Clin Immunol Immunopathol $\underline{80}, 307-310$.

Campos J, Gonzalez-Quintela A, Quinteiro C, Gude F, Perez LF, Torre JA und Vidal C (2005): The -159C/T polymorphism in the promoter region of the CD14 gene is associated with advanced liver disease and higher serum levels of acute-phase proteins in heavy drinkers. Alcohol Clin Exp Res 29, 1206-1213.

Caradonna L, Mastronardi ML, Magrone T, Cozzolongo R, Cuppone R, Manghisi OG, Caccavo D, Pellegrino NM, Amoroso A, Jirillo E et al. (2002): Biological and clinical significance of endotoxemia in the course of hepatitis C virus infection. Curr Pharm Des $\underline{8}$, 995-1005.

Cardullo RA, Agrawal S, Flores C, Zamecnik PC und Wolf DE (1988): Detection of nucleic acid hybridization by nonradiative fluorescence resonance energy transfer. Proc Natl Acad Sci U S A $\underline{85}$, 8790-8794.

Caroff M, Karibian D, Cavaillon JM und Haeffner-Cavaillon N (2002): Structural and functional analyses of bacterial lipopolysaccharides. Microbes Infect $\underline{4}, 915-926$.

Chan CC, Hwang SJ, Lee FY, Wang SS, Chang FY, Li CP, Chu CJ, Lu RH und Lee SD (1997): Prognostic value of plasma endotoxin levels in patients with cirrhosis. Scand J Gastroenterol $\underline{32}, 942-946$. 
Chen SL und Morgan TR (2006): The Natural History of Hepatitis C Virus (HCV) Infection Int J Med Sci 3, 47-52.

Choo QL, Kuo G, Weiner AJ, Overby LR, Bradley DW und Houghton M (1989): Isolation of a cDNA clone derived from a blood-borne non-A, non-B viral hepatitis genome. Science 244, 359-362.

Cleveland MG, Gorham JD, Murphy TL, Tuomanen E und Murphy KM (1996): Lipoteichoic acid preparations of gram-positive bacteria induce interleukin-12 through a CD14-dependent pathway. Infect Immun $\underline{64}$, 1906-1912.

Diebold SS, Kaisho T, Hemmi H, Akira S und Reis e Sousa C (2004): Innate antiviral responses by means of TLR7-mediated recognition of single-stranded RNA. Science $\underline{303}$, 1529-1531.

Dunne A und O'Neill LA (2005): Adaptor usage and Toll-like receptor signaling specificity. FEBS Lett $\underline{579}$, 3330-3335.

Enomoto N, Ikejima K, Bradford B, Rivera C, Kono H, Brenner DA und Thurman RG (1998): Alcohol causes both tolerance and sensitization of rat Kupffer cells via mechanisms dependent on endotoxin. Gastroenterology 115, 443-451.

Enomoto N, Ikejima K, Yamashina S, Hirose M, Shimizu H, Kitamura T, Takei Y, Sato und Thurman RG (2001 a): Kupffer cell sensitization by alcohol involves increased permeability to gut-derived endotoxin. Alcohol Clin Exp Res 25, 51-54.

Enomoto N, Schemmer P, Ikejima K, Takei Y, Sato N, Brenner DA und Thurman RG $(2001$ b): Long-term alcohol exposure changes sensitivity of rat Kupffer cells to lipopolysaccharide. Alcohol Clin Exp Res 25, 1360-1367.

Ferrero E und Goyert SM (1988): Nucleotide sequence of the gene encoding the monocyte differentiation antigen, CD14. Nucliec Acids Res $\underline{16}, 4173$.

Ferrero E, Hsieh CL, Francke U und Goyert SM (1990): CD14 is a member of the family of leucine-rich proteins and is encoded by a gene syntenic with multiple receptor genes. $\mathrm{J}$ Immunol 145, 331-336.

Flamm SL (2003): Chronic Hepatitis C Virus Infection. JAMA 289, 2413-2417.

Flatt T (2005): The evolutionary genetics of canalization. Q Rev Biol 무, 287-316.

Frey EA, Miller DS, Jahr TG, Sundan A, Bazil V, Espevik T, Finlay BB und Wright SD (1992): Soluble CD14 participates in the response of cells to lipopolysaccharide. J Exp Med $\underline{176}, 1665-1671$.

Fukui H, Brauner B, Bode JC und Bode C (1991): Plasma endotoxin concentrations in patients with alcoholic and non-alcoholic liver disease: reevaluation with an improved chromogenic assay. J Hepatol 12, 162-169. 
Gegner JA, Ulevitch RJ und Tobias PS (1995): Lipopolysaccharide (LPS) signal transduction and clearance. Dual roles for LPS binding protein and membrane CD14. J Biol Chem 270, 5320-5325.

Gibson G (2009): Decanalization and the origin of complex disease. Nat Rev Genet 10, 134140.

Gines P, Cardenas A, Arroyo V und Rodes J (2004): Management of cirrhosis and ascites. N Engl J Med 350, 1646-1654.

Gioannini TL, Teghanemt A, Zarember KA und Weiss JP (2003): Regulation of interactions of endotoxin with host cells. J Endotoxin Res $\underline{9}$, 401-408.

Gioannini TL, Teghanemt A, Zhang D, Levis EN und Weiss JP (2005): Monomeric endotoxin:protein complexes are essential for TLR4-dependent cell activation. J Endotoxin Res $\underline{11}, 117-123$.

Gioannini TL und Weiss JP (2007): Regulation of interactions of Gram-negative bacterial endotoxins with mammalian cells. Immunol Res $\underline{39}, 249-260$.

Godowski PJ (2005): A smooth operator for LPS responses. Nat Immunol $\underline{6}$, 544-546.

Gomes I, Collins A, Lonjou C, Thomas NS, Wilkinson J, Watson M und Morton N (1999): Hardy-Weinberg quality control. Ann Hum Genet 63, 535-538.

Griffin JD, Ritz J, Nadler LM und Schlossman SF (1981): Expression of myeloid differentiation antigens on normal and malignant myeloid cells. J Clin Invest $\underline{68}$, 932-941.

Guerra S, Lohman IC, LeVan TD, Wright AL, Martinez FD, Halonen M (2004): The differential effect of genetic variation on soluble CD14 levels in human plasma and milk. Am J Reprod Immunol 52, 204-211.

Guo QS, Xia B, Jiang Y, Morre SA, Cheng L, Li J, Crusius JB und Pena AS (2005): Polymorphisms of CD14 gene and TLR4 gene are not associated with ulcerative colitis in Chinese patients. Postgrad Med J $\underline{81}$, 526-529.

Hailman E, Vasselon T, Kelley M, Busse LA, Hu MC, Lichenstein HS, Detmers PA und Wright SD (1996): Stimulation of macrophages and neutrophils by complexes of lipopolysaccharide and soluble CD14. J Immunol 156, 4384-4390.

Hashimoto C, Hudson KL und Anderson KV (1988): The Toll gene of Drosophila, required for dorsal-ventral embryonic polarity, appears to encode a transmembrane protein. Cell $\underline{52}, 269-279$.

Hayashi F, Smith KD, Ozinsky A, Hawn TR, Yi EC, Goodlett DR, Eng JK, Akira S, Underhill DM und Aderem A (2001): The innate immune response to bacterial flagellin is mediated by Toll-like receptor 5 . Nature $\underline{410}$, 1099-1103.

Hayashi J, Masaka T und Ishikawa I (1999): Increased levels of soluble CD14 in sera of periodontitis patients. Infect Immun $\underline{67}, 417-420$. 
Haziot A, Chen S, Ferrero E, Low MG, Silber R und Goyert SM (1988): The monocyte differentiation antigen, CD14, is anchored to the cell membrane by a phosphatidylinositol linkage. J Immunol 141, 547-552.

Haziot A, Tsuberi BZ und Goyert SM (1993): Neutrophil CD14: biochemical properties and role in the secretion of tumor necrosis factor-alpha in response to lipopolysaccharide. J Immunol 150, 5556-5565.

Hedrick P und Kumar S (2001): Mutation and linkage disequilibrium in human mtDNA. Eur J Hum Genet $\underline{9}$, 969-972.

Heesen M, Blomeke B, Schluter B, Heussen N, Rossaint R und Kunz D (2001): Lack of association between the $-260 \mathrm{C}-->\mathrm{T}$ promoter polymorphism of the endotoxin receptor CD14 gene and the CD14 density of unstimulated human monocytes and soluble CD14 plasma levels. Intensive Care Med 27, 1770-1775.

Heil F, Hemmi H, Hochrein H, Ampenberger F, Kirschning C, Akira S, Lipford G, Wagner H und Bauer S (2004): Species-Specific Recognition of Single-Stranded RNA via Toll-like Receptor 7 and 8. Science 303, 1526-1529.

Hemmi H, Takeuchi O, Kawai T, Kaisho T, Sato S, Sanjo H, Matsumoto M, Hoshino K, Wagner H, Takeda K und Akira S (2000): A Toll-like receptor recognizes bacterial DNA. Nature $\underline{408}, 740-745$.

Hetherington CJ, Kingsley PD, Crocicchio F, Zhang P, Rabin MS, Palis J und Zhang DE (1999): Characterization of human endotoxin lipopolysaccharide receptor CD14Expression in transgenic mice. J Immunol 162, 503-509.

Hirsch-Kaufmann M, Schweiger M: Biologie für Mediziner und Naturwissenschaftler. 6. Auflage; Georg Thieme Verlag, Stuttgart 2004.

Holland PM, Abramson RD, Watson R und Gelfand DH (1991): Detection of specific polymerase chain reaction product by utilizing the $5^{\prime} \rightarrow 3^{\prime}$ exonuclease activity of Thermus aquaticus DNA polymerase. Proc Natl Acad Sci U S A $\underline{88}, 7276-7280$.

Hoofnagle JH (2002): Course and outcome of hepatitis C. Hepatology $\underline{36}$, 21-29.

Hornung V, Guenthner-Biller M, Bourquin C, Ablasser A, Schlee M, Uematsu S, Noronha A, Manoharan M, Akira S, de Fougerolles A et al. (2005): Sequence-specific potent induction of IFN-alpha by short interfering RNA in plasmacytoid dendritic cells through TLR7. Nat Med 11, 263-270.

Hubacek JA, Rothe G, Pit'ha J, Skodova Z, Stanek V, Poledne R und Schmitz G (1999): $\mathrm{C}(-260) \rightarrow \mathrm{T}$ polymorphism in the promoter of the CD14 monocyte receptor gene as a risk factor for myocardial infarction. Circulation 99, 3218-3220.

Hural JA, Kwan M, Henkel G, Hock MB und Brown MA (2000): An intron transcriptional enhancer element regulates IL-4 gene locus accessibility in mast cells. J Immunol 165, 3239-3249. 
Inoue Y, Shimojo N, Suzuki Y, Campos Alberto EJ, Yamaide A, Suzuki S, Arima T, Matsuura T, Tomiita M, Aoyagi M et al. (2007): CD14 -550 C/T, which is related to the serum level of soluble CD14, is associated with the development of respiratory syncytial virus bronchiolitis in the Japanese population. J Infect Dis 195, 1618-1624.

International Human Genom Sequencing Consortium (2004): Finishing the euchromatic sequence of the human genome. Nature $\underline{431}, 931-945$.

Ito D, Murata M, Tanahashi N, Sato H, Sonoda A, Saito I, Watanabe K und Fukuuchi Y (2000): Polymorphism in the promoter of lipopolysaccharide receptor CD14 and ischemic cerebrovascular disease. Stroke $\underline{31}, 2661-2664$.

Jarvelainen HA, Orpana A, Perola M, Savolainen VT, Karhunen PJ und Lindros KO (2001): Promoter polymorphism of the CD14 endotoxin receptor gene as a risk factor for alcoholic liver disease. Hepatology $\underline{33}$, 1148-1153.

Jersmann HP (2005): Time to abandon dogma: CD14 is expressed by non-myeloid lineage cells. Immunol Cell Biol $\underline{83}, 462-467$.

Jiang HR, Muckersie E, Robertson M, Xu H, Liversidge J und Forrester JV (2002): Secretion of interleukin-10 or interleukin-12 by LPS-activated dendritic cells is critically dependent on time of stimulus relative to initiation of purified DC culture. J Leukoc Biol $\underline{72}$, 978-985.

Jirillo E, Caccavo D, Magrone T, Piccigallo E, Amati L, Lembo A, Kalis C und Gumenscheimer M (2002): The role of the liver in the response to LPS: experimental and clinical findings. J Endotoxin Res $\underline{8}, 319-327$.

Juffermans N, Verbon A, van Deventer SJH, Buurman WA, van Deutekom H, Speelman P und van der Poll T (1998): Serum concentrations of lipopolysaccharide activity-modulating proteins during tuberculosis.J Infect Dis $\underline{178}, 1839-1842$.

Kabesch M, Hasemann K, Schickinger V, Tzotcheva I, Bohnert A, Carr D, Baldini M, Hackstein H, Leupold W, Weiland SK et al. (2004): A promoter polymorphism in the CD14 gene is associated with elevated levels of soluble CD14 but not with IgE or atopic diseases. Allergy $\underline{59}$, 520-525.

Kaito M, Watanabe S, Tsukiyama-Kohara K, Yamaguchi K, Kobayashi Y, Konishi M, Yokoi M, Ishida S, Suzuki S und Kohara M (1994): Hepatitis C virus particle detected by immunoelectron microscopic study. J Gen Virol 75, 1755-1760.

Karhukorpi J, Yan Y, Niemela S, Valtonen J, Koistinen P, Joensuu T, Saikku P und Karttunen R (2002): Effect of CD14 promoter polymorphism and H. pylori infection and its clinical outcomes on circulating CD14. Clin Exp Immunol 128, 326-332.

Kitchens RL und Thompson PA (2005): Modulatory effects of sCD14 and LBP on LPShost cell interactions. J Endotoxin Res 11, 225-229.

Kitchens RL, Thompson PA, Viriyakosol S, O'Keefe GE und Munford RS (2001): Plasma CD14 decreases monocyte responses to LPS by transferring cell-bound LPS to plasma lipoproteins. J Clin Invest 108, 485-493. 
Kochi Y, Yamada R, Suzuki A, Harley JB, Shirasawa S, Sawada T, Bae SC, Tokuhiro S, Chang X, Sekine A et al. (2005): A functional variant in FCRL3, encoding Fc receptor-like 3 , is associated with rheumatoid arthritis and several autoimmunities. Nat Genet $\underline{37}, 478-485$.

König W, Khuseyinova N, Hoffmann MM, Marz W, Frohlich M, Hoffmeister A, Brenner H und Rothenbacher D (2002): CD14 C(-260)--> T polymorphism, plasma levels of the soluble endotoxin receptor CD14, their association with chronic infections and risk of stable coronary artery disease. J Am Coll Cardiol 40, 34-42.

Krüger C, Schütt C, Obertacke U, Joka T, Müller FE, Knöller J, Köller M, König W, und Schönfeld W (1991): Serum CD14 levels in polytraumatized and severely burned patients. Clin Exp Immunol 85, 297-301.

Kutyavin IV, Afonina IA, Mills A, Gorn VV, Lukhtanov EA, Belousov ES, Singer MJ, Walburger DK, Lokhov SG, Gall AA et al. (2000): 3'-minor groove binder-DNA probes increase sequence specificity at PCR extension temperatures. Nucleic Acids Res $\underline{28}$, 655-661.

Labeta MO, Durieux JJ, Fernandez N, Herrmann R und Ferrara P (1993): Release from a human monocyte-like cell line of two different soluble forms of the lipopolysaccharide receptor, CD14. Eur J Immunol 23, 2144-2151.

Lamping N, Dettmer R, Schroder NW, Pfeil D, Hallatschek W, Burger R und Schumann RR (1998): LPS-binding protein protects mice from septic shock caused by LPS or gramnegative bacteria. J Clin Invest 101, 2065-2071.

Lander ES, Linton LM, Birren B, Nusbaum C, Zody MC, Baldwin J, Devon K, Dewar K, Doyle M, FitzHugh W et al. (2001): Initial sequencing and analysis of the human genome. Nature $\underline{409}, 860-921$.

Landmann R, Zimmerli W, Sansano S, Link S, Hahn A, Glauser MP und Calandra T (1995): Increased circulating soluble CD14 is associated with high mortality in gram-negative septic shock. J Infect Dis 171, 639-644.

Landmann R, Reber AM, Sansano S und Zimmerli W (1996): Function of soluble CD14 in serum from patients with septic shock. J Infect Dis $\underline{173}$, 661-668.

Lee LG, Connell CR und Bloch W (1993): Allelic discrimination by nick-translation PCR with fluorgenic probes. Nucl. Acids Res. 21, 3761-3766.

Lemaitre B, Nicolas E, Michaut L, Reichhart JM und Hoffmann JA (1996): The dorsoventral regulatory gene cassette spatzle/Toll/cactus controls the potent antifungal response in Drosophila adults. Cell $\underline{86}, 973-983$.

LeVan TD, Bloom JW, Bailey TJ, Karp CL, Halonen M, Martinez FD und Vercelli D (2001): A common single nucleotide polymorphism in the CD14 promoter decreases the affinity of Sp protein binding and enhances transcriptional activity. J Immunol 167, 58385844.

Liang XH, Cheung W, Heng CK, Liu JJ, Li CW, Lim B und Wang DY (2006): CD14 promoter polymorphisms have no functional significance and are not associated with atopic phenotypes. Pharmacogenet Genomics 16, 229-236. 
Lin B, Noring R, Steere A, Klempner M und Hu L (2000): Soluble CD14 levels in the serum, synovial fluid, and cerebrospinal fluid of patients with various stages of Lyme disease. J Infect Dis $181,1185-1188$.

Lin RS, Lee FY, Lee SD, Tsai YT, Lin HC, Lu RH, Hsu WC, Huang CC, Wang SS und Lo KJ (1995): Endotoxemia in patients with chronic liver diseases: relationship to severity of liver diseases, presence of esophageal varices, and hyperdynamic circulation. J Hepatol $\underline{22}$, $165-172$.

Macatonia SE, Hosken NA, Litton M, Vieira P, Hsieh CS, Culpepper JA, Wysocka M, Trinchieri G, Murphy KM und O'Garra A (1995): Dendritic cells produce IL-12 and direct the development of Th1 cells from naive CD4+ T cells. J Immunol $\underline{154}$, 5071-5079.

Mansur A: Überprüfung der Funktionalität des genetischen Polymorphismus rs2569190/T159C im CD14-Gen mittels Allel-spezifischer Transkript-Quantifizierung bei gesunden Probanden und bei Patienten mit chronischer Hepatitis-C-Virus-Infektion. Med. Diss. Göttingen 2008.

Maouzi A: Assoziationen genetischer Polymorphismen in Genen, deren Produkte die angeborene Immunität vermitteln, mit klinischen und viralen Parametern einer Hepatitis-Cvirus-Infektion. Med. Diss. Göttingen 2007.

Martinez FD (2007): CD14, Endotoxin, and asthma risk. proc Am Thorac Soc 4, 221-225.

Mayo O (2008): A century of Hardy-Weinberg equilibrium. Twin Res Hum Genet $\underline{11}$, 249256.

Medzhitov R und Janeway C, Jr. (2000 a): Innate immune recognition: mechanisms and pathways. Immunol Rev 173, 89-97.

Medzhitov R und Janeway C, Jr. (2000 b): Innate immunity. N Engl J Med 년, 338-344.

Medzhitov R, Preston-Hurlburt P und Janeway CA, Jr. (1997): A human homologue of the Drosophila Toll protein signals activation of adaptive immunity. Nature $\underline{388}, 394-397$.

Meiler C, Muhlbauer M, Johann M, Hartmann A, Schnabl B, Wodarz N, Schmitz G, Scholmerich J und Hellerbrand C (2005): Different effects of a CD14 gene polymorphism on disease outcome in patients with alcoholic liver disease and chronic hepatitis $\mathrm{C}$ infection. World J Gastroenterol 11, 6031-6037.

Mertens J, Bregadze R, Mansur A, Askar E, Bickeböller H, Ramadori G und Mihm S (2009): Functional impact of endotoxin receptor CD14 polymorphism on transcriptional activity. J Mol Med 87, 815-824.

Mottagui-Tabar S, Faghihi MA, Mizuno Y, Engstrom PG, Lenhard B, Wasserman WW und Wahlestedt C (2005): Identification of functional SNPs in the 5-prime flanking sequences of human genes. BMC Genomics $\underline{6}, 18$.

Nishimura M und Naito S (2005): Tissue-specific mRNA expression profiles of human toll like receptors and related genes. Biol Pharm Bull $\underline{28}$, 886-892. 
Nolan JP (1975): The role of endotoxin in liver injury. Gastroenterology $\underline{69}$, 1346-1356.

Obana N, Takahashi S, Kinouchi Y, Negoro K, Takagi S, Hiwatashi N und Shimosegawa T (2002): Ulcerative colitis is associated with a promoter polymorphism of lipopolysaccharide receptor gene, CD14. Scand J Gastroenterol 37, 699-704.

Pan Z, Zhou L, Hetherington CJ und Zhang DE (2000): Hepatocytes contribute to soluble CD14 production, and CD14-Expression is differentially regulated in hepatocytes and monocytes. J Biol Chem 275, 36430-36435.

Poltorak A, Smirnova I, He X, Liu MY, Van Huffel C, McNally O, Birdwell D, Alejos E, Silva M, Du X et al. (1998 a): Genetic and physical mapping of the Lps locus: identification of the toll-4 receptor as a candidate gene in the critical region. Blood Cells Mol Dis 24, 340355.

Poltorak A, He X, Smirnova I, Liu MY, Van Huffel C, Du X, Birdwell D, Alejos E, Silva M, Galanos C, Freudenberg M, Ricciardi-Castagnoli P, Layton B und Beutler B (1998 b): Defective LPS signaling in $\mathrm{C} 3 \mathrm{H} / \mathrm{HeJ}$ and $\mathrm{C} 57 \mathrm{BL} / 10 \mathrm{ScCr}$ mice: mutations in $\mathrm{Tlr} 4$ gene. Science 282, 2085-2088.

Pugin J, Schurer-Maly CC, Leturcq D, Moriarty A, Ulevitch RJ und Tobias PS (1993): Lipopolysaccharide activation of human endothelial and epithelial cells is mediated by lipopolysaccharide-binding protein and soluble CD14. Proc Natl Acad Sci U S A 90, 27442748.

Pugin J, Heumann ID, Tomasz A, Kravchenko VV, Akamatsu Y, Nishijima M, Glauser MP, Tobias PS und Ulevitch RJ (1994): CD14 is a pattern recognition receptor. Immunity $\underline{1}, 509-516$.

Radun D: Epidemiologie von Hepatitis C in Deutschland. Robert Koch-Institut, Berlin 2007.

Reijmerink N, Bottema R, Kerkhof M, Gerritsen J, Stelma F, Thijs C, van Schayck C, Smit H, Brunekreef B, Postma D und Koppelman G (2007): CD14 polymorphisms modify early life IgE levels in interaction with environmental tobacco smoke and dog exposure. Thematic Poster Session 355: Epidemiology, genetics, risk assessment for asthma and morbidity - new associations and findigs. September 2007, Poster No. 3656

(http://www.ersnet.org/learning_resources_player/abstract_print_07/files/355.pdf.).

Repo H, Anttonen K, Kilpinen SK, Palotie A, Salven P, Orpana A und Leirisalo-Repo M (2002): CD14 and TNF- $\alpha$ promoter polymorphisms in patients with acute arthritis. Special reference to development of chronic spondyloarthropathy. Scand J Rheumatol 31, 355-361.

Rietschel ET, Kirikae T, Schade FU, Mamat U, Schmidt G, Loppnow H, Ulmer AJ, Zahringer U, Seydel U, Di Padova F und et al. (1994): Bacterial endotoxin: molecular relationships of structure to activity and function. FASEB J $\underline{8}, 217-225$.

Risch NJ (2000): Searching for genetic determinants in the new millennium. Nature $\underline{405}$, 847-856. 
Robertson B, Myers G, Howard C, Brettin T, Bukh J, Gaschen B, Gojobori T, Maertens G, Mizokami M, Nainan O et al. (1998): Classification, nomenclature, and database development for hepatitis $\mathrm{C}$ virus (HCV) and related viruses: proposals for standardization. International Committee on Virus Taxonomy. Arch Virol 143, 2493-2503.

Rock FL, Hardiman G, Timans JC, Kastelein RA und Bazan JF (1998): A family of human receptors structurally related to Drosophila Toll. Proc Natl Acad Sci U S A 95, 588593.

Romagnani S (1992): Induction of TH1 and TH2 responses: a key role for the 'natural' immune response? Immunol Today $\underline{13}, 379-381$.

Saile B und Ramadori G (2007): Inflammation, damage repair and liver fibrosis--role of cytokines and different cell types. Z Gastroenterol $\underline{45}$, 77-86.

Sakuta T, Matsushita K, Yamaguchi N, Oyama T, Motani R, Koga T, Nagaoka S, Abeyama K, Maruyama I, Takada H et al. (2001): Enhanced production of vascular endothelial growth factor by human monocytic cells stimulated with endotoxin through transcription factor SP-1. J Med Microbiol 50, 233-237.

Schreier E und Höhne M (2001): Hepatitis C - Epidemiologie und Prävention. Bundesgesundheitsblatt - Gesundheitsforschung - Gesundheitsschutz 44, 554-561.

Schwabe RF, Seki E und Brenner DA (2006): Toll-like receptor signaling in the liver. Gastroenterology 130, 1886-1900.

Seki E und Brenner DA (2008): Toll-like receptors and adaptor molecules in liver disease: update. Hepatology $\underline{48}, 322-335$.

Setoguchi M, Nasu N, Yoshida S, Higuchi Y, Akizuki S und Yamamoto S (1989): Mouse and human CD14 (myeloid cell-specific leucine-rich glycoprotein) primary structure deduced from cDNA clones. Biochim Biophys Acta 1008, 213-222.

Shakhov AN, Collart MA, Vassalli P, Nedospasov SA und Jongeneel CV (1990): Kappa B-type enhancers are involved in lipopolysaccharide-mediated transcriptional activation of the tumor necrosis factor alpha gene in primary macrophages. J Exp Med 171, 35-47.

Sharp PM, Averof M, Lloyd AT, Matassi G und Peden JF (1995): DNA sequence evolution: the sounds of silence. Philos Trans R Soc Lond B Biol Sci 349, 241-247.

Shepard CW, Finelli L und Alter MJ (2005): Global epidemiology of hepatitis C virus infection. Lancet Infect Dis $\underline{5}, 558-567$.

Simmonds P, Bukh J, Combet C, Deleage G, Enomoto N, Feinstone S, Halfon P, Inchauspe G, Kuiken C, Maertens G et al. (2005): Consensus proposals for a unified system of nomenclature of hepatitis $\mathrm{C}$ virus genotypes. Hepatology $\underline{42}$, 962-973.

Simmons DL, Tan S, Tenen DG, Nicholson-Weller A und Seed B (1989): Monocyte Antigen CD14 is a phospholipid anchored membrane protein. Blood $\underline{73}$, 284-289. 
Simpson A, John SL, Jury F, Niven R, Woodcock A, Ollier WE und Custovic A (2006): Endotoxin exposure, CD14, and allergic disease: an interaction between genes and the environment. Am J Respir Crit Care Med 174, 386-392.

Strachan T und Read AP: Molekulare Humangenetik. 3. Auflage; Elsevier GmbH, Münschen, 2005.

Su GS, Dorko K, Strom SC, Nüssler AK und Wang SC (1999): CD14-Expression and production by human hepatocytes. J Hepatol $\underline{31}$, 435-442.

Szabo G, Dolganiuc A und Mandrekar P (2006): Pattern recognition receptors: a contemporary view on liver diseases. Hepatology $\underline{44}$, 287-298.

Tabor HK, Risch NJ und Myers RM (2002): Candidate-gene approaches for studying complex genetic traits: practical considerations. Nat Rev Genet $\underline{3}$, 391-397.

Takeda K und Akira S (2005): Toll-like receptors in innate immunity. Int Immunol 17, 114.

Takeshita S, Nakatani K, Tsujimoto H, Kawamura Y, Kawase H und Sekine I (2000): Increased levels of circulating soluble CD14 in Kawasaki disease. Clin Exp Immunol 119, $376-381$.

Teo YY, Fry AE, Clark TG, Tai ES und Seielstad M (2007): On the usage of HWE for identifying genotyping errors. Ann Hum Genet 71, 701-703.

Thomas CJ, Kapoor M, Sharma S, Bausinger H, Zyilan U, Lipsker D, Hanau D und Surolia A (2002): Evidence of a trimolecular complex involving LPS, LPS binding protein and soluble CD14 as an effector of LPS response. FEBS Lett 531, 184-188.

Thompson PA, Tobias PS, Viriyakosol S, Kirkland TN und Kitchens RL (2003): Lipopolysaccharide (LPS)-binding protein inhibits responses to cell-bound LPS. J Biol Chem $\underline{278}, 28367-28371$.

Thurman RG (1998): Mechanisms of hepatic toxicity. II. Alcoholic liver injury involves activation of Kupffer cells by endotoxin. Am J Physiol Gastrointest Liver Physiol 275, 605611.

Tukiainen E, Kylanpaa ML, Puolakkainen P, Kemppainen E, Halonen K, Orpana A, Methuen T, Salaspuro M, Haapiainen R und Repo H (2008): Polymorphisms of the TNF, CD14, and HSPA1B genes in patients with acute alcohol-induced pancreatitis. Pancreas $\underline{37}$, 56-61.

Ulevitch RJ und Tobias PS (1995): Receptor-dependent mechanisms of cell stimulation by bacterial endotoxin. Annu Rev Immunol 13, 437-457.

Unkelbach K, Gardemann A, Kostrzewa M, Philipp M, Tillmanns H und Haberbosch W (1999): A new promoter polymorphism in the gene of lipopolysaccharide receptor CD14 is associated with expired myocardial infarction in patients with low atherosclerotic risk profile. Arterioscler Thromb Vasc Biol 19, 932-938. 
Venter JC, Adams MD, Myers EW, Li PW, Mural RJ, Sutton GG, Smith HO, Yandell M, Evans CA, Holt RA et al. (2001): The sequence of the human genome. Science 291, 1304-1351.

Vercelli D (2002): The functional genomics of CD14 and its role in IgE responses: an integrated view. J Allergy Clin Immunol $\underline{109}$, 14-21.

Vidal K und Donnet-Hughes A: CD14: A Soluble Pattern Recognition Receptor in Milk; in: Advances in Experimental Medicine and Biology; hrsg. v. Bösze S; Springer, Secaucus, NJ, 2008, 195-214.

Virta M, Pessi T, Helminen M, Seiskari T, Kondrashova A, Knip M, Hyoty H und Hurme M (2008): Interaction between CD14-159C $>$ T polymorphism and Helicobacter pylori is associated with serum total immunoglobulin E. Clin Exp Allergy 표, 1929-1934.

Von Hahn T, Halangk J, Witt H, Neumann K, Muller T, Puhl G, Neuhaus P, Nickel R, Beuers U, Wiedenmann B et al. (2008): Relevance of endotoxin receptor CD14 and TLR4 gene variants in chronic liver disease. Scand J Gastroenterol $\underline{43}$, 584-592.

Wang DG, Fan JB, Siao CJ, Berno A, Young P, Sapolsky R, Ghandour G, Perkins N, Winchester E, Spencer J et al. (1998): Large-scale identification, mapping, and genotyping of single-nucleotide polymorphisms in the human genome. Science 280, 1077-1082.

Wheeler DL, Barrett T, Benson DA, Bryant SH, Canese K, Chetvernin V, Church DM, DiCuccio M, Edgar R, Federhen S et al. (2007): Database resources of the National Center for Biotechnology Information. Nucleic Acids Res 35, 5-12.

WHO (World Health Organisation) (2009): Hepatitis C. Fact sheet No 164, 2009.

Wilkins JM, Southam L, Price AJ, Mustafa Z, Carr A und Loughlin J (2007): Extreme context specificity in differential allelic expression. Hum Mol Genet $\underline{16}$, 537-546.

Woo JG, Assa'ad A, Heizer AB, Bernstein JA und Hershey GK (2003): The -159 C $\rightarrow$ T polymorphism of CD14 is associated with nonatopic asthma and food allergy. J Allergy Clin Immunol $\underline{112}, 438-444$.

Wright SD, Ramos RA, Tobias PS, Ulevitch RJ und Mathison JC (1990): CD14, a receptor for complexes of lipopolysaccharide (LPS) and LPS binding protein. Science 249, 1431-1433.

Wurfel MM, Kunitake ST, Lichenstein H, Kane JP und Wright SD (1994): Lipopolysaccharide (LPS)-binding protein is carried on lipoproteins and acts as a cofactor in the neutralization of LPS. J Exp Med $\underline{180}$, 1025-1035.

Yamamoto M, Sato S, Hemmi H, Hoshino K, Kaisho T, Sanjo H, Takeuchi O, Sugiyama M, Okabe M, Takeda K et al. (2003a): Role of adaptor TRIF in the MyD88-independent toll-like receptor signaling pathway. Science 301, 640-643.

Yamamoto M, Sato S, Hemmi H, Uematsu S, Hoshino K, Kaisho T, Takeuchi O, Takeda K und Akira S (2003 b): TRAM is specifically involved in the Toll-like receptor 4-mediated MyD88-independent signaling pathway. Nat Immunol $\underline{4}, 1144-1150$. 
Ye S, Dhillon S, Ke X, Collins AR und Day IN (2001): An efficient procedure for genotyping single nucleotide polymorphisms. Nucleic Acids Res $\underline{29}$, E88-8.

Yoshida A und Koide Y (1997): Arabinofuranosyl-terminated and mannosylated lipoarabinomannans from Mycobacterium tuberculosis induce different levels of interleukin12 expression in murine macrophages. Infect Immun $\underline{65}, 1953-1955$.

Zhang DE, Hetherington CJ, Gonzalez DA, Chen HM und Tenen DG (1994 a): Regulation of CD14-Expression during monocytic differentiation induced with $1 \alpha, 25$ dihydroxyvitamin D3. J Immunol 153, 3276-3284.

Zhang DE, Hetherington CJ, Tan S, Dzeinnis SE, Gonzalez DA, Chen HM und Tenen DG (1994 b): Sp1 is a critical factor for the monocytic specific expression of human CD14. J Biol Chem 269, 11425-11434.

Zhang G, Goldblatt J und LeSouef PN (2008): Does the relationship between IgE and the CD14 gene depend on ethnicity? Allergy $\underline{63}, 1411-1417$.

Zhao D, Sun T, Zhang X, Guo Y, Yu D, Yang M, Tan W, Wang G und Lin D (2007): Role of CD14 Promoter Polymorphisms in Helicobacter pylori Infection-Related Gastric Carcinoma. Clin Cancer Res $\underline{13}$, 2362-2368.

Zweigner J, Gramm HJ, Singer OC, Wegscheider K und Schumann RR (2001): High concentrations of lipopolysaccharide-binding protein in serum of patients with severe sepsis or septic shock inhibit the lipopolysaccharide response in human monocytes. Blood $\underline{98}, 3800$ 3808 . 


\section{Danksagung}

Für die Unterstützung beim Erstellen der Doktorarbeit möchte ich mich bei folgenden Personen ganz herzlich bedanken:

Bei Herrn Prof. Dr. med. G. Ramadori kann ich mich kaum genug bedanken: zunächst seine freundliche Unterstützung bei der Bewerbung um ein Forschungsstipendium, dann die Möglichkeit, die Experimente in seiner Abteilung durchzuführen, sein immer offenes Ohr für meine Probleme haben enorm viel zur Fertigstellung der vorliegenden Arbeit beigetragen. Was ich auch immer in meinem weiteren beruflichen Leben leisten mag: ich muss immer an diese Abteilung zurückdenken und ewig dankbar für die exzellenten Chancen und Perspektiven sein, die mir hier gegeben wurden.

Mein ganz besonderer Dank richtet sich an Frau Prof. Dr. rer. nat. S. Mihm, die meine unmittelbare wissenschaftliche Betreuung auf sich genommen hat. Durch ihre Anleitung habe ich im Bereich der Humangenetik und Molekularen Biologie enorm viel dazugelernt. Ihr großes Fachwissen, ihre Erfahrung und ständige Bereitschaft, mir zu helfen, damit ich komplizierte Zusammenhänge sehen und wissenschaftliche Konzepte erfassen konnte, haben das Fertigstellen der vorliegenden Dissertation überhaupt erst ermöglicht. Sogar außerhalb des Rahmens der eigentlichen Arbeit fühlte ich immer ihren Beistand in verschiedenen Situationen und es gab keinen einzigen Fall, wo ich mich mit meinen Fragen oder Problemen an sie wandte, ohne dass sie sich, trotz ihrer großen Arbeitsbelastung, nicht sofort mit vollem Engagement für mich eingesetzt hätte.

Ein herzlicher Dank von mir gilt Frau W. Kopp, die mich gleich an meinem allerersten Tag in der Abteilung nett aufgenommen und dann im Laborleben mit großer Freundlichkeit und viel Geduld eingearbeitet hat. Bei ihrer professionellen technischen Unterstützung in experimentellen Arbeiten waren ihr Mitdenken und ein fast selbstloses Engagement immer selbstverständlich.

Herrn Mag. A. Rosenberger aus der Abteilung Genetische Epidemiologie möchte ich für die professionelle Beratung und weitreichende Unterstützung bei der statistischen Auswertung meiner Arbeit sehr gerne danken. Durch seine Fähigkeit, relevante statistische Fragen in kurzer Zeit gründlich und verständlich zu erklären, hatte ich die Möglichkeit, einen Einblick in statistische Methoden relativ mühelos zu gewinnen und diese auch anzuwenden. Mein 
Interesse für dieses Fach und der Wunsch, mich damit in der Zukunft weiter auseinanderzusetzen, sind dadurch noch größer geworden.

Sehr gerne möchte ich mich auch bei Frau Prof. E. Botsvadze, der Programmleiterin meiner Facharztausbildung in Georgien, bedanken. Neben ihren enormen Verdiensten sowohl in der praktischen Medizin als auch in der Hochschullehre in Georgien (Autorin mehrerer Lehrbücher und Monographien) und neben ihrer internationalen Anerkennung als Gastroenterologe / Hepatologe ist sie durch ihre außerordentliche Fürsorge für die Nachwuchsgeneration in Medizin ausgezeichnet. Sowohl mich als auch meine Kommilitonen hat sie ständig dazu motiviert, neben der praktischen medizinischen Tätigkeit Interesse für wissenschaftliche Arbeit zu entwickeln. Meine Weiterbildungsmöglichkeit in Deutschland hat sie vielseitig unterstützt und sie freut sich aufrichtig über alle meine Erfolge.

Für eine finanzielle Unterstützung bedanke ich mich bei dem Deutschen Akademischen Austauschdienst (DAAD), der mir ein 10-monatiges Forschungsstipendium gewährt hat, um mit einer wissenschaftlichen Arbeit in Deutschland überhaupt anfangen zu können. Ich danke auch herzlich der Georg-August-Universität Göttingen und der Katholischen Hochschulgemeinde (KHG) für finanzielle Beihilfen $\mathrm{zu}$ verschiedenen Zeitpunkten meiner Arbeit.

Das Projekt wurde von der Deutschen Forschungsgemeinschaft gefördert (Förderungsnummer MI 474/1-1). 


\section{Lebenslauf}

Am 3. Februar 1975 wurde ich als Kind von Gulnara Legaschwili und Levan Bregadze in Tbilisi / Georgien geboren.

Von September 1981 bis Juli 1990 busuchte ich die Mittelschule No. 69 in Tbilisi. Ab September 1990 war ich die Schülerin der Mittelschule No. 16 mit erweitertem Unterricht für Naturwissenschaften in Tbilisi, die ich im Juli 1992 mit der Allgemeinen Hochschulreife verließ.

Von September 1992 bis Juli 1999 studierte ich Humanmedizin an der Staatlichen Medizinischen Universität Tbilisi. Im Juli 1999 bestand ich das ärztliche Staatsexamen und die Zertifizierungsprüfung. Darauf erhielt ich das Diplom und Zertifikat der Ärztin der allgemeinen Praxis.

In der Zeit von 1999 bis 2005 absolvierte ich ärztliche Weiterbildungkurse bei der Staatlichen Medizinischen Akademie Tbilisi (innere Medizin, Infektionskrankheiten) sowie längerfristige Praktika in verschiedenen Krankenhäusern in Tbilisi (Sepsisbekämpfungszentrum, Infektionskrankenhaus). Parallel besuchte ich Sprachkurse (Englisch, Deutsch).

Im Januar 2005 nahm ich die dreijährige Facharztausbildung (Residentur) im Bereich der Infektionskrankheiten bei dem Wissenschaftlich-Praktischen Zentrum für Infektionskrankheiten, AIDS \& Klinische Immunologie auf, koordiniert durch die Staatliche Medizinische Akademie Tbilisi. Im Oktober 2007, kurz vor dem Abschluss der Facharztausbildung, wurde ich beurlaubt, um meine wissenschaftliche Weiterbildung an der Georg-August-Universität Göttingen, unterstützt von dem Stipendium des Deutschen Akademischen Austauschdiensts (DAAD), zu absolvieren.

Seit Oktober 2007 bin ich in der Abteilung Gastroenterologie \& Endokrinologie des UniKlinikums Göttingen mit Forschungsarbeit beschäftigt. Seit November 2007 bin ich an der Medizinischen Fakultät der Universität Göttingen als Promotionsstudentin angenommen und arbeitete unter Anleitung von Frau Prof. Dr. rer. nat. S. Mihm an der vorliegenden Dissertation.

Göttingen, 20. Januar 2010

Rusudan Bregadze 
